\title{
Farmland heterogeneity effects on biodiversity, community traits and insect pollination
}

\author{
Dissertation \\ zur Erlangung des mathematisch-naturwissenschaftlichen Doktorgrades \\ „Doktor rerum naturalium“ \\ Der Georg-August-Universität Göttingen \\ im Promotionsprogramm „Biodiversität und Ökologie“ \\ der Georg-August University School of Science (GAUSS)
}

vorgelegt von

Annika Louise Haß

aus Berlin

Göttingen, März 2018 


\section{Betreuungsausschuss:}

Prof. Dr. Teja Tscharntke, Agroecology, G.-A.-Universität Göttingen

PD Dr. Péter Batáry, MTA ÖK Landscape and Conservation Ecology Research Group

Prof. Dr. Yann Clough, Centre for Environmental and Climate Research, Lund University

\section{Mitglieder der Prüfungskommission:}

Referent: Prof. Dr. Teja Tscharntke, Agroecology, G.-A.-Universität Göttingen

1. Koreferent: Prof. Dr. Yann Clough, Centre for Environmental and Climate Research, Lund University

2. Koreferent: PD Dr. Péter Batáry, MTA ÖK Landscape and Conservation Ecology Research Group

Weitere Mitglieder der Prüfungskommssion:

Prof. Dr. Kerstin Wiegand, Ecosystem Modelling, G.-A.-Universität Göttingen

Prof. Dr. Holger Kreft, Biodiversity, Macroecology and Conservation Biogeography, G.-A.Universität Göttingen

PD Dr. Klaus Hövemeyer, J.F. Blumenbach Institute of Zoology and Anthropology, G.-A.Universität Göttingen

Tag der mündlichen Prüfung: 15.05.2018 
"The more clearly we can focus our attention on the wonders and realities of the universe about us the less taste we shall have for the destruction of our race."

Rachel Carson 


\section{Contents}

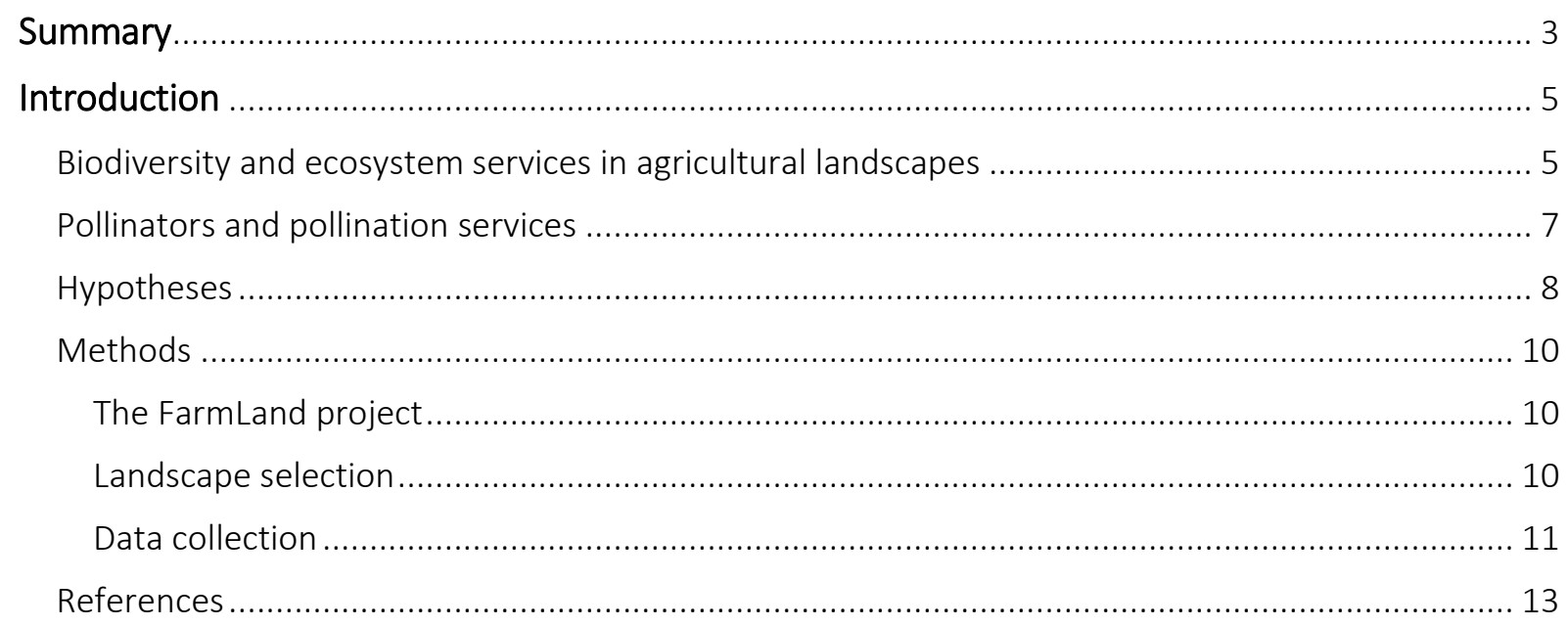

Chapter 1 Increasing crop diversity and increasing field size enhance multidiversity across agricultural regions 16

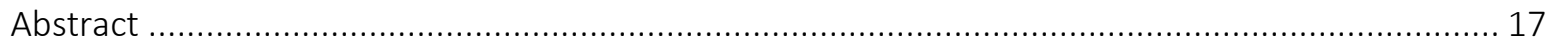

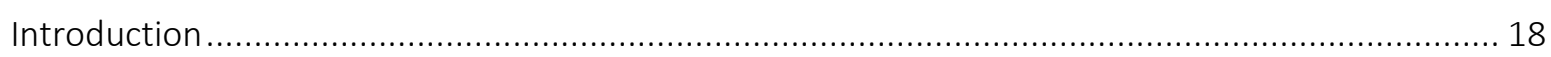

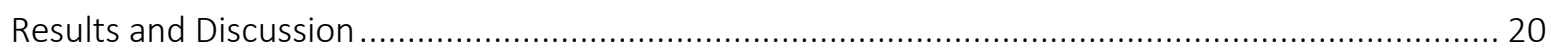

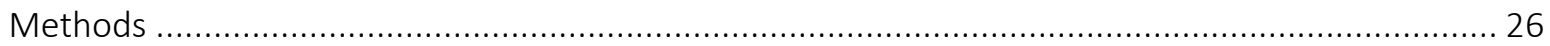

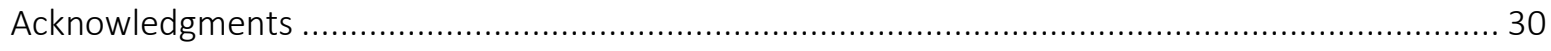

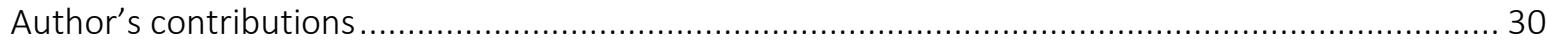

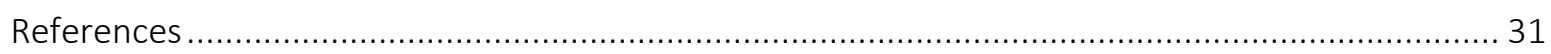

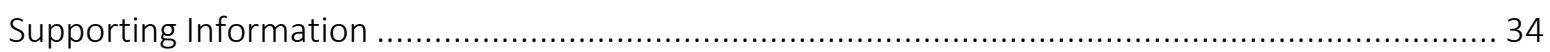

Chapter 2 Configurational and compositional heterogeneity of farmland heterogeneity affect

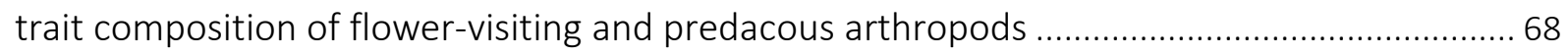

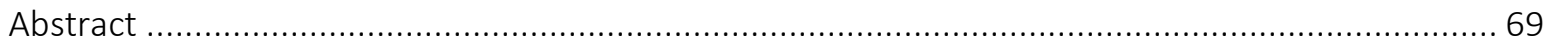

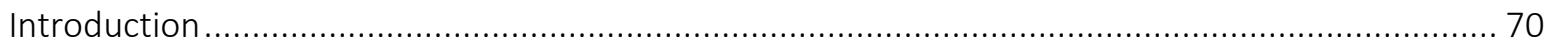

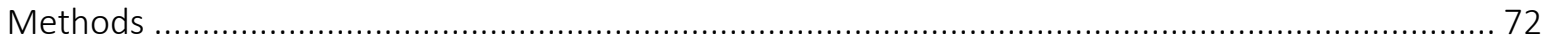

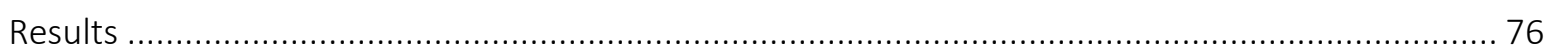

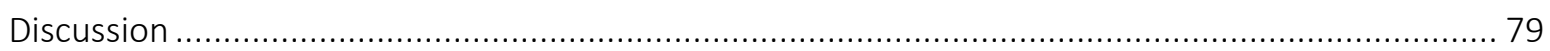

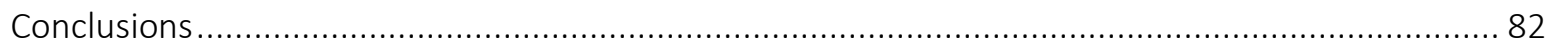

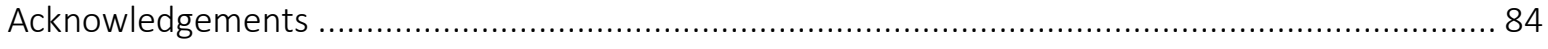

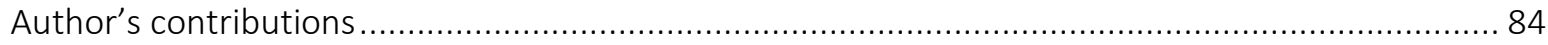

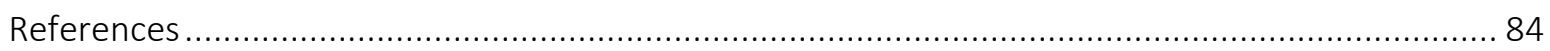

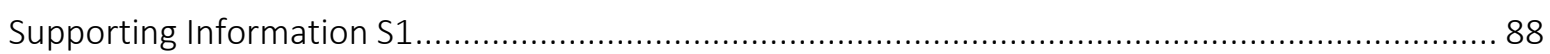

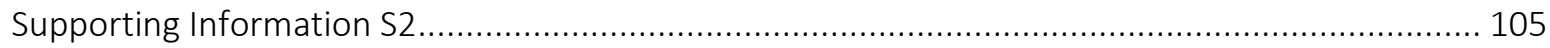


Chapter 3 Landscape configurational heterogeneity by small-scale agriculture, not crop diversity, maintains pollinators and plant reproduction in western Europe ........................... 110

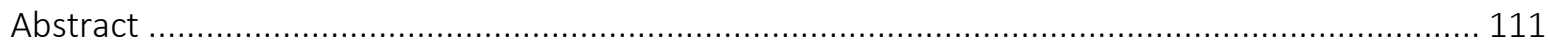

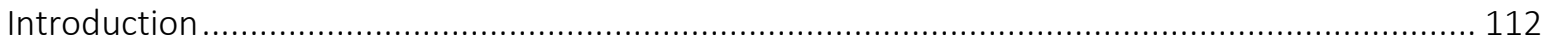

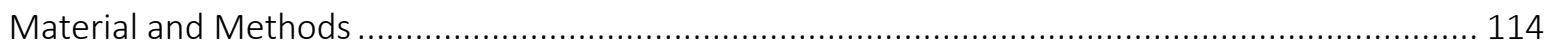

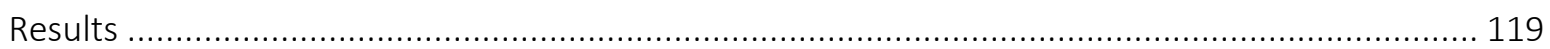

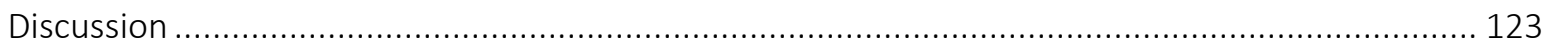

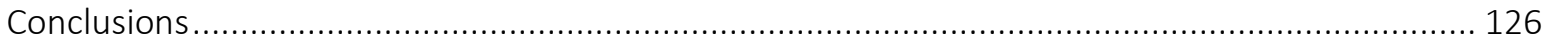

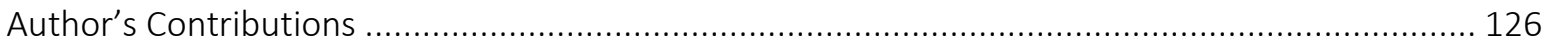

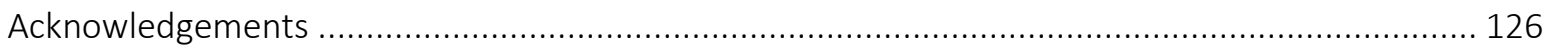

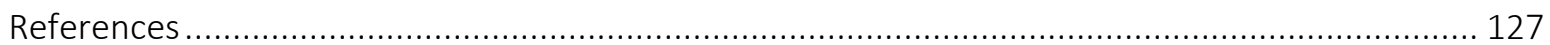

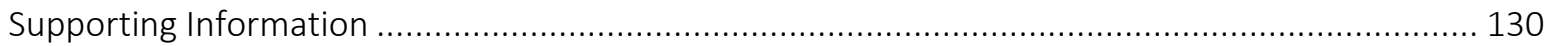

Chapter 4 Maize dominated landscapes reduce bumble bee colony growth through pollen

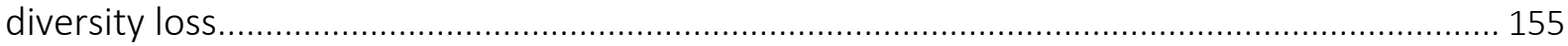

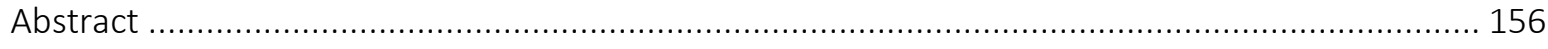

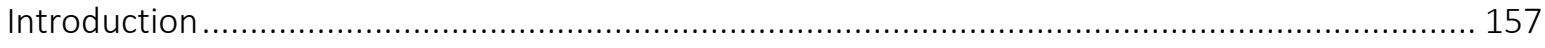

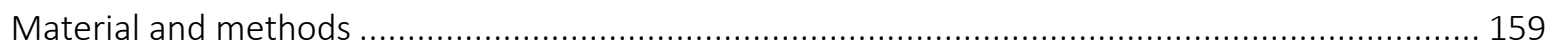

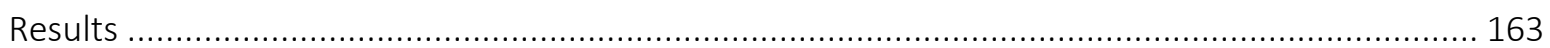

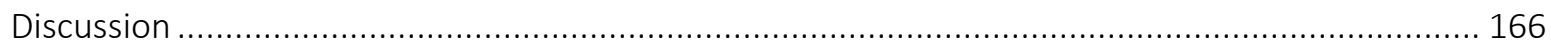

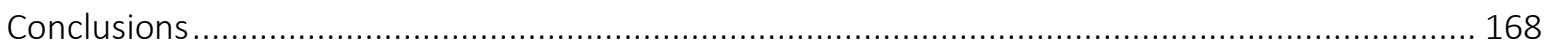

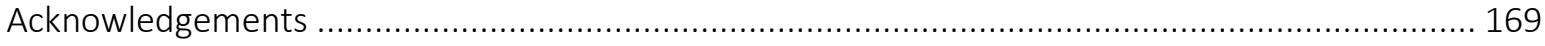

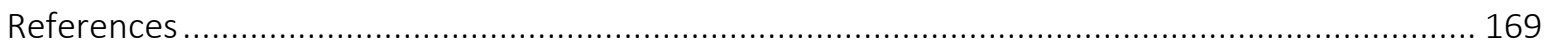

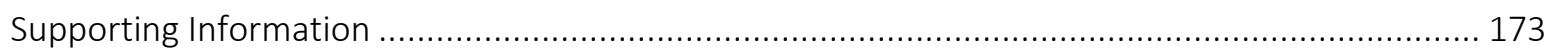

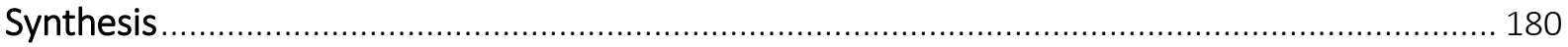

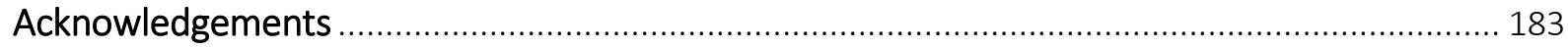

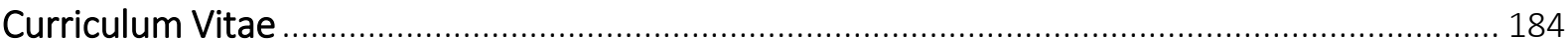

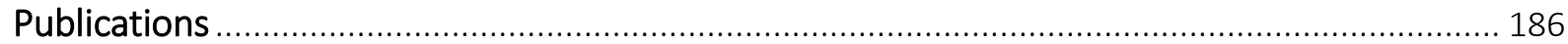




\section{Summary}

Agricultural intensification has led to severe biodiversity losses. One reason is the drastic reduction of (semi-)natural habitat, but there is also a global trend to reduced farmland heterogeneity due to larger field sizes (less field borders) and lower crop diversity. Reversing habitat loss is often difficult or not possible due to ecological, economic and social constraints, but increasing the farmland configurational heterogeneity (field border length) and farmland compositional heterogeneity (crop diversity) at the landscape scale might compensate for some habitat loss without taking land out of production. By increasing biodiversity these measures might also enhance associated ecosystem services in farmland like pollination. In the chapters of this PhD thesis we investigated the effects of landscape scale farmland compositional and configurational heterogeneity on different aspects of biodiversity with a special focus on pollinators and pollination services as well as underlying mechanisms.

In the first chapter we disentangled the effects of field border length and crop diversity on multidiversity. We sampled species of seven taxa (plants, birds, butterflies, hoverflies, bees, carabids and spiders) in 435 landscapes located in seven European and one North-American agricultural region. We found that compositional heterogeneity had a positive effect on multidiversity if semi-natural habitat was high and configurational heterogeneity had a positive effect if semi-natural habitat was low. These results indicate that the amount of semi-natural habitat modulates the effectiveness of crop heterogeneity on farmland multidiversity.

In the second chapter we investigated whether arthropod species with particular traits benefited from farmland heterogeneity. Thus, we collected traits on body size, dispersal ability, feeding type and reproduction ability of four arthropod groups (butterflies, hoverflies, carabids and spiders) across the seven European regions. Higher field border length supported butterflies, hoverflies and carabids with larger body sizes, possibly because enhanced landscape connectivity through field borders is especially important for large species with high resource demand. Effects of crop diversity were less evident, but favoured, for example, hoverflies with low dispersal and reproduction ability.

In the third and fourth chapter we focused on farmland heterogeneity effects on pollinators and pollination services. Increased abundances of wild bees in landscapes with high field border length enhanced seed set of experimental plants (radish, Raphanus sativus) exposed in 94 landscapes in four European countries. With a further experiment we demonstrated the elevated transfer of artificial pollen along borders between directly adjacent crops supporting the hypotheses that field borders enhance pollinator movement and thus connectivity at the landscape scale. In contrast, wild bee 
abundance decreased in landscapes with high crop diversity, presumably because crop diversity was correlated with the cover of crop types with particularly intensive management and low plant diversity such as maize. This was supported by the reduced pollen diversity collected by 33 experimental bumble bee colonies in the Göttingen region in landscapes with a high maize cover leading to impaired colony growth. However, we found no effect of farmland heterogeneity on colony performance.

In conclusion, farmland heterogeneity at the landscape scale is an important driver for biodiversity and ecosystem services. Configurational heterogeneity (field border length) benefits biodiversity and pollination services by enhancing connectivity, especially for arthropods with large body sizes, and thereby enhances pollination and seed set of plants. Compositional heterogeneity (crop diversity) had a positive effect on multidiversity if the amount of semi-natural habitat was high, but it became apparent that crop composition is crucial, as very intensively managed crops like maize can reduce pollinator food diversity and thereby potential pollination services. Therefore, future agrienvironmental policies should halt and reverse the current trend for larger field sizes as well as consider crop identity effects and landscape complexity when promoting crop diversity. 


\section{Introduction}

\section{Biodiversity and ecosystem services in agricultural landscapes}

Agricultural landscapes in Europe have undergone tremendous changes during the last decades (Robinson \& Sutherland 2002; Benton et al. 2003; van Vliet et al. 2015). These included at the field scale increased pesticide and fertilizer application and at the landscape scale the loss of structural elements and fragmentation of wildlife habitats (Foley et al. 2011). Thereby, crop yield was greatly enhanced, but simultaneously these land use changes had detrimental effects on biodiversity (Godfray et al. 2010; Dirzo et al. 2014). This is a pressing issue, because agricultural intensification and expansion rank among the main drivers of global biodiversity loss (Maxwell et al. 2016). In Europe farmland bird populations decreased by more than 50 \% since 1980 (Chamberlain et al. 2000; EBCC 2017) and roughly $30 \%$ of the plant species growing in arable fields are threatened (Storkey et al. 2012). Additionally, there is a trend towards impoverished community compositions resulting in communities dominated by species with generalist traits that can tolerate a high level of disturbance (Henle et al. 2004; Gámez-Virués et al. 2015). Species with sensitive traits like low dispersal capacity, high feeding specialization and low reproductive potential cannot adapt to these highly intensified systems and become rare, threatened or (locally) extinct (Purvis et al. 2000; De Palma et al. 2015). These trends are alarming as taxonomic and functional diversity are important for the provision and stability of ecosystem services in farmland like pollination and pest control by natural enemies, questioning the stability of food production in the future (Cardinale et al. 2012; Dirzo et al. 2014).

The detrimental impacts of habitat loss in agricultural landscapes like hedges, fallows and semi-natural grasslands is well documented (Billeter et al. 2008; Garibaldi et al. 2011). Taxonomic and functional diversity as well as ecosystem services decline in landscapes with low amounts of these habitat types (De Palma et al. 2015; Gámez-Virués et al. 2015; Wood et al. 2015). However, agricultural intensification did not only drastically reduce semi-natural habitats, but affected also the heterogeneity of the cropped area leading to a homogenization of crop fields in agricultural production landscapes (Robinson \& Sutherland 2002; Garibaldi et al. 2017). Farmers nowadays focus on a small number of cash crops leading to simpler crop rotations and low crop diversity at the landscape scale. At the same time fields were often combined to achieve better access and more efficient management with modern machineries leading to larger field sizes (Robinson \& Sutherland 2002; Batáry et al. 2017). However, evidence on the effects of heterogeneity loss in the crop production fields on biodiversity is scarce. Indeed, many species use resources from agricultural fields, i.e. birds feed on grains or arthropods in fields (Inger et al. 2015), carabids feed on aphids (Wood et al. 
2015) and pollinators collect pollen and nectar from mass-flowering crops or weeds (Westphal et al. 2003; Requier et al. 2015). Due to the intensive management these fields have been seen mostly as 'hostile matrix' between habitats although it is well known that species move constantly between agricultural fields and other habitat types and vice versa (Blitzer et al. 2012; Mandelik et al. 2012; Brudvig et al. 2016). The restoration or expansion of semi-natural habitats is often constrained by economic interests of farmers. To spare land for wildlife habitats, it needs to be taken out of production reducing the overall yield (Rey Benayas \& Bullock 2012). Although there are few examples demonstrating that the establishment of wildlife habitat on crop fields can be profitable after several years through improved ecosystem services (Blaauw \& Isaacs 2014; Pywell et al. 2015; Tschumi et al. 2016), this might not always be the case or the costs might be higher than the profits for farmers (Olschewski et al. 2006; Campbell et al. 2012; Sutter et al. 2017). Therefore, a paradigm shift that acknowledges the importance of crop heterogeneity might be an important step forward to ecologically sustainable agricultural landscapes, complementing measures to increase semi-natural habitats. Enhanced crop heterogeneity might contribute to balance the increasing demands of agricultural products and diverse and stable populations of wildlife in farmland (Godfray et al. 2010).

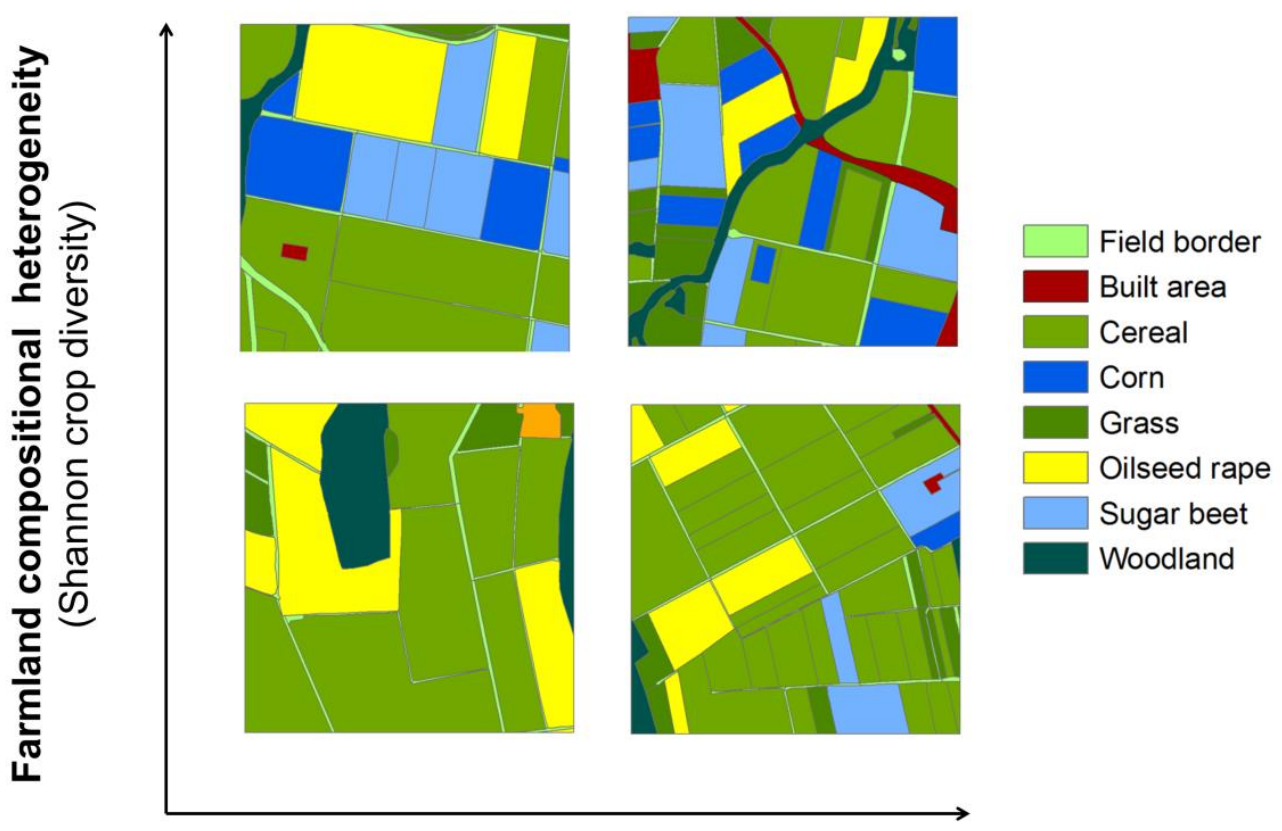

Farmland configurational heterogeneity (Field size, field border length)

Figure 1: Four example landscapes representing the uncorrelated gradients of farmland compositional heterogeneity (measured as Shannon diversity index of crop types) and farmland configurational heterogeneity (measured as field size or field border length). The four example landscapes were sampled in the Göttingen region in 2013. (Adapted from Fahrig et al. 2011) 
Farmland heterogeneity is composed of two components (Fig. 1) (Fahrig et al. 2011): Landscape compositional heterogeneity is the diversity of crop types in a landscape. It can be measured for example as the Shannon diversity index of crop types considering the richness and cover of crop types in a landscape. The second component is configurational heterogeneity. It describes the size or spatial arrangement of fields and can be measured for example as the mean size of fields or as the total length of field borders in a landscape. Disentangling the effects of compositional and configurational farmland heterogeneity and semi-natural habitat is a major challenge, as these might not be equally effective in promoting biodiversity, but are usually highly correlated in agricultural landscapes (Fahrig et al. 2011). There are few studies showing that biodiversity and natural pest control can benefit from compositional and configurational heterogeneity of crops (Palmu et al. 2014; Bertrand et al. 2015; Fahrig et al. 2015; Redlich et al. 2018), but these studies have been conducted in a limited regional context and mainly focused on predatory arthropods and natural pest control. However, the effects on different taxa in diverse regional contexts and on pollination services remain unexplored.

\section{Pollinators and pollination services}

Pollination services contribute to roughly $10 \%$ of the global value of agricultural production (Gallai et al. 2009). Although the honey bee (Apis mellifera) is the most dominant pollinator worldwide, wild pollinators also contribute to crop pollination and are typically more efficient than honey bees (Garibaldi et al. 2013). Although many crops are only pollinated by few generalist wild pollinators (Kleijn et al. 2015), it is important to conserve their diversity, as different species complement each other through different traits, for example activity during different seasons or daytimes or in different parts of the crop and therefore increase and stabilize crop yield over time (Hoehn et al. 2008; Albrecht et al. 2012; Brittain et al. 2013; Garibaldi et al. 2014). Additionally, they are also vital pollinators for wild plant species (Biesmeijer et al. 2006). There is a great diversity of wild bees, the most important group of wild pollinators (Rader et al. 2015): in Europe 1,956 wild bee species have been described of which nearly $10 \%$ are threatened by extinction. However, for more than the half of all European bee species available data is insufficient to assess their status indicating that many more species could be endangered (Nieto et al. 2014).

Pollinators depend on flowers providing pollen and nectar resources and on nesting sites as well as their temporal continuous availability (Schellhorn et al. 2015). The landscape context by increased amounts of semi-natural habitats (compositional heterogeneity) and their spatial arrangement (configurational heterogeneity) can be important factors for pollinator abundance, diversity and population viability (Holzschuh et al. 2010; Kennedy et al. 2013; Steckel et al. 2014; Carvell et al. 2017). It is also known that bees utilize resources in agricultural fields by foraging on 
mass-flowering crops and weed species (Requier et al., 2015; Westphal et al., 2003). However, there is only one study showing that the configurational and compositional heterogeneity of crop fields can be beneficial for pollinator species (Fahrig et al. 2015), but in this study crop types sampled were not independent from the landscape heterogeneity gradients, which might have biased the results. Additionally, different regional contexts were not considered, the hypothesized mechanisms have not been tested to date and the impacts on pollination services remain unclear.

\section{Hypotheses}

In the chapters of this thesis we investigate whether the landscape scale configurational and compositional heterogeneity of crops affect multidiversity (average scaled species richness of plants, birds, butterflies, hoverflies, bees, carabids and spiders, Chapter 1), species trait composition of flower visiting and predatory arthropods (Chapter 2), pollinator diversity, abundance and pollination services (Chapter 3) as well as bumble bee colony growth (Chapter 4). Additionally, we explore possible underlying mechanisms of the effects of crop heterogeneity on pollinator species with experiments on pollinator movement and the diversity of pollen collected by bumble bees (Chapter 3+4). A diagram of the hypothesis tested in this thesis is presented in Fig. 2.

Farmland configurational heterogeneity is expected to increase the connectivity of habitats as smaller fields provide more field borders that might enhance species movement across landscapes (Fahrig et al. 2011). These enhanced movements are expected to affect the community trait composition by favouring species with low dispersal capacity in landscapes with high configurational heterogeneity (Gámez-Virués et al. 2015). Additionally, species with high feeding specialization and low reproduction potential could also benefit from increased configurational heterogeneity, as these species usually depend on high amounts of well-connected habitats (Henle et al. 2004). The presence of species with these traits in landscapes with high configurational heterogeneity could then also increase multidiversity. Likewise, pollinator colony growth (Chapter 4), diversity, abundance and finally also pollination services (Chapter 3 ) are expected to increase. Pollinators move along semi-natural field borders (Van Geert et al. 2010; Cranmer et al. 2012), but the role of field borders without accompanying semi-natural vegetation has to our knowledge not been investigated yet. The movement of pollinators along different agricultural field borders was tested in Chapter 3.

Furthermore, we hypothesize that the crop compositional heterogeneity increases the diversity of resources provided, including food resources and different structures. These different resources and structures are expected to increase multidiversity (Chapter 1 ) and also species with high feeding specialization (Chapter 2) (Fahrig et al. 2011; Gámez-Virués et al. 2015). Regarding pollinators the presence of different weeds in different crop types (Hyvönen \& Salonen 2002) could enhance the diversity of pollen resources available and collected in landscapes with high compositional 
heterogeneity, which might then increase pollinator colony growth (Tasei \& Aupinel 2008; Eckhardt et al. 2014) (Chapter 4). We also expected that the cover of different crop types (i.e. oilseed rape and maize) in the landscape is an important factor for pollinator colony growth. Oilseed rape can enhance colony growth (Westphal et al. 2009) and maize fields have a low plant diversity (Fagúndez et al. 2016) with possibly negative effects on pollen diversity collected by bees (Chapter 4). Finally, we expected that higher compositional heterogeneity possibly also mediated by increased food diversity would increase pollinator abundance, diversity and pollination services (Chapter 3).

\section{Configurational heterogeneity}

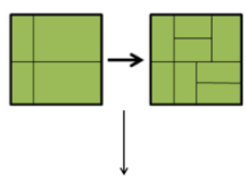

Habitat connectivity

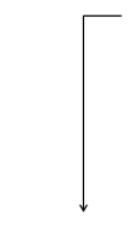

Pollinator movement (Ch. 3)

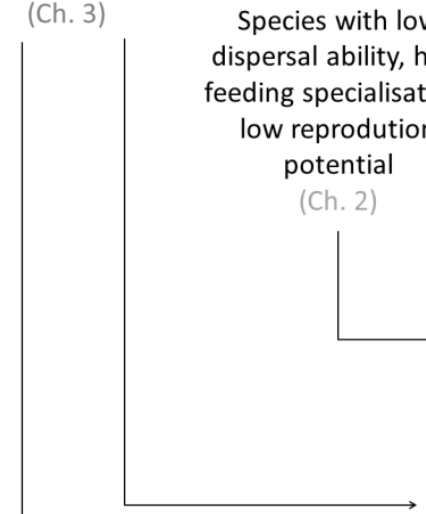

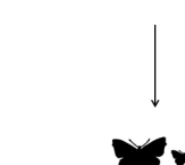

Community trait

$$
\text { composition: }
$$

Species with low

dispersal ability, high ding specialisation,

2)

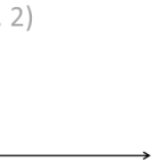
(Ch.1)

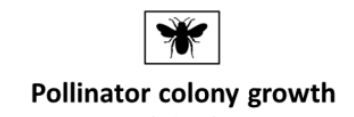

(Ch.4)

\section{Compositional heterogeneity}

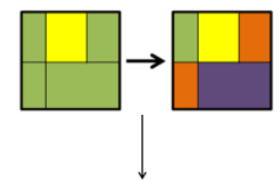

Diversity of resources (e.g. food, structure,

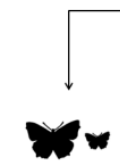

Community trait composition: Species with high feeding specialisation (Ch. 2) overwintering)

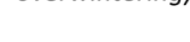

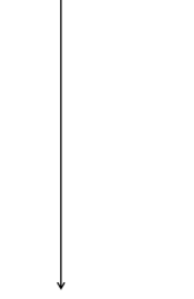

diversity $\longleftarrow$ Maize (Ch.4) (Ch. 4)

(Ch. 3)

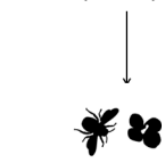

Pollination services

(Ch. 3)

Figure 2: Hypotheses investigated in this thesis by testing the effects of compositional and configurational heterogeneity on multidiversity, community trait composition of flower visiting and predatory arthropods, pollinator diversity, abundance, colony growth and on pollination services. 


\section{Methods}

\section{The FarmLand project}

The hypotheses of this thesis were tested on data sampled within the framework of the FarmLand project (www.farmland-biodiversity.org). This project comprised research teams from eight different regions (Figure 3 ) to study the effects of farmland heterogeneity on biodiversity and ecosystem services. The different regions represent different agricultural systems with different land use histories, species pools and different climatic conditions across the temperate climate zone in the northern hemisphere, with a focus on Western Europe. The regions were located in Canada, France, Germany, Spain and the UK. Farming systems differed significantly, e.g. with a focus on dairy in Armorique, tree crops like almonds and olives in Lleida and rice in the Camargue. However, in most regions cereals were the dominating crop.

Common standardized protocols were developed to record different taxa (multidiversity) in all regions. Additionally, experiments were conducted in some of the regions (pollination experiment in Armorique, East Anglia, Lleida and Göttingen, bumble bee colony experiment in Göttingen only, Figure 3).

\section{Landscape selection}

Overall 435 landscapes were selected for sampling across all eight regions. In each region sampling was conducted in two years (2011 and 2012 in Ontario, 2012 and 2013 in East Anglia and 2013 and 2014 in all other regions) and different sets of landscapes were selected in each year due to crop rotation. We aimed at maximizing the cover of agricultural land and selecting landscapes with independent gradients of compositional and configurational farmland heterogeneity within and across all regions. Therefore, we used the best available data in each region before the cropping season. Landscapes were then selected to maximize the gradient of each of the two farmland heterogeneity variables (configurational and compositional heterogeneity) and to avoid correlations between them (Pasher et al. 2013). Additionally, we conducted detailed mappings of all crop fields and other land use types during the field season. In the Göttingen region we selected overall 52 landscapes of which 32 were sampled in 2013 and 20 in 2014 (Figure 4a). 


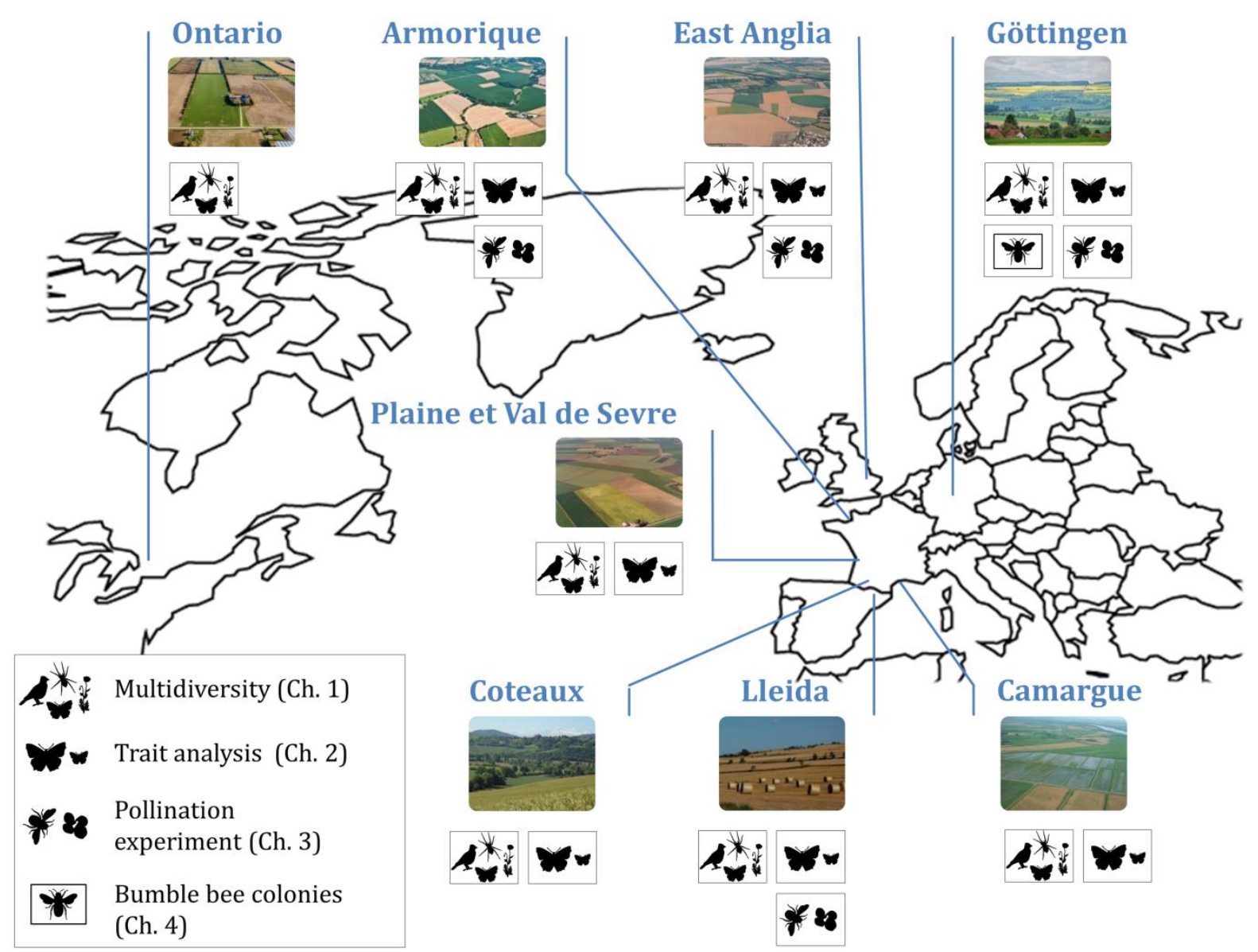

Figure 3: Location of the eight regions included in the FarmLand project. Mulitdiversity (species richness of plants, birds, bees, butterflies hoverflies, spiders and carabids) was investigated in all regions, the trait analysis was conducted in all seven European regions, the pollination potential was tested in four European regions and the bumble bee colony experiment was established in Göttingen (Germany) only. (Photo credits: www.farmland-biodiversity.org)

\section{Data collection}

In each landscape we selected four fields. Birds were sampled in all four fields and plants and arthropods only in three of the fields (Figure 4b, Chapter 1). In each field we established two $50 \mathrm{~m}$ transects (border and interior of field) and installed 4 pitfall traps and 6 pairs of pan traps (Figure 4c). Bird point counts were conducted in the field margin directly adjacent to the sampled crop field. Plants and butterflies were recorded along both transects. The data of butterflies, hoverflies, carabids and spiders was also used to assess the community composition based on the species traits (Chapter 2). 


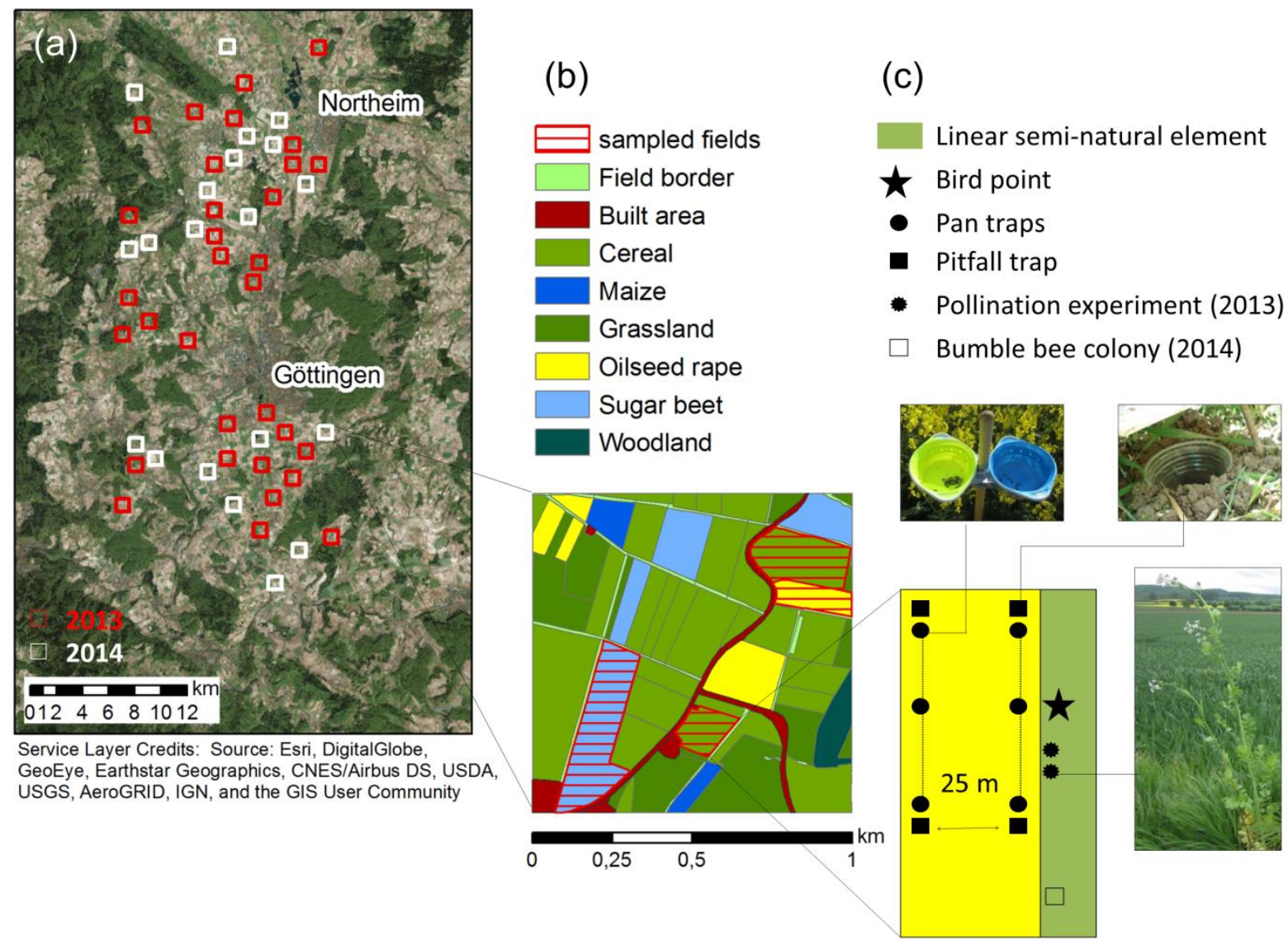

Figure 4: Sampling design in the Göttingen region: (a) location of the 52 landscapes sampled in 2013 and 2014, (b) example landscape with showing the four sampled (for birds, arthropods and plants were sampled in only 3 landscapes) and (c) biodiversity and pollination service sampling methods in the field. (Photo credits: Annika Hass, Aliette Bosem Baillod)

Additionally, in four regions across four European countries (Göttingen, Lleida, Armorique and East Anglia) two pots with experimental plants of radish (Raphanus sativus) were placed in the field border (only in 2013, Chapter 3). To assess the pollination service in each field, we collected from the radish plants all pods of flowers that were open during field exposure and determined seed set. Additionally, an experiment with bumble bee colonies was conducted in the Göttingen region in 2014 only (Chapter 4). We placed small colonies of Bombus terrestris in the field margin of two fields per landscape (one oilseed rape and one wheat field). For each colony we measured weight gain during 6 weeks in the field and we also collected pollen samples to assess the pollen diversity for each colony. An additional experiment was conducted in six landscapes in the Göttingen region in 2014 to investigate pollinator movement along different agricultural field border types with fluorescent dye serving as an artificial pollen surrogate (Chapter 3). 


\section{References}

Albrecht, M., Schmid, B., Hautier, Y. \& Muller, C.B. (2012). Diverse pollinator communities enhance plant reproductive success. Proc. Biol. Sci., 279.

Batáry, P., Gallé, R., Riesch, F., Fischer, C., Dormann, C.F., Mußhoff, O., et al. (2017). The former Iron Curtain still drives biodiversity-profit trade-offs in German agriculture. Nat. Ecol. Evol., 1, 1279-1284.

Benton, T.G., Vickery, J.A. \& Wilson, J.D. (2003). Farmland biodiversity: is habitat heterogeneity the key? Trends Ecol. Evol., 18, 182-188.

Bertrand, C., Burel, F. \& Baudry, J. (2015). Spatial and temporal heterogeneity of the crop mosaic influences carabid beetles in agricultural landscapes. Landsc. Ecol., 31, 451-466.

Biesmeijer, J.C., Roberts, S.P.M., Reemer, M., Ohlemueller, R., Edwards, M., Peeters, T., et al. (2006). Parallel declines in pollinators and insect-pollinated plants in Britain and the Netherlands. Science, 313, 351-354.

Billeter, R., Liira, J., Bailey, D., Bugter, R., Arens, P., Augenstein, I., et al. (2008). Indicators for biodiversity in agricultural landscapes: a pan-European study. J. Appl. Ecol., 45, 141-150.

Blaauw, B.R. \& Isaacs, R. (2014). Flower plantings increase wild bee abundance and the pollination services provided to a pollination-dependent crop. J. Appl. Ecol., 51, 890-898.

Blitzer, E.J., Dormann, C.F., Holzschuh, A., Klein, A.-M., Rand, T.A. \& Tscharntke, T. (2012). Spillover of functionally important organisms between managed and natural habitats. Agric. Ecosyst. Environ., 146, 34-43.

Brittain, C., Kremen, C. \& Klein, A.-M. (2013). Biodiversity buffers pollination from changes in environmental conditions. Glob. Change Biol., 19, 540-547.

Brudvig L.A., Leroux S.J., Albert C.H., Bruna E.M., Davies K.F., Ewers R.M., et al. (2016). Evaluating conceptual models of landscape change. Ecography, 40, 74-84.

Campbell, A.J., Biesmeijer, J.C., Varma, V. \& Wäckers, F.L. (2012). Realising multiple ecosystem services based on the response of three beneficial insect groups to floral traits and trait diversity. Basic Appl. Ecol., 13, 363-370.

Cardinale, B.J., Duffy, J.E., Gonzalez, A., Hooper, D.U., Perrings, C., Venail, P., et al. (2012). Biodiversity loss and its impact on humanity. Nature, 486, 59-67.

Carvell, C., Bourke, A.F.G., Dreier, S., Freeman, S.N., Hulmes, S., Jordan, W.C., et al. (2017). Bumblebee family lineage survival is enhanced in high-quality landscapes. Nature, 543, 547-549.

Chamberlain, D. e., Fuller, R. j., Bunce, R. g. h., Duckworth, J. c. \& Shrubb, M. (2000). Changes in the abundance of farmland birds in relation to the timing of agricultural intensification in England and Wales. J. Appl. Ecol., 37, 771-788.

Cranmer, L., McCollin, D. \& Ollerton, J. (2012). Landscape structure influences pollinator movements and directly affects plant reproductive success. Oikos, 121, 562-568.

De Palma, A., Kuhlmann, M., Roberts, S.P.M., Potts, S.G., Börger, L., Hudson, L.N., et al. (2015). Ecological traits affect the sensitivity of bees to land-use pressures in European agricultural landscapes. J. Appl. Ecol., 52, 1567-1577.

Dirzo, R., Young, H.S., Galetti, M., Ceballos, G., Isaac, N.J.B. \& Collen, B. (2014). Defaunation in the Anthropocene. Science, 345, 401-406.

EBCC. (2017). (European Bird Census Counsil) European wild bird indicators. http://www.ebcc.info/index.php?ID=623, visited 20 $0^{\text {th }}$ March 2018

Eckhardt, M., Haider, M., Dorn, S. \& Müller, A. (2014). Pollen mixing in pollen generalist solitary bees: a possible strategy to complement or mitigate unfavourable pollen properties? J. Anim. Ecol.

Fagúndez, J., Olea, P.P., Tejedo, P., Mateo-Tomás, P. \& Gómez, D. (2016). Irrigation and maize cultivation erode plant diversity within crops in Mediterranean dry cereal agro-ecosystems. Environ. Manage., 58, 164-174.

Fahrig, L., Baudry, J., Brotons, L., Burel, F.G., Crist, T.O., Fuller, R.J., et al. (2011). Functional landscape heterogeneity and animal biodiversity in agricultural landscapes. Ecol. Lett., 14, 101-112. 
Fahrig, L., Girard, J., Duro, D., Pasher, J., Smith, A., Javorek, S., et al. (2015). Farmlands with smaller crop fields have higher within-field biodiversity. Agric. Ecosyst. Environ., 200, 219-234.

Foley, J.A., Ramankutty, N., Brauman, K.A., Cassidy, E.S., Gerber, J.S., Johnston, M., et al. (2011). Solutions for a cultivated planet. Nature, 478, 337-342.

Gallai, N., Salles, J.-M., Settele, J. \& Vaissière, B.E. (2009). Economic valuation of the vulnerability of world agriculture confronted with pollinator decline. Ecol. Econ., 68, 810-821.

Gámez-Virués, S., Perović, D.J., Gossner, M.M., Börschig, C., Blüthgen, N., de Jong, H., et al. (2015). Landscape simplification filters species traits and drives biotic homogenization. Nat. Commun., 6, 8568.

Garibaldi, L.A., Carvalheiro, L.G., Leonhardt, S.D., Aizen, M.A., Blaauw, B.R., Isaacs, R., et al. (2014). From research to action: enhancing crop yield through wild pollinators. Front. Ecol. Environ., 12, 439-447.

Garibaldi, L.A., Gemmill-Herren, B., D’Annolfo, R., Graeub, B.E., Cunningham, S.A. \& Breeze, T.D. (2017). Farming approaches for greater biodiversity, livelihoods, and food security. Trends Ecol. Evol., 32, 68-80.

Garibaldi, L.A., Steffan-Dewenter, I., Kremen, C., Morales, J.M., Bommarco, R., Cunningham, S.A., et al. (2011). Stability of pollination services decreases with isolation from natural areas despite honey bee visits. Ecol. Lett., 14, 1062-1072.

Garibaldi, L.A., Steffan-Dewenter, I., Winfree, R., Aizen, M.A., Bommarco, R., Cunningham, S.A., et al. (2013). Wild pollinators enhance fruit set of crops regardless of honey bee abundance. Science, 339, 1608-1611.

Godfray, H.C.J., Beddington, J.R., Crute, I.R., Haddad, L., Lawrence, D., Muir, J.F., et al. (2010). Food security: The challenge of feeding 9 billion people. Science, 327, 812-818.

Henle, K., Davies, K.F., Kleyer, M., Margules, C. \& Settele, J. (2004). Predictors of Species Sensitivity to Fragmentation. Biodivers. Conserv., 13, 207-251.

Hoehn, P., Tscharntke, T., Tylianakis, J.M. \& Steffan-Dewenter, I. (2008). Functional group diversity of bee pollinators increases crop yield. Proc. R. Soc. Lond. B Biol. Sci., 275, 2283-2291.

Holzschuh, A., Steffan-Dewenter, I. \& Tscharntke, T. (2010). How do landscape composition and configuration, organic farming and fallow strips affect the diversity of bees, wasps and their parasitoids? J. Anim. Ecol., 79, 491-500.

Hyvönen, T. \& Salonen, J. (2002). Weed species diversity and community composition in cropping practices at two intensity levels - a six-year experiment. Plant Ecol., 159, 73-81.

Inger, R., Gregory, R., Duffy, J.P., Stott, I., Voříšek, P. \& Gaston, K.J. (2015). Common European birds are declining rapidly while less abundant species' numbers are rising. Ecol. Lett., 18, 28-36.

Kennedy, C.M., Lonsdorf, E., Neel, M.C., Williams, N.M., Ricketts, T.H., Winfree, R., et al. (2013). A global quantitative synthesis of local and landscape effects on wild bee pollinators in agroecosystems. Ecol. Lett., 16, 584-599.

Kleijn, D., Winfree, R., Bartomeus, I., Carvalheiro, L.G., Henry, M., Isaacs, R., et al. (2015). Delivery of crop pollination services is an insufficient argument for wild pollinator conservation. Nat. Commun., 6, 7414.

Mandelik, Y., Winfree, R., Neeson, T. \& Kremen, C. (2012). Complementary habitat use by wild bees in agro-natural landscapes. Ecol. Appl., 22, 1535-1546.

Maxwell, S.L., Fuller, R.A., Brooks, T.M. \& Watson, J.E.M. (2016). Biodiversity: The ravages of guns, nets and bulldozers. Nat. News, 536, 143.

Nieto, A., Roberts, S.P.M., Kemp, J., Rasmont, P., Kuhlmann, M., García Criado, M., et al. (2014). European Red List of bees. Publication Office of the European Union, Luxembourg.

Olschewski, R., Tscharntke, T., Benítez, P.C., Schwarze, S. \& Klein, A.-M. (2006). Economic Evaluation of Pollination Services Comparing Coffee Landscapes in Ecuador and Indonesia. Ecol. Soc., 11, 7.

Palmu, E., Ekroos, J., Hanson, H.I., Smith, H.G. \& Hedlund, K. (2014). Landscape-scale crop diversity interacts with local management to determine ground beetle diversity. Basic Appl. Ecol., 15, 241-249. 
Pasher, J., Mitchell, S.W., King, D.J., Fahrig, L., Smith, A.C. \& Lindsay, K.E. (2013). Optimizing landscape selection for estimating relative effects of landscape variables on ecological responses. Landsc. Ecol., 28, 371-383.

Purvis, A., Gittleman, J.L., Cowlishaw, G. \& Mace, G.M. (2000). Predicting extinction risk in declining species. Proc. R. Soc. B-Biol. Sci., 267, 1947-1952.

Pywell, R.F., Heard, M.S., Woodcock, B.A., Hinsley, S., Ridding, L., Nowakowski, M., et al. (2015). Wildlife-friendly farming increases crop yield: evidence for ecological intensification. Proc $R$ Soc B, 282, 20151740.

Rader, R., Bartomeus, I., Garibaldi, L.A., Garratt, M.P.D., Howlett, B.G., Winfree, R., et al. (2015). Nonbee insects are important contributors to global crop pollination. Proc. Natl. Acad. Sci., 201517092.

Redlich, S., Martin, E.A. \& Steffan-Dewenter, I. (n.d.). Landscape-level crop diversity benefits biological pest control. J. Appl. Ecol., in press

Requier, F., Odoux, J.-F., Tamic, T., Moreau, N., Henry, M., Decourtye, A., et al. (2015). Honey bee diet in intensive farmland habitats reveals an unexpectedly high flower richness and a major role of weeds. Ecol. Appl., 25, 881-890.

Rey Benayas, J.M. \& Bullock, J.M. (2012). Restoration of Biodiversity and Ecosystem Services on Agricultural Land. Ecosystems, 15, 883-899.

Robinson, R.A. \& Sutherland, W.J. (2002). Post-war changes in arable farming and biodiversity in Great Britain. J. Appl. Ecol., 39, 157-176.

Schellhorn, N.A., Gagic, V. \& Bommarco, R. (2015). Time will tell: resource continuity bolsters ecosystem services. Trends Ecol. Evol., 30, 524-530.

Steckel, J., Westphal, C., Peters, M.K., Bellach, M., Rothenwoehrer, C., Erasmi, S., et al. (2014). Landscape composition and configuration differently affect trap-nesting bees, wasps and their antagonists. Biol. Conserv., 172, 56-64.

Storkey, J., Meyer, S., Still, K.S. \& Leuschner, C. (2012). The impact of agricultural intensification and land-use change on the European arable flora. Proc. R. Soc. B Biol. Sci., 279, 1421-1429.

Sutter, L., Jeanneret, P., Bartual, A.M., Bocci, G. \& Albrecht, M. (2017). Enhancing plant diversity in agricultural landscapes promotes both rare bees and dominant crop-pollinating bees through complementary increase in key floral resources. J. Appl. Ecol., 54, 1856-1864.

Tasei, J.-N. \& Aupinel, P. (2008). Nutritive value of 15 single pollens and pollen mixes tested on larvae produced by bumblebee workers (Bombus terrestris, Hymenoptera: Apidae). Apidologie, 39, 397-409.

Tschumi, M., Albrecht, M., Bärtschi, C., Collatz, J., Entling, M.H. \& Jacot, K. (2016). Perennial, speciesrich wildflower strips enhance pest control and crop yield. Agric. Ecosyst. Environ., 220, 97103.

Van Geert, A., Van Rossum, F. \& Triest, L. (2010). Do linear landscape elements in farmland act as biological corridors for pollen dispersal? J. Ecol., 98, 178-187.

van Vliet, J., de Groot, H.L.F., Rietveld, P. \& Verburg, P.H. (2015). Manifestations and underlying drivers of agricultural land use change in Europe. Landsc. Urban Plan., 133, 24-36.

Westphal, C., Steffan-Dewenter, I. \& Tscharntke, T. (2003). Mass flowering crops enhance pollinator densities at a landscape scale. Ecol. Lett., 6, 961-965.

Westphal, C., Steffan-Dewenter, I. \& Tscharntke, T. (2009). Mass flowering oilseed rape improves early colony growth but not sexual reproduction of bumblebees. J. Appl. Ecol., 46, 187-193.

Wood, S.A., Karp, D.S., DeClerck, F., Kremen, C., Naeem, S. \& Palm, C.A. (2015). Functional traits in agriculture: agrobiodiversity and ecosystem services. Trends Ecol. Evol., 30, 531-539. 


\section{Chapter 1}

\section{Increasing crop diversity and decreasing field size enhance multidiversity across agricultural regions}

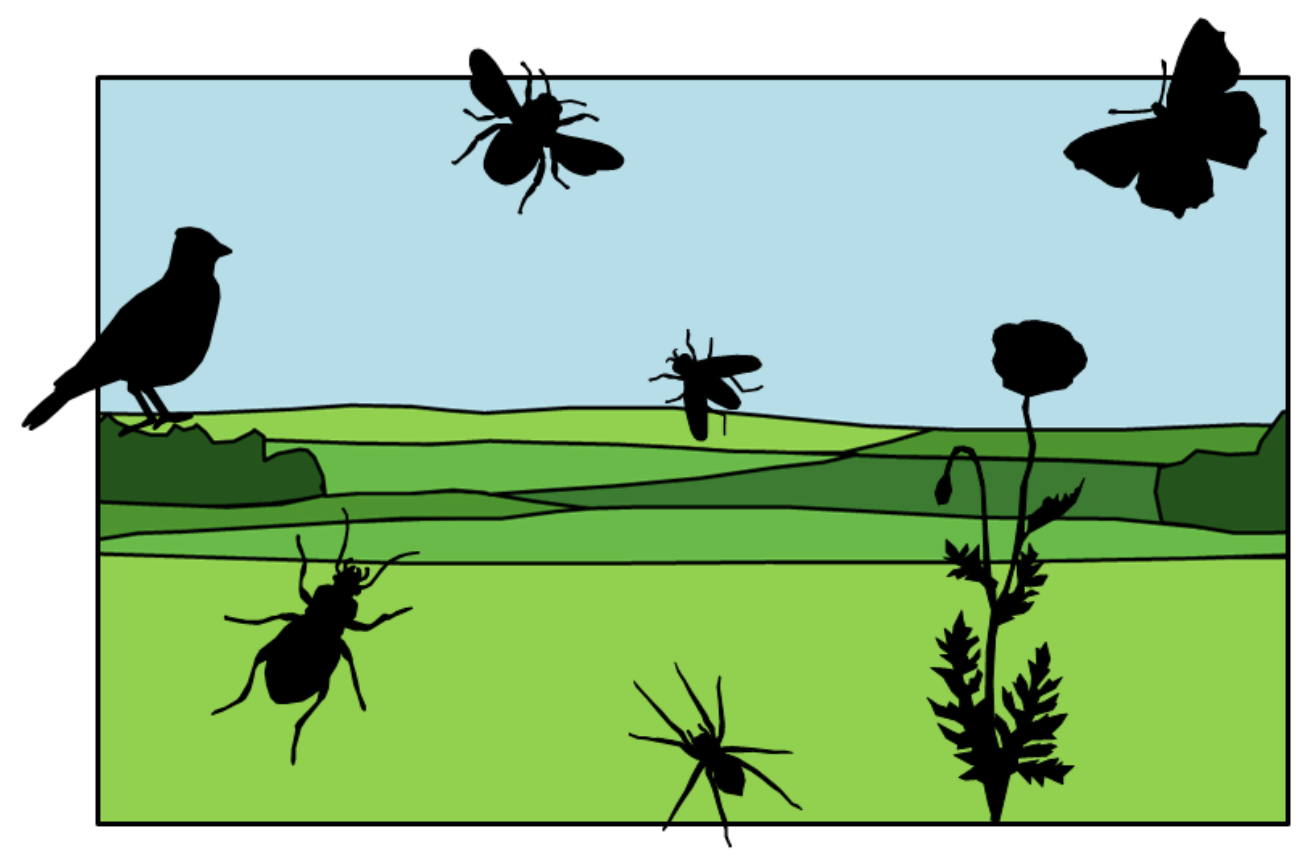

Clélia Sirami, Nicolas Gross, Aliette Bosem Baillod*, Colette Bertrand*, Romain Carrié*, Annika Hass*, Laura Henckel*, Paul Miguet*, Carole Vuillot*, Audrey Alignier, Jude Girard, Péter Batáry, Yann Clough, Cyrille Violle, David Giralt, Gerard Bota, Isabelle Badenhauser, Gaetan Lefebvre, Bertrand Gauffre, Aude Vialatte, François Calatayud, Assu Gil-Tena, Lutz Tischendorf, Scott Mitchell, Kathryn Lindsay, Romain Georges, Samuel Hilaire, Jordi Recasens, Xavier Oriol SoléSenan, Irene Robleño, Jordi Bosch, Jose Antonio Barrientos, Antonio Ricarte, Maria Ángeles Marcos-Garcia, Jesus Minano, Raphael Mathevet, Annick Gibon, Jacques Baudry, Gerard Balent, Brigitte Poulin, Françoise Burel, Teja Tscharntke, Vincent Bretagnolle, Gavin Siriwardena, Annie Ouin, Lluis Brotons, Jean-Louis Martin**, Lenore Fahrig** *These co-authors contributed equally as part of their PhDs. **These co-authors contributed equally to the project coordination.

submitted to PNAS Jan. $9^{\text {th }} 2018$ (resubmission invited) 


\section{Abstract}

Agricultural landscape homogenization has detrimental effects on biodiversity and ecosystem services. Increasing agricultural landscape heterogeneity by increasing the amount of semi-natural covers can help mitigating biodiversity loss. However, the amount of semi-natural covers is generally low and difficult to increase in many intensively-managed agricultural landscapes. We hypothesized that increasing the heterogeneity of the crop mosaic itself (hereafter "crop heterogeneity"), by increasing crop diversity and decreasing mean field size, can also have positive effects on biodiversity. In eight contrasting regions of Europe and North America, we selected 435 landscapes along independent gradients of crop diversity and mean field size. We sampled seven taxa (plants, bees, butterflies, hoverflies, carabids, spiders, and birds) within fields and calculated a synthetic index of multitrophic biodiversity. Crop heterogeneity had a much stronger positive effect on biodiversity than the amount of semi natural cover. For instance, the effect of decreasing mean field size from 5 to 2.75 ha was as strong as the effect of increasing semi-natural cover from 0.5 to $11 \%$. The effects of crop diversity and mean field size were modulated by the amount of semi-natural cover: decreasing mean field size had a stronger effect in landscapes with low semi-natural cover whereas increasing crop diversity had a stronger effect in landscapes with high semi-natural cover. Our study provides the first large-scale, multitrophic, cross-regional evidence that increasing crop diversity and decreasing mean field size represent effective ways to reduce the impacts of agriculture on biodiversity without taking land out of agricultural production.

Keywords: biodiversity, multi-taxa, agricultural landscapes, crop mosaic, farmland, landscape complementation 


\section{Introduction}

Agriculture dominates the world's terrestrial area (Tilman et al. 2001; Foley et al. 2005) and agricultural landscape homogenization through semi-natural habitat loss, crop specialization and field enlargement (Barr \& Gillespie 2000; Robinson \& Sutherland 2002; Aguilar et al. 2015; White \& Roy 2015) represents a continuing worldwide threat to biodiversity and the delivery of key ecosystem services to people (Newbold et al. 2015; Maxwell et al. 2016). There is ample evidence that enhancing landscape heterogeneity by reversing the decline in semi-natural habitats can benefit biodiversity in agricultural landscapes (Benton et al. 2003; Batáry et al. 2011; Miyashita et al. 2012; Perović et al. 2015). However, the amount of semi-natural habitat keeps decreasing in many agricultural landscapes due to competition for space with crops, and the efficiency of policies focusing solely on maintaining or restoring semi-natural habitats has been questioned (Batáry et al. 2015).

While half of the biodiversity in agricultural landscapes occurs exclusively in semi-natural habitats (Lüscher et al. 2016), the crop mosaic offers a wide range of resources to the other half, including to species occurring exclusively in crops and providing key ecosystem services such as crop pollination or biological pest control (Henderson et al. 2004; Holzschuh et al. 2013; Raymond et al. 2014). It is therefore of increasing interest to evaluate whether enhancing landscape heterogeneity by increasing the heterogeneity of the crop mosaic itself (hereafter "crop heterogeneity") can also benefit biodiversity (Fig. 1). Given the growing pressure on land for food and energy production, measures to benefit biodiversity consisting of a re-arrangement of the production area, as opposed to measures focusing solely on its reduction, could provide valuable new policy options.

Crop heterogeneity can be decomposed into compositional heterogeneity, i.e. the composition of the crop mosaic (e.g. crop diversity), and configurational heterogeneity, i.e. the shape and spatial arrangement of fields (e.g. mean field size, (Fahrig et al. 2011); see further explanation in Methods). These two components of crop heterogeneity may influence farmland biodiversity in several ways (see detailed alternative hypotheses in SI 1). Increasing crop diversity should benefit biodiversity if many species are specialists of distinct crop types (i.e. habitat specialization; 19) or require multiple resources provided by different crop types (i.e. landscape complementation; (Dunning et al. 1992). Decreasing mean field size should benefit biodiversity if small fields provide easier access to adjacent fields for many species (i.e. landscape complementation; (Dunning et al. 1992). Moreover, biodiversity response to crop heterogeneity may be non-linear and non-additive, e.g. if decreasing mean field size or increasing crop diversity benefits biodiversity only when fields are small enough for adjacent fields to be reached easily. Additionally, benefits of increasing crop heterogeneity for biodiversity may depend on the amount of semi-natural habitats. For instance, the intermediate landscape-complexity hypothesis suggests that the positive biodiversity-crop heterogeneity relationship may be stronger in landscapes with intermediate amounts of semi-natural 
habitats (e.g. 5-20\%) than in landscapes with little (e.g. <5\%) or much semi-natural habitat (e.g. >20\%; (Tscharntke et al. 2012). Considering the response of biodiversity across a wide range of contexts is therefore necessary to understand the general effect of crop heterogeneity on farmland biodiversity.

The biodiversity-crop heterogeneity relationship may vary among taxa (e.g. (Burel et al. 2004; Dormann et al. 2007). For instance, it may be more positive for species and taxa that have lower habitat area requirements (e.g. small species; (Ponjoan et al. 2012) or higher habitat specialization levels (e.g. (Gaba et al. 2010). Although studying the effect of crop heterogeneity on each taxa is fundamental, it is also critical to understand how human activities affect biodiversity as a whole (Allan et al. 2014; Soliveres et al. 2016) and to develop environmental policies that are effective across a wide range of regional contexts and species pools (Pe'er et al. 2014; Díaz et al. 2015). To achieve this, we here use a cross-regional sampling scheme across Europe and Canada and a synthetic multidiversity index integrating information on contrasting taxa in order to identify landscape structures that simultaneously increase the diversity of most taxa (Allan et al. 2014).

\section{Representations of farmland heterogeneity}
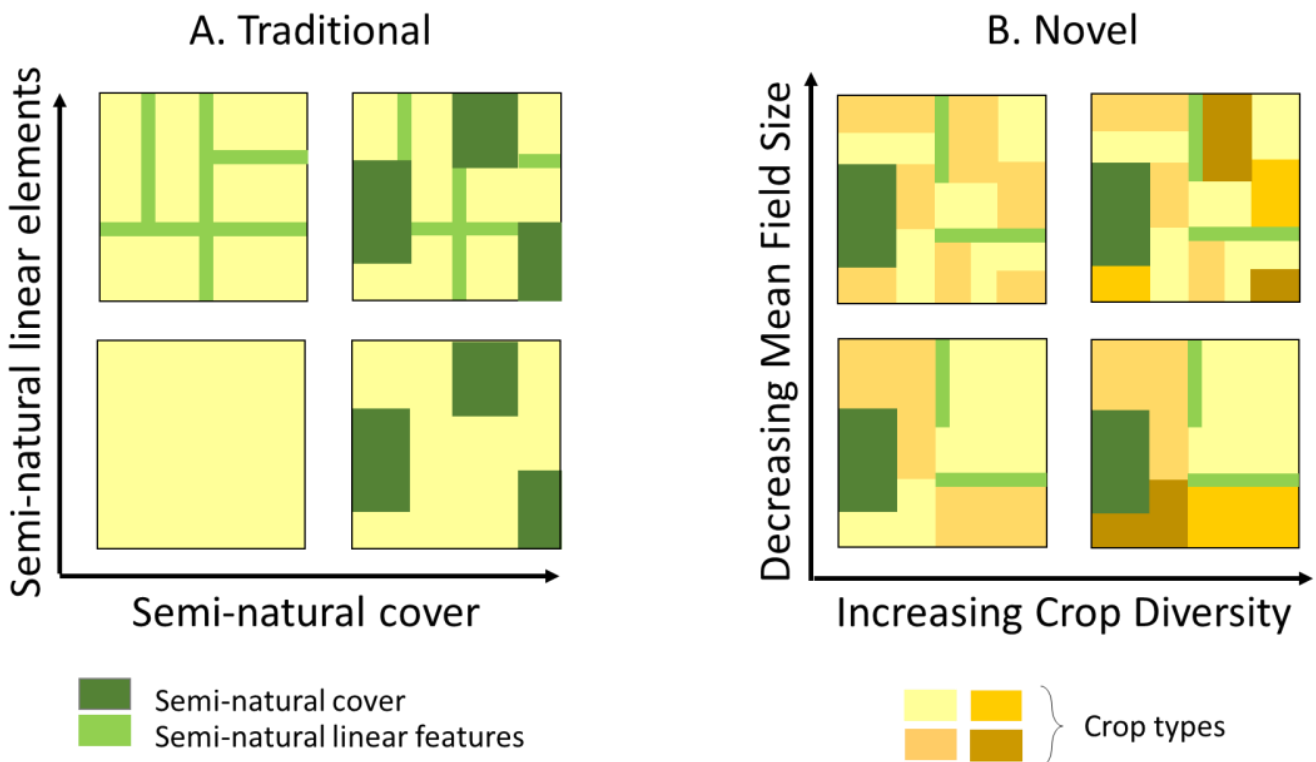

Figure 1. A) Traditional representations of agricultural landscapes have focused on the amount of semi-natural covers and semi-natural linear elements, often considering the farmed part of the landscape as a homogeneous matrix. These representations are associated with the hypothesis that increasing the amount of semi-natural covers and semi-natural linear elements benefits biodiversity. B) Novel representations of agricultural landscapes consider the heterogeneity of the farmed part of the landscape. These representations are associated with new hypotheses: increasing crop heterogeneity by increasing crop diversity and/or decreasing mean field size, while maintaining seminatural cover and semi-natural linear elements constant, benefits biodiversity (large squares represent landscapes, adapted from Fahrig et al. 2011). 
We selected 435 landscapes along orthogonal gradients of crop diversity and mean field size in eight contrasting agricultural regions in France, the United Kingdom, Germany, Spain and Canada (Fig. S2.1 in SI 2). In each landscape, we selected three fields in which we sampled seven taxa representing a wide range of ecological traits, functions and trophic levels (plants, bees, butterflies, hoverflies, carabids, spiders and birds). We then computed a multidiversity index, as a proxy for biodiversity observed within each landscape (Methods). We tested the relative effects of crop diversity and mean field size on biodiversity and evaluated whether these effects were non-linear, non-additive, and influenced by semi-natural cover (see detailed hypotheses in SI 1).

\section{Results and Discussion}

Our study provides the first large-scale evidence that crop heterogeneity is a major driver of multitropic biodiversity in agricultural landscapes (Fig. 2). Crop diversity, the number of crop types sampled and mean field size were consistently included in all models (Fig. 2A). Crop heterogeneity accounted for $60.7 \%$ of the explained variance while semi-natural cover only accounted for $23.6 \%$ of the explained variance in biodiversity (Fig. 2B). Interactions between crop diversity / mean field size and semi-natural cover also accounted for an important part of the explained variance (15.6\%), indicating that their effects on biodiversity are largely modulated by the amount of semi-natural cover in the landscape (Fig. 2B). Increasing crop diversity was more beneficial to biodiversity in landscapes with high semi-natural cover (Fig. 2C) whereas decreasing mean field was more beneficial in landscapes with low semi-natural cover (Fig. 2D). The effects of crop diversity and mean field size on biodiversity were consistent across eight European and North American regions (Fig. S5.4 in SI 5). They hold true when considering either landscape-level or field-level multitrophic biodiversity, including when focusing only on cereal fields, the most dominant crop type across our eight regions (Table S5.10 in SI 5). Their effects also remained unchanged when the number and identity of crop types sampled, the composition of the crop mosaic, the amount of grassland, the amount of hedgerows, or land-use intensity (i.e. an index combining data on ploughing, fertilizer, herbicide and insecticide) were taken into account in our analyses (see additional analyses in SI 5).

\section{Effects of decreasing mean field size on biodiversity}

Decreasing mean field size was the main driver of biodiversity in our averaged model, mean field size and mean field size ${ }^{2}$ explaining $47.4 \%$ of its variance (Fig. 2B). The positive effect of decreasing mean field size was particularly strong when mean field size decreased below 6 ha, the effect of decreasing mean field size from 5 to 2.75 ha being as strong as the effect of increasing semi-natural habitat from 0.5 to $11 \%$ (Fig. 2D). Such positive effect of decreasing mean field size on biodiversity is consistent 
with the hypothesis that smaller fields provide easier access to multiple cover patches for species that require resources occurring in different cover types (landscape complementation; (Dunning et al. 1992).

A

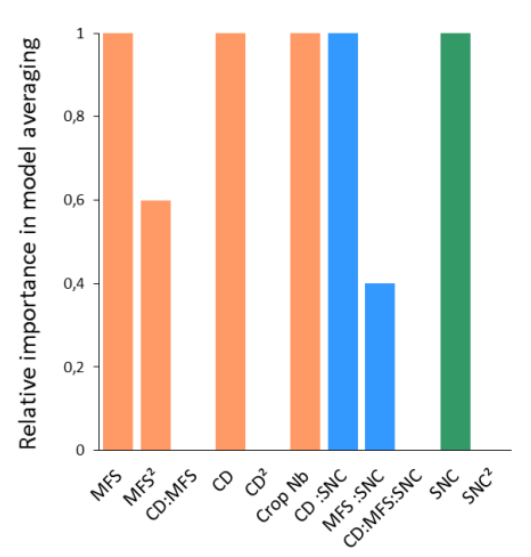

C

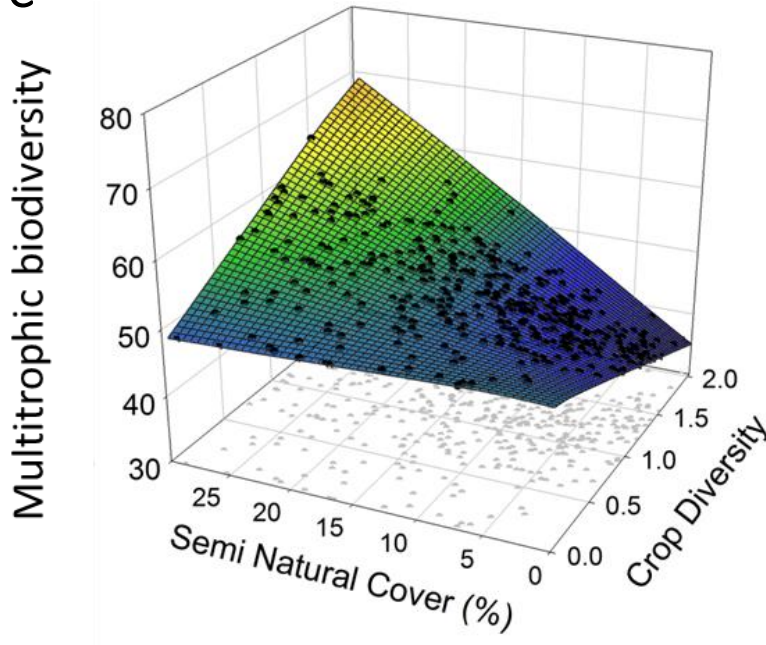

B

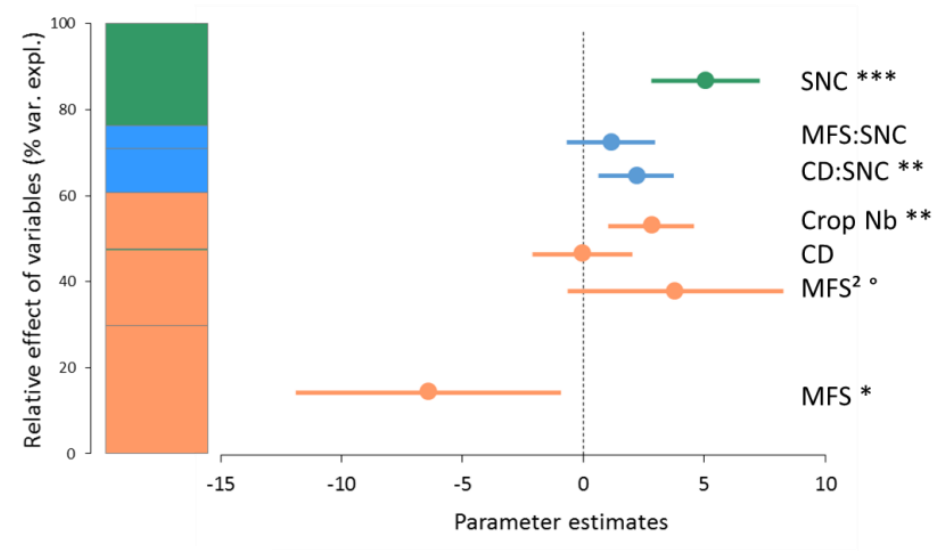

D

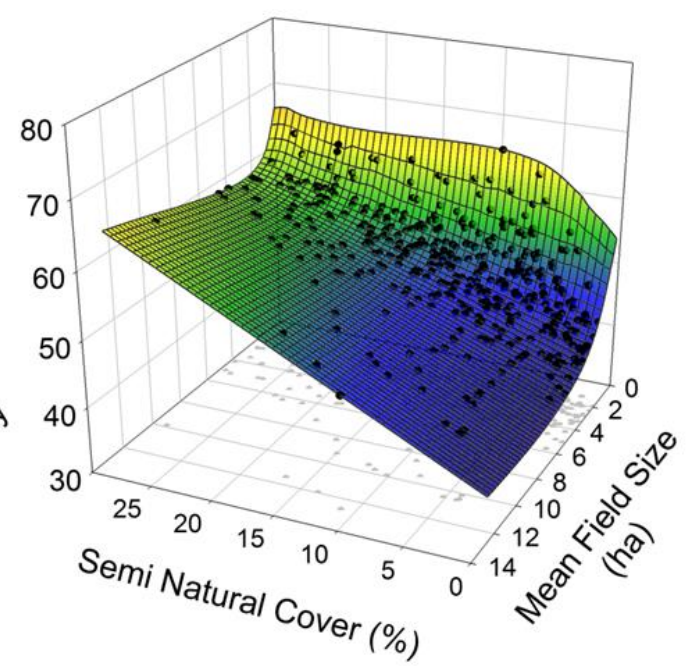

Figure 2. Effect of crop diversity (CD), the number of crops sampled (Crop Nb), mean field size (MFS), semi-natural cover (SNC), and their interaction terms on multitrophic biodiversity (T60.landscape) based on data collected in 435 landscapes located in 8 agricultural regions. A) Importance of each variable in the model averaging approach, estimated as the proportion of models where the variable was selected. B) Parameter estimates, based on model 2 and the model averaging approach defined in the Methods. ${ }^{\circ} \mathrm{p}<0.1 ;{ }^{*} \mathrm{p}<0.05 ;{ }^{* *} \mathrm{p}<0.01 ;{ }^{* *} \mathrm{p}<0.001$. The relative effect of each variable corresponds to the ratio between its parameter estimate and the sum of all parameter estimates (i.e. the \% or variance explained, as explained in (Grace \& Bollen 2005). Variables are grouped in three components: orange $=$ crop heterogeneity (MFS, MFS $\left.{ }^{2}, C D, C D^{2}, M F S: C D, C r o p ~ N b\right)$, green = seminatural cover $\left(S N C, S N C^{2}\right)$, blue = interactive effects between crop heterogeneity and semi-natural cover (CD:SNC, MFS:SNC, CD:MFS:SNC). C) Interactive effects of crop diversity and semi-natural cover on multitrophic biodiversity. D) Interactive effects of mean field size and semi-natural cover on multitrophic biodiversity. The direction of the mean field size axis is reversed to improve readability. In Figure $C$ and $D$, the parameter estimates of all other variables were fixed to their mean values, i.e., 0 as all predictors were scaled. Surfaces correspond to values of biodiversity predicted by model 2 and the model averaging approach defined in Methods. The colour gradient corresponds to biodiversity values, ranging from low values (blue) to high values (red). Dots represent the 435 landscapes sampled and show the overall gradients of crop diversity and mean field size across the eight regions. 
Although the strength of this effect varied significantly among regions, it remained consistently positive across all regions (Fig. S5.4 in SI 5) and was also consistent across all taxa studied, from primary producers to top predators (Fig. 3A and Table S5.1 in SI 5). Previous studies have already reported positive effect of decreasing mean field size on the diversity of several taxa considered separately (Fahrig et al. 2015; Collins \& Fahrig 2017; Hass et al. 2018; Monck-Whipp et al. 2018; Šálek et al. 2018). Our study, based on multiple regions and multiple trophic groups, shows that the benefits of decreasing mean field size can be generalized to multitrophic biodiversity across a wide range of agricultural regions.

Previous studies suggested that the positive effect of decreasing mean field size on biodiversity may be primarily due to the presence of semi-natural vegetation between fields (Fahrig et al. 2015; Collins \& Fahrig 2017; Hass et al. 2018; Monck-Whipp et al. 2018; Šálek et al. 2018). To test this hypothesis, we selected a subset of landscapes for which mean field size and the amount of seminatural vegetation between fields were uncorrelated (see details in section 5.4 in SI 5). The analysis based on this subset showed that increasing the amount of semi-natural elements between fields had a positive effect on biodiversity but that it did not change the effect of mean field size on biodiversity (Table S5.7 in SI 5). This result suggests for the first time that smaller fields may benefit biodiversity even in the absence of semi-natural vegetation between fields.

Finally, the presence of the interaction term between mean field size and semi-natural cover in our model (Fig. 2B) suggested that the effect of mean field size on biodiversity may be modulated by the amount of semi-natural cover available in the landscape (Fig. 2D). To further explore this interaction, we used a moving window modeling approach (Berdugo et al. 2019); see details in section S5.7 in SI 5). This analysis confirmed that decreasing mean field size had a consistent positive effect on multitrophic biodiversity along the gradient of semi-natural cover, with a stronger effect when seminatural cover was below $8 \%$ (Fig. 4B). This result suggests that decreasing mean field size may be less effective when semi-natural cover is high enough (above $8 \%$ ) to provide sufficient access to the multiple ressources required by most species occurring in agricultural landscapes.

\section{Effects of increasing crop diversity on biodiversity}

Increasing crop diversity may benefit biodiversity as a result of two processes: 1) if many species are specialists of distinct crop types (i.e. habitat specialization process; Weibull et al. 2003); and 2) if many species require multiple resources provided by different crop types (i.e. landscape complementation process; (Dunning et al. 1992); and see detailed hypotheses in SI 1). To disentangle these two processes, we included both the number of crop types sampled within each landscape (to test the habitat specialization hypothesis) and the crop diversity available within each landscape (to test the landscape complementation hypothesis) as explanatory variables in our model. Both variables were 
consistently included in all models (Fig. 2A). We found a positive effect of the number of crop types sampled on biodiversity explaining $13 \%$ of its variance (Fig. 2A). In line with the habitat specialization hypothesis, this result confirms that increasing crop diversity benefits multitrophic biodiversity across a wide range of agricultural regions by providing a higher number of habitats (e.g. Gaba et al. 2010).

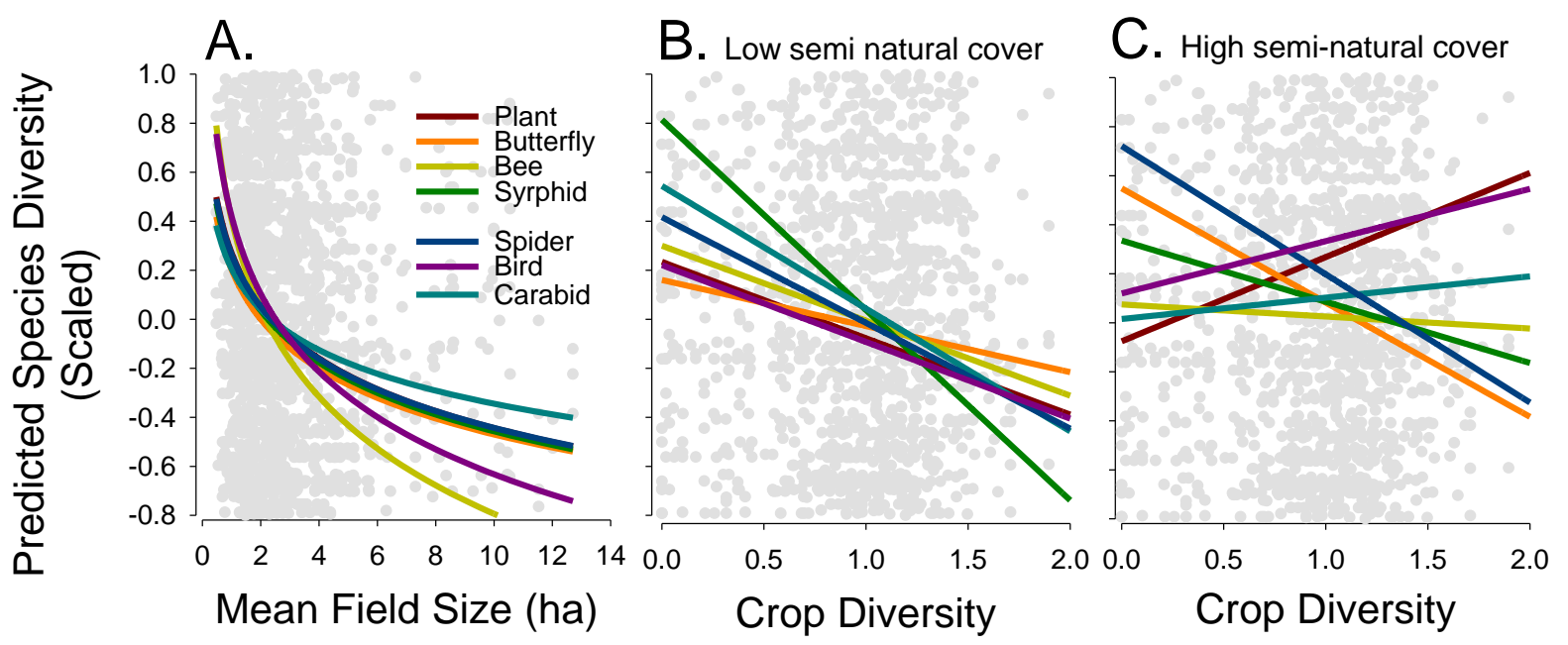

Figure 3. Predicted response of each taxa to: A) mean field size; B) crop diversity at low semi natural cover (e.g. $<5 \%$ ); and C) crop diversity at high semi natural cover (e.g. $>15 \%)$. Predicted values are scaled. Light grey points correspond to species diversity observed for each taxa in the 435 landscapes. Lines correspond to the outcomes of model 1 with Taxa as a fixed effect (Table S5.1 in SI 5). Colours correspond to taxa.
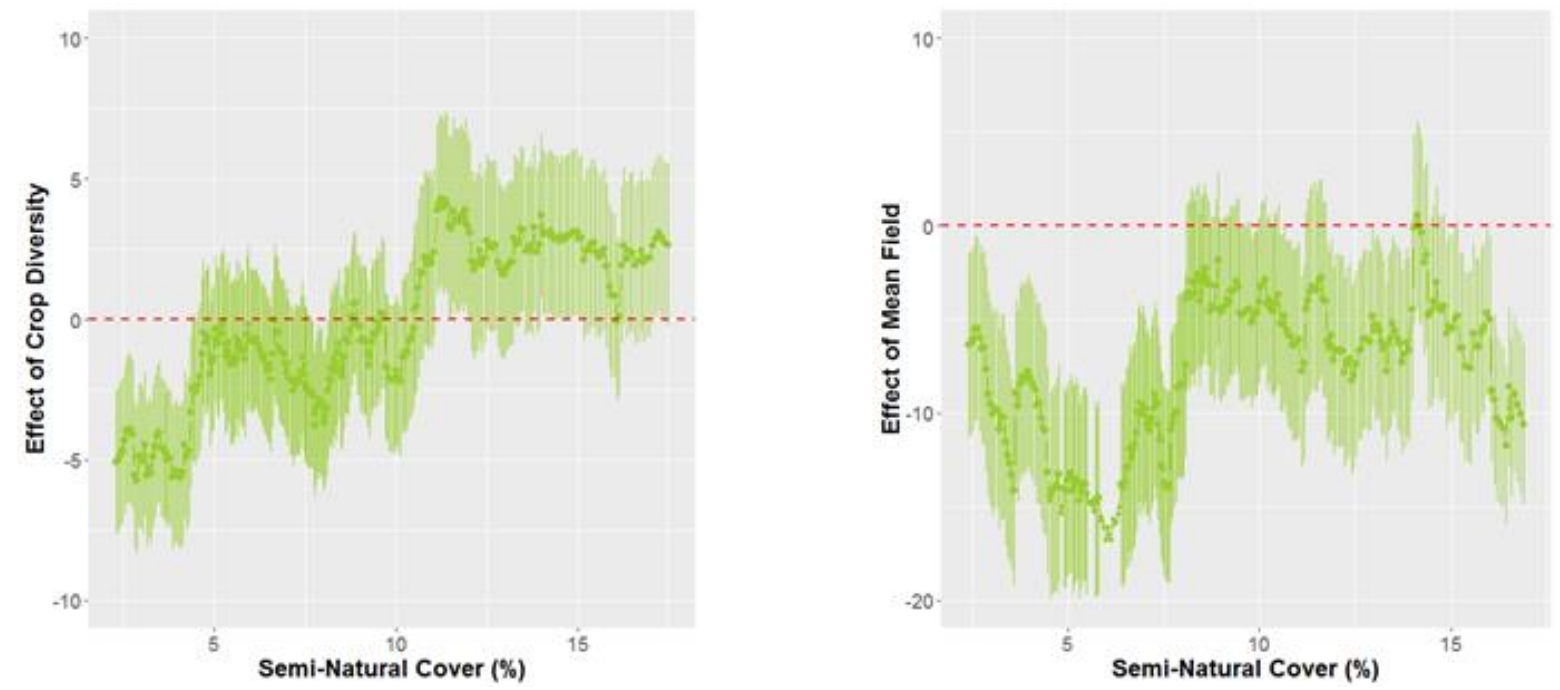

Figure 4. Effect of crop diversity (A) and mean field size (B) on biodiversity for different levels of seminatural cover. Parameter estimates and confidence intervals are based on a moving window analysis (see detailed description in SI5). The red line indicates a null effect. Each dot and confidence interval corresponds to the average semi-natural cover for a given window along the semi-natural cover gradient. Due to the low number of landscapes with semi-natural cover $>17.5 \%$ (Table S4.1), we only represent the gradient between 0 and $17.5 \%$ of semi-natural cover on these figures. 
Although crop diversity was consistently included in all models (Fig. 2A), its effect on biodiversity was complex. Indeed, the interaction between crop diversity and semi-natural cover was also consistently included in all models (Fig. 2A) and had a significant positive effect on biodiversity explaining 10.25\% of its variance (Fig. 2B). Our model therefore suggested that increasing crop diversity was more beneficial to biodiversity in landscapes with high semi-natural cover (Fig. 2C). To further explore this interaction, we used the same moving window modeling approach described above (see section S5.7 in SI 5 for details). This analysis confirmed that increasing crop diversity had a positive effect on biodiversity in landscapes with high semi-natural cover (above 11\%; Fig. 4A). Additionally, it suggested that increasing crop diversity had a non-significant effect on biodiversity in landscapes with 4 to $11 \%$ semi-natural cover, and a negative effect on biodiversity in landscapes with less than $4 \%$ semi-natural cover (Fig. 4A).

The positive effect of crop diversity on biodiversity in landscapes with high semi-natural cover is consistent with the landscape complementation hypothesis predicting that a diverse crop matrix provides a temporal continuity of food sources (Schellhorn et al. 2015) while semi-natural patches provide stable resources, for example, for nesting or shelter (e.g. Sirami et al. 2011). Such complementation among multiple cover types has been described for several species (e.g. Pope et al. 2000; Mueller et al. 2009; Marrec et al. 2015). It is interesting to note that the positive effect of crop diversity in landscapes with high semi-natural cover was not observed for all taxa (Fig. 3C). This result is consistent with the variability observed across previous studies on single taxa (Fahrig et al. 2015; Josefsson et al. 2017; Hass et al. 2018; Monck-Whipp et al. 2018; Olimpi \& Philpott 2018). Such variability highlights the value of using a synthetic index of multitrophic biodiversity to identify landscape conditions that simultaneously maximize the diversity of most taxa.

The negative effect of crop diversity in landscapes with low semi-natural cover is more challenging to explain. That this effect is consistent across regions and across taxa (Fig. 3B) indicates that it may be biologically significant and underlying causes may be general across farming systems and taxa. Previous studies have hypothesized that the effect of crop diversity on biodiversity may be tightly related to management practices (e.g. Olimpi \& Philpott 2018). To explore this hypothesis, we conducted a model averaging approach using a synthetic index of multitrophic biodiversity calculated at the field level as response variable and adding land-use intensity (i.e. an index combining data on ploughing, fertilizer, herbicide and insecticide) to the set of explanatory variables (section 5.5.3 in SI 5). Although land-use intensity had a significant negative effect on biodiversity, the effects of crop diversity, and the interaction between crop diversity and semi-natural cover, remained unchanged (Table S5.11 in SI 5). An alternative explanation could be that cleared landscapes are likely to host fewer species specialized on specific crop types (Tscharntke et al. 2012). If these species have high total habitat requirements, an increase in the number of crop types may result in insufficient 
resources for species associated with individual crop types (e.g. habitat-specialists that have very large territories; (Fahrig et al. 2011). Uncovering mechanisms explaining this counter-intuitive effect requires further investigation, in particular on the role of crop functional diversity (Josefsson et al. 2017).

\section{Implications for agricultural policies}

Our study has two important implications for large-scale policy schemes implemented across a wide range of contexts, e.g. the European Common Agricultural Policy and its recent greening (Pe'er et al. 2014), the Canadian Agriculture Policy Frameworks (Deaton \& Boxall 2017), or the United States Farm Bill (Reimer 2015).

First, our results suggest that increasing crop heterogeneity, especially by decreasing mean field sizes, may have a similar or greater benefit for biodiversity than increasing semi-natural cover (Fig. 2A) or even decreasing field-level land use intensity (Table S5.11 in SI 5). Given current challenges to increase semi-natural cover and limit agro-chemical use in agricultural landscapes (Pe'er et al. 2017), policies aiming at increasing crop heterogeneity may represent an effective and complementary way to improve biodiversity conservation in agricultural landscapes. Policy measures favouring crop heterogeneity may be more easily implemented (Rodríguez \& Wiegand 2009). They may also be more favourably perceived by farmers and thus lead to higher uptake than measures requiring farmers to take land out of production (Pe'er et al. 2017). They also represent important potential steps towards the development of new frameworks that reward farmers for sustainable land stewardship.

Second, by identifying thresholds in the response of biodiversity to crop heterogeneity along semi-natural cover gradients, our study may contribute to the development of policies adapted to different landscape contexts. For instance, our results suggest that effective policies should particularly promote 1) measures aimed at decreasing field sizes to below 6 ha in landscapes where semi-natural cover is below 8\%; 2) measures aimed at increasing crop diversity in landscapes where semi-natural cover exceeds $11 \%$.

\section{Conclusions}

Our study demonstrates the importance of crop heterogeneity for multitrophic biodiversity in agricultural landscapes: the effect of maintaining/increasing crop heterogeneity is likely to be as important as the effect of maintaining/increasing semi-natural cover. Our study therefore provides the first large scale evidence that crop specialization and field enlargment are underestimated drivers of past and ongoing biodiversity declines. More importantly, our study shows that increasing crop 
diversity and decreasing field size represent major leverages to increase synergies between food production and biodiversity conservation.

\section{Methods}

\section{Region and landscape selection}

We selected eight agricultural regions (Armorique, Camargue, Coteaux de Gascogne and Plaine et Val de Sèvre in France, East Anglia in the United Kingdom, Goettingen in Germany, Lleida in Spain and Eastern Ontario in Canada; Fig. S2.1 in SI 2) belonging to six different ecoregions (Olson et al. 2001) and differing in topography, climate, field shapes, and agricultural cover types and products (e.g. rice, dairy, tree crops). We used the best spatial data available within each region prior to field work to identify all $1 \mathrm{~km} \times 1 \mathrm{~km}$ rural landscapes, i.e. those dominated by agricultural cover $(>60 \%$, including all crops and grassland managed for agricultural production). We then developed a protocol to select a combination of landscapes that maximised the gradients of crop compositional heterogeneity (crop diversity) and crop configurational heterogeneity (mean field size) while minimizing the correlation between them (Pasher et al. 2013). Crop diversity may theoretically be constrained by the number and size of fields in landscapes with large fields. However, in our dataset, mean field size was smaller than 12 ha and was therefore not a limiting factor for crop diversity within the $1 \mathrm{~km} \times 1 \mathrm{~km}$ landscapes. We selected between 32 and 93 landscapes within each region, totalling 435 landscapes across all regions.

\section{Biodiversity sampling}

We selected seven taxa representing a wide range of ecological traits, functions and trophic levels which, combined into the multidiversity index (see below), represent a proxy for biodiversity: plants, bees, butterflies, hoverflies, carabids, spiders and birds. All taxa were sampled using standardized sampling protocols across all regions, allowing us to test the consistency of effects across the eight regions (SI 3).

We selected three sampling sites within each landscape, totalling 1305 sampling sites across all regions. The three sampling sites were at least $200 \mathrm{~m}$ from each other, at least $50 \mathrm{~m}$ from the border of the landscape, and at least $50 \mathrm{~m}$ from patches of non-agricultural cover types such as forests and urban areas. Where feasible, we located sampling sites in dominant agricultural cover types within each region (e.g. wheat fields and oilseed rape in Goettingen). When this was not feasible, we located sampling sites in the agricultural cover types that were accessible within a given landscape (SI 3).

At each sampling site, we selected two parallel $50 \mathrm{~m}$ 'transects', one located at the field edge and the other inside the field $25 \mathrm{~m}$ away from the first transect, totalling 2610 transects across all 
regions (Fig. S3.1 and S3. 2 in SI 3). Birds were sampled using point-counts centred on the field-edge transect. Plants were surveyed along both transects. Butterflies were surveyed visually using timed walks along both transects. Bees and hoverflies were sampled using coloured pan traps on poles erected at each end and in the centre of all transects. Carabids and spiders were sampled using pitfall traps installed at each end of all transects. Captured arthropods were preserved in ethanol for identification later. Multiple survey visits were conducted during the season when relevant (SI 3). Each landscape was sampled during one year and sampling of landscapes was distributed across two years within each region, between 2011 and 2014 (see further details on the timing of our sampling in Table S3.1 in SI 3).

We identified more than 167,000 individuals from 2795 species (Table S3.2 in SI 3). For each taxa, we calculated species richness at the landscape level, i.e. across all three sampling sites and across all visits when multiple survey visits were conducted. The average species richness per landscape varied greatly among taxa, from 5.4 for butterflies to 44.9 for plants. Correlations in average species richness between pairs of taxa were weak $(<0.41)$ with an average correlation of 0.07 (Table $\mathrm{S} 3.3$ in SI 3).

\section{Assessing multitrophic biodiversity at the landscape scale}

To test the effects of crop heterogeneity on landscape-level biodiversity, we used an approach that was originally developed to study ecosystem multifunctionality (e.g. Allan et al. 2014). The idea is to identify landscape conditions that benefit the diversity of most taxa simultaneously within a given landscape. A first approach used in the literature consisted of calculating the average standardized diversity values of multiple taxa (Byrnes et al. 2014). However, this approach has limitations (see SI 3): although very high/low values imply that all taxa exhibit high/low diversity, intermediate values are difficult to interpret as they may correspond to situations where (i) diversity values are intermediate for all taxa; or (ii) diversity values are high for some taxa and low for others, i.e. trade-offs among taxa.

To overcome these limitations, we adapted the threshold approach developed to aggregate multiple ecosystem functions (Zavaleta et al. 2010) to multiple taxa. The objective of this approach is to assess the ability of agricultural landscapes to simultaneously host at least a given percentage, or threshold ( $\mathrm{x}$ ), of the maximum species richness observed for each taxa (SRmax). Because SRmax is likely to vary between regions, we chose to use the 95th percentile of the maximum observed species richness within each region for each taxa. We then calculated a multidiversity index (TX.landscape) for each landscape based on the following formula, where SR $\mathrm{i}$ is the number of species for taxa $\mathrm{i}, \mathrm{x}$ is the minimum \% to be reached and SRmax.region $j$ is the maximum species richness for taxa $i$ in the region the landscape considered belong to: 


$$
\text { Multidiversity (Tx. landscape })=\frac{1}{7} \sum_{i=1}^{\mathrm{n}=7}(\mathrm{SR} \mathrm{i}>(\mathrm{x} \times \text { SR max. region } \mathrm{j}))
$$

We calculated this multidiversity index for each threshold $\mathrm{x}$ between 20 and $90 \%$ using a moving average with intervals [x-10\%] to smooth the calculation (see details in section 3.3 in SI 3). Landscape multidiversity indices calculated for different thresholds were strongly correlated. We chose to use the intermediate threshold T60.landscape beause 1) intermediate thresholds have been shown to provide an effective measure of biodiversity in agricultural landscapes (Byrnes et al. 2014) and 2) T60.landscape shows a distribution ranging from 0, i.e. none of the taxa reach $60 \%$ of the regional maximum, to 100 i.e. all taxa reach $60 \%$ of the regional maximum (mean value for T60.landscape $=$ 45.1). Nevertheless, we verified that our results were not sensitive to the threshold selected (Fig. S5.3 in SI 5).

\section{Crop compositional and configurational heterogeneity}

We used a standardized protocol across all regions to produce land cover maps allowing us to compare consistency of effects across the eight regions (SI 4). We conducted extensive groundtruthing surveys during the field seasons to map all fields, linear elements between adjacent fields and non-agricultural covers. We built a common land cover classification for the eight regions. Agricultural cover types included all crops, as well as temporary and permanent grassland managed for production purposes (SI 4). Linear elements between fields included hedgerows, grassy margins, ditches and tracks. Non-agricultural cover types included woodland (including woody linear elements), open land (e.g. extensive grassland, shrubland, grassy linear elements), wetland, and built-up areas (including roads). We then used these standardized detailed maps to calculate four explanatory variables for each landscape: crop diversity, mean field size, semi-natural cover, and total length of semi-natural linear elements between fields.

We used the Shannon diversity of agricultural cover types (hereafter "crop diversity"; CD) as a measure of crop compositional heterogeneity. We used mean field size in hectares (MFS) as a measure of crop configurational heterogeneity. Neither CD nor MFS was correlated with local land use intensity (an index combining data on ploughing, fertilizer, herbicide and insecticide, see section 5.5 in SI 5) or the composition of agricultural cover types within the landscape (section 5.4 in SI 5). CD and MFS were correlated with the type of crops sampled in some regions and MFS was correlated with the proportion of grassland in the crop mosaic, but none of these correlations affected our conclusions (SI 5). We calculated the percentage of each landscape in semi-natural cover types, i.e. woodland, open land and wetland (SNC). We also calculated the total length of linear semi-natural elements between fields, e.g. hedgerows, grassy margins (SNL; measured in meters). SNL and MFS were highly correlated in some regions (SI 5). As a result, we did not include SNL in the main analyses and only tested the 
relative effect of MFS and SNL using a subset of our dataset for which MFS and SNL were not strongly correlated (SI 5).

\section{Data analysis}

We first tested whether the effects of crop diversity and mean field size on species diversity were consistent across taxa. We fitted a linear mixed model with Restricted Maximum Likelihood using species richness per taxa and per landscape (SR) as the response variable. We included crop diversity (CD), mean field size (MFS) and semi-natural cover (SNC) as explanatory variables (see alternative hypotheses on crop heterogeneity-biodiversity relationships in SI 1). We included both interactive effects and quadratic effects. Due to positive skew in the distribution of mean field size, we used log mean field size in all analyses. We also added the number of crop types sampled (CropNb) as a covariate. We added Taxa and the interaction between Taxa and all fixed terms of the model. To reflect the large scale spatial and temporal structure of our dataset, we added sampling year (Year) nested within study region (Region) as a random effect. To reflect the spatial structure of our dataset within each region we included the longitude and latitude of the center of each landscape (Lat, Lon) as covariates. We standardized all fixed effects to allow for a direct comparison of estimates.

Model 1:

$\operatorname{Imer}\left(\mathrm{SR} \sim \operatorname{Taxa} *\left(\mathrm{CD} * \mathrm{MFS} * \mathrm{SNC}+\mathrm{CD}^{2}+\mathrm{MFS}^{2}+\mathrm{SNC}^{2}+\right.\right.$ CropNb $)+$ Lat + Lon + (1| Region/Year $\left.)\right)$

We then tested the overall effects of crop heterogeneity on biodiversity. To do this, we fitted the same model using landscape-level multidiversity (T60.landscape) as the response variable, after removing the fixed term Taxa.

\section{Model 2:}

Imer (T60.landscape $\sim$ CD * MFS * SNC + CD² MFS $^{2}+$ SNC $^{2}+$ CropNb + Lat + Lon + (1| Region/Year $\left.)\right)$

We fitted both models with Imer in the Ime4 package using LMER (Bates et al. 2015), we removed outliers using function romr.fnc from package LMERConvenienceFunctions (Tremblay \& Ransijn 2015) and ran diagnostic tools to verify that residuals were independently and normally distributed, and showed no spatial correlation. We selected all models with $\triangle \mathrm{AIC}<2$ based on AIC value fitted with Maximum Likelihood (Zuur et al. 2009). We then used the model averaging approach using LMER to estimate parameters and associated p-values, using the function model.avg from package MuMIn (Barton 2009). We ran all analyses using the software R 3.4.0 (R Core Team 2016).

We ran additional analyses to check that the composition of the crop mosaic, the proportion of grassland in the crop mosaic, the amount of semi-natural vegetation occurring between fields do 
not affect our conclusion (section 5.4 in SI 5). We also ran complementary analyses using field-level multidiversity (T60.field) as the response variable (rather than landscape-level multidiversity, T60.landscape) to check that our results hold true at the field level, in particular within a subset of cereal fields, and that the type of crop sampled or the level of land use intensity within sampled fields do not affect our conclusions (section 5.5 in SI 5). We then tested whether the effects of crop diversity and mean field size hold true within each region (section 5.6 in SI 5). Finally, we used a moving window analysis to identify potential discontinuities in biodiversity response to crop diversity and mean field size along the gradient of semi-natural cover (section 5.7 in SI 5).

\section{Acknowledgments}

This research was funded by the ERA-Net BiodivERsA, with the national funders French National Research Agency (ANR-11-EBID-0004), German Ministry of Research and Education, German Research Foundation and Spanish Ministry of Economy and Competitiveness, part of the 2011 BiodivERsA call for research proposals. The UK component of this research was funded by the UK Government Department of the Environment, Food and Rural Affairs (Defra), as project WC1034. The Canadian component of this research was funded by a Natural Sciences and Engineering Research Council of Canada (NSERC) Strategic Project, the Canada Foundation for Innovation, Environment Canada (EC), and Agriculture and Agri-Food Canada (AAFC). N.G. was support by the AgreenSkillst fellowship programme which has received funding from the EU's Seventh Framework Programme under grant agreement N FP7-609398 (AgreenSkills+ contract). A. Gil-Tena (Juan de la Cierva fellow, JCl-201212089) was funded by Ministerio de Economía y Competitividad (Spain). C Violle was supported by the European Research Council (ERC) Starting Grant Project "Ecophysiological and biophysical constraints on domestication of crop plants" (Grant ERC-StG-2014-639706-CONSTRAINTS). We would like to thank the hundreds of farmers and farm owners from all eight regions who graciously permitted us to work on their lands. In addition to the co-authors, the project involved direct assistance from more than 150 individuals for geomatics analyses, field sampling, and species identification. We would like to thank all of them for their huge contribution to the FarmLand project and this study. Finally, we are grateful to the GLEL Friday Discussion Group for very helpful input.

\section{Author's contributions}

CS and NG wrote the first draft of the manuscript; $B P, F B, T T, V B, G S, A O, L B, J L M$ and $L F$ designed the FarmLand project; $C S, A B B, C B, R C, A H, L H, P M, A A, J G, D G, G$ Bota, FC, AGT, RG, SH, JR, XOSS, IR, JB, $J A B, A R, M A M-G, J M$ and $G S$ contributed data; $C S, N G, A B B, C B, R C, A H, L H, P M$ and $A A$ analyzed data; $C S, N G, A B B, C B, R C, A H, L H, P M, C$ Vuillot, AA, JG, PB, YC, C Violle, DG, G Bota, IB, GL, BG, AV, AGT, LT, 
$S M, K L, R G, S H, J R, X O S S, I R, J B, J A B, A R, M A M-G, J M, R M, A G, J B, G$ Balent, $B P, F B, T T, V B, G S, A O, L B$, JLM and LF provided feedback on the manuscript.

\section{References}

Aguilar, J., Gramig, G.G., Hendrickson, J.R., Archer, D.W., Forcella, F. \& Liebig, M.A. (2015). Crop Species Diversity Changes in the United States: 1978-2012. PLOS ONE, 10.

Allan, E., Bossdorf, O., Dormann, C.F., Prati, D., Gossner, M.M., Tscharntke, T., et al. (2014). Interannual variation in land-use intensity enhances grassland multidiversity. Proc. Natl. Acad. Sci. U. S. A., 111, 308-313.

Barr, C.J. \& Gillespie, M.K. (2000). Estimating hedgerow length and pattern characteristics in Great Britain using Countryside Survey data. J. Environ. Manage., 60, 23-32.

Barton, K. (2009). MuMIn : multi-model inference, R package version 0.12.0. Httpr-Forg.-Proj.

Batáry, P., Dicks, L.V., Kleijn, D. \& Sutherland, W.J. (2015). The role of agri-environment schemes in conservation and environmental management. Conserv. Biol., 29, 1006-1016.

Batáry, P., Fischer, J., Báldi, A., Crist, T.O. \& Tscharntke, T. (2011). Does habitat heterogeneity increase farmland biodiversity? Front. Ecol. Environ., 9, 152-153.

Bates, D., Mächler, M., Bolker, B.M. \& Walker, S.C. (2015). Fitting linear mixed-effects models using Ime4. J. Stat. Softw., 67, 1-48.

Benton, T.G., Vickery, J.A. \& Wilson, J.D. (2003). Farmland biodiversity: is habitat heterogeneity the key? Trends Ecol Evol, 18, 182-188.

Berdugo, M., Maestre, F.T., Kéfi, S., Gross, N., Bagousse-Pinguet, Y.L. \& Soliveres, S. (2019). Aridity preferences alter the relative importance of abiotic and biotic drivers on plant species abundance in global drylands. J. Ecol., 107, 190-202

Burel, F., Butet, A., Delettre, Y.R. \& de la Pena, N.M. (2004). Differential response of selected taxa to landscape context and agricultural intensification. Landsc. Urban Plan., 67, 195-204.

Byrnes, J.E.K., Gamfeldt, L., Isbell, F., Lefcheck, J.S., Griffin, J.N., Hector, A., et al. (2014). Investigating the relationship between biodiversity and ecosystem multifunctionality: challenges and solutions. Methods Ecol. Evol., 5, 111-124.

Collins, S.J. \& Fahrig, L. (2017). Responses of anurans to composition and configuration of agricultural landscapes. Agric. Ecosyst. Environ., 239, 399-409.

Deaton, B.J. \& Boxall, P. (2017). Canadian Agricultural Policy in the Twenty-First Century: Looking Back and Going Forward. Can. J. Agric. Econ. Can. Daposagroeconomie, 65, 519-522.

Díaz, S., Demissew, S., Carabias, J., Joly, C., Lonsdale, M., Ash, N., et al. (2015). The IPBES Conceptual Framework - connecting nature and people. Curr. Opin. Environ. Sustain., Open Issue, 14, 116.

Dormann, C.F., Schweiger, O., Augenstein, I., Bailey, D., Billeter, R., De Blust, G., et al. (2007). Effects of landscape structure and land-use intensity on similarity of plant and animal communities. Glob. Ecol. Biogeogr., 16, 774-787.

Dunning, J.B., Danielson, B.J. \& Pulliam, H.R. (1992). Ecological processes that affect populations in complex landscapes. Oikos, 65, 169-175.

Fahrig, L., Baudry, J., Brotons, L., Burel, F.G., Crist, T.O., Fuller, R.J., et al. (2011). Functional landscape heterogeneity and animal biodiversity in agricultural landscapes. Ecol. Lett., 14, 101-112.

Fahrig, L., Girard, J., Duro, D., Pasher, J., Smith, A., Javorek, S., et al. (2015). Farmlands with smaller crop fields have higher within-field biodiversity. Agric. Ecosyst. Environ., 200, 219-234.

Foley, J.A., DeFries, R., Asner, G.P., Barford, C., Bonan, G.B., Carpenter, S.R., et al. (2005). Global consequences of land use. Science, 309, 570-574.

Gaba, S., Chauvel, B., Dessaint, F., Bretagnolle, V. \& Petit, S. (2010). Weed species richness in winter wheat increases with landscape heterogeneity. Agric. Ecosyst. Environ., 138, 318-323. 
Grace, J.B. \& Bollen, K.A. (2005). Interpreting the Results from Multiple Regression and Structural Equation Models. Bull. Ecol. Soc. Am., 86, 283-295.

Hass, A.L., Kormann, U.G., Tscharntke, T., Clough, Y., Baillod, A.B., Sirami, C., et al. (2018). Landscape configurational heterogeneity by small-scale agriculture, not crop diversity, maintains pollinators and plant reproduction in western Europe. Proc R Soc B, 285, 20172242.

Henderson, I.G., Vickery, J.A. \& Carter, N. (2004). The use of winter bird crops by farmland birds in lowland England. Biol. Conserv., 118, 21-32.

Holzschuh, A., Dormann, C.F., Tscharntke, T. \& Steffan-Dewenter, I. (2013). Mass-flowering crops enhance wild bee abundance. Oecologia, 172, 477-484.

Josefsson, J., Berg, Å., Hiron, M., Pärt, T. \& Eggers, S. (2017). Sensitivity of the farmland bird community to crop diversification in Sweden: does the CAP fit? J. Appl. Ecol., 54, 518-526.

Lüscher, G., Ammari, Y., Andriets, A., Angelova, S., Arndorfer, M., Bailey, D., et al. (2016). Farmland biodiversity and agricultural management on 237 farms in 13 European and two African regions. Ecology, 97, 1625-1625.

Marrec, R., Badenhausser, I., Bretagnolle, V., Börger, L., Roncoroni, M., Guillon, N., et al. (2015). Crop succession and habitat preferences drive the distribution and abundance of carabid beetles in an agricultural landscape. Agric. Ecosyst. Environ., 199, 282-289.

Maxwell, S.L., Fuller, R.A., Brooks, T.M. \& Watson, J.E.M. (2016). Biodiversity: The ravages of guns, nets and bulldozers. Nature, 536, 143-145.

Miyashita, T., Chishiki, Y. \& Takagi, S.R. (2012). Landscape heterogeneity at multiple spatial scales enhances spider species richness in an agricultural landscape. Popul. Ecol., 54, 573-581.

Monck-Whipp, L., Martin, A.E., Francis, C.M. \& Fahrig, L. (2018). Farmland heterogeneity benefits bats in agricultural landscapes. Agric. Ecosyst. Environ., 253, 131-139.

Mueller, T., Selva, N., Pugacewicz, E. \& Prins, E. (2009). Scale-sensitive landscape complementation determines habitat suitability for a territorial generalist. Ecography, 32, 345-353.

Newbold, T., Hudson, L.N., Hill, S.L.L., Contu, S., Lysenko, I., Senior, R.A., et al. (2015). Global effects of land use on local terrestrial biodiversity. Nature, 520, 45-50.

Olimpi, E.M. \& Philpott, S.M. (2018). Agroecological farming practices promote bats. Agric. Ecosyst. Environ., 265, 282-291.

Olson, D.M., Dinerstein, E., Wikramanayake, E.D., Burgess, N.D., Powell, G.V.N., Underwood, E.C., et al. (2001). Terrestrial Ecoregions of the World: A New Map of Life on Earth A new global map of terrestrial ecoregions provides an innovative tool for conserving biodiversity. BioScience, 51, 933-938.

Pasher, J., Mitchell, S., King, D., Fahrig, L., Smith, A. \& Lindsay, K. (2013). Optimizing landscape selection for estimating relative effects of landscape variables on ecological responses. Landsc. Ecol., 28, 371-383.

Pe'er, G., Dicks, L.V., Visconti, P., Arlettaz, R., Báldi, A., Benton, T.G., et al. (2014). EU agricultural reform fails on biodiversity. Science, 344, 1090-1092.

Pe'er, G., Zinngrebe, Y., Hauck, J., Schindler, S., Dittrich, A., Zingg, S., et al. (2017). Adding Some Green to the Greening: Improving the EU's Ecological Focus Areas for Biodiversity and Farmers. Conserv. Lett., 10, 517-530.

Perović, D., Gámez-Virués, S., Börschig, C., Klein, A.-M., Krauss, J., Steckel, J., et al. (2015). Configurational landscape heterogeneity shapes functional community composition of grassland butterflies. J. Appl. Ecol., 52, 505-513.

Ponjoan, A., Bota, G. \& Mañosa, S. (2012). Ranging behaviour of little bustard males, Tetrax tetrax, in the lekking grounds. Behav. Processes, 91, 35-40.

Pope, S.E., Fahrig, L. \& Merriam, N.G. (2000). Landscape complementation and metapopulation effects on leopard frog populations. Ecology, 81, 2498-2508.

R Core Team. (2016). R: A language and environment for statistical computing. R Foundation for Statistical Computing. ISBN 3-900051-07-0, URL http://www.R-project.org., Vienna, Austria. 
Raymond, L., Sarthou, J.-P., Plantegenest, M., Gauffre, B., Ladet, S. \& Vialatte, A. (2014). Immature hoverflies overwinter in cultivated fields and may significantly control aphid populations in autumn. Agric. Ecosyst. Environ., 185, 99-105.

Reimer, A. (2015). Ecological modernization in U.S. agri-environmental programs: Trends in the 2014 Farm Bill. Land Use Policy, 47, 209-217.

Robinson, R.A. \& Sutherland, W.J. (2002). Post-war changes in arable farming and biodiversity in Great Britain. J Appl Ecol, 39, 157-176.

Rodríguez, C. \& Wiegand, K. (2009). Evaluating the trade-off between machinery efficiency and loss of biodiversity-friendly habitats in arable landscapes: The role of field size. Agric. Ecosyst. Environ., 129, 361-366.

Šálek, M., Hula, V., Kipson, M., Daňková, R., Niedobová, J. \& Gamero, A. (2018). Bringing diversity back to agriculture: Smaller fields and non-crop elements enhance biodiversity in intensively managed arable farmlands. Ecol. Indic., 90, 65-73.

Schellhorn, N.A., Gagic, V. \& Bommarco, R. (2015). Time will tell: resource continuity bolsters ecosystem services. Trends Ecol. Evol., 30, 524-530.

Sirami, C., Brotons, L. \& Martin, J. (2011). Woodlarks Lullula arborea and landscape heterogeneity created by land abandonment. Bird Study, 58, 99-106.

Soliveres, S., van der Plas, F., Manning, P., Prati, D., Gossner, M.M., Renner, S.C., et al. (2016). Biodiversity at multiple trophic levels is needed for ecosystem multifunctionality. Nature, 536, 456-459.

Tilman, D., Fargione, J., Wolff, B., D’Antonio, C., Dobson, A., Howarth, R., et al. (2001). Forecasting agriculturally driven global environmental change. Science, 292, 281-284.

Tremblay, A. \& Ransijn, J. (2015). LMERConvenienceFunctions: Model Selection and Post-hoc Analysis for (G)LMER Models.

Tscharntke, T., Tylianakis, J.M., Rand, T.A., Didham, R.K., Fahrig, L., Batáry, P., et al. (2012). Landscape moderation of biodiversity patterns and processes - eight hypotheses. Biol. Rev., 87, 661-685.

Weibull, A.-C., Östman, Ö. \& Granqvist, Å. (2003). Species richness in agroecosystems: the effect of landscape, habitat and farm management. Biodivers. Conserv., 12, 1335-1355.

White, E.V. \& Roy, D.P. (2015). A contemporary decennial examination of changing agricultural field sizes using Landsat time series data. Geo Geogr. Environ., 2, 33-54.

Zavaleta, E.S., Pasari, J.R., Hulvey, K.B. \& Tilman, G.D. (2010). Sustaining multiple ecosystem functions in grassland communities requires higher biodiversity. Proc. Natl. Acad. Sci. U. S. A., 107, 1443-1446.

Zuur, A., leno, E.N., Walker, N., Saveliev, A.A. \& Smith, G.M. (2009). Mixed effects models and extensions in ecology with $R$. Springer New York. 


\section{Supporting Information}

SI 1 - Hypotheses on the effects of crop heterogeneity on multidiversity

SI 2 - Region and landscape selection

SI 3 - Biodiversity sampling

SI 4 - Land cover mapping and landscape metrics

SI 5 - Complementary analysis 


\section{SI 1- Hypotheses on the effects of crop heterogeneity on multidiversity}

\subsection{Crop compositional heterogeneity (increasing crop diversity)}

Hyp 1a. Multidiversity increases with increasing crop diversity if different crop types can serve as habitat for different specialised species (single habitat specialisation; Andreasen et al. 1991; Weibull et al. 2003). Multidiversity may also increase with crop diversity if different crop types provide different resources required for single species (landscape complementation; Dunning et al. 1992). When sampling only a subset of crops within the landscape, it may be challenging to disentangle the role of landscape complementation from spill-over processes. Indeed, the higher number of habitat sources within the landscape may also result in the spillover of more species from adjacent fields (Schneider et al. 2016).

Hyp 1b. Multidiversity decreases with crop diversity if most species have high minimum total habitat area requirements, i.e. require high amount of a single crop type. An increase in the number of crop types results in a decrease in the total area of each crop type, which can result in insufficient resources for species associated with individual crop types (Fahrig et al. 2011; Tscharntke et al. 2012).

Hyp 1c. Multidiversity shows a peaked relationship with crop diversity (Allouche et al. 2012) if there is an initial increase in multidiversity with increasing crop diversity for reasons explained in Hyp 1a, but at higher levels of crop diversity, each crop type has a lower spatial cover and multidiversity decreases for reasons explained in Hyp $1 b$.

\subsection{Crop configurational heterogeneity (decreasing mean field size)}

Hyp 2a. Multidiversity increases with decreasing mean field size if landscapes with smaller fields provide easier access to multiple fields for species that require resources occurring in different crop types (landscape complementation). When sampling only a subset of crops within the landscape, it may be challenging to disentangle the role of landscape complementation from spill-over processes. Indeed, smaller fields may also increase mass effects, i.e. spillover from adjacent fields or from adjacent semi-natural vegetation occurring between fields.

Hyp 2b. Multidiversity decreases with decreasing mean field size if most species show negative edge effects and/or if most species have minimum patch size requirements (separate from their total habitat area requirements, see Hyp1b). 
Hyp 2c. Multidiversity shows a peaked relationship with decreasing mean field size if there is an initial increase in multidiversity for reasons explained in Hyp 2a and when mean field size reaches minimum patch size requirements for most species (Hyp 2b), multidiversity decreases.

\subsection{Interactions between crop compositional and configurational heterogeneity}

Hyp 3a. The positive effect of crop diversity on multidiversity is stronger when mean field size decreases (and vice-versa) if most species require multiple land cover types easily accessible (landscape complementation). Indeed, increasing crop diversity increases the chance that all required crop types are available, and decreasing field sizes increases accessibility among the required crop types.

Hyp 3b. The positive effect of crop diversity on multidiversity is weaker when mean field size is low if most species require landscape complementation and have minimum patch size requirements. Similarly, the positive effect of decreasing mean field size on multidiversity is weaker when crop diversity is high if the presence of a distinct crop type in the adjacent field results in a negative edge effect for most species within the sampled field.

Hyp 3c. The positive effect of crop diversity on multidiversity is independent of mean field size if most species are highly mobile and can access multiple fields regardless of mean field size. The positive effect of decreasing mean field size on multidiversity is independent of crop diversity if most species in landscapes with low mean field size primarily benefit from an easier access to semi-natural cover, in particular to semi-natural linear elements, rather than to multiple fields.

\subsection{Interactions between crop heterogeneity and semi-natural cover}

Hyp 4a. The positive effect of crop diversity on multidiversity is stronger when semi-natural cover (SNC) increases if most species require complementary resources found in semi-natural cover types and several crop types (e.g. species require SNC + crop A + crop B).

Hyp 4b. The positive effect of decreasing mean field size on multidiversity is stronger when seminatural cover (SNC) increases if most species in landscapes with low mean field size primarily benefit from an easier access to semi-natural cover, in particular to semi-natural linear elements, rather than an easier access to multiple fields. 
Hyp 4c. The positive effects of crop heterogeneity on biodiversity is stronger in landscapes with intermediate amounts of semi-natural cover (0-20\% semi-natural cover) than in cleared landscapes (0\%) or landscapes with high amounts of semi-natural cover (>20\% semi-natural cover) due to the intermediate landscape-complexity hypothesis (Tscharntke et al. 2012).

\section{References}

Allouche O, et al. (2012) Area-heterogeneity tradeoff and the diversity of ecological communities. Proc Natl Acad Sci 109(43):17495-17500.

Andreasen C, et al. (1991) Soil properties affecting the distribution of 37 weed species in Danish fields. Weed Res 31(4):181-187.

Dunning JB, et al. (1992) Ecological processes that affect populations in complex landscapes. Oikos 65(1):169-175.

Fahrig L, et al. (2011) Functional landscape heterogeneity and animal biodiversity in agricultural landscapes. Ecol Lett 14(2):101-112.

Schneider G, Krauss J, Boetzl FA, Fritze M-A, Steffan-Dewenter I (2016) Spillover from adjacent crop and forest habitats shapes carabid beetle assemblages in fragmented semi-natural grasslands. Oecologia 182(4):1141-1150.

Tscharntke T, et al. (2012) Landscape moderation of biodiversity patterns and processes - eight hypotheses. Biol Rev 87(3):661-685.

Weibull A-C, et al. (2003) Species richness in agroecosystems: the effect of landscape, habitat and farm management. Biodivers Conserv 12(7):1335-1355. 


\section{SI 2 - Region and landscape selection}

\subsection{Region selection}

We selected eight agricultural regions (Fig. S2.1) that belong to six different ecoregions (Olson et al. 2001) : Eastern Great Lakes lowland forests (Eastern Ontario in Canada), Celtic broadleaf forests and English lowland beech forests (East Anglia in United Kingdom), Atlantic mixed forests (Armorique, Plaine et Val de Sèvre in France), Western European broadleaf forests (Goettingen in Germany, Coteaux de Gascogne in France), Iberian sclerophyllous and semi-deciduous forests (Lleida in Spain) and Northeastern Spain \& Southern France Mediterranean forests (Camargue in France). Topography varied from flat (e.g. Camargue, Eastern Ontario) to intermediate (e.g. Goettingen, Lleida), to hilly (e.g. Coteaux de Gascogne). Climate varied from dry (e.g. Lleida) to humid (e.g. East Anglia). Complexity in crop field shapes varied from rectilinear (e.g. Camargue, Eastern Ontario) to intermediate complexity (e.g. Coteaux de Gascogne, Armorique) to complex field shapes (e.g. Lleida). Specific agricultural products were found in some regions, e.g. dairy (Armorique), olives (Lleida) or rice (Camargue). Diversity of agricultural cover types varied from low (e.g. Camargue, Lleida) to high (e.g. Coteaux de Gascogne, Plaine et Val de Sèvre). Mean field size varied from 1.2 ha in Lleida and 1.4 ha in Armorique to 4.4 ha in Eastern Ontario and 4.7 ha in East Anglia.

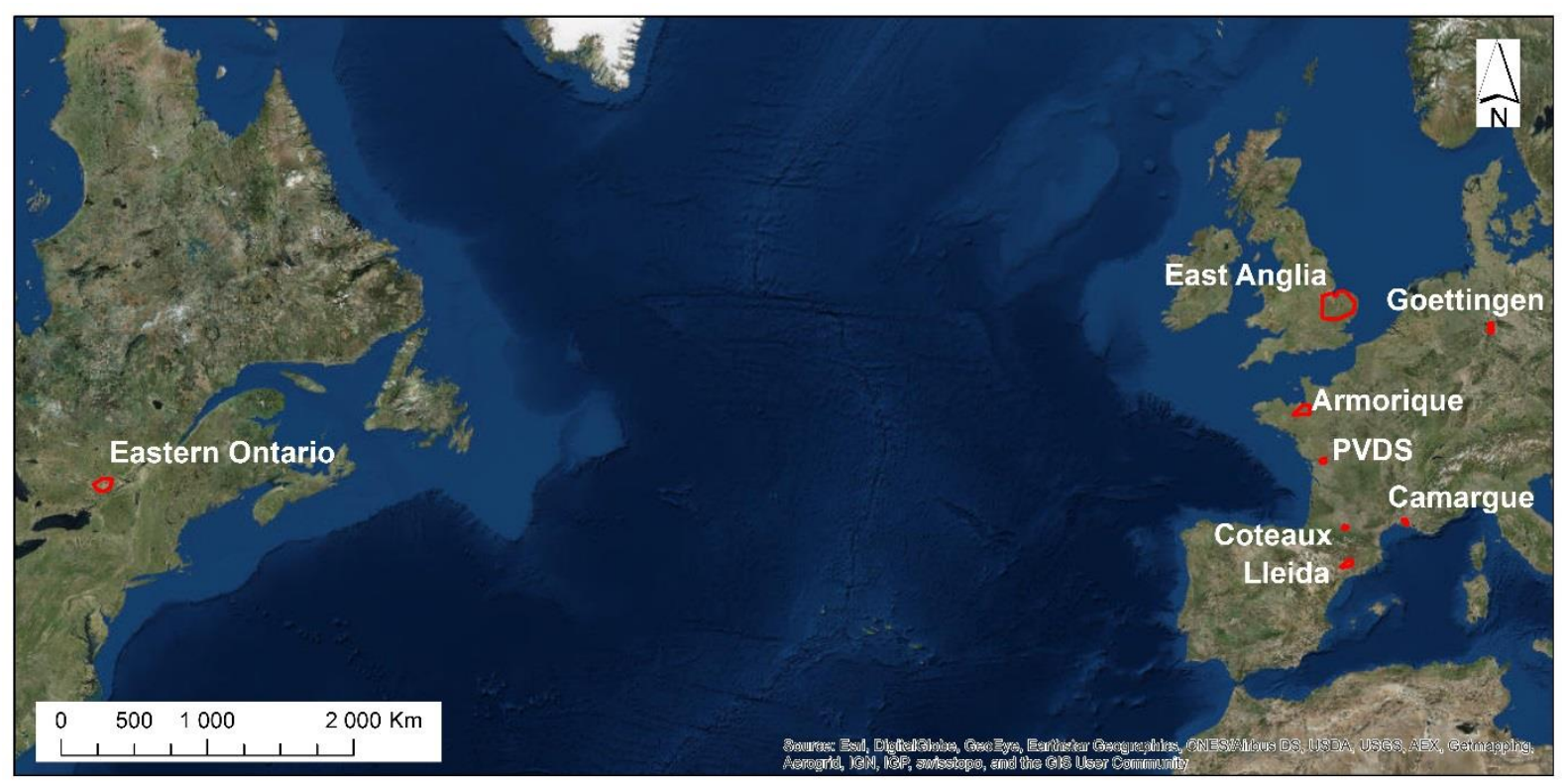

Figure S2.1. Locations of the eight study regions in Europe and North America. 


\subsection{Landscape selection}

The purpose of the landscape selection protocol was to select in each region a set of landscapes in a pseudo-experimental design (also called a "mensurative experiment") which aimed at selecting landscapes along two independent gradients of crop compositional and configurational heterogeneity while controlling for confounding variables (e.g. amount of semi-natural cover). The general protocol is detailed in Pasher et al. (2013).

We used the highest resolution and most recent remotely sensed data or the best land cover map available within each region. We delineated all fields (contiguous production cover), even when adjacent fields contain the same agricultural cover type (as they may belong to different farmers or may be managed differently). We attributed each field to one of the 34 agricultural cover types: cereal, fallow, alfalfa, clover, ryegrass, grassland, rice, corn, sunflower, sorghum, millet, moha, oilseed rape, mustard, pea, bean, soybean, linseed, orchard, almond, olive, vineyard, mixed vegetables, sugar beet, asparagus, carrot, onion, parsnip, potato, tomato, melon, strawberry, raspberry, wild bird cover (i.e. a spring sown crop left unharvested over winter to provide food for farmland birds). We also delineated patches of non-agricultural cover (woodland, open land, wetland and built-area). We then calculated crop compositional heterogeneity (Shannon diversity index of agricultural cover) and crop configurational heterogeneity (mean field size). We also calculated agricultural cover. We selected spatially independent landscapes within each region (Fig. S2.2), representing the maximum variation for both crop compositional heterogeneity and crop configurational heterogeneity.

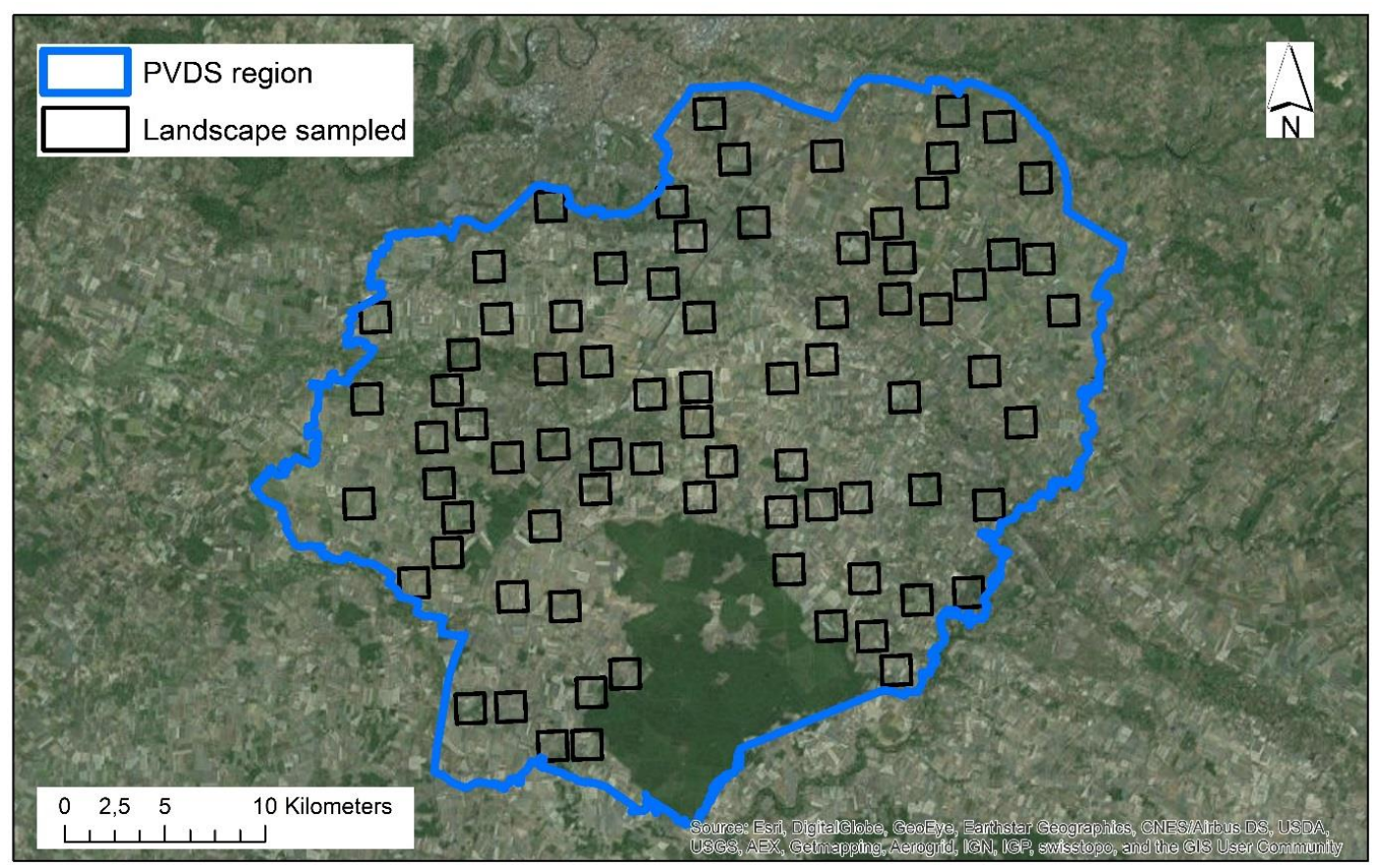

Figure S2.2. Spatial distribution of landscapes sampled in one of the eight regions (PVDS = Plaine et Val de Sèvre). 
References

Olson, D.M., Dinerstein, E., Wikramanayake, E.D., Burgess, N.D., Powell, G.V.N., Underwood, E.C., D’amico, J.A., Itoua, I., Strand, H.E., Morrison, J.C., Loucks, C.J., Allnutt, T.F., Ricketts, T.H., Kura, Y., Lamoreux, J.F., Wettengel, W.W., Hedao, P. \& Kassem, K.R. (2001) Terrestrial ecoregions of the world: A new global map of terrestrial ecoregions provides an innovative tool for conserving biodiversity. BioScience, 51, 933-938.

Pasher, J., Mitchell, S., King, D., Fahrig, L., Smith, A. \& Lindsay, K. (2013) Optimizing landscape selection for estimating relative effects of landscape variables on ecological responses. Landscape Ecology, 28, 371-383. 


\section{SI 3-Biodiversity sampling}

\subsection{Sampling site selection}

Disentangling the effects of crop diversity and mean field size on biodiversity required sampling many landscapes. Trade-offs between the number of landscapes sampled and the number of sampling sites per landscape were unavoidable. Whereas studies assessing the effect of landscape structure on biodiversity are often based on a single sampling site per landscape, we decided to sample three sampling sites within each landscape of $1 \times 1 \mathrm{~km}$ (Fig. S3.1). These sites were located at least $200 \mathrm{~m}$ apart from each other, at least $50 \mathrm{~m}$ from the border of the $1 \mathrm{~km} \times 1 \mathrm{~km}$ landscape, and at least $50 \mathrm{~m}$ from non-agricultural cover such as forests. Moreover, we located these sampling sites in dominant crop types within each region. When this was not feasible, we located sampling sites in crop types available within a given landscape while limiting correlations between crop types sampled and the two heterogeneity gradients within each region (see further details in SI 5).

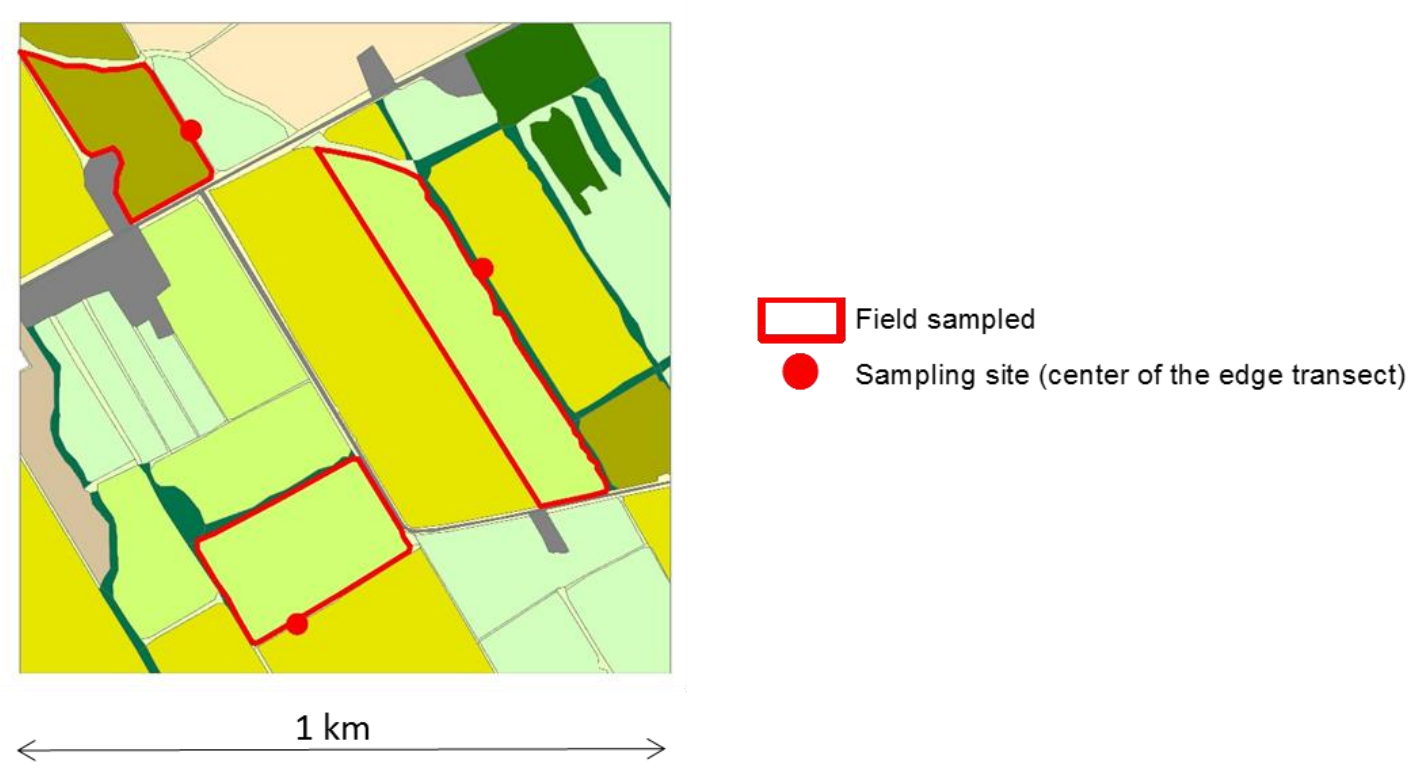

Figure S3.1. Example landscape showing the three selected sampling sites. 


\section{Biodiversity sampling within each sampling site}

Biodiversity sampling occurred between 2011 and 2014 depending on the region and landscape (Table S3.1).

Table S3.1. Number of landscapes sampled and main crop types sampled within each region and each year.

\begin{tabular}{|c|c|c|c|c|c|c|}
\hline Region & 2011 & 2012 & 2013 & 2014 & Total & Crop types sampled \\
\hline Armorique & & & 30 & 10 & 40 & cereal, corn, grassland \\
\hline Camargue & & & 32 & 8 & 40 & rice, cereal \\
\hline Coteaux & & & 20 & 12 & 32 & cereal, corn, sunflower \\
\hline EastAnglia & & 30 & 30 & & 60 & cereal, sugar beet, oilseed rape \\
\hline Goettingen & & & 32 & 20 & 52 & cereal, oilseed rape, grassland \\
\hline Lleida & & & 25 & 15 & 40 & cereal, almond, olive \\
\hline Eastern Ontario & 46 & 47 & & & 93 & corn, soybean, grassland \\
\hline PVDS & & & 48 & 48 & 96 & cereal, grassland, oilseed rape \\
\hline
\end{tabular}

All taxa were sampled using sampling methods commonly used in the literature (point counts, traps, visual surveys; Fig. S3.2).

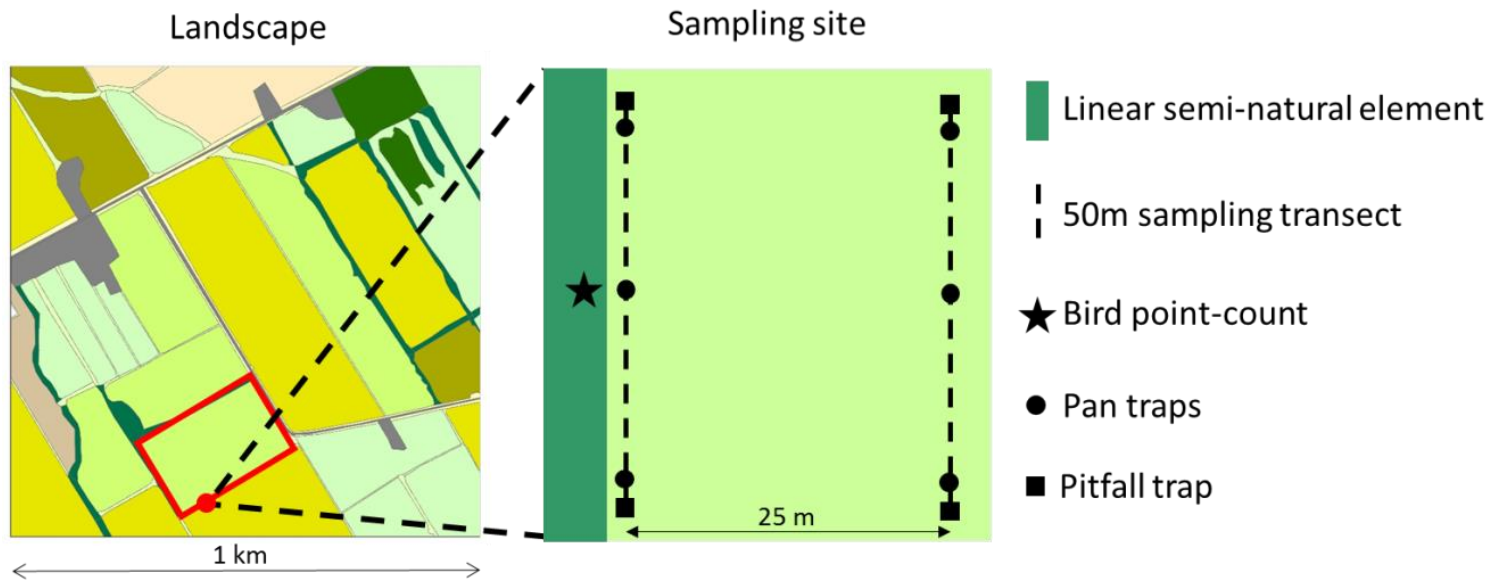

Figure S3.2. Biodiversity sampling design within each sampling site within each landscape $(1 \mathrm{~km} \times 1$ $\mathrm{km})$.

While trade-offs between the number of sites sampled and sampling intensity at each site were necessary, our sampling efforts (see below: number of traps, length of transects, number of visits) were consistent with the literature (e.g. Fahrig et al. 2015, Bertrand et al. 2016, Pollard and Yates 1993, Bibby et al. 2005). Table S3.2 shows the number of species and specimens we sampled for each taxa. 
Table S3.2. Number of species and specimens (occurrences for plants) for each taxonomic group. These figures include specimens that were identified to the genus level when no other species from this genus was observed.

\begin{tabular}{lll} 
& Species & Specimens \\
\hline All taxa & 2795 & 167028 \\
\hline Bees & 343 & 13326 \\
Birds & 208 & 10911 \\
Butterflies & 109 & 10605 \\
Carabids & 256 & 42547 \\
Hoverflies & 146 & 21491 \\
Plants & 1229 & 30276 \\
Spiders & 504 & 37872 \\
\hline
\end{tabular}

Plants - Plant surveys were conducted along the field edge and in the field interior. Percentage cover was recorded for each species. Each transect was $1 \mathrm{~m}$ wide and $50 \mathrm{~m}$ long and represented a total surveyed area of $20 \mathrm{~m}^{2}$, except in Eastern Ontario where plant survey transects were $2 \mathrm{~m}$ wide, represented a total surveyed area of $100 \mathrm{~m}^{2}$ and the field edge transect included both the field and the boundary vegetation. Plant surveys were conducted once, except in Eastern Ontario, Goettingen and East Anglia where surveys were conducted twice.

Bees and hoverflies - Bees and hoverflies were sampled using coloured pan traps, except for hoverflies in Eastern Ontario which were sampled by sweep-netting along the two transects. Plastic bowls painted in UV blue, white or UV yellow were placed in pairs at each end and at the center of each transect. As a result, we used six pan traps per transect, 12 pan traps per sampling site and 36 pan traps per landscape. The height of pan traps was adjusted to vegetation height. Cups were filled with water, with three drops of soap added per $1 \mathrm{~L}$ of water. The traps were left in the field for four days. The insects were then stored in $70 \%$ ethanol and later identified to species level. Bee and hoverfly sampling was carried out twice during the growing season (April-July), the dates being selected in each region based on regional climatic conditions. As there is often a patchy species distribution within fields, species diversity at the pan trap level is not representative of species diversity at the sampling site level. Therefore rarefied species richness could not be calculated. Due to technical and financial constraints, bees could only be identified to species level in seven of the eight regions, and in a total of 183 landscapes. This did not affect our results (see section 3.3 of this SI).

Carabids and spiders - Carabids and spiders were sampled using pitfall traps. Cups were half-filled with a solution of 10 drops of soap and $10 \mathrm{~g}$ of salt per $1 \mathrm{~L}$ of water and placed in the ground. One trap was placed at each end of each transect (two traps per transect and four per sampling site in total). The traps were left in the field for four days. Arthropods were then stored in $70 \%$ ethanol and carabids and adult spiders were later identified to species. Carabids and spiders were sampled at the same time as the bee and hoverfly sampling (above). Carabid and spider sampling was carried out only once in 
East Anglia in 2012 due to bad weather conditions and could not be conducted in rice fields in Camargue due to the presence of water. As there is often a patchy species distribution within fields, species diversity at the pitfall trap level is not representative of species diversity at the sampling site level. Therefore rarefied species richness could not be calculated.

Butterflies - Butterfly surveys were conducted along two $5 \mathrm{~m}$ wide and $50 \mathrm{~m}$ long transects (Pollard and Yates 1993), along the field edge and in the field interior. Surveys were conducted on calm (Beaufort scale $<3$ ), sunny days, when the temperature was $>15^{\circ} \mathrm{C}$. The observer recorded all butterfly species observed within an imaginary $5 \mathrm{~m}$-sided box ( $2.5 \mathrm{~m}$ to each side, $5 \mathrm{~m}$ in front and $5 \mathrm{~m}$ high) during approximately 10 min per transect (Pollard and Yates 1993). Individuals that could not be identified by sight were captured with a butterfly net for closer examination (survey time was stopped during capture and identification). Surveys were conducted once, except in Eastern Ontario, Goettingen and Lleida were surveys were conducted twice.

Birds - Birds were surveyed using 10-minutes point counts (Bibby et al. 2005) located the center of the border transect. All individuals singing or seen within a distance of $100 \mathrm{~m}$ were recorded. Birds flying across were considered as transients and thus not included. Counts were conducted twice, except in East Anglia in 2012 due to bad weather conditions, in Ontario and in rice fields in Camargue due to the specific phenology of this crop type, where they were conducted once. Surveys were conducted during the peak breeding season, between April and June depending on the region, and during peak activity hours, from 1 to 4 hours after sunrise and under good weather conditions.

Note on detection and rare species - Our sampling scheme presents the following characteristics : 1) the three fields within each landscape host different crops and therefore correspond to different species pools; 2) we only sampled each landscape during a single year; 3) we sampled some taxa across two sessions within the sampling season but these sessions target distinct communities (e.g. spring versus summer spider communities); 4) some protocols involve multiple sampling within the field (e.g. several pitfall traps along the edge transect and several pitfall traps along the center transect) but these traps cannot be considered as replicates due to the high level of heterogeneity within fields, both between transects and within a transect. As a result, we do not think we have truly replicated data that would allow us computing species richness estimators such as the Chao estimator. Nevertheless, because we used standard protocols commonly used in the literature, we believe our uncorrected data is a good proxy of species richness for each taxa studied. 


\subsection{Multidiversity}

An important challenge when studying the overall effects of crop heterogeneity on biodiversity is that different taxa might respond differently (Flynn et al. 2009; Kormann et al. 2015; Concepción 2016). Indeed, we observed weak correlations among taxa within our dataset (Table S3.3) and significant differences in the response of taxa (Fig. 2).

Table S3.3. Mean species richness per landscape \pm standard deviation for each taxa and correlations among taxa (Pearson correlation coefficients). ${ }^{*} p<0.05 ;{ }^{* *} p<0.01 ; * * p<0.001$.

\begin{tabular}{llllllll} 
& Mean SR & birds & bees & butterflies & carabids & hoverflies & plants \\
\hline birds & $18.7 \pm 6.7$ & & & & & & \\
bees & $11.2 \pm 4.6$ & 0.11 & & & & & \\
butterflies & $5.4 \pm 2.9$ & 0.03 & 0.14 & & & & \\
carabids & $12.3 \pm 6.8$ & 0.01 & $-0.18^{*}$ & $0.13^{* *}$ & & & \\
hoverflies & $6.4 \pm 3.7$ & -0.04 & 0.14 & 0.09 & 0.25 & & \\
plants & $44.9 \pm 17.5$ & 0.19 & -0.07 & 0.23 & -0.21 & 0.12 & \\
spiders & $20.6 \pm 11.5$ & $0.17^{*}$ & $0.41^{* * *}$ & $-0.20^{* *}$ & $0.34^{* * *}$ & $0.16^{* * *}$ & -0.27 \\
\hline
\end{tabular}

To test the overall effects of crop heterogeneity on biodiversity, we invetigated methods developed by Allan et al. (2014) to study ecosystem multifunctionality. Such approach differs from testing how crop heterogeneity impacts each taxa separately by searching for optimal landscape conditions that maximize the diversity of most taxa simultaneously.

A first approach to achieve this is to calculate a multidiversity index based on the averaged approach (Byrnes et al. 2014). This approach consists simply in calculating the average standardized values of multiple taxonomic diversities for each landscape, as follows:

$$
\text { Average-based Multidiversity }=\frac{1}{7} \times \sum_{i=1}^{\mathrm{n}=7} \mathrm{scale}\left(\mathrm{SR}_{\mathrm{i}} \text {, center }=\mathrm{T} \text {, scale }=\mathrm{T}\right)
$$

where $S R_{i}$ is the number of species for taxa $i$ in a given landscape.

Although this averaging approach provides an intuitive method to assess changes in diversity across multiple taxa simultaneously (Allan et al. 2014), the averaged-approach includes some biases. For instance, very high averaged-multidiversity values implies that all groups exhibit high diversity. However, intermediate averaged-multidiversity values are difficult to interpret and it is impossible to differentiate situations where (i) diversity values are intermediate for all taxa simultaneously; or (ii) diversity values are very high for some groups while they are very low for others, i.e. trade-offs among taxa (Byrnes et al. 2014).

To overcome this limitation, we used a threshold approach (Zavaleta et al. 2010) not biased by potential trade-offs among taxa (Byrnes et al. 2014). The objective of this approach is to assess the ability of agricultural landscapes to simultaneously host at least a given percentage, or threshold $(\mathrm{x})$, of 
the maximum species richness observed for each taxa (SRmax). Because SRmax is likely to vary between regions, we chose to use the 95th percentile of the maximum observed species richness within each region as SRmax.region for each taxa. We then calculated the umtidiversity index based on the following formula:

Threshold - based Multidiversity (Tx. landscape) $=\frac{1}{7} \sum_{\mathrm{i}=1}^{\mathrm{n}=7}(\mathrm{SR} \mathrm{i}>(x \times$ SRmax. region $\mathrm{j}))$ where $S R_{i}$ is the number of species for taxa $i, x$ is the minimum \% to reach and SRmax.region is the maximum species richness for group $i$ in the region the landscape considered belong to.

We calculated threshold-based landscape multidiversity for each threshold T.landscape between 20 and 90\% using a moving average with intervals [T-10\%] to smooth the calculation. It is recommended to focus on intermediate thresholds since care should be taken to avoid overinterpreting high or low thresholds (Lefcheck et al. 2015) and intermediate thresholds have been shown to provide an effective measure of biodiversity in agricultural landscapes (Byrnes et al. 2014). We chose to focus our analyses on T60.landscape (T60) after checking that the distribution of the obtained multidiversity index allows developing robust linear statistics (Fig.S3.3).
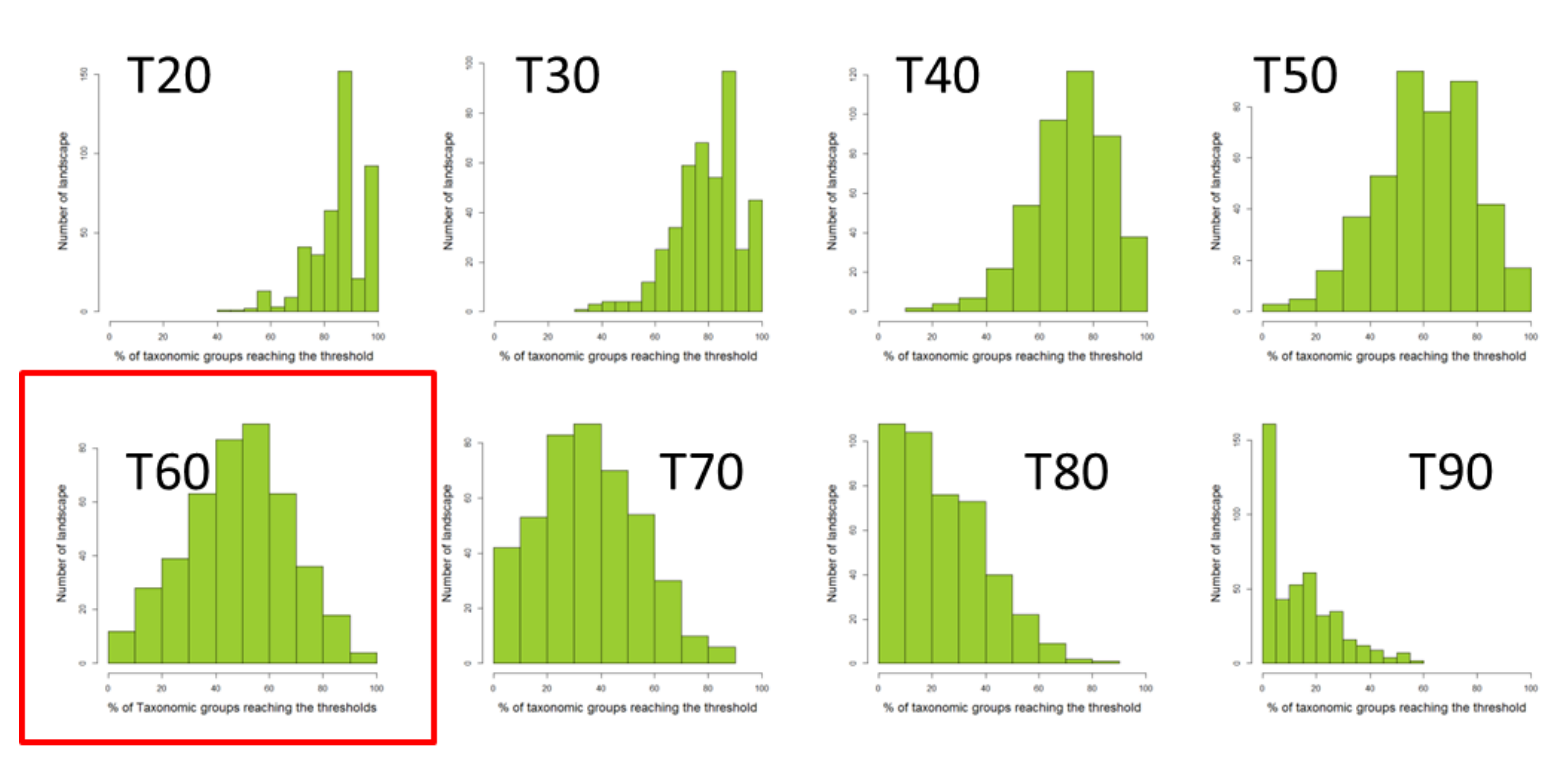

Figure S3.3. Distribution of the threshold-based multitrophic biodiversity calculated at the landscape level for thresholds between 10 and 100\%.

A high multidiversity value based on a threshold of $60 \%$ means that most taxa are associated with species richness levels higher than $60 \%$ of the regional maximum (SRmax.region) observed in our study. Note that (i) T60.landscape was highly correlated with averaged multidiversity in our dataset and other multidiversity thresholds (Table S3.4) (ii) our results were not sensitive to the threshold selected (Fig. S5.1 in SI 5). 
Table S3.4. Correlation between average-based multidiversity (M), various threshold-based multidiversity variables calculated at the landscape level $(T)$ and species richness for each taxa. Colours correspond to increasing correlation values (from orange to dark red).

\begin{tabular}{|c|c|c|c|c|c|c|c|c|c|c|c|c|c|c|c|}
\hline & M & $\mathrm{T} 20$ & T30 & T40 & T50 & T60 & $\mathrm{T} 70$ & T80 & Plant & Bee & Syrphid & Butterfly & Carabid & Spider & Bird \\
\hline M & 1 & 0.48 & 0.60 & 0.71 & 0.80 & 0.86 & 0.88 & 0.86 & 0.51 & 0.59 & 0.39 & 0.54 & 0.56 & 0.64 & 0.37 \\
\hline T20 & 0.48 & 1 & 0.92 & 0.77 & 0.65 & 0.58 & 0.52 & 0.47 & 0.08 & 0.19 & 0.23 & 0.21 & 0.07 & 0.22 & 0.61 \\
\hline T30 & 0.60 & 0.92 & 1 & 0.93 & 0.79 & 0.69 & 0.62 & 0.56 & 0.15 & 0.31 & 0.23 & 0.28 & 0.21 & 0.31 & 0.59 \\
\hline T40 & 0.71 & 0.77 & 0.93 & 1 & 0.93 & 0.82 & 0.74 & 0.66 & 0.23 & 0.45 & 0.27 & 0.34 & 0.33 & 0.40 & 0.54 \\
\hline T50 & 0.80 & 0.65 & 0.79 & 0.93 & 1 & 0.94 & 0.85 & 0.74 & 0.32 & 0.54 & 0.28 & 0.39 & 0.41 & 0.48 & 0.50 \\
\hline T60 & 0.86 & 0.58 & 0.69 & 0.82 & 0.94 & 1 & 0.95 & 0.84 & 0.38 & 0.57 & 0.28 & 0.44 & 0.45 & 0.54 & 0.46 \\
\hline T70 & 0.88 & 0.52 & 0.62 & 0.74 & 0.85 & 0.95 & 1 & 0.95 & 0.42 & 0.54 & 0.29 & 0.45 & 0.46 & 0.59 & 0.43 \\
\hline T80 & 0.86 & 0.47 & 0.56 & 0.66 & 0.74 & 0.84 & 0.95 & 1 & 0.42 & 0.48 & 0.29 & 0.43 & 0.45 & 0.57 & 0.44 \\
\hline Plant & 0.51 & 0.08 & 0.15 & 0.23 & 0.32 & 0.38 & 0.42 & 0.42 & 1 & 0.04 & 0.01 & 0.22 & 0.21 & 0.18 & 0.00 \\
\hline Bee & 0.59 & 0.19 & 0.31 & 0.45 & 0.54 & 0.57 & 0.54 & 0.48 & 0.04 & 1 & 0.25 & 0.24 & 0.19 & 0.30 & 0.12 \\
\hline Syrphid & 0.39 & 0.23 & 0.23 & 0.27 & 0.28 & 0.28 & 0.29 & 0.29 & 0.01 & 0.25 & 1 & 0.07 & 0.06 & 0.06 & -0.06 \\
\hline Butterfly & 0.54 & 0.21 & 0.28 & 0.34 & 0.39 & 0.44 & 0.45 & 0.43 & 0.22 & 0.24 & 0.07 & 1 & 0.14 & 0.20 & 0.03 \\
\hline Carabid & 0.56 & 0.07 & 0.21 & 0.33 & 0.41 & 0.45 & 0.46 & 0.45 & 0.21 & 0.19 & 0.06 & 0.14 & 1 & 0.34 & -0.02 \\
\hline Spider & 0.64 & 0.22 & 0.31 & 0.40 & 0.48 & 0.54 & 0.59 & 0.57 & 0.18 & 0.30 & 0.06 & 0.20 & 0.34 & 1 & 0.15 \\
\hline Bird & 0.37 & 0.61 & 0.59 & 0.54 & 0.50 & 0.46 & 0.43 & 0.44 & 0.00 & 0.12 & -0.06 & 0.03 & -0.02 & 0.15 & 1 \\
\hline
\end{tabular}

Data for bee species richness were only available for 183 landscapes. To determine whether this affected our results, we also calculated multidiversity across six taxa (all groups except bees). As there was no difference in results obtained with six or seven taxa, we here only present results for multidiversity calculated across seven taxa within 435 landscapes.

\section{References}

Allan E, et al. (2014) Interannual variation in land-use intensity enhances grassland multidiversity. Proc Natl Acad Sci U S A 111(1):308-313.

Bertrand C, Burel F, Baudry J (2015) Spatial and temporal heterogeneity of the crop mosaic influences carabid beetles in agricultural landscapes. Landsc Ecol:1-16.

Bibby, C.J., et al. (2005) Bird Census Techniques. Academic Press, London, UK.

Byrnes JEK, et al. (2014) Investigating the relationship between biodiversity and ecosystem multifunctionality: challenges and solutions. Methods Ecol Evol 5(2):111-124.

Concepción ED, et al. (2016) Contrasting trait assembly patterns in plant and bird communities along environmental and human-induced land-use gradients. Ecography 40(6):753-763.

Fahrig L, et al. (2015) Farmlands with smaller crop fields have higher within-field biodiversity. Agric Ecosyst Environ 200:219-234.

Flynn DFB, et al. (2009) Loss of functional diversity under land use intensification across multiple taxa. Ecol Lett 12(1):22-33.

Kormann U, et al. (2015) Local and landscape management drive trait-mediated biodiversity of nine taxa on small grassland fragments. Divers Distrib 21(10):1204-1217.

Lefcheck JS, et al. (2015) Biodiversity enhances ecosystem multifunctionality across trophic levels and habitats. Nat Commun 6:6936.

Pollard, E., Yates, T.J. (1993). Monitoring butterflies for ecology and conservation. Chapman et Hall, London.

Zavaleta ES, Pasari JR, Hulvey KB, Tilman GD (2010) Sustaining multiple ecosystem functions in grassland communities requires higher biodiversity. Proc Natl Acad Sci U S A 107(4):1443-1446. 


\section{SI 4 - Land cover mapping and landscape metrics}

\subsection{Land cover mapping}

Land cover was mapped based on remotely-sensed data and ground-truthing. All cover types, including fields, linear elements between fields and non-agricultural cover types, were mapped as polygons ('patches') (Fig. S4.1). We here refer to 'cover types' rather than 'habitats' because 'habitat' refers to the specific ecological requirements of a given species while 'cover type' refers to a category of land cover without any assumption on species use. This is important in the present study where we assume that many farmland species are likely to use several cover types (landscape complementation). Agricultural cover types included: cereal, fallow, alfalfa, clover, ryegrass, rice, corn, sunflower, sorghum, millet, moha, oilseed rape, mustard, pea, bean, soybean, linseed, orchard, almond, olive, vineyard, mixed vegetables, sugar beet, asparagus, carrot, onion, parsnip, potato, tomato, melon, strawberry, raspberry, wild bird cover, grassland (including temporary and permanent grassland managed for production purpose) and other crops (unknown or rare crops). We chose to include managed grassland within agricultural cover types because we were interested in assessing the role of spatial heterogeneity within the farmed part of the landscape. We considered grasslands where more than $50 \%$ of the biomass was removed as agricultural cover whereas those where less than $50 \%$ of the biomass was removed were considered as non-agricultural cover. Linear elements between fields were classified either as woody, grassy, water (e.g. ditches) or tracks. Non-agricultural cover types included woodland (including woody linear elements), open land (e.g. shrubland, grassy linear elements), wetland and built-area (including roads).
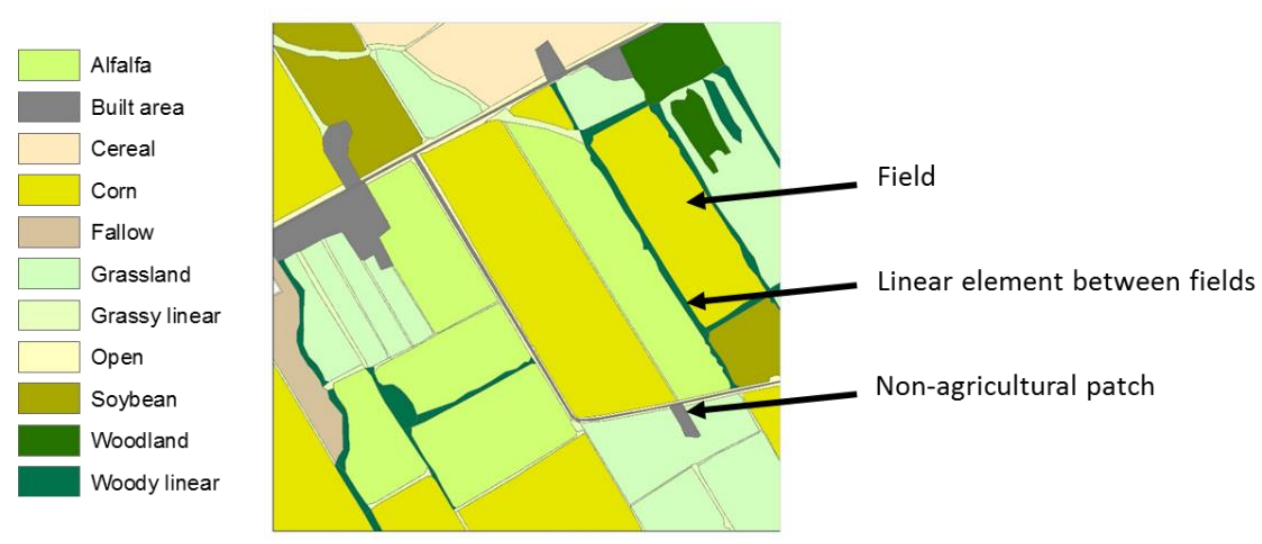

Figure S4.1. Example of land cover map used to calculate crop heterogeneity variables and covariates within each landscape $(1 \mathrm{~km} \times 1 \mathrm{~km})$. 


\subsection{Landscape metrics}

It is well known that different taxa and even species are likely to respond to the landscape structure at different spatial scales. Since our aim was to assess the overall effects of crop diversity and mean field size on a range of contrasted taxa, we chose to calculate landscape variables within a $1 \times 1 \mathrm{~km}$ because this spatial extent represent the best compromise between highly mobile taxa (e.g. birds) and taxa with more limited dispersal abilities (e.g. plants or spiders).

\subsubsection{Crop compositional heterogeneity}

We used crop diversity as a measure of crop compositional heterogeneity. We measured crop diversity using the Shannon diversity index, a widely used metric of landscape heterogeneity (e.g. Bertrand et al. 2016; Bosem Baillod et al. 2017): $H^{\prime}=-\sum_{i=1}^{n} p_{i} \ln p_{i}$ where $p_{\mathrm{i}}$ is the proportion of crop type $i$ in the agricultural mosaic. Note that this metric assumes that all agricultural cover types (defined in 4.1) are considered equally different. This variable does not take into account within-field crop heterogeneity, e.g. intercropping patterns.

\subsubsection{Crop configurational heterogeneity}

We used mean field size (ha) as a measure of crop compositional heterogeneity. We chose this metric over total field perimeter length per landscape (e.g. Bosem Baillod et al. 2017) because it is directly related to our hypotheses (see SI 1). Moreover it is easier to base practical recommendations for future agricultural policies on mean field size rather than on total field perimeter length. Fields located partly outside of the $1 \mathrm{~km}^{2}$ landscape were "truncated", i.e. only their area contained within the landscape was considered in calculating mean field size.

\subsubsection{Semi-natural cover proportion}

We calculated the sum of woodland (including woody linear elements), open land (e.g. shrubland, grassy margins) and wetland cover (including lakes, rivers, ditches) in the landscape.

\subsubsection{Total length of semi-natural linear elements}

We assessed the total length of semi-natural linear elements between fields (SNL, in meters) by calculating half the sum of all semi-natural linear elements located between two crops. Note that semi-natural linear elements located along roads or urban areas were not included in the calculation of SNL. SNL and mean field size are highly correlated (see SI 3). 


\subsubsection{Latitude and longitude}

We calculated the latitude and longitude of the center of each landscape using the WGS 1984 World Mercator projection system.

\section{Descriptive statistics for the 435 landscapes selected}

The 435 landscapes selected across eight regions of Europe and North America had the following characteristics (mean $\pm \mathrm{sd}$; see also Table 54.1 ): $81.3 \pm 9.6 \%$ of agricultural cover, $12.7 \pm 8.9 \%$ of seminatural cover, $5631 \pm 3822 \mathrm{~m}$ of linear semi-natural elements between fields, mean field size $2.99 \pm 2.02$ ha and a Shannon diversity index of agricultural cover types of 1.03 \pm 0.39 (Fig S5.3). These gradients are representative of most Western European agricultural landscapes (Herzog et al. 2006) and most American agricultural landscapes (Yan \& Roy 2016).

Table S4.1. Descriptive statistics for each explanatory variable (mean, median, 25th and 75th quartiles, min and max): crop diversity, mean field size (ha), the percentage of semi-natural cover types (SNC), and the length of semi-natural linear elements (SNL).

\begin{tabular}{lrrrr} 
& Crop diversity & Mean field size (ha) & SNC (\%) & \multicolumn{1}{c}{ SNL (m) } \\
\hline Min & 0.0 & 0.48 & 0.0 & 0 \\
1st quartile & 0.8 & 1.71 & 6.0 & 3108 \\
Median & 1.09 & 2.43 & 10.9 & 4824 \\
Mean & 1.03 & 2.99 & 12.7 & 5632 \\
3rd quartile & 1.31 & 3.69 & 17.6 & 7370 \\
Max & 2.03 & 12.71 & 49.5 & 27989 \\
\hline
\end{tabular}




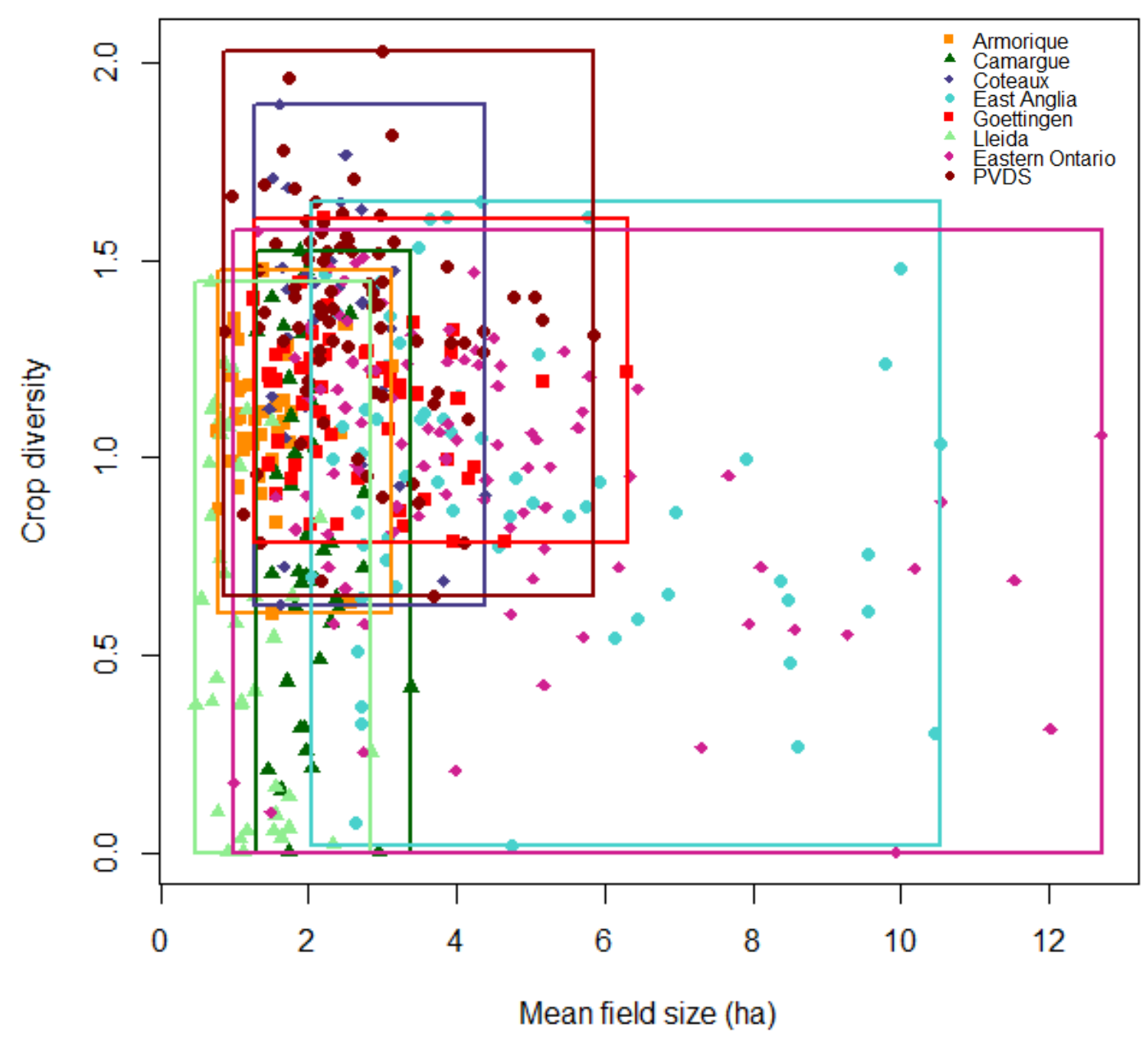

Figure S4.3. Variation in crop diversity and mean field size (ha) across the eight regions. Points correspond to selected landscapes $(\mathrm{N}=435)$ and boxes corresponds to the range of crop diversity and mean field size sampled within each region (orange=Armorique, dark green=Camargue, dark blue=Coteaux, light blue=East Anglia, light red=Goettingen, light green=Lleida, pink=Eastern Ontario, dark red=PVDS).

\section{References}

Bertrand C, Burel F, Baudry J (2016) Spatial and temporal heterogeneity of the crop mosaic influences carabid beetles in agricultural landscapes. Landsc Ecol 31: 451-466.

Bosem Baillod A, Tscharntke T, Clough Y, Batáry P (2017) Landscape-scale interactions of spatial and temporal cropland heterogeneity drive biological control of cereal aphids. J Appl Ecol, 54: 1804-1813.

Herzog F, et al. (2006) Assessing the intensity of temperate European agriculture at the landscape scale. Eur J Agron 24(2): 165-181.

Yan, L. \& Roy, D.P. (2016) Conterminous United States crop field size quantification from multitemporal Landsat data. Remote Sensing of Environment, 172: 67-86. 


\section{SI 5 - Complementary analyses}

\subsection{Variations among taxa}

We tested whether the effects of crop diversity and mean field size on species diversity were consistent across taxa using Model 1.

Model 1: Imer $\left(S R \sim \operatorname{Taxa}^{*}\left(C D^{*} M F S^{*} S N C+C D^{2}+\mathrm{MFS}^{2}+S N C^{2}+\right.\right.$ CropNb) + Lat + Lon + (1/Region/Year $\left.)\right)$

The analysis of variance (function Anova in R) showed that 1) mean field size had a consistent negative effect on all taxa and did not vary significantly among taxa; 2) the effect of crop diversity was significantly different among taxa; and 3) semi-natural cover had a marginally significant effect, that was marginally significantly different between taxa (Table S5.1).

Table S5.1. Analysis of variance for model 1. Parameter listed are based on the model selection procedure. ${ }^{\circ} p<0.1 ;{ }^{*} p<0.05 ; * * p<0.01 ; * * * p<0.001$.

\begin{tabular}{lrrr} 
& Chi-square & Df & p-value \\
\hline Crop diversity (CD) & 0.2797 & 1 & 0.60 \\
Mean field size (MFS) & 12.2948 & 1 & $<0.001{ }^{*} * *$ \\
Semi-Natural Cover (SNC) & 2.8085 & 1 & 0.094 \\
Latitude & 1.6402 & 1 & 0.20 \\
CD $^{2}$ & 2.0311 & 1 & 0.15 \\
MFS $^{2}$ & 2.4987 & 1 & 0.11 \\
SNC & 0.3833 & 1 & 0.54 \\
Nb of Crops sampled & 17.1562 & 1 & $<0.001{ }^{* * *}$ \\
CD :SNC & 6.6784 & 1 & $0.010 * *$ \\
MFS :SNC & 1.6508 & 1 & 0.20 \\
CD :MFS & 0.1926 & 1 & 0.66 \\
Taxa: CD & 15.3639 & 6 & $0.018 *$ \\
Taxa: MFS & 7.2123 & 6 & 0.30 \\
Taxa: SNC & 9.2962 & 6 & 0.16 \\
Taxa: CD :MFS & 2.2654 & 6 & 0.89 \\
Taxa: CD :SNC & 10.7556 & 6 & 0.096 \\
Taxa: MFS :SNC & 5.2484 & 6 & 0.51 \\
\hline
\end{tabular}

\subsection{Model averaging}

The model selection approach based on $\triangle \mathrm{AICC}<2$ resulted in the selection of 10 models for model 2 (Table S5.2). Using a $\triangle \mathrm{AICC}$ of $7 \mathrm{did}$ not change the results of the model averaging or results on variable importance. All models included crop diversity (CD), mean field size (MFS), semi-natural cover (SNC), the number of crops sampled (Crop nb.) and the interaction between crop diversity and seminatural cover (CD X SNC). The AICC of the Null model was 3709 while theAICC of the best model was 3667 , i.e. with a $\triangle A I C C$ of 42 , suggesting that the best selected models were far more parsimonious than the null model including only Region and Year as random effects. 
Table S5.2. List of all models selected and used for the model averaging approach for model 2.

\begin{tabular}{|c|c|c|c|c|c|c|c|c|c|c|c|}
\hline Model & 1 & 2 & 3 & 4 & 5 & 6 & 7 & 8 & 9 & 10 & Null \\
\hline \multicolumn{12}{|l|}{ Lat } \\
\hline \multicolumn{12}{|l|}{ Lon } \\
\hline \multicolumn{12}{|l|}{$C D$} \\
\hline \multicolumn{12}{|l|}{$C D^{2}$} \\
\hline \multicolumn{12}{|l|}{ MFS } \\
\hline \multicolumn{12}{|l|}{$\mathrm{MFS}^{2}$} \\
\hline \multicolumn{12}{|l|}{ SNC } \\
\hline \multicolumn{12}{|l|}{ Crop nb. } \\
\hline \multicolumn{12}{|l|}{$\mathrm{CD} \times \mathrm{SNC}$} \\
\hline \multicolumn{12}{|l|}{ MFS $\times$ SNC } \\
\hline \multicolumn{12}{|l|}{$\mathrm{CD} \times \mathrm{MFS} \times \mathrm{SNC}$} \\
\hline Marginal $\mathrm{R}^{2}$ & 0.13 & 0.13 & 0.12 & 0.15 & 0.15 & 0.12 & 0.14 & 0.12 & 0.14 & 0.13 & 0 \\
\hline Conditonal $\mathrm{R}^{2}$ & 0.36 & 0.37 & 0.35 & 0.38 & 0.38 & 0.36 & 0.37 & 0.37 & 0.37 & 0.36 & 0.23 \\
\hline$d f$ & 10 & 11 & 9 & 11 & 12 & 10 & 10 & 11 & 11 & 11 & - \\
\hline $\mathrm{AICC}$ & 3667.5 & 3668.09 & 3668.16 & 3668.21 & 3668.75 & 3668.75 & 3668.86 & 3669.36 & 3669.39 & 3669.56 & 3709.7 \\
\hline delta & 0 & 0.59 & 0.66 & 0.7 & 1.24 & 1.24 & 1.35 & 1.85 & 1.89 & 2.05 & 42.23 \\
\hline weight & 0.17 & 0.13 & 0.12 & 0.12 & 0.09 & 0.09 & 0.09 & 0.07 & 0.07 & 0.06 & - \\
\hline
\end{tabular}

\subsection{Threshold-based multidiversity}

To test whether the choice of threshold (T60.landscape, i.e. proportion of taxa for which the species richness is equal or higher than $60 \%$ of the regional maximum species richness per landscape (SRmax.region) impacted our conclusions, we ran model 1 for all thresholds from T20 to T80 (i.e. proportion of taxa for which the species richness is equal to or higher than $20 \%$ to $80 \%$ of the regional maximum species richness per landscape).

Parameters estimates were consistent across the range of thresholds (Fig. S5.1). Moreover, variations in parameter estimates suggests that increasing mean field size may be particularly effective to reach intermediate multidiversity thresholds (i.e. between 30 and $50 \%$ of regional maximum) whether increasing semi natural cover may be effective to reach higher multidiversity threshold (i.e. above $50 \%$ of regional maximum). 


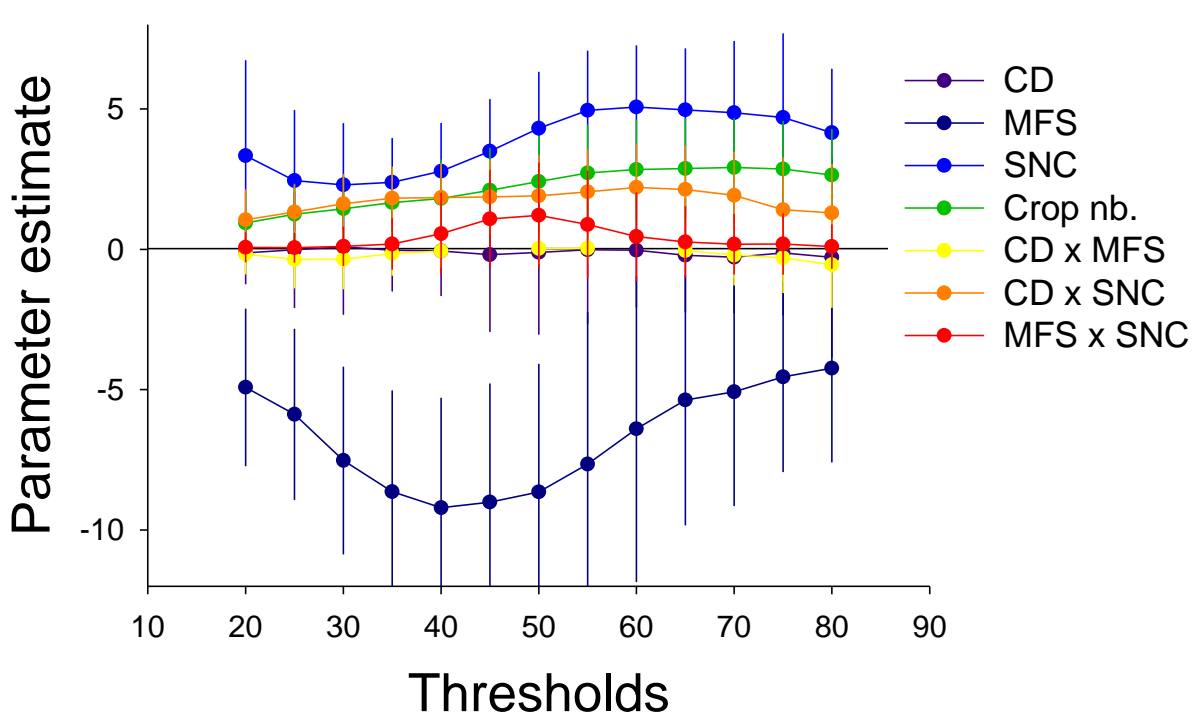

Figure S5.1. Parameter estimates based on model 1 ran with different multidiversity threshold as response variable.

\subsection{Correlations and alternative mechanisms at the landscape level}

Crop diversity and mean field size are likely to be correlated with several variables, including the overall crop composition, the proportion of grassland in the mosaic or the length of semi-natural vegetation occurring between fields. Disentangling the role of crop heterogeneity from the effects of these other variables is necessary in order to infer potential mechanisms explaining the positive effect of crop heterogeneity on biodiversity. In the present study, some of these additional variables were correlated among themselves, or with our variables of interest. Exploring their role sometimes required running models using a data subset for which relevant variables were uncorrelated. As a result, we could not include all these variables in a single model and present these analyses as separate, complementary analyses.

\subsubsection{Role of the identity of crops in the agricultural mosaic}

The identity of crop types in the mosaic may vary along the gradients of crop diversity and mean field size. For instance, landscapes with small fields may be composed of more biodiversity-friendly crops. Such a correlation would represent a potential bias in our study and hamper our ability to test the effects of crop heterogeneity on biodiversity.

We investigated the correlation between each crop heterogeneity gradient and the identity of crop types in the mosaic for 435 landscapes from 8 regions. We conducted a Principal Components Analysis on the matrix of percentage cover per agricultural cover type per landscape. The first axis represented $40 \%$ of the variance, while the second axis represented $19 \%$ of the variance. 
The Pearson correlations between crop diversity and the first two axes of the PCA were weak (axis 1: $r=-0.03, p=0.56$ and axis 2: $r=-0.19, p<0.001)$, as were the Pearson correlations between mean field size and the first two axes of the PCA (axis 1: $r=0.21, p<0.001$ and axis 2: $r=-0.12, p=0.01$; Fig. S5.2).
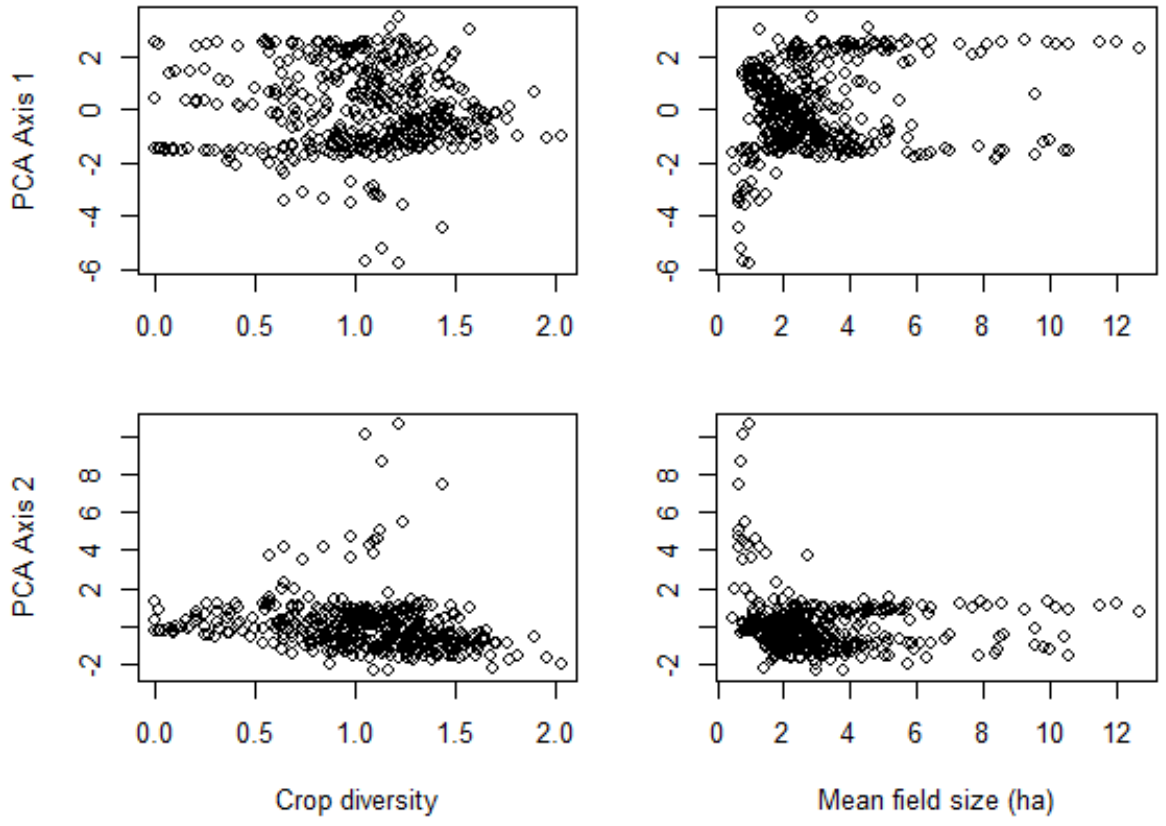

Figure S5.2. Relationships between the two crop heterogeneity gradients and the identity of crop types in the mosaic (axes 1 and 2 of the Principal Components Analysis).

We added the scores of landscapes along axes 1 and 2 of the PCA to model 2 and compared the outcomes of the obtained model (model 3) with those of model 2.

Model 2:

Imer (T60.landscape $\sim C D^{*}$ MFS * SNC $+C D^{2}+$ MFS $^{2}+S N C^{2}+$ CropNb + Lat + Lon + (1/ Region/Year) $)$

Model 3:

Imer (T60.landscape $\sim C D * M F S * S N C+C D^{2}+M F S^{2}+S N C^{2}+$ CropNb + Lat + Lon + Axis $1+$ Axis $2+(1)$ Region/Year))

The average model selected based on model 3 included the same variables as the average model selected based on model 2, plus variable PCA Axis 1. Parameter estimates and significance for variables of interest remained unchanged (Table S5.3). This result suggests that the effects of $C D$, in combination with SNC, and MFS cannot be explained by the identity of crops occurring in the mosaic. 
Table S5.3. Comparison of model 2 and model 3 - mosaic crops id (i.e. model taking into account the identity of crop types in the mosaic). Parameter listed are based on the model selection procedure. Parameter estimates are based on the model averaging approach. ${ }^{\circ} p<0.1 ;{ }^{*} p<0.05 ;{ }^{* *} p<0.01 ; * * *$ $\mathrm{p}<0.001$.

\begin{tabular}{lll} 
& model 2 & $\begin{array}{l}\text { model } 3-\text { mosaic crops } \\
\text { id }\end{array}$ \\
\hline Crop diversity (CD) & $-0.03(-2.07 ; 2.01)$ & $-0.06(-2.1 ; 1.96)$ \\
Mean field size (MFS) & $-6.39(-11.85 ;-0.94)^{*}$ & $-6.44(-11.88 ;-1.01) *$ \\
Semi-Natural Cover (SNC) & $5.07(2.87 ; 7.26)^{* * *}$ & $5.07\left(2.88 ; 7.27^{* * *}\right.$ \\
Nb of Crops sampled & $2.84(1.07 ; 4.62)^{* * *}$ & $2.84(1.06 ; 4.62)^{* *}$ \\
Latitude & $1.5(-3.55 ; 6.55)$ & $1.5(-3.55 ; 6.55)$ \\
Longitude & $3.73(2.47 ; 9.93)$ & $3.73(-2.47 ; 9.93)$ \\
MFS $^{2}$ & $3.78(-0.67 ; 8.23)^{\circ}$ & $3.73(-0.72 ; 8.19)$ \\
CD :SNC & $2.20(0.64 ; 3.76)^{* *}$ & $2.21(0.65 ; 3.77)^{* *}$ \\
MFS :SNC & $1.15(-0.66 ; 2.96)$ & $1.15(-0.66: 2.96$ \\
PCA axis 1 & & $1.5(-3.55 ; 6.55)$ \\
\hline
\end{tabular}

\subsubsection{Role of the proportion of grassland in the crop mosaic}

The identity of some ecologically important crop types in the mosaic may vary along the gradients of crop diversity and mean field size. In this study, we chose to include managed grassland within agricultural cover types because we were interested in assessing the role of spatial heterogeneity within the farmed part of the landscape. However, we were aware that the proportion of grassland in the crop mosaic, in particular permanent grassland, is likely to have a strong positive effect on biodiversity (Öckinger \& Smith 2007). We added the proportion of grassland to model 2 (using data collected in 435 landscapes from 8 regions) and compared the outcomes of the following model (model 4) with those of model 2.

Model 4:

Imer (T60.landscape $\sim C D *$ MFS * SNC +CD2 $+\mathrm{MFS}^{2}+\mathrm{SNC}^{2}+$ CropNb + Lat + Lon + Grassland + (1) Region/Year))

Model selection based on model 4 included the same variables as for model 2, plus Grassland, which had a significant positive effect. However, parameter estimates and significance for other variables of interest remained unchanged (Table S5.4). This result suggests that the effects of CD, in combination with SNC, and MFS cannot be explained by the proportion of grassland in the mosaic. 
Table S5.4. Comparison of model 2 and model 4 - grassland (i.e. complete model taking into account the proportion of grassland in the mosaic). Parameter listed are based on the model selection procedure. Parameter estimates are based on the model averaging approach. ${ }^{\circ} p<0.1 ;{ }^{*} p<0.05 ;{ }^{* *}$ $p<0.01 ; * * p<0.001$.

\begin{tabular}{lll} 
& model 2 & model $4-$ grassland \\
\hline Crop diversity (CD) & $-0.03(-2.07 ; 2.01)$ & $0.18(-1.9 ; 2.26)$ \\
Mean field size (MFS) & $-6.39(-11.85 ;-0.94)^{*}$ & $-6.2(-11.83 ;-0.59)^{*}$ \\
Semi-Natural Cover (SNC) & $5.07(2.87 ; 7.26)^{* * *}$ & $5.07(2.88 ; 7.27)^{* * *}$ \\
Nb of Crops sampled & $2.84(1.07 ; 4.62)^{* * *}$ & $2.73(0.94 ; 4.52)^{* *}$ \\
Latitude & $1.5(-3.55 ; 6.55)$ & \\
Longitude & $3.73(2.47 ; 9.93)$ & $4.07(-2.34 ; 10.47)$ \\
MFS & $3.78(-0.67 ; 8.23)^{\circ}$ & $3.98(-0.48 ; 8.44)^{\circ}$ \\
CD :SNC & $2.20(0.64 ; 3.76)^{* *}$ & $2.25(0.69 ; 3.81)^{* *}$ \\
MFS :SNC & $1.15(-0.66 ; 2.96)$ & $1.33(-0.51: 3.16)$ \\
Grassland & & $1.87(-0.26 ; 4.00)^{\circ}$ \\
\hline
\end{tabular}

\subsubsection{Role of semi-natural vegetation occurring between fields}

Mean field size (MFS in ha) and the length of semi-natural linear elements between fields (SNL) or the length of hedgerows $(\mathrm{H})$ were strongly correlated, particularly in some regions (e.g. Armorique, Table S5.5). As a result, we could not include both MFS and SNL (or MFS and H) in our models and disentangle their effects on biodiversity.

Table S5.5. Pearson correlation coefficients among explanatory variables across and within regions. CD = crop diversity, MFS = mean field size, $\mathrm{SNC}=$ proportion of semi-natural cover, $\mathrm{SNL}=$ length of seminatural linear elements between fields, $\mathrm{H}=$ length of hedgerows between fields. $\mathrm{N}=$ number of landscapes.

\begin{tabular}{lllllllll} 
& CD-MFS & CD-SNC & CD-SNL & MFS-SNC & MFS-SNL & MFS-H & SNC-SNL & $N$ \\
\hline All regions & -0.13 & -0.27 & -0.30 & -0.02 & -0.44 & -0.37 & 0.13 & 435 \\
\hline Armorique & -0.03 & 0.09 & 0.10 & -0.01 & -0.71 & -0.67 & -0.06 & 40 \\
Camargue & -0.20 & -0.25 & 0.11 & -0.06 & -0.55 & -0.17 & -0.59 & 40 \\
Coteaux & -0.27 & -0.22 & 0.51 & -0.31 & -0.57 & -0.50 & -0.24 & 32 \\
East Anglia & -0.18 & 0.21 & 0.18 & -0.16 & -0.34 & -0.23 & -0.41 & 60 \\
Goettingen & -0.17 & 0.15 & 0.05 & 0.15 & -0.43 & -0.10 & -0.10 & 52 \\
Lleida & -0.40 & -0.14 & 0.16 & -0.15 & -0.50 & -0.23 & -0.20 & 40 \\
Eastern Ontario & -0.34 & -0.13 & 0.27 & -0.40 & -0.53 & -0.43 & -0.08 & 93 \\
PVDS & -0.16 & -0.08 & -0.02 & -0.37 & -0.51 & -0.57 & 0.29 & 78 \\
\hline
\end{tabular}

To test whether our results for MFS were likely due to the correlation with SNL or $\mathrm{H}$, we selected a subset of landscapes for which all explanatory variables, in particular MFS and SNL as well as MFS and $\mathrm{H}$, were uncorrelated i.e. with a Pearson correlation coefficient $<0.4$ for each pair of explanatory variables, within each region (Table S5.6). 
Table S5.6. Correlation coefficients for Pearson correlations across and within regions among the explanatory variables within the subset of landscapes (274 landscapes) used to test for the influence of SNL and $\mathrm{H}$ on our results for the effects of crop heterogeneity. $\mathrm{CD}=$ crop diversity, MFS = mean field size, $S N C=$ proportion of semi-natural cover, $S N L=$ length of semi-natural linear elements between fields, $\mathrm{H}=$ length of hedgerows between fields. $\mathrm{N}=$ number of landscapes.

\begin{tabular}{lllllllll} 
& CD-MFS & CD-SNC & CD-SNL & MFS-SNC & MFS-SNL & MFS-H & SNC-SNL & N \\
\hline All regions & -0.15 & -0.30 & -0.40 & -0.08 & -0.27 & -0.28 & 0.30 & 274 \\
\hline Armorique & -0.02 & 0.29 & 0.40 & -0.06 & -0.04 & -0.15 & -0.33 & 20 \\
Camargue & -0.25 & -0.19 & -0.14 & -0.56 & -0.05 & -0.15 & -0.09 & 20 \\
Coteaux & 0.31 & -0.38 & 0.20 & -0.46 & 0.06 & -0.12 & -0.52 & 20 \\
East Anglia & -0.15 & -0.04 & 0.35 & -0.32 & -0.18 & -0.31 & -0.40 & 43 \\
Goettingen & -0.26 & 0.10 & 0.10 & -0.02 & -0.22 & -0.01 & -0.07 & 45 \\
Lleida & -0.33 & 0.08 & -0.51 & -0.37 & 0.24 & -0.20 & 0.08 & 20 \\
Eastern Ontario & -0.18 & -0.07 & -0.03 & -0.43 & -0.21 & -0.32 & -0.32 & 44 \\
PVDS & -0.16 & -0.15 & -0.08 & -0.41 & -0.28 & -0.46 & 0.29 & 62 \\
\hline
\end{tabular}

We built a model similar to model 2 including both SNL and MFS in order to disentangle their effects on biodiversity:

Model 5:

Imer (T60.landscape $\sim C D * M F S * S N C+C D^{2}+M_{F S}^{2}+S N C^{2}+C r o p N b+L a t+L o n+S N L+(1)$ Region/Year))

Model selection based on model 5 included almost the same variables as for model 2, plus SNL. SNL was marginally significant. However, parameter estimates and significance for variables of interest remained mostly unchanged (Table S5.6). This results does not confirm the general assumption that the positive effect of MFS is due to the positive effect of the amount of SNL.

Our variable SNL included a variety of semi-natural linear elements (e.g. hedgerows, grassy margins) that may not play the same role for biodiversity. Therefore, we built another model similar to model 4 including the length of hedgerows (Hedgerow) instead of SNL in order to test whether the effect of MFS on biodiversity may be due to the increase in the length of hedgerows:

Model 6:

Imer (T60.landscape $\sim C D * M F S * S N C+C D^{2}+M^{*} S^{2}+S N C^{2}+C r o p N b+$ Lat + Lon + Hedgerows $+(1)$ Region/Year))

Model selection based on model 6 included the same variables as for model 2, plus Hedgerows. Hedgerows were non-significant; parameter estimates and significance for other variables of interest 
remained mostly unchanged, except for MFS, which changed from marginally significant to nonsignificant (Table S5.7). This result does not confirm the general assumption that the positive effect of MFS is to the positive effect of the amount of SNL or hedgerows. Instead, this result lends support to the idea that farmlands with smaller fields provide better access to different field types for species that require landscape complementation.

Table S5.7. Comparison of models 2, 5 (with SNL) and 6 (with Hedegrows) based on the uncorrelated subset. Parameter listed are based on the model selection procedure. Parameter estimates are based on the model averaging approach. ${ }^{\circ} p<0.1{ }^{*} p<0.05 ;{ }^{* *} p<0.01 ; * * * 0.001$.

\begin{tabular}{|c|c|c|c|}
\hline & model 2 (subset) & model $5-\mathrm{SNL}$ & model 6 - Hedgerows \\
\hline Crop diversity (CD) & $-0.14(-2.9 ; 2.62)$ & $0.39(-2.39 ; 3.17)$ & $-0.03(-2.8 ; 2.74)$ \\
\hline Mean field size (MFS) & $-9.9(-18.1 ;-1.68) *$ & $-8.92(-17.24 ;-0.61) *$ & $-8.28(-16.94 ; 0.38)^{\circ}$ \\
\hline Semi-Natural Cover (SNC) & $3.09 ; 0.15 ; 6.03) *$ & $3.16(0.25 ; 6.07) *$ & $3.17(0.21 ; 6.14) *$ \\
\hline Latitude & & $2.94(-3.03 ; 8.9)$ & \\
\hline Longitude & $2.61(-2.01 ; 8.89)$ & $2.06(-4.5 ; 8.62)$ & $2.74(-4.1 ; 9.58)$ \\
\hline $\mathrm{MFS}^{2}$ & $6.71(-0.07 ; 13.49)^{\circ}$ & $6.54(-0.16 ; 13.24)^{\circ}$ & $6.33(-0.44 ; 13.11)^{\circ}$ \\
\hline $\mathrm{SNC}^{2}$ & & $2.71(0.14 ; 5.34) *$ & $2.6(-0.03 ; 5.24)^{\circ}$ \\
\hline $\mathrm{Nb}$ of Crops sampled & $3.87(1.58 ; 6.17) * * *$ & $4.28(1.98 ; 6.58) * * *$ & $3.86(1.57 ; 6.15) * *$ \\
\hline CD :SNC & $1.85(-0.28 ; 3.98)^{\circ}$ & $1.79(-0.31 ; 3.89)^{\circ}$ & $1.83(-0.29 ; 3.96)^{\circ}$ \\
\hline MFS :SNC & $0.66(-2.01 ; 3.32)$ & $0.83(-1.81 ; 3.47)$ & \\
\hline SNL & & $3.64(-0.06 ; 7.34)^{\circ}$ & \\
\hline Hedgerows & & & $2.69(-0.22 ; 5.56)^{\circ}$ \\
\hline
\end{tabular}

\subsection{Correlations and alternative mechanisms at the field level}

Crop diversity and mean field size are also likely to be correlated with several variables at the field level, including the identity of crops sampled, the local land-use intensity (e.g. herbicide use, ploughing frequency). Disentangling the role of crop heterogeneity from the effects of these other variables is also necessary in order to infer potential mechanisms explaining the positive effect of crop heterogeneity on biodiversity. This required running models at the field level, using a data subset for which co-variable data were available. As a result, we could not include all these variables in a single model and therefore present these analyses as separate, complementary analyses.

\subsubsection{Role of the identity of sampled crop types}

We tried to limit correlations between the two crop heterogeneity gradients and the identity of sampled crop types. In some cases, correlations were impossible to avoid because some crops occurred or were dominant only in some regions (e.g. rice in Camargue, almond and olive in Lleida) or some landscapes (e.g. landscapes with low crop compositional heterogeneity). As a result, different types of crop sampled were associated with significantly different values of crop diversity or mean field size (Table S5.8). 
Table S5.8. Analysis of variance showing the relationship between the two heterogeneity gradients (crop diversity and mean field size) and sampled crop type within each region. Since sampled crop type is a categorical variable, correlation coefficient cannot be used. We therefore used the function aov in $\mathrm{R}$, crop diversity and mean field size being the response variables and sampled crop type being the predictor variable. Values correspond to the $\mathrm{F}$ value of the function aov in $\mathrm{R}$. ${ }^{*} p<0.05 ;{ }^{* *} p<0.01$; $* * * p<0.001$.

\begin{tabular}{lll} 
& Crop diversity & Mean field size \\
\hline All regions & $5.78^{* * *}$ & $9.28^{* * *}$ \\
\hline Armorique & 1.95 & 0.29 \\
Camargue & $8.54^{* *}$ & 0 \\
Coteaux & 1.16 & 0.59 \\
East Anglia & $3.35^{* * *}$ & 1.29 \\
Goettingen & 0 & 0 \\
Lleida & $9.43^{* * *}$ & 2.18 \\
Eastern Ontario & $2.57^{*}$ & $2.61^{* *}$ \\
PVDS & 0.35 & 0.53 \\
\hline
\end{tabular}

To evaluate whether the sampled crop type influenced our results, we built a model similar to model 2 but using multidiversity calculated at the field level as the response variable (T60.field). We compared models with and without adding crop type as a random effect (using data collected in 1305 fields in 435 landscapes from 8 regions). Crop type was added as a random effect because we were not interested in estimating the specific effect of each particular crop type. Note there were enough crop types (16) to estimate the random effect adequately.

Model 7: Imer (T60.field $\sim C D *$ MFS * SNC $+C^{2}+D^{2}$ MSS $^{2}+S N C^{2}+$ Lat + Lon + (1) Region/Year/Landscape))

Model 8: Imer (T60.field $\sim C D * M F S * S N C+C D^{2}+M_{F S}^{2}+S N C^{2}+$ Lat + Lon + (1) Region/Year/Landscape) $+(1 /$ Crop type $))$

To test whether crop type had a significant effect on field-level biodiversity, we used a restricted likelihood-ratio test based on simulated values from the finite sample distribution available in the function exactRLRT from package RLRsim. We then compared the estimates and p-values associated with models 7 and 8 to determine whether any effects of crop type influenced our conclusions regarding the effects of crop heterogeneity on biodiversity.

Although we detected a significant effect of crop type on field-level biodiversity (RLRT = 125.43, p-value < 0.001), adding crop type as a random effect in the model did not change the outcome of model selection or the significance of variables of interest (Table S5.9). This result suggests that variations in the identity of crops sampled do not explain the effects of $C D$, in combination with SNC, and MFS on biodiversity detected in our study. 
Table S5.9. Comparison of models built at the field level for biodiversity (model 7 - field level, i.e. without sampled crop type as a random effect; model 8 - sampled crop id, i.e. with sampled crop type as a random effect). Parameter listed are based on the model selection procedure. Parameter estimates are based on the model averaging approach. ${ }^{*} p<0.05 ;{ }^{* *} p<0.01 ;{ }^{* *} p<0.001$.

\begin{tabular}{lll} 
& model 7 (field) & model 8 (field) - sampled crop ID \\
\hline Crop diversity (CD) & $0.78(-0.79 ; 2.36)$ & $0.25(-2.08 ; 2.58)$ \\
Mean field size (MFS) & $-3.14(-6.57 ; 0.28)^{\circ}$ & $-2.44(-4.77 ;-0.10)^{*}$ \\
Semi-Natural Cover (SNC) & $3.14(-1.12 ; 7.4)$ & $3.79(0.98 ; 6.60))^{* *}$ \\
Latitude & $0.97(-3.4 ; 5.33)$ & \\
Longitude & $3.63(-1.68 ; 8.93)$ & $1.2(-4.88 ; 7.28)$ \\
CD $^{2}$ & & $0.67(-4.25 ; 5.6)$ \\
MFS $^{2}$ & $2.07(-1.52 ; 5.66)$ & $1.19(-2.38 ; 4.76)$ \\
SNC & $2.9(-1.27 ; 7.06)$ & $2.05(-2.08 ; 6.18)$ \\
CD :SNC & $1.35(0.08 ; 2.63)^{*}$ & $1.39(0.14 ; 2.63)^{*}$ \\
MFS :SNC & $1.55(0.09 ; 3.00)^{*}$ & $1.91(0.47 ; 3.34)^{* *}$ \\
CD :MFS & & $0.2(-1.12 ; 5.56)$ \\
\hline
\end{tabular}

\subsubsection{Role of crop heterogeneity in cereal fields}

To further assess the role of crop identity, we applied model 7 to the subset of data collected in cereal fields. Indeed, cereal is the most widespread crop type sampled in our dataset and the only one present in all regions. We therefore applied model 6 on 615 fields in 334 landscapes in our 8 regions (after removing the random effect of landscape since most landscape contain only one cereal field). This analysis confirms that MFS and CD, combined with SNC, have positive effects on biodiversity in cereal crop fields (Table S5.10).

Table S5.10. Comparison of models built at the field level for biodiversity (model 6) with the complete dataset and with the cereal subset. Parameter listed are based on the model selection procedure. Parameter estimates are based on the model averaging approach. ${ }^{*} p<0.05 ;{ }^{* *} p<0.01 ;{ }^{* * *} p<0.001$.

\begin{tabular}{lll} 
& model 7 (field) - complete dataset & model 7 (field) - cereal subset \\
\hline Crop diversity (CD) & $0.78(-0.79 ; 2.36)$ & $-2.78(-8.62 ; 3.06)$ \\
Mean field size (MFS) & $-3.14(-6.57 ; 0.28)^{\circ}$ & $-4.51(-9.24 ; 0.23)^{\circ}$ \\
Semi-Natural Cover (SNC) & $3.14(-1.12 ; 7.4)$ & $3.16(0.26 ; 6.06)^{*}$ \\
Latitude & $0.97(-3.4 ; 5.33)$ & \\
Longitude & $3.63(-1.68 ; 8.93)$ & $2.03(-0.87 ; 4.94)$ \\
MFS $^{2}$ & $2.07(-1.52 ; 5.66)$ & $3.62(-0.19 ; 7.43)^{\circ}$ \\
SNC & $2.9(-1.27 ; 7.06)$ & $1.49(-3.09 ; 6.08)$ \\
CD :SNC & $1.35(0.08 ; 2.63)^{*}$ & $1.76(0.17 ; 3.36)^{*}$ \\
MFS :SNC & $1.55(0.09 ; 3.00)^{*}$ & $3.31(1.73 ; 4.9)^{* * *}$ \\
CD :MFS & & $0.46 \quad(-1.17 ; 2.09)$ \\
\hline
\end{tabular}




\subsubsection{Role of field-level Land-Use Intensity}

Land-use intensity may be correlated with crop heterogeneity in some regions. For instance, landscapes with larger mean field sizes may be associated with higher fertilizer inputs (Levers et al. 2016, Roschewitz et al. 2005). Such correlations could hamper our ability to draw conclusion on the effects of crop heterogeneity on biodiversity.

We conducted farmer surveys to collect data on land use intensity of the sampled fields. Information included ploughing $(0=n o / 1=y e s)$, use of fertilizer $(0=n o / 1=y e s)$, frequency of herbicide use (from 0 to 7) and frequency of insecticide use (from 0 to 6) in 324 fields located in 132 landscapes across five regions (Armorique, Camargue, Coteaux, Goettingen and Eastern Ontario). We calculated a local Land-Use Intensity index (local LUI) based on the normalized mean of these four variables (after scaling each variable) following a formula similar to the one developed by Herzog et al. (2006): LUI = ploughing + fertilizer + herbicide + insecticide. This local LUI index therefore varies between 0 (low intensity) and 1 (high intensity).

The Pearson correlation between local LUI and crop diversity was weak and not significant $(r=0.10 ; p=0.12)$. The Pearson correlation between local LUI and mean field size was significant but weak and, within the subset of data considered, it was negative (i.e. opposite to expectation) ( $r=-0.27$; p<0.001; Fig. S5.3).
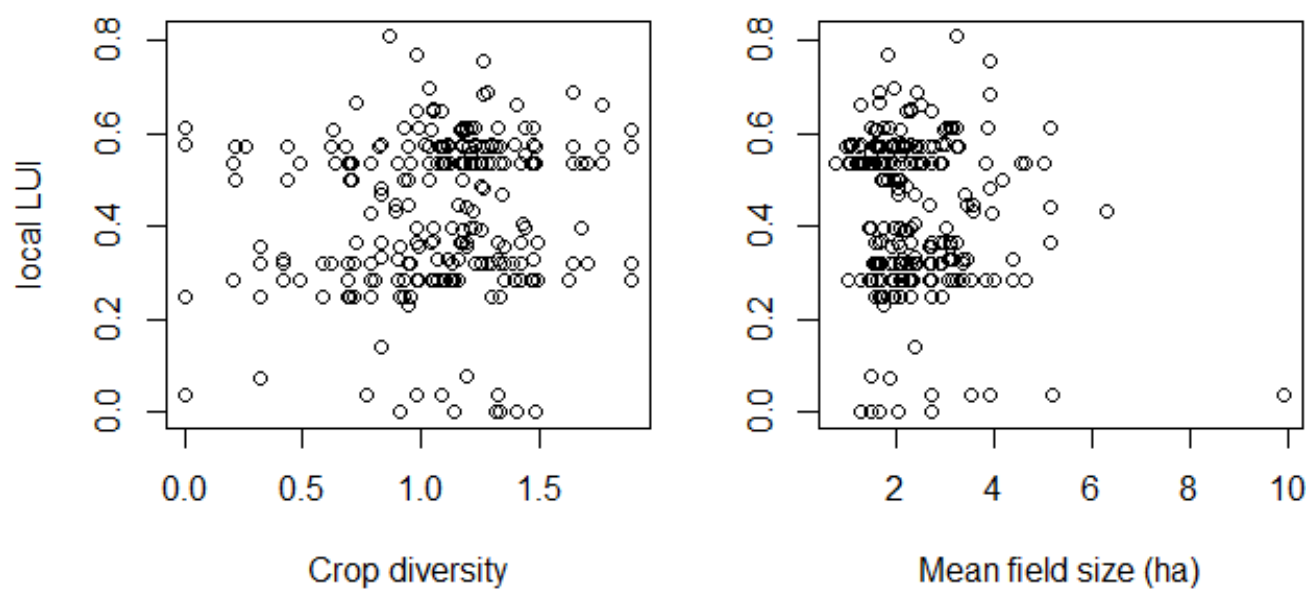

Figure S5.3. Relationship between the two crop heterogeneity gradients and Land-Use Intensity (LUI).

We added local LUI to model 8 and compared the outcomes of model 8 and model 9 using the data subset for which Field LUI data was available.

Model 9: Imer (T60.field $\sim C D * M F S * S N C+C D^{2}+M_{F S}^{2}+S N C^{2}+$ Lat + Lon + Field LUI + (1) Region/Year/Landscape) $+(1 /$ Crop type $))$ 
Model selection based on model 8 included almost the same variables as for model 8, plus Field LUI, which had a significant negative effect. Parameter estimates and significance for other variables of interest remained mostly unchanged (Table S5.11). This result suggests that the negative effect of mean field size or the positive effect of crop diversity cannot be explained by variations in field-level land-use intensity. Moreover, we observed a significant negative interaction between crop diversity and mean field size which is consistent with the landscape complementation hypothesis, i.e. the fact that biodiversity benefit more from increasing crop diversity when fields become smaller and can be reached more easily.

Table S5.11. Comparison of models built at the field level for biodiversity with and without field-level land use intensity (LUI). Parameter listed are based on the model selection procedure. Parameter estimates are based on the model averaging approach. ${ }^{\circ} p<0.1 ;{ }^{*} p<0.05 ;{ }^{* *} p<0.01 ;{ }^{* *} p<0.001$.

\begin{tabular}{lll} 
& model 8 (field level LUI subset) & model 9 (field level LUI subset) - LUI \\
\hline Crop diversity (CD) & $18.1(5.35 ; 20.85)^{* *}$ & $16.14(3.42 ; 28.86)^{*}$ \\
Mean field size (MFS) & $8.81(0.31 ; 17.31)^{*}$ & $8.32(-0.41 ; 17.05)^{\circ}$ \\
Semi-Natural Cover (SNC) & $17.69(6.26 ; 29.12)^{* *}$ & $19.11(7.9 ; 30.33)^{* * *}$ \\
Latitude & $4.38(0.95 ; 7.82)^{*}$ & $5.91(1.72 ; 10.09)^{* *}$ \\
Longitude & $2.98(-0.19 ; 6.15)^{\circ}$ & \\
CD $^{2}$ & $-15.54(-27.25 ;-3.83)^{* *}$ & $-14.25(-25.88 ;-2.61)^{*}$ \\
MFS $^{2}$ & $-12.27(-21.8 ;-2.7)^{*}$ & $-13.33(-22.78 ;-3.88)^{* *}$ \\
SNC & $-15.76(-27.97 ;-3.54)^{*}$ & $-17.9(-29.89 ;-5.91)^{* *}$ \\
CD :SNC & $-4.8(-8.53 ;-1.06)^{*}$ & $-5.2(-8.86 ;-1.55)^{* *}$ \\
MFS :SNC & $2.55(-0.77 ; 5.86)^{*}$ & \\
CD :MFS & $-4.06(-7.55 ;-0.57)^{*}$ & $-3.8(-6.71 ;-0.87)^{*}$ \\
CD :MFS :SNC & $1.6(-0.99 ; 4.19)$ & \\
Field LUI & & $-2.53(-4.79 ;-0.26)^{*}$ \\
\hline
\end{tabular}

\subsection{Variation among regions}

To test whether the effects of crop diversity and mean field size on multitrophic biodiversity measured at the landscape level (T60.landscape) varied significantly among regions we added random effects for region on the slopes of crop diversity and mean field size. We assumed that the effects of region on the intercept and slopes were uncorrelated. To test whether Region had a significant effect on the slope of either crop diversity or mean field size, we used the function exactRLRT from package RLRsim.

Model 10: Imer (T60.landscape $\sim C D * M F S * S N C+C D^{2}+M^{*} S^{2}+S N C^{2}+$ CropNb + Lat + Lon + $(1 /$ Region/Year $)+(0+C D /$ Region $))+(0+M F S /$ Region $)+(0+S N C /$ Region $)+(0+C D: S N C /$ Region $))$ 
Table S5.12. Comparison of model 2 and model 10 (i.e. model including a random effect of region on slope). Parameter listed are based on the model selection procedure. Parameter estimates are based on the model averaging approach. ${ }^{\circ} p<0.1{ }^{*} p<0.05 ;{ }^{* *} p<0.01 ; * * *<0.001$.

\begin{tabular}{lll} 
& model 2 & model 10 \\
\hline Crop diversity (CD) & $-0.03(-2.07 ; 2.01)$ & $-0.16(-2.22 ; 1.9)$ \\
Mean field size (MFS) & $-6.39(-11.85 ;-0.94)^{*}$ & $-5.22(-11.29 ; 0.85)^{\circ}$ \\
Semi-Natural Cover (SNC) & $5.07(2.87 ; 7.26)^{* * *}$ & $4.35(0.79 ; 7.91)^{*}$ \\
Nb of Crops sampled & $2.84(1.07 ; 4.62)^{* * *}$ & $3.05(1.29 ; 4.8)^{* * *}$ \\
Latitude & $1.5(-3.55 ; 6.55)$ & \\
Longitude & $3.73(2.47 ; 9.93)$ & $-2.39(-8.39 ; 3.62)$ \\
MFS $^{2}$ & $3.78(-0.67 ; 8.23)^{\circ}$ & $3.78(-2.26 ; 9.83)$ \\
SNC $^{2}$ & & $-2.39(-8.39 ; 3.62)$ \\
CD :SNC & $2.20(0.64 ; 3.76)^{* *}$ & $2.06(0.29 ; 3.82)^{*}$ \\
MFS :SNC & $1.15(-0.66 ; 2.96)$ & $1.51(-0.44 ; 3.46)$ \\
\hline
\end{tabular}

The random effect of region on the slope of MFS was significant in model 10 ( $R L R T=3.28, p=0.02$ ) whereas the effects on CD (RLRT=0, $p=1)$, SNC (RLRT=0.04, $p=0.33)$ and CD:SNC (RLRT=0.19, $p=0.24)$ were not (Fig. S5.4). This result confirms that the regional context can modulate the effect of mean field size on biodiversity, but that the positive effects of $C D$, combined with SNC, and MFS remain valid across all regions (Table S5.12). 

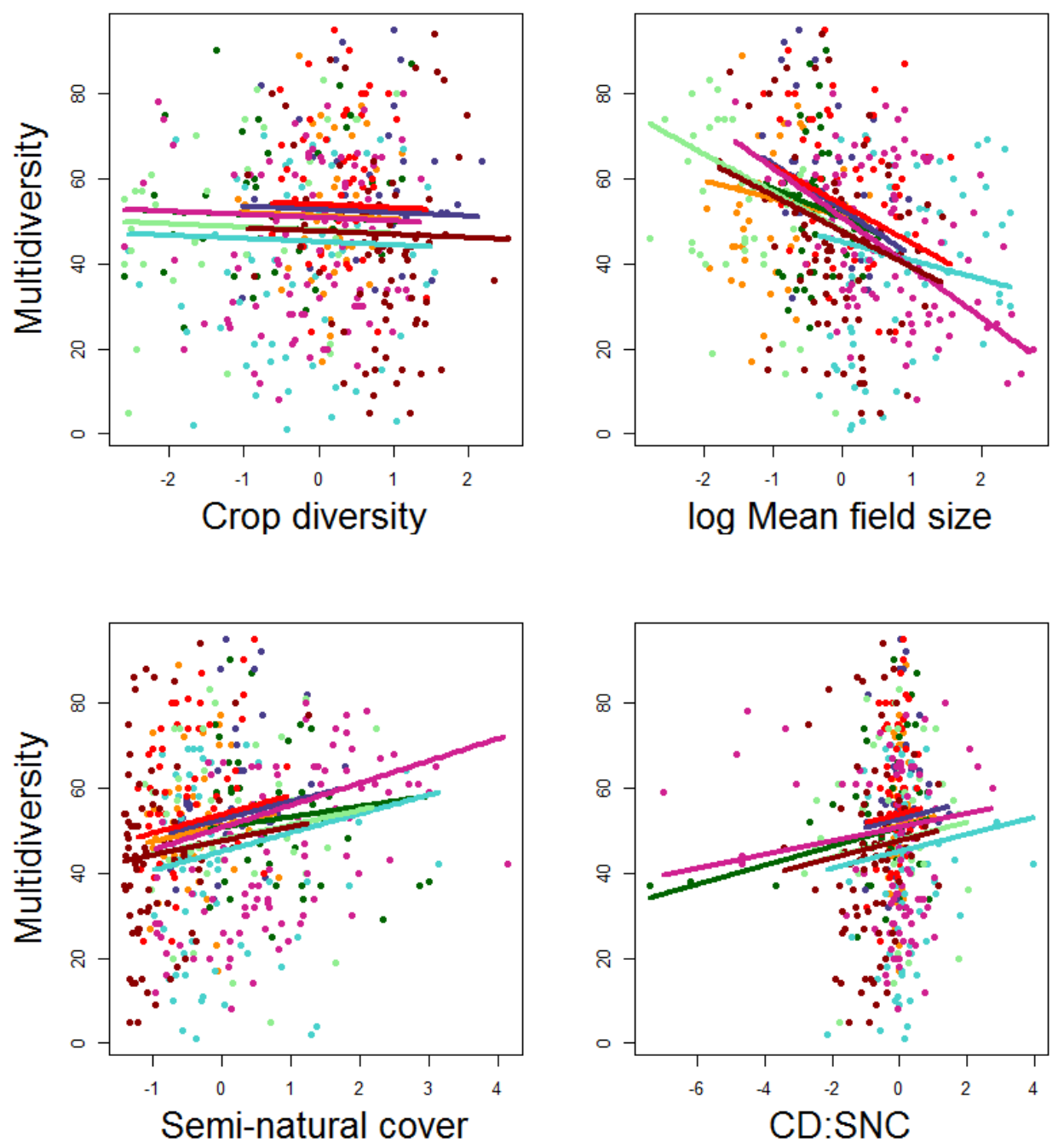
Armorique
- Camargue
- Coteaux
East Anglia
- Goettingen
- Lleida
- Ontario

- PVDS

Figure S5.4. Effects of crop diversity, mean field size (log), semi-natural cover and the interaction between crop diversity and semi-natural cover (CD:SNC) on biodiversity in different regions. Slopes are based on the outputs of model 9 including a random effect of region on these four slopes ( $n=435$ landscapes). Colours indicate the region.

\subsection{Moving window modeling approach for Crop heterogeneity $\times$ Semi-natural cover interaction}

We used a moving window modeling approach (Humpries et al. 2010; Berdugo et al. 2018) to identify potential discontinuities in biodiversity response to crop diversity and mean field size along the gradient of semi-natural cover. To do so, we ordered all landscapes $(n=435)$ along the gradient of semi-natural cover (\%) and selected the first 75 landscapes with the lowest semi-natural cover. Using this subset, we ran the best selected model (Fig. 2 main text) including all explanatory variables, except the effect of semi natural cover, such as:

Model 11: Imer (T60.landscape CD*MFS + MFS ${ }^{2}+$ CropNb + Lat + Lon + (1/ Region/Year) $)$ 
We then extracted and stored the model coefficient for crop diversity (CD), mean field size (MFS) and the confidence intervals $(\mathrm{Cls})$. We then removed the landscape with the lowest value of semi-natural cover from the subset of 75 landscapes, added the landscape scoring the next higher value, ran model 11 and extracted model coefficients and Cls. We repeated this loop as many times as landscapes remained along the entire gradient of semi-natural cover ( $n=286$ subsets, see $R$ code below). We saved all coefficients and confident intervals for each step and plotted them against the gradient of semi-natural cover (Fig. 4 in main text).

Consistently with our multiple regression analyses (Fig. 2 in main text), this moving window analysis showed that the effect of crop diversity and mean field size on biodiversity changes along the gradient of semi-natural cover (Fig. 4 A and B in main text). The effect of crop diversity is positive for high values of semi-natural cover, neutral as semi-natural cover decreases and negative for the low values of semi-natural cover. The effect of mean field size is neutral for the high values of semi-natural cover and negative for low values of semi-natural cover.

However, this analysis reveals that changes in the effect of crop diversity and mean field size on biodiversity are not smooth but instead show abrupt transitions when semi-natural cover decreases. For crop diversity, there is an abrupt change at $11.2 \%$ of semi-natural cover where the effect of crop diversity shifts abruptly from positive to neutral and one at $4.5 \%$ where the effect of crop diversity shifts from neutral to negative. For mean field size, there is one abrupt change at $8 \%$ where the effect of mean field size shifts abruptly from neutral to negative. This analysis allows identifying three thresholds that can be used to guide recommendations on how to manage the three main components of agricultural landscape heterogeneity, namely crop diversity, mean field size and the amount of semi-natural cover (see main text for more details).

R Code for the Moving Window Analysis (the code provided only concerns crop diversity)

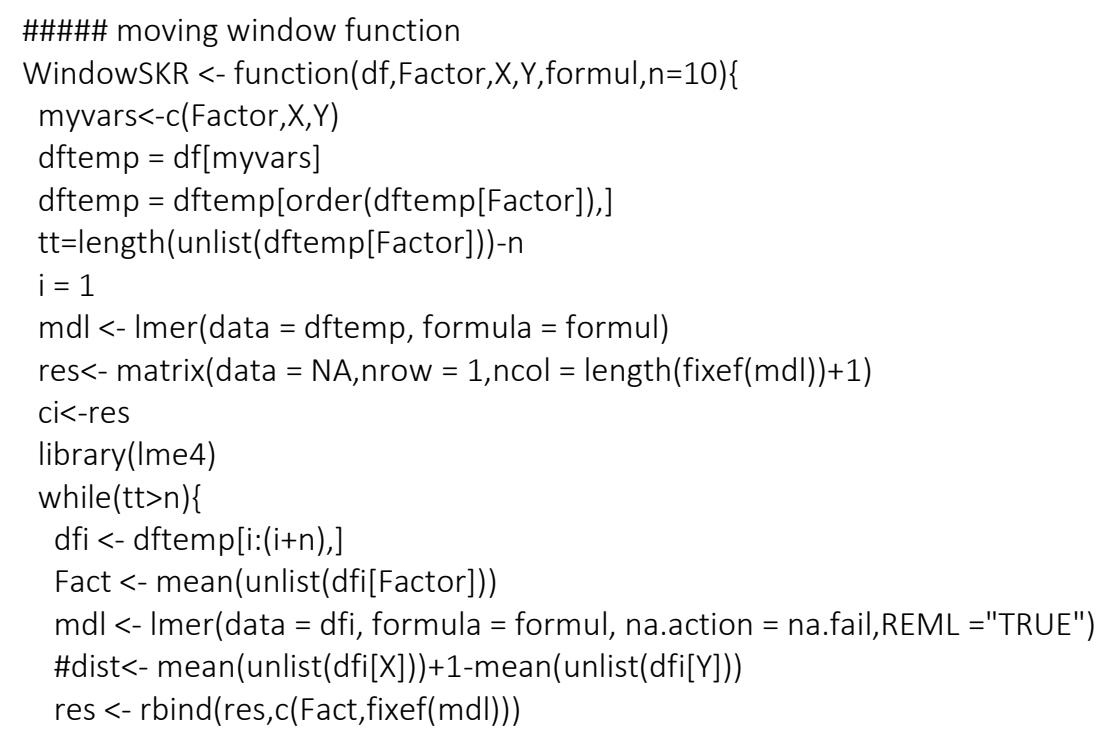




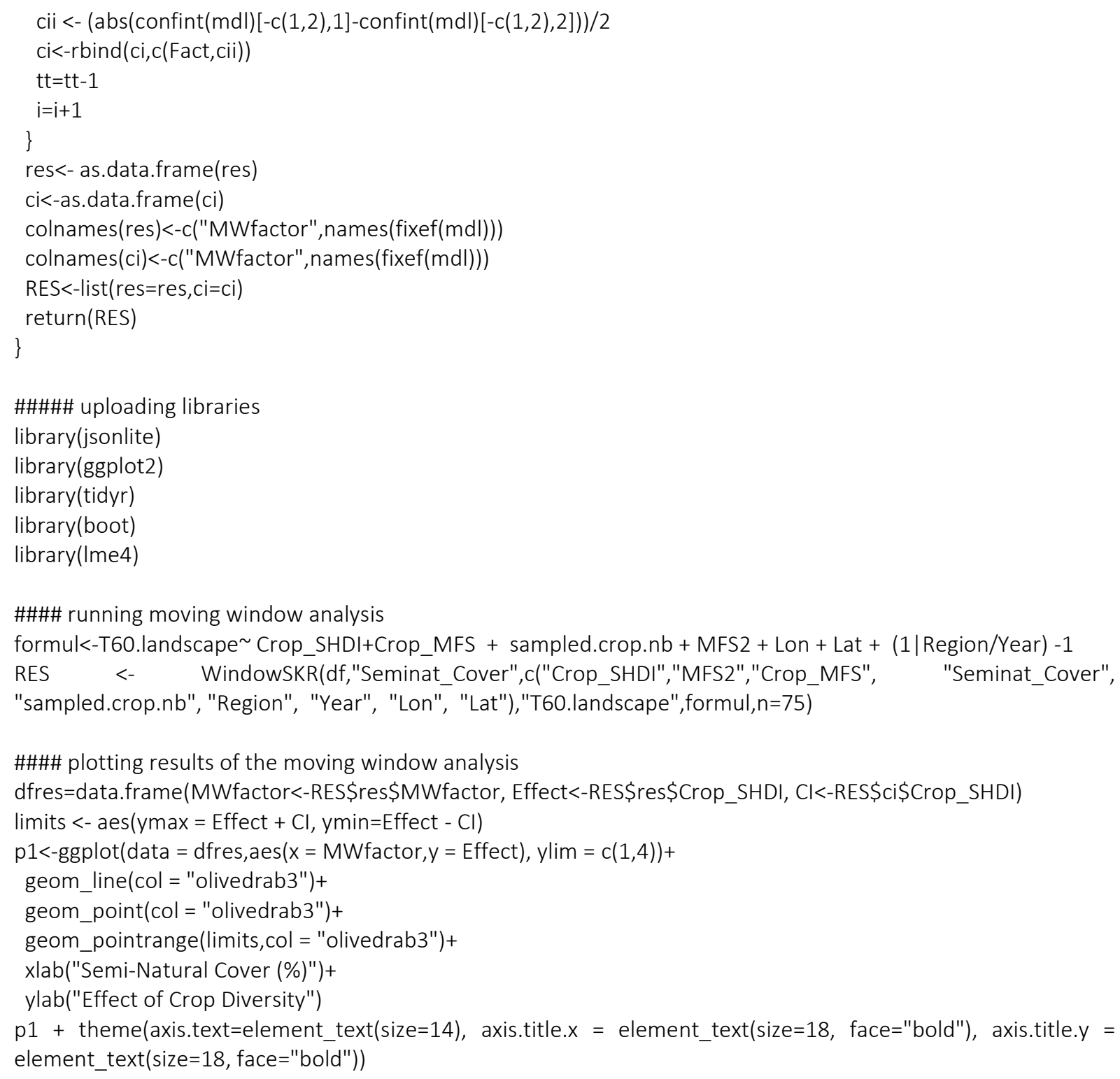

\section{References}

Berdugo $\mathrm{M}$, et al. Aridity preferences alter the relative importance of abiotic and biotic drivers on plant species abundance in global drylands. J Ecol 0(0). doi:10.1111/1365-2745.13006.

Herzog F, et al. (2006) Assessing the intensity of temperate European agriculture at the landscape scale. Eur J Agron 24(2):165-181.

Humphries NE, et al. (2010) Environmental context explains Lévy and Brownian movement patterns of marine predators. Nature 465(7301):1066-1069.

Levers C, Butsic V, Verburg PH, Müller D, Kuemmerle T (2016) Drivers of changes in agricultural intensity in Europe. Land Use Policy 58(Supplement C):380-393.

Öckinger E \& Smith HG (2007) Semi-natural grasslands as population sources for pollinating insects in agricultural landscapes. Journal of applied ecology 44(1): 50-59.

Roschewitz I, Thies C, Tscharntke T (2005) Are landscape complexity and farm specialisation related to land-use intensity of annual crop fields? Agric Ecosyst Environ 105(1-2):87-99. 


\section{Chapter 2}

Configurational and compositional farmland heterogeneity affect trait composition of flower-visiting and predacous arthropods

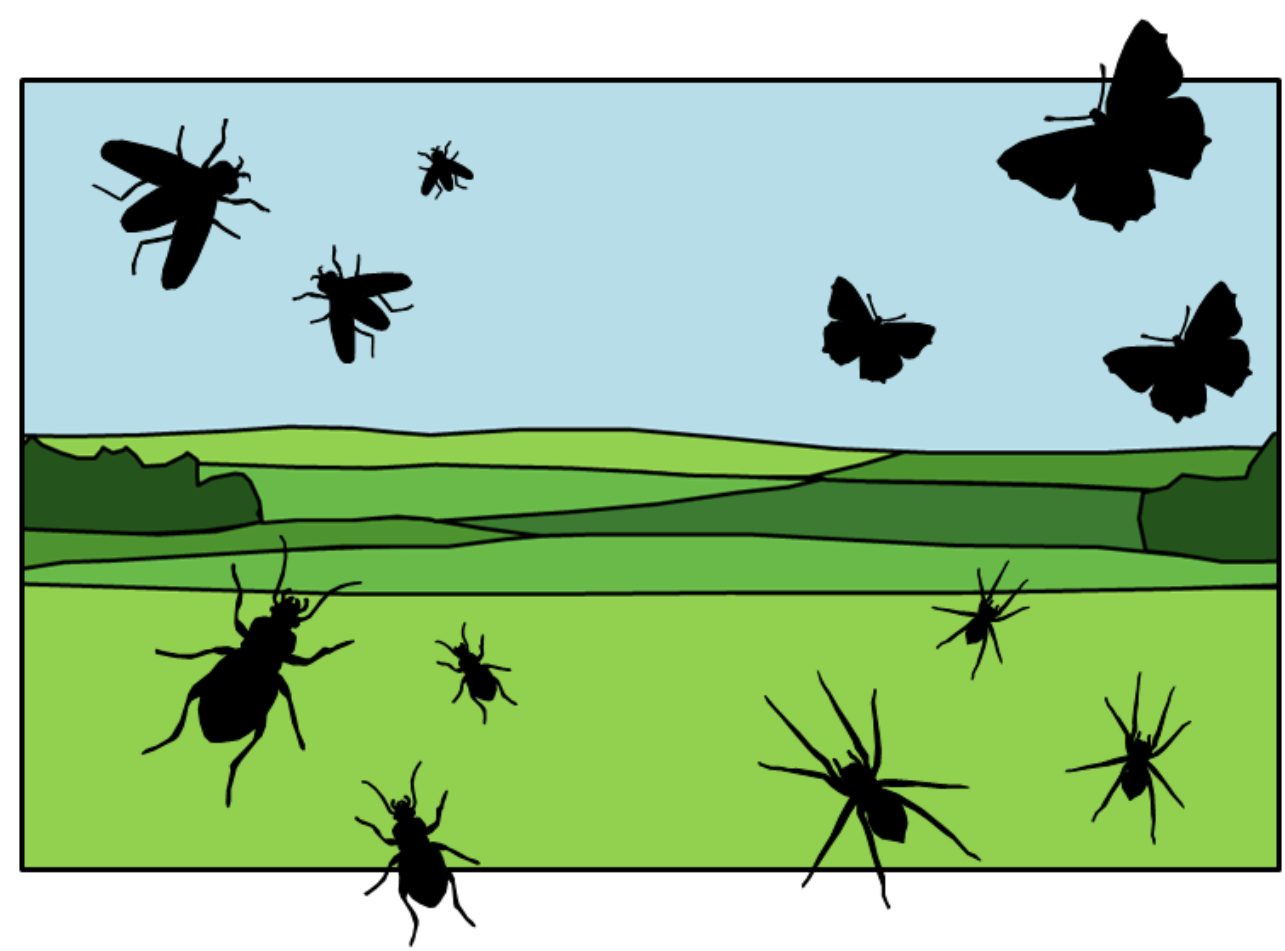

Aliette Bosem Baillod*, Annika L. Hass*, Péter Batáry, Yann Clough, Clélia Sirami, JeanLouis Martin, Lenore Fahrig, Maria Ángeles Marcos-Garcia, José Antonio Barrientos, Jacques Baudry, Colette Bertand, Gerard Bota, Lluis Brotons, Françoise Burel, Romain Carrié, Romain Georges, Bertrand Gauffre, David Giralt, Samuel Hilaire, Jesus Minano, Annie Ouin, Brigitte Poulin, Antonio Ricarte, Alexis Saintilan, Gavin Siriwardena, Aude Vialatte, Teja Tscharntke

*equally contributing authors

To be submitted to Ecology Letters 


\begin{abstract}
Biodiversity conservation in agricultural landscapes has mainly focused on the maintenance and restoration of semi-natural habitats, whereas the heterogeneity of the crop mosaic has received much less attention. We aimed at determining the effects of configurational and compositional crop heterogeneity in the landscape (field size and crop diversity) on community trait composition of butterflies, hoverflies, carabids and spiders in crop fields across different European regions. We found that especially large species (butterflies, hoverflies and carabids) benefit from increased connectivity provided by high configurational heterogeneity. High compositional heterogeneity supported hoverflies with low reproductive and dispersal ability and particularly generalist species of butterflies and spiders. We conclude that reducing field size and increasing crop diversity in the landscape complement the heterogeneity of semi-natural habitats for diverse arthropod trait communities. Some species sensitive to habitat loss are promoted, but also generalists that are probably crucial for sustaining ecosystem services like pollination or biocontrol.
\end{abstract}

Key words: Butterflies, Carabids, Crop diversity, Field border, Field size, Functional community composition, Hoverflies, Landscape heterogeneity, RLQ analysis, Spiders 


\section{Introduction}

Arthropods provide essential ecosystem services in agricultural landscapes such as pollination and biological control (Klein et al. 2007; Tscharntke et al. 2007). However, arthropod diversity and abundance are declining worldwide, which risks undermining the stability of ecosystem service provision for crop production in the future (Dirzo et al. 2014; Newbold et al. 2015; Hallmann et al. 2017). One of the main causes of decline is agricultural intensification with increased chemical input, reduction of semi-natural habitats and simplified crop rotations (Foley et al. 2011; Maxwell et al. 2016). The sensitivity of species to these land use changes is often determined by their traits (Purvis et al. 2000; De Palma et al. 2015). For example, species at high trophic levels, with restricted geographic ranges, large body sizes and slow life histories have higher risk of extinction (Purvis et al. 2000). Therefore, it is essential to understand which landscape characteristics support these sensitive species in order to protect and promote overall biodiversity and ecosystem functioning in agro-ecosystems.

Semi-natural habitats in the landscape can positively affect arthropod communities by promoting disturbance-sensitive species, for example species with low dispersal ability (Hendrickx et al. 2009; Ekroos et al. 2013). However, Fahrig et al. (2011) questioned the traditional perspective that semi-natural patches are the only valuable habitat for species conservation in agricultural landscapes, and that crop production areas are a homogenous 'hostile matrix'. Spill-over of species from crops to other land cover types and vice versa are commonly observed (Blitzer et al. 2012), emphasizing the potential importance of landscape scale crop heterogeneity. Therefore, enhancing crop heterogeneity could benefit species and ecosystem services in agricultural systems without taking land out of production (Fahrig et al. 2011; Palmu et al. 2014), but its contribution to the community composition of traits has not been investigated to date. Crop heterogeneity has two main components: crop compositional heterogeneity includes the diversity of crop types grown in a landscape, whereas crop configurational heterogeneity describes their size, shape or spatial arrangement, for example mean field size or field border length per unit area in the landscape (Fahrig et al. 2011).

Higher crop configurational heterogeneity, with smaller fields providing a higher density of field borders, could play an important role through two different mechanisms. First, increasing resource accessibility through higher resource interspersion (Fahrig et al. 2011; Batáry et al. 2017) might facilitate spill-over between habitats during foraging flights or between seasons and could therefore be beneficial for species with low dispersal ability, feeding specialists and species with low reproductive potential. These species are most sensitive to habitat loss and strongly depend on habitat connectivity (Öckinger et al. 2010), because they are slow to recolonize habitats following local extinction processes due to their low population growth rates, special feeding requirements or slow movement (Henle et al. 2004). In grasslands, high configurational heterogeneity of semi-natural habitats promotes arthropod species with small body sizes (Gámez-Virués et al. 2015) as well as 
butterflies with high feeding specialization (Perović et al. 2015). Second, crop configurational heterogeneity might promote arthropod movement along field borders with and without semi-natural boundary vegetation (Cranmer et al. 2012; Hass et al. 2018). This indicates the potential importance of field interspersion for functionally diverse arthropod communities, but studies across different taxa and regional contexts are missing so far.

Regarding crop compositional heterogeneity, different crops are expected to provide different food resources as different crops are associated with different weeds (Hyvönen \& Salonen 2002). Landscape compositional heterogeneity with greater semi-natural habitat diversity promotes feeding specialists in grasslands across a wide range of arthropod taxa (Gámez-Virués et al. 2015), and therefore we expect that crop diversity would have a similar beneficial effect on feeding specialists. Additionally, herbivores could benefit from the higher plant diversity as well as species depending on the structural heterogeneity provided by crop diversity.

With a highly replicated data set, comprising $2901 \mathrm{~km}^{2}$ landscapes across seven contrasting regions in four different European countries sampled in two consecutive years, we investigated how trait community composition of four arthropod taxa that provide important pollination and predation services in agricultural landscapes (butterflies, hoverflies, carabids and spiders) is influenced by landscape scale crop heterogeneity by disentangling the effects of crop compositional heterogeneity, crop configurational heterogeneity and the proportion of semi-natural habitats. We focussed on four groups of traits, that are available for most taxa and that have been shown to be influenced by landscape structure (Ribera et al. 2001; Hendrickx et al. 2009; Öckinger et al. 2010): body size (wing span, body length), foraging related traits (trophic level, feeding specialisation, foraging stratum, hunting mode), dispersal capacity (dispersal ability, migratory tendency, wing morphology and ballooning behaviour) and reproductive ability (number of generations per year, breeding season). We tested the following hypotheses:

I) Landscape scale crop configurational heterogeneity favours species with low dispersal ability (Perović et al. 2015), due to enhanced habitat connectivity and interspersion. Therefore, we expect that butterflies with low dispersal capacity, hoverflies with no migration tendency, carabids with short wings and non-ballooning spiders will be enhanced. Body size is often correlated with dispersal capacity and therefore we expect to find smaller species in landscapes with high configurational heterogeneity (Gámez-Virués et al. 2015). Additionally, we expect increased connectivity to facilitate access to resources for species with high feeding specialization (monophagous butterflies) and low reproduction rates (butterflies and hoverflies with a low number of generations per year and late breeding carabids) (Henle et al. 2004). 
II) Landscape scale crop compositional heterogeneity promotes feeding specialists because more diverse resources are provided by different crops. Therefore, we expect more monophagous butterflies in these landscapes. Herbivorous species (hoverfly larvae and carabids) will benefit from a high diversity of plants associated with different weeds in different crops. Additionally, we expect that spiders foraging in different strata, i.e. the soil and vegetation, would benefit from high crop diversity due to a higher structural diversity. For body size the effect could be negative or positive due to the correlation with several other traits like dispersal ability or trophic position.

III) A larger proportion of semi-natural habitats at the landscape scale benefits species that are sensitive to disturbance: species with larger body sizes, feeding specialists (mono- and oligophagous butterflies) and herbivores (carabids and hoverflies larvae) due to the availability of high plant diversity, as well as species with low dispersal capacity (butterflies, hoverflies with low migration tendency, short winged carabids, nonballooning spiders) and low reproductive ability (low number of generations for hoverflies and butterflies, late breeding carabids) due to high habitat quality, lower managementinduced disturbance and high plant species richness (Henle et al. 2004).

\section{Methods}

\section{Study area, landscape and site selection}

We studied seven European regions, which differ substantially in climate and farming systems. We conducted our study in Armorique, Camargue, Coteaux de Gascogne and Plaine et Val de Sèvre (PVDS) in France, near Göttingen in Germany, in East Anglia in the U.K., and near Lleida in Spain (for details see Appendix S1, Fig. S1.1).

In each region we selected $1 \times 1 \mathrm{~km}$ landscapes that represented orthogonal gradients of crop configurational and crop compositional heterogeneity. Across all regions we selected 296 landscapes (Armorique: 37, Camargue: 34, Coteaux: 32, PVDS: 75, Göttingen: 52, East Anglia: 26, Lleida: 40). In each landscape, one or two cereal fields were selected for a total of 560 fields sampled. All sampled fields in each landscape were situated at least $100 \mathrm{~m}$ from the landscape border and at least $200 \mathrm{~m}$ from each other.

\section{Sampling}

In all regions sampling was conducted during the cropping seasons of 2013 and 2014 (in East Anglia sampling took place in 2013 only). Each landscape was sampled during a single year, either 2013 or 2014. In all fields we established two 50 m transects: one directly in the field edge, next to a semi- 
natural linear element and one interior transect, $25 \mathrm{~m}$ away from the boundary. We used pitfall traps to sample carabids and spiders and pan traps for hoverflies (Appendix S1, Fig. S1.2). There were two sampling rounds within each field during each cropping season. We collected all traps after four days in the field. All arthropods were stored in $70 \%$ ethanol and hoverflies, carabid beetles and spiders were identified to species level in the lab. We surveyed butterflies with transect walks along the same $50 \mathrm{~m}$ transects during warm, sunny and windless weather conditions (Appendix S1, Fig. S1.2). There was one sampling round per season for butterflies in most regions, only in Lleida and East Anglia there were two.

\section{Landscape scale variables}

In each $1 \times 1 \mathrm{~km}$ landscape, crop configurational heterogeneity, crop compositional heterogeneity and proportion of semi-natural habitats were calculated. We conducted ground-truthing to record all crops grown in the sampled landscapes and we measured the total field border length (sum of all field perimeters) in the landscape. Then we calculated crop configurational heterogeneity as total border length per total crop area ( $\mathrm{km} / \mathrm{ha}$ ) (TBL). Crop compositional heterogeneity was calculated as the Shannon diversity index of all crop types (SHDI). Additionally, we measured the total area of areal and linear semi-natural habitats (SNH) (\% cover). These included, for example, unimproved grasslands, forests, hedges and grassy field boundaries. For statistical descriptions of variables, see Appendix 1 , Table S1.1. As we found moderate correlations between some of our landscape variables we compiled a subset of our data by excluding sites for each taxa until the correlation between all landscape variables was lower than 0.30 (Pearson's correlation) within and across all regions (Appendix S1, Table S1.2). This procedure resulted in a final data set of overall 290 landscapes with 519 fields in 277 landscapes for butterflies, 350 fields in 205 landscapes for hoverflies, 483 fields in 272 landscapes for carabids and 492 fields in 276 landscapes for spiders.

\section{Arthropod traits}

To analyse the effects of landscape variables we collected traits from the literature that we categorized into four trait groups to better compare the trait responses across taxa (body size, foraging related traits, dispersal capacity and reproductive ability, see Table 1 for details). Butterfly traits were collected from Bink (1992) and hoverfly traits from Syrph The Net database (Speight et al. 
Table 1 Trait description and correlations between trait variables and partial RLQ axes. All variables are categorical, apart from body size trait for all taxa and dispersal ability for butterflies. Spearman |rho| are showed for continuous variables and Kendall $\mid$ tau| for categorical variables. Significant correlations $(P<0.05)$ with Spearman $\mid$ rho $\mid>0.5$ (continuous variables) or with Kendall $\mid$ tau $\mid>0.5$ are in bold characters.

\begin{tabular}{|c|c|c|c|}
\hline Traits & Variables & Axis 1 & Axis 2 \\
\hline \multicolumn{4}{|l|}{ Butterfly } \\
\hline Body size & Wing span (mm) & $-0.47 *$ & $-0.51 *$ \\
\hline \multirow[t]{3}{*}{ Foraging } & Polyphagous & $-0.31 *$ & $-0.66 *$ \\
\hline & Oligophagous & $0.62 *$ & $0.36 *$ \\
\hline & Monophagous & $-0.44 *$ & $0.48^{*}$ \\
\hline Dispersal & Estimation from low (0) to high (6) dispersal ability & $-0.68 *$ & -0.28 \\
\hline Reproduction & Number of generation per year ( 1 to 4 ) & $-0.78 *$ & 0.17 \\
\hline \multicolumn{4}{|l|}{ Hoverfly } \\
\hline Body size & Body length (mm) & $-0.68 *$ & 0.14 \\
\hline \multirow[t]{2}{*}{ Foraging } & Predator & $0.47 *$ & $-0.33 *$ \\
\hline & Non predator & $-0.47 *$ & $0.33 *$ \\
\hline \multirow[t]{3}{*}{ Dispersal } & No migration & 0.07 & $0.60 *$ \\
\hline & Weak migration & -0.24 & $-0.42 *$ \\
\hline & Strong migration & 0.12 & $-0.31 *$ \\
\hline \multirow[t]{3}{*}{ Reproduction } & 1 generation per year & 0.27 & $0.50 *$ \\
\hline & 2 generations per year & $-0.48 *$ & $-0.30 *$ \\
\hline & More than 2 generations per year & 0.27 & -0.07 \\
\hline \multicolumn{4}{|l|}{ Carabid beetle } \\
\hline Body size & Body length (mm) & $0.58 *$ & $0.35 *$ \\
\hline \multirow[t]{3}{*}{ Foraging } & Predatory & 0.03 & $-0.64 *$ \\
\hline & Omnivorous & $-0.29 *$ & $0.21 *$ \\
\hline & Herbivorous & $0.31 *$ & $0.56^{*}$ \\
\hline \multirow[t]{3}{*}{ Dispersal } & Short winged & $0.39 *$ & $-0.32 *$ \\
\hline & Wing dimorphic & $-0.47^{*}$ & $-0.20 *$ \\
\hline & Fully winged & $0.21 *$ & $0.37 *$ \\
\hline \multirow[t]{2}{*}{ Reproduction } & Early breeder (spring) & 0.14 & $-0.33 *$ \\
\hline & Late breeder (summer/ autumn/ winter) & -0.14 & $0.33 *$ \\
\hline \multicolumn{4}{|l|}{ Spiders } \\
\hline Body size & Body length (mm) & $0.75 *$ & $-0.32 *$ \\
\hline \multirow[t]{4}{*}{ Foraging } & Soil dwelling & $0.30 *$ & $0.57 *$ \\
\hline & Vegetation and soil dwelling & $-0.30 *$ & $-0.57^{*}$ \\
\hline & Hunting & $0.70 *$ & 0.07 \\
\hline & Web builder & $-0.70 *$ & -0.07 \\
\hline \multirow[t]{2}{*}{ Dispersal } & Ballooning & $-0.55^{*}$ & $0.37 *$ \\
\hline & Uncommon ballooning & $0.55 *$ & $-0.37 *$ \\
\hline
\end{tabular}

*P-value $<0.05$ 
2015). Spider and carabid beetle traits were collected mainly from the BETSI (Hedde et al. 2012) and the carabids.org (Homburg et al. 2013) databases. Six carabid beetle and spider species (respectively $6 \%$ and less than $1 \%$ of the sampled communities before the subset creation) were excluded to avoid categories with very few species (e.g. carabid species that could not be categorized as "early breeder" or "late breeder" in reproduction traits). Species traits missing from the databases were collected from further literature, as well as from expert knowledge for spiders (Appendix 1, Table S1.3). The body size traits corresponded to wing span for butterflies and to body length for the other taxa. The "foraging related traits" corresponded to foraging specialization for butterfly larvae, to trophic position for carabid beetles and hoverfly larvae, and to hunting mode as well as preferred vertical foraging stratum for spiders (see Table 1 for details). The trait "dispersal capacity" corresponded to gradients from low (1) to high (9) mobility estimates for dispersal ability in butterflies (Bink 1992) and migration tendency for hoverflies as migrating species are expected to be more mobile than nonmigrating species (Speight et al. 2015). For spiders, dispersal capacity was measured as ballooning behaviour as species that use ballooning are able to disperse further than others (Bell et al. 2005), and wing morphology for carabid beetles, because short winged species are expected to disperse less through flight than fully winged species (Hendrickx et al. 2009). The trait "reproductive ability" corresponded to the number of generations per year for flower-visitors (hoverflies and butterflies) and the breeding season for carabid beetles as species with a low number of generations and carabids breeding late in the year are expected to be more sensitive, because they have a higher chance of being disturbed by agricultural practices during reproduction (Duflot et al. 2014; Bartonova et al. 2016). For spiders, data on reproductive ability were not available and therefore not analysed in this study. We explored correlations between all traits within each taxon (Spearman rank correlations for continuous trait variables and Kendall's tau for categorical trait variables).

\section{Statistical analysis}

We analysed the link between arthropod abundance, traits and landscape environmental variables with RLQ and partial RLQ analysis using ade4 package in R (Dray \& Dufour 2007). These analyses link three tables: an environmental-variable-by-site-matrix (R-table), a species-by-site-matrix (L-table) and a trait-by-species-matrix (Q-table). Our sites were the sampled fields. The R-table included landscape variables for the $1 \mathrm{~km}^{2}$ in which each site was situated. Additionally, region was added as a variable to this table. To avoid different weighting of regions due to different value ranges for landscape variables, we standardised these variables within each region. Values ranged between 0 and 1 as follows: $X$ range $=(X$ value $-X \min ) /(X \max -X \min )$ where $X$ range is the range value, $X$ value is the natural value, $\mathrm{X}$ min and $\mathrm{X}$ max are respectively the minimum and maximum value of the variables 
range. The L-table included species abundances summed over visits and traps from both transects in each field, because we decided to focus on the landscape variables. Rare species occurring fewer than five times were excluded from the analysis. The number of sites analysed differed for each taxon: for hoverflies, we excluded transects if more than one of the six pan traps was lost; for butterflies and hoverflies, the whole field was excluded from the analysis if at least one transect during one of the visits could not be conducted. For spiders and carabid beetles, we excluded the whole field if more than one of the four pitfall traps per visit could not be recovered.

As a preliminary step to the RLQ analysis, we conducted separate ordinations of each of the three tables for each of the four taxa. We conducted a principal components analysis on the R- and Qtables. We used the Hill and Smith method for mixed quantitative and categorical variables (Dray et al. 2014). The data in the L-table were Hellinger transformed (Legendre \& Gallagher 2001) to standardise species abundances before it underwent a correspondence analysis. Then, we performed a classical RLQ analysis of the three tables for each taxon including region as an explanatory variable. Region identity explained most of the variance on the two first RLQ axes (Appendix S1, Fig. S1.3). As this study focuses on transregional trends, we performed partial RLQ analysis to control for the region by removing the variation that was linked to this factor (Wesuls et al. 2012). We used rank correlation to test the significance of species traits and environmental variables with the two first partial RLQ axes. Spearman's rho was used for continuous variables and Kendall tau for nominal variables. Both correlation coefficients take values between -1 and 1 . We considered significant correlations with a coefficient $\mid$ rho $\mid$ or $\mid$ tau $\mid>0.5$ to be strong correlations (Cohen 1988). We considered arthropod traits to be associated with certain environmental variables when both were highly and significantly correlated with the same partial RLQ axis (taking into account the two first partial RLQ axes, i.e. either Spearman $\mid$ rho $\mid$ or Kendall $\mid$ tau $\mid>0.5)$. We accounted for different species pools by adding latitude and longitude as environmental variables to the partial RLQ analysis. We did not detect any signs of spatial autocorrelation, since the latitude and longitude variables were not significantly correlated to any of the partial RLQ axes.

\section{Results}

Overall, our final data set contained 329 arthropod species (30 butterflies, 35 hoverflies, 83 carabids and 181 spiders) and 70,013 individuals (3,522 butterflies, 16,996 hoverflies, 21,336 carabids and 28,159 spiders (See species list and abundances in Appendix S1, Table S1.4). For all four taxa, the association between traits and landscape environmental variables explained a high proportion of the variation in the partial RLQ analysis (92.96-97.90\%, Table 2). The correlations of all trait and landscape variables with the first and second axes are shown in Fig. 1 and Fig. 2. The exact position of each landscape and trait variable is shown in the partial RLQ biplot (Appendix S1, Fig. S1.4). A summary of 


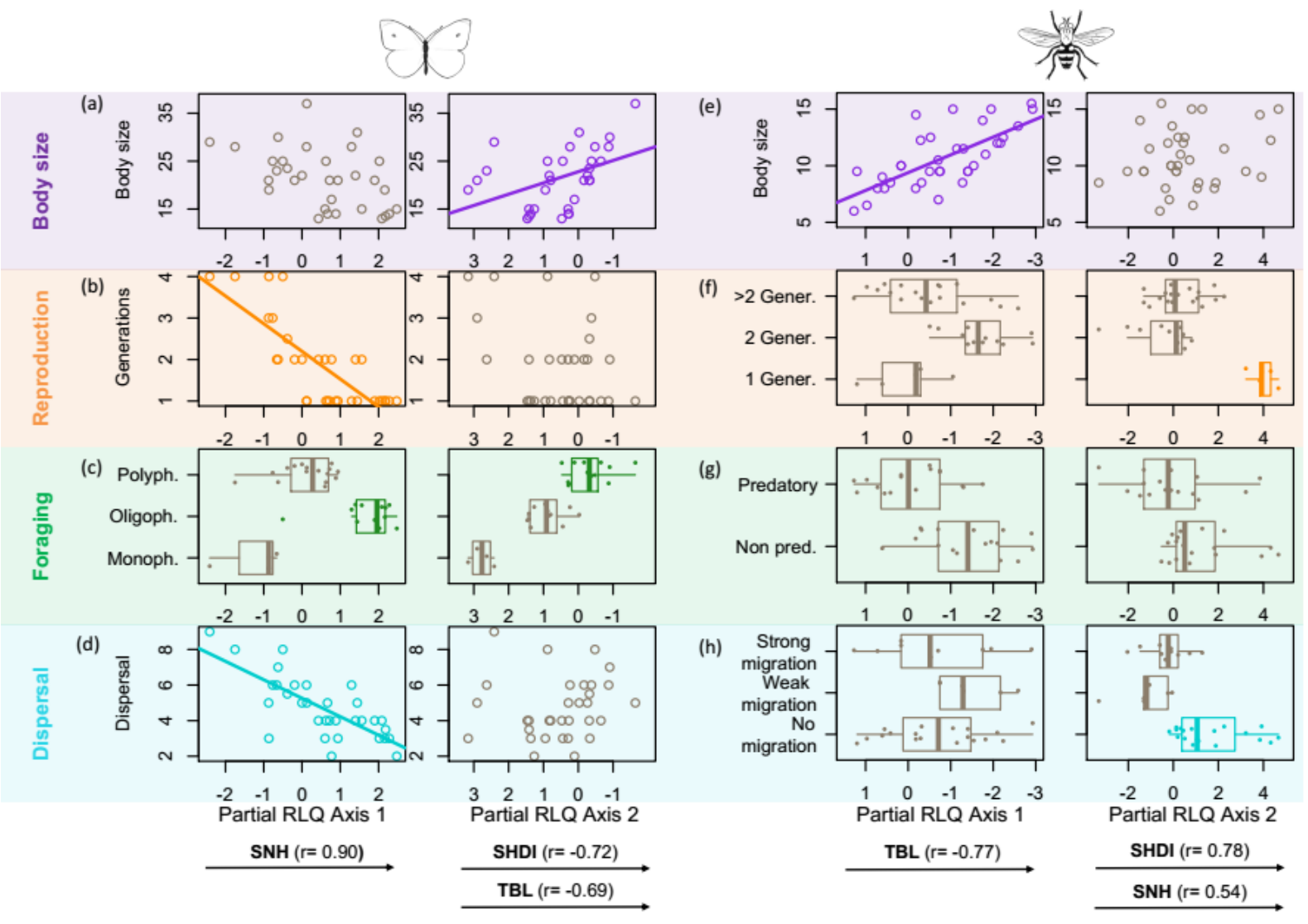

Figure 1 Correlations of traits and landscape variables for flower-visiting arthropods, butterflies (a-d) and hoverflies (e-h). Each point indicates the position of one species. Arrows below plots indicate the direction of landscape variables highly correlated with the axis above (Spearman's $\mid$ rho $\mid>0.5$, TBL: total border length, SHDI: Shannon crop diversity, SNH: semi-natural habitat). Numbers after landscape variable names indicate the correlation strength. If necessary, axes have been reversed for better comparability between taxa so that all landscape variables increase from left to right. Highlighted with colours are effects that are significant $(P>0.05)$ and show a strong correlation with the corresponding axis: Spearman's $\mid$ rho| (for continuous variables) or Kendall |tau| (for nominal variables) $>0.5$.

species scores on partial RLQ axes is provided in Table S1.4. The correlation of the landscape variables with the first two axes is presented in Appendix S1, Fig. S1.5 and Fig. S1.6).

Configurational heterogeneity was an important factor shaping the trait community composition of arthropods. We found larger butterfly (Fig. 1a), hoverfly (Fig. 1e) and carabid (Fig. 2a) species in landscapes with high field border density. However, configurational heterogeneity did not influence dispersal capacity for any of the taxa (Fig. 1d,h, Fig. 2). Similarly, butterflies with high feeding specialisation (monophagous species) were not affected by higher configurational heterogeneity, but polyphagous butterflies increased (Fig. 1c). Additionally, species with low reproduction ability (butterflies and hoverflies with a low number of generations (Fig. 1b,f) and carabids breeding late in the season (Fig. 2b)) were unaffected by configurational heterogeneity. Furthermore, higher configurational heterogeneity led to more predatory and less herbivorous carabid species in the community (Fig. 2c). 


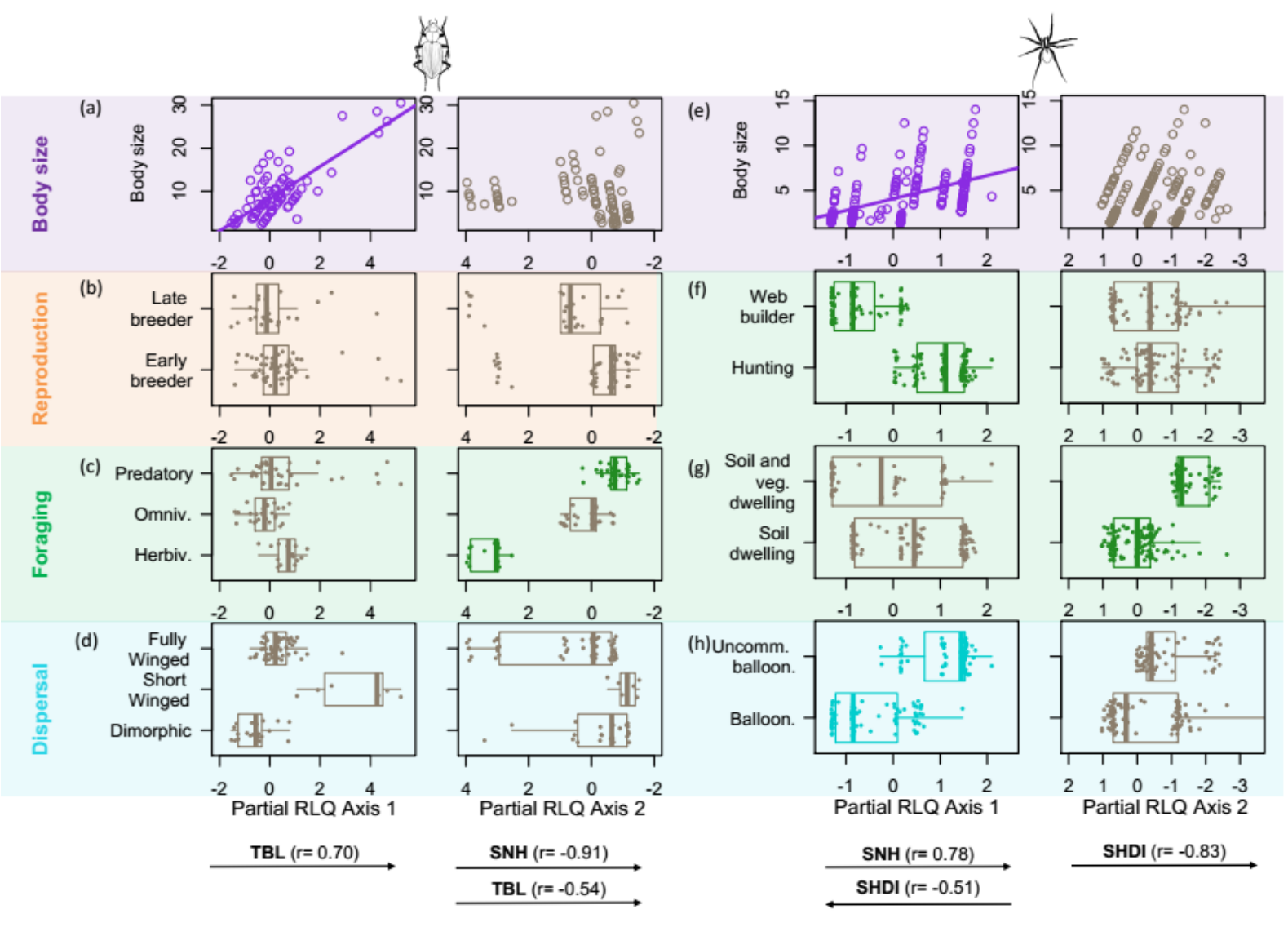

Figure 2 Correlations of traits and landscape variables for predatory arthropods, carabid beetles (a-d) and spiders (e-h). Each point indicates the position of one species. Arrows below plots indicate the direction of landscape variables highly correlated with the axis above (Spearman's $\mid$ rho $\mid>0.5$, TBL: total border length, SHDI: Shannon crop diversity, SNH: semi-natural habitat). Numbers after landscape variable names indicate the correlation strength. If necessary, axes have been reversed for better comparability between taxa so that all landscape variables increase from left to right. Highlighted with colours are effects that are significant $(P>0.05)$ and show a strong correlation with the corresponding axis: Spearman's |rho| (for continuous variables) or Kendall |tau| (for nominal variables) $>0.5$.

Compositional heterogeneity also had a strong effect on the community trait composition of our arthropods. Spiders foraging in different strata (soil and vegetation) were more abundant in landscapes with higher compositional heterogeneity as hypothesised (Fig. 2g). Additionally, small, web-building and ballooning spiders benefited from higher compositional heterogeneity (Fig 2e,f,h). However, higher crop diversity promoted polyphagous butterflies and not monophagous butterflies as we had expected (Fig. 1c). Additionally, there was no effect on herbivorous species, neither for hoverflies nor for carabids (Fig. 1g, Fig. 2c), but hoverfly species with only one generation per year and no migration tendency benefited from higher crop diversity (Fig 1f,h).

In some cases we found that the amount of semi-natural habitat was important for species that are sensitive to disturbance. For example, body size increased with semi-natural habitat, but only for spiders (Fig. 2e). Regarding feeding specialization, oligophagous butterflies that only feed on a small number of plant species increased with semi-natural habitat, but not monophagous butterflies 
as we had expected (Fig. 1c). Butterflies and hoverflies with a low number of generations per year benefited from high amounts of semi-natural habitat in the landscape and also butterflies, hoverflies and spiders with low dispersal capacity (Fig. 1b,d,f,h, Fig. 2h). Nevertheless, these effects were not evident for carabids (Fig. 2d). Additionally, we found more predatory carabids and more hunting spiders in landscapes with high semi-natural habitat proportion (Fig. 2c).

The results of the correlations between traits are presented in Appendix S2 (Table S2.1 and Fig. S2.1-S2.4)

Table 2 Results of the partial RLQ analysis for the first two axes showing Eigenvalues and explained variation for the study taxa.

\begin{tabular}{|c|c|c|c|c|}
\hline & \multicolumn{2}{|l|}{ Eigenvalue } & \multicolumn{2}{|c|}{ Cumulative projected Inertia \% } \\
\hline & Axis 1 & Axis 2 & Axis 1 & Axis 2 \\
\hline Butterfly & 0.014 & 0.003 & 82.41 & 97.90 \\
\hline Hoverfly & 0.006 & 0.003 & 66.95 & 96.71 \\
\hline Carabid beetle & 0.002 & 0.002 & 55.42 & 94.50 \\
\hline Spider & 0.002 & 0.001 & 69.25 & 92.96 \\
\hline
\end{tabular}

Table 3 Spearman rank correlation between variables and partial RLQ. Landscape parameters were calculated within $1 \mathrm{~km}^{2}(1 \times 1 \mathrm{~km}$ square). Significant correlations $(P<0.05)$ with Spearman $\mid$ rho $\mid>0.5$ are in bold characters. SHDI: Shannon diversity index, TBL: Total field border length, SNH: Semi-natural habitat.

\begin{tabular}{|c|c|c|c|c|c|c|c|c|}
\hline \multirow[b]{2}{*}{$\begin{array}{l}\text { Landscape } \\
\text { parameters }\end{array}$} & \multicolumn{2}{|c|}{ Butterfly } & \multicolumn{2}{|c|}{ Hoverfly } & \multicolumn{2}{|c|}{ Carabid beetle } & \multicolumn{2}{|l|}{ Spider } \\
\hline & Axis 1 & Axis 2 & Axis 1 & Axis 2 & Axis 1 & Axis 2 & Axis 1 & Axis 2 \\
\hline SHDI & $-0.28 *$ & $-0.72 *$ & 0.34 & $0.78 *$ & $-0.20 *$ & -0.02 & $-0.51 *$ & $-0.83 *$ \\
\hline TBL & $0.14 *$ & $-0.69 *$ & $-0.77^{*}$ & $0.39 *$ & $0.70 *$ & $-0.54 *$ & -0.07 & $-0.13 *$ \\
\hline $\mathrm{SNH}$ & $0.90 *$ & $-0.36 *$ & -0.41 & $0.54 *$ & $-0.28 *$ & $-0.91 *$ & $0.78 *$ & $-0.43 *$ \\
\hline
\end{tabular}

* P-value $<0.05$

\section{Discussion}

We show that crop configurational heterogeneity at the landscape scale promotes species with larger body sizes, but not species with low dispersal capacity, low reproduction potential and high feeding specialisation. These results highlight the critical role of field borders for large species with the greatest resource demand. Higher crop compositional heterogeneity favoured generalists (polyphagous butterflies and spiders living in different soil/vegetation strata). Additionally, disturbance-sensitive species, i.e. hoverflies with low reproductive ability and low migration tendency, benefited from increased crop diversity. 


\section{Crop configurational heterogeneity}

Across three of the four taxa investigated, body size increased with higher crop configurational heterogeneity in the landscape. This result was surprising, because a previous study on grassland communities showed that body size of different arthropods decreased with higher configurational heterogeneity (Gámez-Virués et al. 2015). The authors concluded that small species have a low dispersal capacity and could therefore benefit from lower distances between habitats and higher connectivity. However, configurational heterogeneity in their study was the average patch size of semi-natural habitats and it is therefore not directly comparable to our study. Additionally, our study had the advantage that we also included traits on dispersal capacity, which were mostly independent of body size (except for butterflies Table S2.1, Fig. S2.1c), and none of the dispersal traits was affected by configurational heterogeneity. Therefore, our results suggest that in crop systems the importance of body size is not related to its correlation with dispersal capacity. Species with larger body sizes have larger energy, resource and habitat requirements and therefore depend more on well-connected habitats than smaller species that might be able to fulfil their needs at smaller spatial scales (Purvis et al. 2000; Dirzo et al. 2014). Higher crop configurational heterogeneity provides more opportunities for spill-over between crop fields, since higher field interspersion lowers the distances between patches and thus increases connectivity between habitats (Fahrig et al. 2011). Additionally, in landscapes with higher configurational heterogeneity we find more linear structures with or without semi-natural boundary vegetation that can facilitate insect movements in agricultural landscapes (Van Geert et al. 2010; Cranmer et al. 2012; Hass et al. 2018). Moroń et al. (2017) recently found that that especially large bodied bee, butterfly and hoverfly species seem to use linear railway embankments as a mean for dispersing, supporting our results that large arthropods benefit most from more linear structures in the landscape. However, evidence on land use and landscape heterogeneity effects on body size is contradictory, some studies find that smaller species are more sensitive to land use changes (De Palma et al. 2015; Gámez-Virués et al. 2015; Carrié et al. 2017), but others show that larger species are more prone to extinction (Bartomeus et al. 2013; Dirzo et al. 2014; Duflot et al. 2014). This indicates that the relationship between body size and landscape heterogeneity is more complex due to the correlation with different traits that are not always easy to measure or due to behavioral differences between species. For example, Hillaert et al. (2018) found that the response of body size to habitat fragmentation depends strongly on the perception of the resources in the landscape by each taxon, and Ripple et al. (2017) showed that for vertebrates both, the largest and smallest species have the highest extinction risk.

Our results did not confirm our hypothesis that species with low dispersal capacity, low reproduction ability and high feeding specialization benefit from high crop configurational heterogeneity (Henle et al. 2004). One explanation could be that for these sensitive species more field 
borders, at least at the measured spatial scale of $1 \mathrm{~km}^{2}$, are not as important as the composition and configuration of semi-natural habitat (Hendrickx et al. 2009; Perović et al. 2015). However, the nonevident effect of configurational heterogeneity might also be due to the trait categories that were available for this study. For example, although there are studies showing that wingless, large and late breeding carabids are promoted in undisturbed, more woody landscapes (Duflot et al. 2014), wing morphology might not always reflect the dispersal capacity of the species, since not all winged species do fly (Hendrickx et al. 2009). Thus, fully winged species might not always be better dispersers than walking species that are dimorphic or short winged.

Finally, we found, contrary to our expectations, that predatory carabid species benefited from higher configurational heterogeneity. However, this result is in line with the hypothesis that species in higher trophic levels like predatory carabids depend more strongly on high quality habitats (Tscharntke \& Brandl 2004) and might therefore be promoted by increased habitat interspersion and connectivity in landscapes with high configurational heterogeneity. Indeed, predatory carabids have been found to be more sensitive to landscape simplification, possibly due to larger habitat requirements (Purtauf et al. 2005).

\section{Crop compositional heterogeneity}

We could confirm our hypothesis that spiders that use multiple strata (i.e. on the soil and in the vegetation) benefit from higher compositional heterogeneity. Higher crop diversity at the landscape scale probably increased the structural vegetation heterogeneity which might have been beneficial for these generalist spider species. Independent from this effect, compositional heterogeneity was also beneficial for small, web building and ballooning spiders. However, these three traits were highly correlated in spiders (Table S2.1, Fig. S2.4) making it difficult to disentangle their effects. If we assume that the ballooning behaviour is mainly driving this trend, small spiders that are able to balloon could benefit most from different resources provided by different crops at various times as it might be easier for ballooning species to reach distant resources across the landscape.

Higher compositional heterogeneity of semi-natural habitats supports feeding specialists in grasslands (Gámez-Virués et al. 2015). Therefore, we had expected that butterfly feeding specialists would also be promoted by higher crop compositional heterogeneity. However, polyphagous and not monophagous butterflies were positively affected by higher crop diversity in our landscapes. One possible explanation could be that different crops host different weed communities (Hyvönen \& Salonen 2002) and that especially the polyphagous generalist butterflies can exploit the higher diversity of plant resources associated with higher crop diversity, because they are not limited to 
certain plant taxa. Generalist species can therefore be expected to benefit most from landscape supplementation and complementation (Dunning et al. 1992).

The hypothesis that more herbivorous carabids and hoverflies would be found in landscapes with higher compositional heterogeneity was also not confirmed indicating that crop diversity has no effect on the different trophic levels of arthropods in the landscape. Likewise, Schirmel et al. (2018) found that aphidophagous and non-aphidophagous hoverflies respond similarly to landscape heterogeneity. However, we did find positive effects of crop diversity on species with sensitive traits. Hoverflies with a low number of generations per year and no migration tendency benefited from higher crop compositional heterogeneity. Here again the correlation between these two traits (Table S2.1 and Fig S2.2) makes it difficult to conclude which trait drives these pattern. However, Henle et al. (2004) predict that both, species with low reproductive potential and low dispersal capacity, depend strongly on heterogeneous landscapes as their ability to find and colonize new habitats in case of resource shortages is limited. This might explain why hoverfly species with only one generation and no migration benefited from higher crop diversity, because complementary weed communities in different crops as mentioned above (Hyvönen \& Salonen 2002) possibly also results in greater diversity of flowering resources that are provided more evenly throughout the season.

\section{Semi-natural habitat}

Semi-natural habitats such as calcareous grasslands or field margins in agricultural landscapes provide food resources and shelter from within-field disturbance, which benefits many arthropod species (Bianchi et al. 2006; Marshall et al. 2006; Öckinger \& Smith 2007; Vickery et al. 2009). Therefore, we expected positive effects of the proportion of semi-natural habitat on species with larger body sizes due to their high resource requirements, on species with low reproductive and dispersal ability due to slow recolonization after local extinctions, and on species with specialised foraging. This hypothesis was partly confirmed. First, higher amounts of semi-natural habitats in the landscape were beneficial for larger species, but only for spiders. However, this result is confounded by several correlations among the spider traits as larger species tend to be hunters that do not balloon (Table S2.1, Fig. S2.4) (Bell et al. 2005). Second, more semi-natural habitats promoted butterflies with specialised feeding (oligophagous butterfly species), probably due to their provision of high plant species richness (van Swaay 2002; Billeter et al. 2008). Interestingly, monophagous butterflies were not affected by the amount of semi-natural habitat. An explanation could be that in our study monophagous butterflies were mostly feeding on widespread plants in cultivated landscapes (Rand \& Tscharntke 2007), e.g. nettle (Urtica dioica). Third, semi-natural habitat was beneficial for butterflies and hoverflies with low dispersal capacity and low reproductive ability as expected. However, these two traits were correlated 
for both taxa indicating that they should be targeted together and not independent of each other, because species with a low number of generations per year are often also poor dispersers.

Contrary to our expectation, these positive effects on species with sensitive traits were not evident for carabids as body size, breeding season and wing morphology were not affected by landscape heterogeneity in contrast to previous studies (Ribera et al. 2001; Hendrickx et al. 2009; Woodcock et al. 2014). We only found more predatory carabid species in landscapes with higher seminatural habitat. Again this is in line with the hypothesis that especially species at higher trophic levels are promoted by high habitat quality (Tscharntke \& Brandl 2004).

\section{Conclusions}

Homogenization by loss of configurational and compositional heterogeneity in agricultural landscapes is expected to promote arthropods with generalist traits. However, previous studies only investigated grassland communities and ignored the pattern and diversity of crop fields in the measures of landscape heterogeneity (Gámez-Virués et al. 2015; Perović et al. 2015). We show that arthropod communities in agricultural fields respond completely differently to the landscape crop heterogeneity than grassland communities to the heterogeneity of semi-natural habitats. High configurational heterogeneity of semi-natural habitats promoted smaller species in grassland communities (GámezVirués et al. 2015). In contrast, we found larger species in landscapes with higher crop configurational heterogeneity for three of the four taxa investigated (butterflies, hoverflies and carabids). Furthermore, Gámez-Virués et al. (2015) found more specialised species in landscapes with high compositional heterogeneity of semi-natural habitats whereas in our study generalist species benefited from high crop compositional heterogeneity (butterflies and spiders), but also sensitive species with low dispersal and reproductive ability. These differences might be due to the high disturbance regimes and the less diverse resources in agricultural fields compared to different seminatural habitats and highlight that the heterogeneity of crops by decreasing field size and increasing crop diversity might complement the heterogeneity of semi-natural habitats by promoting different arthropod community trait compositions.

Our findings are especially relevant because the groups we studied include species that provide ecosystem services of pollination (Fründ et al. 2013; Lavorel et al. 2013) and biological pest control (Rusch et al. 2015). For example, we found more generalist species (butterflies, spiders) in landscapes with high crop compositional heterogeneity and these generalists can be most important for the provision of ecosystem services (Kleijn et al. 2015). Thus, we recommend that future landscape management strategies take the heterogeneity of crops into account, encourage the reduction in crop field size and promote higher crop diversity. 


\section{Acknowledgements}

This study was part of the FarmLand project funded by the ERA-Net BiodivERsA (http://farmlandbiodiversity.org). Specific national funders were: French National Research Agency (ANR-11-EBID0004), German Federal Ministry of Education and Research (BMBF) and Spanish Ministry of Economy and Competitiveness, part of the 2011 BiodivERsA call for research proposals. The funding scheme for UK was the UK Government Department of the Environment, Food and Rural Affairs (Defra, project WC1034). The author A.B.B. was supported by a scholarship from the German Academic Exchange Service (DAAD). The current fellowship of the author A.R. at the University of Alicante is supported by the 'Vicerrectorado de Investigación y Transferencia de Conocimiento'. We thank all farmers who allowed us to sample on their fields, and the many fieldwork-helpers and identification specialists. A special thank goes to Yvan Capowiez and Alain Pasquet for providing further expert knowledge and help with spider traits. We are especially thankful to David Perović for help on statistical analysis and constructive comments on an earlier version of the manuscript and to Stéphane Dray for statistical advice.

\section{Author's contributions}

A.B.B. and A.L.H with help of P.B., T.T and Y.C. developed the concept of this manuscript. A.B.B, A.LH, C.B., R.C., R.G., D.G., S.H. and G.S. performed field work. A.B.B., A.L.H, M.A.M.G, J.A.B, C.B., R.C., R.G., S.H., J.M., A.R. and A.S. identified species. A.B.B, A.L.H, J.A.B and A.S. compiled trait data. C.S., L.F. and J.M. developed and coordinated the project FarmLand. All other authors contributed to the sampling design and/or coordinated field work. A.B.B. and A.L.H equally wrote the manuscript and analysed data. All authors contributed to revisions.

\section{References}

Bartomeus, I., Ascher, J.S., Gibbs, J., Danforth, B.N., Wagner, D.L., Hedtke, S.M., et al. (2013). Historical changes in northeastern US bee pollinators related to shared ecological traits. Proc. Natl. Acad. Sci., 110, 4656-4660.

Bartonova, A., Benes, J., Fric, Z.F., Chobot, K. \& Konvicka, M. (2016). How universal are reserve design rules? A test using butterflies and their life history traits. Ecography, 39, 456-464.

Batáry, P., Gallé, R., Riesch, F., Fischer, C., Dormann, C.F., Mußhoff, O., et al. (2017). The former Iron Curtain still drives biodiversity-profit trade-offs in German agriculture. Nat. Ecol. Evol., 1, 1279-1284.

Bell, J.R., Bohan, D.A., Shaw, E.M. \& Weyman, G.S. (2005). Ballooning dispersal using silk: world fauna, phylogenies, genetics and models. Bull. Entomol. Res., 95, 69-114.

Bianchi, F.J.J.A., Booij, C.J.H. \& Tscharntke, T. (2006). Sustainable pest regulation in agricultural landscapes: a review on landscape composition, biodiversity and natural pest control. Proc. $R$. Soc. Lond. B Biol. Sci., 273, 1715-1727. 
Billeter, R., Liira, J., Bailey, D., Bugter, R., Arens, P., Augenstein, I., et al. (2008). Indicators for biodiversity in agricultural landscapes: a pan-European study. J. Appl. Ecol., 45, 141-150.

Bink, F.A. (1992). Ecologische Atlas van de Dagvlinders van Noordwest-Europa. Schuyt \& Co, Haarlem.

Blitzer, E.J., Dormann, C.F., Holzschuh, A., Klein, A.-M., Rand, T.A. \& Tscharntke, T. (2012). Spillover of functionally important organisms between managed and natural habitats. Agric. Ecosyst. Environ., 146, 34-43.

Carrié, R., Andrieu, E., Cunningham, S.A., Lentini, P.E., Loreau, M. \& Ouin, A. (2017). Relationships among ecological traits of wild bee communities along gradients of habitat amount and fragmentation. Ecography, 40, 85-97.

Cohen, J. (1988). Statistical Power Analysis for the Behavioral Sciences. 2nd Edition. Lawrence Erlbaum, Hillsdale.

Cranmer, L., McCollin, D. \& Ollerton, J. (2012). Landscape structure influences pollinator movements and directly affects plant reproductive success. Oikos, 121, 562-568.

De Palma, A., Kuhlmann, M., Roberts, S.P.M., Potts, S.G., Börger, L., Hudson, L.N., et al. (2015). Ecological traits affect the sensitivity of bees to land-use pressures in European agricultural landscapes. J. Appl. Ecol., 52, 1567-1577.

Dirzo, R., Young, H.S., Galetti, M., Ceballos, G., Isaac, N.J.B. \& Collen, B. (2014). Defaunation in the Anthropocene. Science, 345, 401-406.

Dray, S., Choler, P., Dolédec, S., Peres-Neto, P.R., Thuiller, W., Pavoine, S., et al. (2014). Combining the fourth-corner and the RLQ methods for assessing trait responses to environmental variation. Ecology, 95, 14-21.

Dray, S. \& Dufour, A.B. (2007). The ade4 Package: Implementing the Duality Diagram for Ecologists. J. Stat. Softw., 22.

Duflot, R., Georges, R., Ernoult, A., Aviron, S. \& Burel, F. (2014). Landscape heterogeneity as an ecological filter of species traits. Acta Oecologica, 56, 19-26.

Dunning, J.B., Danielson, B.J. \& Pulliam, H.R. (1992). Ecological Processes That Affect Populations in Complex Landscapes. Oikos, 65, 169-175.

Ekroos, J., Rundlöf, M. \& Smith, H.G. (2013). Trait-dependent responses of flower-visiting insects to distance to semi-natural grasslands and landscape heterogeneity. Landsc. Ecol., 28, 12831292.

Fahrig, L., Baudry, J., Brotons, L., Burel, F.G., Crist, T.O., Fuller, R.J., et al. (2011). Functional landscape heterogeneity and animal biodiversity in agricultural landscapes. Ecol. Lett., 14, 101-112.

Foley, J.A., Ramankutty, N., Brauman, K.A., Cassidy, E.S., Gerber, J.S., Johnston, M., et al. (2011). Solutions for a cultivated planet. Nature, 478, 337-342.

Fründ, J., Dormann, C.F., Holzschuh, A. \& Tscharntke, T. (2013). Bee diversity effects on pollination depend on functional complementarity and niche shifts. Ecology, 94, 2042-2054.

Gámez-Virués, S., Perović, D.J., Gossner, M.M., Börschig, C., Blüthgen, N., de Jong, H., et al. (2015). Landscape simplification filters species traits and drives biotic homogenization. Nat. Commun., 6, 8568.

Hallmann, C.A., Sorg, M., Jongejans, E., Siepel, H., Hofland, N., Schwan, H., et al. (2017). More than 75 percent decline over 27 years in total flying insect biomass in protected areas. PLOS ONE, 12, e0185809.

Hass, A.L., Kormann, U., Tscharntke, T., Clough, Y., Bosem Baillod, A., Sirami, C., et al. (2018). Landscape configurational heterogeneity by small-scale agriculture, not crop diversity, maintains pollinators and plant reproduction in Western Europe. Proc R Soc B, 285, 20172242.

Hedde, M., Pey, B., Auclerc, A., Capowiez, Y., Cluzeau, D., Cortet, J., et al. (2012). BETSI, a complete framework for studying soil invertebrate functional traits.

Hendrickx, F., Maelfait, J.-P., Desender, K., Aviron, S., Bailey, D., Diekotter, T., et al. (2009). Pervasive effects of dispersal limitation on within- and among-community species richness in agricultural landscapes. Glob. Ecol. Biogeogr., 18, 607-616.

Henle, K., Davies, K.F., Kleyer, M., Margules, C. \& Settele, J. (2004). Predictors of Species Sensitivity to Fragmentation. Biodivers. Conserv., 13, 207-251. 
Hillaert, J., Vandegehuchte, M.L., Hovestadt, T. \& Bonte, D. (2018). Information use during movement regulates how fragmentation and loss of habitat affect body size. Proc. R. Soc. B Biol. Sci., 285, 20180953.

Homburg, K., Homburg, N., Schäfer, F., Schuldt, A., Assmann, T., Dytham, C., et al. (2013). Carabids.org - a dynamic online database of ground beetle species traits (Coleoptera, Carabidae). Insect Conserv. Divers., 7, 195-205.

Hyvönen, T. \& Salonen, J. (2002). Weed species diversity and community composition in cropping practices at two intensity levels - a six-year experiment. Plant Ecol., 159, 73-81.

Kleijn, D., Winfree, R., Bartomeus, I., Carvalheiro, L.G., Henry, M., Isaacs, R., et al. (2015). Delivery of crop pollination services is an insufficient argument for wild pollinator conservation. Nat. Commun., 6, 7414.

Klein, A.-M., Vaissiere, B.E., Cane, J.H., Steffan-Dewenter, I., Cunningham, S.A., Kremen, C., et al. (2007). Importance of pollinators in changing landscapes for world crops. Proc. R. Soc. B-Biol. Sci., 274, 303-313.

Lavorel, S., Storkey, J., Bardgett, R.D., Bello, F., Berg, Roux, X., et al. (2013). A novel framework for linking functional diversity of plants with other trophic levels for the quantification of ecosystem services. J. Veg. Sci., 24, 942-948.

Legendre, P. \& Gallagher, E.D. (2001). Ecologically meaningful transformations for ordination of species data. Oecologia, 129, 271-280.

Marshall, E.J.P., West, T.M. \& Kleijn, D. (2006). Impacts of an agri-environment field margin prescription on the flora and fauna of arable farmland in different landscapes. Agric. Ecosyst. Environ., 113, 36-44.

Maxwell, S.L., Fuller, R.A., Brooks, T.M. \& Watson, J.E.M. (2016). Biodiversity: The ravages of guns, nets and bulldozers. Nat. News, 536, 143.

Moroń, D., Skórka, P., Lenda, M., Celary, W. \& Tryjanowski, P. (2017). Railway lines affect spatial turnover of pollinator communities in an agricultural landscape. Divers. Distrib., 23, 10901097.

Newbold, T., Hudson, L.N., Hill, S.L.L., Contu, S., Lysenko, I., Senior, R.A., et al. (2015). Global effects of land use on local terrestrial biodiversity. Nature, 520, 45-50.

Öckinger, E., Schweiger, O., Crist, T.O., Debinski, D.M., Krauss, J., Kuussaari, M., et al. (2010). Lifehistory traits predict species responses to habitat area and isolation: a cross-continental synthesis. Ecol. Lett., 13, 969-979.

Öckinger, E. \& Smith, H.G. (2007). Do corridors promote dispersal in grassland butterflies and other insects? Landsc. Ecol., 23, 27-40.

Palmu, E., Ekroos, J., Hanson, H.I., Smith, H.G. \& Hedlund, K. (2014). Landscape-scale crop diversity interacts with local management to determine ground beetle diversity. Basic Appl. Ecol., 15, 241-249.

Perović, D., Gámez-Virués, S., Börschig, C., Klein, A.-M., Krauss, J., Steckel, J., et al. (2015). Configurational landscape heterogeneity shapes functional community composition of grassland butterflies. J. Appl. Ecol., 52, 505-513.

Purtauf, T., Dauber, J. \& Wolters, V. (2005). The response of carabids to landscape simplification differs between trophic groups. Oecologia, 142, 458-464.

Purvis, A., Gittleman, J.L., Cowlishaw, G. \& Mace, G.M. (2000). Predicting extinction risk in declining species. Proc. R. Soc. B-Biol. Sci., 267, 1947-1952.

Rand, T.A. \& Tscharntke, T. (2007). Contrasting effects of natural habitat loss on generalist and specialist aphid natural enemies. Oikos, 116, 1353-1362.

Ribera, I., Dolédec, S., Downie, I.S. \& Foster, G.N. (2001). Effect of Land Disturbance and Stress on Species Traits of Ground Beetle Assemblages. Ecology, 82, 1112-1129.

Ripple, W.J., Wolf, C., Newsome, T.M., Hoffmann, M., Wirsing, A.J. \& McCauley, D.J. (2017). Extinction risk is most acute for the world's largest and smallest vertebrates. Proc. Natl. Acad. Sci., 114, 10678-10683. 
Rusch, A., Birkhofer, K., Bommarco, R., Smith, H.G. \& Ekbom, B. (2015). Predator body sizes and habitat preferences predict predation rates in an agroecosystem. Basic Appl. Ecol., 16, 250259.

Schirmel, J., Albrecht, M., Bauer, P.-M., Sutter, L., Pfister, S.C. \& Entling, M.H. (2018). Landscape complexity promotes hoverflies across different types of semi-natural habitats in farmland. J. Appl. Ecol., 55, 1747-1758.

Speight, M.C.D., Castella, E. \& Sarthou, J.-P. (2015). StN 2015. In: Syrph the Net on CD, Issue 10. Speight, M.C.D., Castella, E., Sarthou, J.-P. \& Vanappelghem, C. (Eds.). Syrph the Net Publications, Dublin.

van Swaay, C.A.M. (2002). The importance of calcareous grasslands for butterflies in Europe. Biol. Conserv., 104, 315-318.

Tscharntke, T., Bommarco, R., Clough, Y., Crist, T.O., Kleijn, D., Rand, T.A., et al. (2007). Conservation biological control and enemy diversity on a landscape scale. Biol. Control, 43, 294-309.

Tscharntke, T. \& Brandl, R. (2004). Plant-Insect Interactions in Fragmented Landscapes. Annu. Rev. Entomol., 49, 405-430.

Van Geert, A., Van Rossum, F. \& Triest, L. (2010). Do linear landscape elements in farmland act as biological corridors for pollen dispersal? J. Ecol., 98, 178-187.

Vickery, J.A., Feber, R.E. \& Fuller, R.J. (2009). Arable field margins managed for biodiversity conservation: A review of food resource provision for farmland birds. Agric. Ecosyst. Environ., $133,1-13$.

Wesuls, D., Oldeland, J. \& Dray, S. (2012). Disentangling plant trait responses to livestock grazing from spatio-temporal variation: the partial RLQ approach. J. Veg. Sci., 23, 98-113.

Woodcock, B.A., Harrower, C., Redhead, J., Edwards, M., Vanbergen, A.J., Heard, M.S., et al. (2014). National patterns of functional diversity and redundancy in predatory ground beetles and bees associated with key UK arable crops. J. Appl. Ecol., 51, 142-151. 


\section{Supporting Information}

\section{Appendix S1: Supplementary tables and figures}

Table S1.1 Mean, minimum and maximum values for all regions and taxa for the variables TBL (Total border length in m/ha), SHDI (Shannon crop diversity) and SNH (semi-natural habitat cover in \%). The values differ for each taxon, because different fields were excluded for different taxa, for example when samples were lost.

\begin{tabular}{|c|c|c|c|c|c|c|c|c|c|c|c|c|}
\hline & \multicolumn{3}{|c|}{ Butterflies } & \multicolumn{3}{|c|}{ Hoverflies } & \multicolumn{3}{|c|}{ Carabids } & \multicolumn{3}{|c|}{ Spiders } \\
\hline & mean & $\min$ & $\max$ & mean & $\min$ & $\max$ & mean & $\min$ & $\max$ & mean & $\min$ & $\max$ \\
\hline \multicolumn{13}{|c|}{ Armorique } \\
\hline TBL & 3.33 & 1.96 & 4.60 & 3.28 & 1.96 & 4.43 & 3.34 & 1.96 & 4.60 & 3.34 & 1.69 & 4.60 \\
\hline SHDI & 1.09 & 0.60 & 1.47 & 1.11 & 0.91 & 1.35 & 1.09 & 0.60 & 1.47 & 1.09 & 0.60 & 1.47 \\
\hline $\mathrm{SNH}$ & 10.77 & 3.46 & 22.65 & 10.58 & 3.46 & 17.79 & 10.77 & 3.46 & 22.65 & 10.77 & 3.46 & 22.65 \\
\hline \multicolumn{13}{|c|}{ Camargue } \\
\hline TBL & 2.26 & 1.86 & 3.33 & 2.56 & 1.86 & 2.99 & 2.63 & 2.22 & 3.33 & 2.63 & 2.22 & 3.33 \\
\hline SHDI & 0.92 & 0.16 & 1.52 & 0.29 & 0.16 & 1.52 & 0.92 & 0.16 & 1.52 & 0.91 & 0.16 & 1.52 \\
\hline SNH & 22.88 & 15.35 & 32.18 & 22.57 & 15.35 & 32.18 & 22.76 & 15.35 & 32.18 & 22.77 & 15.35 & 32.18 \\
\hline \multicolumn{13}{|c|}{ Coteaux } \\
\hline TBL & 2.57 & 1.54 & 3.33 & 2.45 & 2.03 & 3.25 & 2.53 & 1.54 & 3.33 & 2.59 & 1.54 & 3.46 \\
\hline SHDI & 1.31 & 0.63 & 1.90 & 1.35 & 0.98 & 1.77 & 1.31 & 0.63 & 1.90 & 1.30 & 0.63 & 1.90 \\
\hline $\mathrm{SNH}$ & 17.27 & 8.01 & 31.45 & 17.14 & 8.01 & 22.81 & 16.89 & 8.01 & 31.45 & 17.52 & 9.02 & 31.45 \\
\hline \multicolumn{13}{|c|}{ East Anglia } \\
\hline TBL & 1.26 & 0.68 & 2.01 & 1.21 & 0.68 & 2.01 & 1.27 & 0.68 & 2.01 & 1.27 & 0.68 & 2.01 \\
\hline SHDI & 0.82 & 0.31 & 1.48 & 0.85 & 0.31 & 1.60 & 0.88 & 0.31 & 1.60 & 0.88 & 0.31 & 1.60 \\
\hline $\mathrm{SNH}$ & 7.95 & 3.80 & 13.55 & 7.15 & 3.57 & 13.55 & 7.87 & 3.57 & 13.55 & 7.87 & 3.57 & 13.55 \\
\hline \multicolumn{13}{|c|}{ Goettingen } \\
\hline TBL & 2.25 & 1.23 & 3.46 & 2.25 & 1.23 & 3.46 & 2.26 & 1.23 & 3.46 & 2.26 & 1.23 & 3.46 \\
\hline SHDI & 1.13 & 0.79 & 1.60 & 1.12 & 0.79 & 1.60 & 1.13 & 0.79 & 1.60 & 1.13 & 0.79 & 1.60 \\
\hline SNH & 11.46 & 3.21 & 23.80 & 11.47 & 3.21 & 23.80 & 11.49 & 3.21 & 23.80 & 11.49 & 3.20 & 23.80 \\
\hline \multicolumn{13}{|l|}{ Lleida } \\
\hline TBL & 3.97 & 1.96 & 6.52 & 4.26 & 2.63 & 6.52 & 4.08 & 1.96 & 6.52 & 3.98 & 1.96 & 6.52 \\
\hline SHDI & 0.51 & 0.00 & 1.44 & 0.54 & 0.00 & 1.44 & 0.50 & 0.00 & 1.44 & 0.51 & 0.00 & 1.44 \\
\hline SNH & 17.43 & 5.82 & 34.50 & 17.41 & 5.82 & 34.50 & 17.19 & 5.82 & 34.50 & 17.71 & 5.82 & 34.50 \\
\hline \multicolumn{13}{|l|}{ PVDS } \\
\hline TBL & 2.20 & 1.37 & 4.07 & 2.23 & 1.12 & 4.07 & 2.26 & 1.37 & 4.07 & 2.23 & 1.37 & 4.07 \\
\hline SHDI & 1.40 & 0.65 & 2.03 & 1.44 & 0.89 & 2.03 & 1.38 & 0.65 & 2.03 & 1.37 & 0.65 & 2.03 \\
\hline SNH & 4.77 & 0.18 & 14.98 & 4.66 & 0.18 & 16.73 & 5.21 & 0.18 & 16.73 & 5.00 & 0.18 & 16.73 \\
\hline
\end{tabular}


Table S1.2 Pearson correlation between variables in the seven regions and across all regions after the subset creation. All correlations are below 0.30. The range of correlation coefficient between the four taxa are shown. SHDI: Shannon diversity index of crop types, TBL: Total border length and SNH: Seminatural habitat

\begin{tabular}{|c|c|c|c|}
\hline \multirow[b]{2}{*}{ Variables } & \multicolumn{3}{|c|}{ Pearson correlation coefficient $r$} \\
\hline & SHDI & TBL & SNH \\
\hline \multicolumn{4}{|l|}{ All regions } \\
\hline SHDI & 1 & & \\
\hline TBL & $0.14-0.17$ & 1 & \\
\hline SNH & $-0.04--0.02$ & $0.12-0.24$ & 1 \\
\hline \multicolumn{4}{|l|}{ Armorique } \\
\hline SHDI & 1 & & \\
\hline TBL & $-0.20--0.02$ & 1 & \\
\hline semi & $0.12-0.28$ & $0.07-0.29$ & 1 \\
\hline \multicolumn{4}{|l|}{ Camargue } \\
\hline SHDI & 1 & & \\
\hline TBL & $-0.01-0.21$ & 1 & \\
\hline SNH & $-0.10-0.03$ & $0.18-0.28$ & 1 \\
\hline \multicolumn{4}{|l|}{ Coteaux } \\
\hline SHDI & 1 & & \\
\hline TBL & $-0.14-0.08$ & 1 & \\
\hline $\mathrm{SNH}$ & $-0.11--0.12$ & $0.23-0.29$ & 1 \\
\hline \multicolumn{4}{|c|}{ East-Anglia } \\
\hline SHDI & 1 & & \\
\hline TBL & 0.29 & 1 & \\
\hline SNH & $0.22-0.23$ & $0.06-0.20$ & 1 \\
\hline \multicolumn{4}{|l|}{ Goettingen } \\
\hline SHDI & 1 & & \\
\hline TBL & $0.18-0.19$ & 1 & \\
\hline SNH & 0.09 & $-0.03-0.05$ & 1 \\
\hline \multicolumn{4}{|l|}{ Lleida } \\
\hline SHDI & 1 & & \\
\hline TBL & $0.25-0.28$ & 1 & \\
\hline $\mathrm{SNH}$ & $-0.19--0.23$ & $0.15-0.29$ & 1 \\
\hline \multicolumn{4}{|l|}{$P V D S$} \\
\hline SHDI & 1 & & \\
\hline TBL & $0.10-0.24$ & 1 & \\
\hline SNH & $0.02-0.13$ & $0.11-0.29$ & 1 \\
\hline
\end{tabular}


Table S1.3 Further reference list used for the collection of carabid beetles and spider species traits. Full references are listed in the Reference list.

\begin{tabular}{|c|c|c|}
\hline Traits & Carabid beetles & Spiders \\
\hline Body size & Hedde et al. 2012; Homburg et al. 2013 & Hedde et al. 2012 \\
\hline Reproduction & $\begin{array}{l}\text { Ribera et al. 2001; Hedde et al. 2012; } \\
\text { Homburg et al. } 2013\end{array}$ & \\
\hline Foraging & $\begin{array}{l}\text { Larochelle 1990; Hedde et al. 2012; } \\
\text { Homburg et al. } 2013\end{array}$ & $\begin{array}{l}\text { Hänggi et al. 1995; Uetz et al. 1999, Jose Antonio } \\
\text { Barrientos. pers. communication }\end{array}$ \\
\hline Dispersal & Hedde et al. 2012; Homburg et al. 2013 & $\begin{array}{l}\text { Bell et al. 2005; Hedde et al. } 2012 \text {. Alain Pasquet } \\
\text { and Jose Antonio Barrientos. pers. communication }\end{array}$ \\
\hline
\end{tabular}


Table S1.4. Species list, scores on the two first partial RLQ axes and abundance per region.

\begin{tabular}{|c|c|c|c|c|c|c|c|c|c|c|}
\hline & & & \multirow{2}{*}{\multicolumn{7}{|c|}{ Species abundance }} & \multirow[b]{3}{*}{ Total } \\
\hline \multirow[b]{2}{*}{ Species } & \multicolumn{2}{|c|}{ Scores on partial RLQ axes } & & & & & & & & \\
\hline & Axis 1 & Axis 2 & $\mathrm{Ar}$ & $\mathrm{Ca}$ & Co & EA & Go & $\mathrm{Ll}$ & $\mathrm{PV}$ & \\
\hline \multicolumn{11}{|l|}{ Butterfly } \\
\hline Aglais io & 0.16 & -0.92 & 6 & 0 & 11 & 106 & 0 & 0 & 3 & 126 \\
\hline Aglais urticae & -0.92 & 2.76 & 1 & 0 & 3 & 28 & 167 & 0 & 0 & 199 \\
\hline Aphantopus hyperantus & 1.30 & -0.35 & 0 & 0 & 0 & 17 & 429 & 0 & 0 & 446 \\
\hline Aporia crataegi & 2.00 & -0.03 & 0 & 0 & 6 & 0 & 0 & 0 & 0 & 6 \\
\hline Aricia agestis & 0.60 & 0.50 & 0 & 0 & 0 & 0 & 0 & 0 & 8 & 8 \\
\hline Celastrina argiolus & 0.92 & 0.30 & 0 & 0 & 1 & 2 & 1 & 0 & 1 & 5 \\
\hline Coenonympha pamphilus & 0.83 & 0.31 & 0 & 1 & 36 & 0 & 0 & 0 & 1 & 38 \\
\hline Colias croceus & -0.70 & 0.93 & 0 & 1 & 9 & 0 & 0 & 2 & 61 & 73 \\
\hline Gonepteryx rhamni & 1.80 & 0.25 & 2 & 0 & 1 & 0 & 2 & 0 & 0 & 5 \\
\hline Issoria lathonia & -1.21 & 3.05 & 0 & 0 & 2 & 0 & 4 & 0 & 9 & 15 \\
\hline Lasiommata megera & 1.94 & 0.87 & 0 & 0 & 1 & 0 & 0 & 8 & 2 & 11 \\
\hline Maniola jurtina & 0.87 & -0.68 & 118 & 0 & 219 & 49 & 143 & 0 & 15 & 544 \\
\hline Melanargia galathea & 2.81 & 0.47 & 7 & 1 & 59 & 0 & 15 & 0 & 5 & 87 \\
\hline Melitaea cinxia & -1.20 & 3.32 & 0 & 0 & 5 & 0 & 0 & 0 & 0 & 5 \\
\hline Melitaea didyma & 1.00 & -0.33 & 0 & 0 & 7 & 0 & 0 & 0 & 0 & 7 \\
\hline Melitaea parthenoides & 1.07 & 0.11 & 0 & 0 & 7 & 0 & 0 & 0 & 0 & 7 \\
\hline Ochlodes sylvanus & 1.23 & 0.28 & 14 & 6 & 0 & 3 & 0 & 0 & 1 & 24 \\
\hline Papilio machaon & 0.17 & -1.72 & 0 & 0 & 3 & 0 & 3 & 5 & 1 & 12 \\
\hline Pararge aegeria & 2.63 & 0.83 & 16 & 1 & 0 & 1 & 0 & 0 & 17 & 35 \\
\hline Pieris brassicae & -0.87 & -0.95 & 35 & 39 & 97 & 78 & 17 & 120 & 19 & 405 \\
\hline Pieris napi & 0.00 & -0.28 & 8 & 29 & 1 & 51 & 77 & 0 & 2 & 168 \\
\hline Pieris rapae & -1.06 & -0.40 & 13 & 88 & 24 & 75 & 92 & 273 & 51 & 616 \\
\hline Pieris rapae or $P$. napi & -0.53 & -0.34 & 0 & 0 & 10 & 43 & 271 & 52 & 0 & 376 \\
\hline Polyommatus icarus & 2.17 & 1.49 & 0 & 0 & 5 & 5 & 0 & 2 & 4 & 16 \\
\hline Pontia daplidice & -0.27 & -0.17 & 0 & 0 & 0 & 0 & 0 & 19 & 0 & 19 \\
\hline Pyronia tithonus & 3.00 & 0.99 & 13 & 0 & 0 & 13 & 0 & 0 & 10 & 36 \\
\hline Satyrium esculi & 3.44 & 1.33 & 0 & 0 & 0 & 0 & 0 & 13 & 0 & 13 \\
\hline Thymelicus lineola & 2.89 & 1.54 & 10 & 0 & 78 & 4 & 30 & 2 & 0 & 124 \\
\hline Thymelicus sylvestris & 3.16 & 1.43 & 0 & 0 & 0 & 9 & 2 & 0 & 0 & 11 \\
\hline $\begin{array}{l}\text { Thymelicus sylvestris or } T \text {. } \\
\text { lineola }\end{array}$ & 3.03 & 1.48 & 0 & 0 & 0 & 3 & 4 & 4 & 0 & 11 \\
\hline Vanessa atalanta & -3.35 & 2.54 & 7 & 0 & 4 & 3 & 24 & 1 & 3 & 42 \\
\hline Vanessa cardui & -2.43 & -0.50 & 2 & 3 & 10 & 2 & 0 & 5 & 10 & 32 \\
\hline \multicolumn{11}{|l|}{ Hoverfly } \\
\hline Episyrphus balteatus & 0.21 & -0.11 & 297 & 268 & 158 & 240 & 436 & 1493 & 830 & 3722 \\
\hline Eristalinus aeneus & -1.48 & 2.41 & 0 & 17 & 7 & 0 & 2 & 1 & 0 & 27 \\
\hline Eristalinus sepulchralis & -0.41 & 2.01 & 18 & 9 & 3 & 0 & 7 & 0 & 3 & 40 \\
\hline Eristalis abusiva & -2.00 & 0.21 & 0 & 0 & 0 & 0 & 5 & 0 & 0 & 5 \\
\hline Eristalis arbustorum & -0.91 & 0.77 & 10 & 25 & 127 & 0 & 8 & 7 & 9 & 186 \\
\hline Eristalis interrupta & -2.89 & 0.54 & 9 & 0 & 0 & 0 & 0 & 0 & 0 & 9 \\
\hline Eristalis pertinax & -3.35 & -0.05 & 5 & 0 & 1 & 0 & 16 & 0 & 0 & 22 \\
\hline Eristalis similis & -3.79 & 0.87 & 4 & 0 & 53 & 0 & 1 & 1 & 0 & 59 \\
\hline
\end{tabular}


Eristalis tenax

Eumerus strigatus

Eupeodes corollae

Eupeodes luniger

Eupeodes nuba

Ferdinandea cuprea

Helophilus pendulus

Helophilus trivittatus

Melanostoma mellinum

Melanostoma scalare

Meliscaeva auricollis

Merodon equestris

Mesembrius peregrinus

Myathropa florea

Platycheirus albimanus

Platycheirus manicatus

Platycheirus peltatus

Rhingia campestris

Scaeva pyrastri

Scaeva selenitica

Sphaerophoria rueppelli

Sphaerophoria scripta

Syritta pipiens

Syrphus ribesii

Tropidia scita

Volucella bombylans

Xylota segnis

Carabid beetle

Agonum muelleri

Amara aenea

Amara communis

Amara consularis

Amara convexior

Amara eurynota

Amara familiaris

Amara fulva

Amara lunicollis

Amara ovata

Amara plebeja

Amara rufipes

Amara similata

Anchomenus dorsalis

Anisodactylus binotatus

Anisodactylus signatus

Asaphidion flavipes

Asaphidion stierlini

Badister bullatus
$-2.52$

$-0.92$

0.93

$-0.66$

$-0.96$

$-1.82$

$-2.81$

$-3.75$

1.65

0.72

$-0.96$

$-1.36$

$-0.38$

$-2.71$

0.54

$-1.65$

1.56

$-1.82$

$-0.68$

$-2.27$

1.26

0.21

$-0.23$

$-1.68$

0.79

$-0.24$

$-2.35$

0.38

$-0.23$

0.79

$-0.86$

$-0.14$

1.39

0.82

0.39

$-0.17$

1.14

$-0.26$

0.35

1.11

0.28

0.24

0.46

$-0.68$

$-0.19$

0.05
1.37

$-0.19$

$-0.37$

$-2.18$

$-1.40$

0.14

$-0.25$

$-0.56$

$-0.64$

1.13

$-1.40$

4.99

4.62

0.48

1.20

$-3.54$

3.44

0.14

0.23

$-1.58$

0.93

$-0.11$

1.95

$-1.13$

4.19

4.11

0.34

$-0.68$

$-0.15$

3.01

0.78

$-0.13$

3.12

3.02

3.99

$-0.14$

3.08

$-0.16$

3.98

3.07

$-0.70$

$-0.06$

$-0.02$

$-0.23$

$-0.78$

$-0.74$

92

\begin{tabular}{rrrrrrrr}
27 & 15 & 29 & 2 & 23 & 36 & 33 & 165 \\
0 & 0 & 0 & 1 & 8 & 0 & 0 & 9 \\
210 & 2493 & 19 & 47 & 499 & 4886 & 628 & 8782 \\
2 & 13 & 0 & 2 & 1 & 10 & 0 & 28 \\
0 & 5 & 0 & 0 & 0 & 0 & 0 & 5 \\
3 & 0 & 0 & 0 & 2 & 0 & 7 & 12 \\
163 & 1 & 9 & 1 & 6 & 0 & 5 & 185 \\
1 & 39 & 0 & 2 & 33 & 0 & 1 & 76 \\
33 & 112 & 74 & 23 & 58 & 35 & 20 & 355 \\
0 & 0 & 1 & 3 & 0 & 4 & 2 & 10 \\
0 & 0 & 0 & 0 & 0 & 3 & 6 & 9 \\
6 & 0 & 3 & 0 & 6 & 0 & 2 & 17 \\
0 & 141 & 0 & 0 & 0 & 0 & 0 & 141 \\
9 & 0 & 0 & 0 & 2 & 1 & 1 & 13 \\
2 & 0 & 0 & 4 & 2 & 0 & 0 & 8 \\
2 & 0 & 0 & 145 & 0 & 0 & 0 & 147 \\
6 & 0 & 0 & 11 & 6 & 0 & 0 & 23 \\
89 & 0 & 0 & 0 & 3 & 0 & 0 & 92 \\
2 & 11 & 1 & 0 & 15 & 44 & 28 & 101 \\
0 & 0 & 0 & 0 & 8 & 0 & 0 & 8 \\
0 & 24 & 0 & 0 & 0 & 53 & 0 & 77 \\
35 & 733 & 85 & 14 & 189 & 1203 & 339 & 2598 \\
6 & 1 & 2 & 2 & 1 & 1 & 0 & 13 \\
3 & 0 & 2 & 0 & 1 & 0 & 0 & 6 \\
0 & 12 & 0 & 0 & 14 & 0 & 0 & 26 \\
4 & 0 & 1 & 0 & 2 & 0 & 0 & 7 \\
6 & 0 & 0 & 0 & 4 & 0 & 0 & 10 \\
\hline & & & & & & &
\end{tabular}

\begin{tabular}{llllllll}
\hline 68 & 0 & 7 & 2 & 38 & 0 & 0 & 115
\end{tabular}

$\begin{array}{llllllll}17 & 24 & 1 & 2 & 3 & 0 & 5 & 52\end{array}$

$\begin{array}{llllllll}10 & 0 & 0 & 0 & 0 & 0 & 0 & 10\end{array}$

$\begin{array}{llllllll}0 & 0 & 0 & 0 & 0 & 0 & 32 & 32\end{array}$

$\begin{array}{llllllll}2 & 0 & 0 & 0 & 5 & 0 & 0 & 7\end{array}$

$\begin{array}{llllllll}0 & 0 & 0 & 21 & 0 & 0 & 0 & 21\end{array}$

$\begin{array}{llllllll}5 & 0 & 0 & 0 & 2 & 0 & 3 & 10\end{array}$

$\begin{array}{llllllll}0 & 0 & 0 & 0 & 0 & 5 & 0 & 5\end{array}$

$\begin{array}{llllllll}12 & 0 & 0 & 9 & 8 & 0 & 0 & 29\end{array}$

$\begin{array}{llllllll}3 & 0 & 1 & 3 & 14 & 0 & 0 & 21\end{array}$

$\begin{array}{llllllll}10 & 0 & 0 & 1 & 4 & 0 & 0 & 15\end{array}$

$\begin{array}{llllllll}0 & 7 & 0 & 0 & 0 & 0 & 0 & 7\end{array}$

$\begin{array}{rrrrrrrr}28 & 0 & 0 & 0 & 5 & 0 & 12 & 45\end{array}$

$\begin{array}{llllllll}391 & 48 & 377 & 59 & 3690 & 3 & 450 & 5018\end{array}$

$\begin{array}{llllllll}7 & 1 & 0 & 0 & 7 & 0 & 0 & 15\end{array}$

$\begin{array}{rrrrrrrr}0 & 0 & 7 & 0 & 0 & 0 & 0 & 7\end{array}$

$\begin{array}{llllllll}59 & 1 & 0 & 1 & 75 & 0 & 0 & 136\end{array}$

$\begin{array}{llllllll}0 & 0 & 0 & 0 & 0 & 0 & 5 & 5\end{array}$

$\begin{array}{llllllll}0 & 0 & 0 & 4 & 6 & 0 & 2 & 12\end{array}$

.

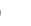

9

12

6

9

17

7

23

2

8

77

6

.

?




\begin{tabular}{|c|c|c|c|c|c|c|c|c|c|c|}
\hline Badister sodalis & -0.74 & -1.22 & 3 & 0 & 0 & 0 & 7 & 0 & 1 & 11 \\
\hline $\begin{array}{l}\text { Bembidion } \\
\text { quadrimaculatum }\end{array}$ & -0.29 & -0.80 & 11 & 0 & 0 & 1 & 8 & 0 & 0 & 20 \\
\hline Brachinus crepitans & 0.48 & -0.66 & 0 & 0 & 41 & 0 & 47 & 2 & 421 & 511 \\
\hline Brachinus elegans & 0.38 & -0.68 & 0 & 3 & 6 & 0 & 0 & 0 & 0 & 9 \\
\hline Brachinus sclopeta & 0.11 & -0.73 & 12 & 17 & 7 & 0 & 0 & 0 & 44 & 80 \\
\hline Calathus fuscipes & -0.86 & 0.45 & 0 & 0 & 6 & 12 & 12 & 20 & 36 & 86 \\
\hline Calosoma maderae & 3.19 & -0.16 & 0 & 9 & 0 & 0 & 0 & 0 & 0 & 9 \\
\hline Carabus auratus & 4.78 & -1.56 & 5 & 1 & 138 & 0 & 48 & 0 & 0 & 192 \\
\hline Carabus cancellatus & 5.17 & -1.49 & 0 & 0 & 49 & 0 & 0 & 0 & 0 & 49 \\
\hline Carabus granulatus & 0.86 & -0.28 & 7 & 0 & 0 & 0 & 14 & 0 & 0 & 21 \\
\hline Carabus violaceus & 4.72 & -0.52 & 0 & 0 & 0 & 25 & 0 & 0 & 0 & 25 \\
\hline $\begin{array}{l}\text { Carabus violaceus } \\
\text { purpurascens }\end{array}$ & 5.77 & -1.38 & 5 & 0 & 0 & 0 & 0 & 0 & 0 & 5 \\
\hline Chlaeniellus nigricornis & 0.87 & -0.59 & 0 & 5 & 0 & 0 & 0 & 0 & 1 & 6 \\
\hline Chlaenius chrysocephalus & 0.52 & -0.65 & 0 & 10 & 43 & 0 & 0 & 0 & 69 & 122 \\
\hline Chlaenius festivus & 0.81 & -0.93 & 0 & 37 & 0 & 0 & 0 & 0 & 0 & 37 \\
\hline Clivina fossor & -1.00 & -0.63 & 2 & 0 & 1 & 0 & 18 & 0 & 0 & 21 \\
\hline Demetrias atricapillus & 0.03 & -0.74 & 14 & 9 & 5 & 3 & 32 & 0 & 6 & 69 \\
\hline Dixus capito & -0.24 & 0.90 & 0 & 0 & 0 & 0 & 0 & 35 & 0 & 35 \\
\hline Epaphius secalis & 1.20 & -1.17 & 0 & 0 & 0 & 0 & 243 & 0 & 0 & 243 \\
\hline Harpalus affinis & 0.20 & -0.07 & 17 & 0 & 1 & 48 & 273 & 1 & 68 & 408 \\
\hline Harpalus cupreus & 0.57 & 0.00 & 0 & 0 & 5 & 0 & 0 & 0 & 2 & 7 \\
\hline Harpalus dimidiatus & 1.65 & 3.17 & 0 & 3 & 37 & 0 & 1 & 0 & 164 & 205 \\
\hline Harpalus distinguendus & 0.10 & -0.09 & 0 & 25 & 15 & 0 & 3 & 13 & 55 & 111 \\
\hline Harpalus latus & 0.48 & 4.00 & 0 & 0 & 0 & 0 & 35 & 0 & 0 & 35 \\
\hline Harpalus rubripes & -0.62 & 0.82 & 7 & 0 & 0 & 0 & 0 & 0 & 3 & 10 \\
\hline Harpalus tardus & 1.20 & 3.09 & 0 & 0 & 0 & 1 & 1 & 0 & 13 & 15 \\
\hline Laemostenus terricola & 2.72 & -0.89 & 0 & 0 & 0 & 0 & 0 & 5 & 0 & 5 \\
\hline Limodromus assimilis & 0.94 & -0.58 & 1 & 0 & 0 & 0 & 54 & 0 & 0 & 55 \\
\hline Metallina lampros & -1.40 & -0.70 & 388 & 8 & 10 & 195 & 1083 & 3 & 6 & 1693 \\
\hline Metallina properans & -0.79 & -1.23 & 44 & 0 & 0 & 0 & 1 & 0 & 4 & 49 \\
\hline Microlestes luctuosus & -0.37 & -0.82 & 0 & 26 & 0 & 0 & 0 & 0 & 0 & 26 \\
\hline Microlestes maurus & -1.53 & -0.72 & 2 & 0 & 0 & 0 & 0 & 0 & 10 & 12 \\
\hline Microlestes minutulus & -1.69 & -0.34 & 1 & 0 & 0 & 3 & 0 & 0 & 11 & 15 \\
\hline Nebria brevicollis & -0.36 & 0.87 & 68 & 0 & 10 & 16 & 142 & 0 & 23 & 259 \\
\hline Notiophilus palustris & -0.58 & -1.19 & 3 & 0 & 0 & 1 & 18 & 0 & 0 & 22 \\
\hline $\begin{array}{l}\text { Notiophilus } \\
\text { quadripunctatus }\end{array}$ & -1.41 & -0.29 & 11 & 0 & 0 & 1 & 0 & 0 & 43 & 55 \\
\hline Notiophilus substriatus & -0.64 & -1.20 & 0 & 0 & 0 & 2 & 0 & 0 & 9 & 11 \\
\hline Ocydromus tetracolus & -0.59 & -1.19 & 65 & 0 & 0 & 36 & 406 & 0 & 0 & 507 \\
\hline Ophonus ardosiacus & 0.83 & 4.07 & 0 & 0 & 0 & 5 & 0 & 0 & 0 & 5 \\
\hline Ophonus azureus & 0.35 & 2.60 & 0 & 0 & 0 & 0 & 3 & 0 & 16 & 19 \\
\hline Ophonus rufibarbis & 1.03 & 3.06 & 1 & 0 & 0 & 0 & 7 & 0 & 0 & 8 \\
\hline Orthomus expansus & 2.11 & -1.00 & 0 & 0 & 0 & 0 & 0 & 7 & 0 & 7 \\
\hline Parophonus mendax & 1.00 & 3.05 & 0 & 4 & 5 & 0 & 0 & 0 & 0 & 9 \\
\hline Philochthus iricolor & -0.12 & -0.77 & 7 & 0 & 3 & 0 & 0 & 0 & 0 & 10 \\
\hline Philochthus lunulatus & -0.19 & -0.78 & 2 & 5 & 0 & 1 & 5 & 0 & 2 & 15 \\
\hline
\end{tabular}




\begin{tabular}{|c|c|c|c|c|c|c|c|c|c|c|}
\hline Phyla obtusa & -1.47 & -0.71 & 63 & 6 & 3 & 16 & 229 & 0 & 28 & 345 \\
\hline Poecilus cupreus & 0.25 & -0.06 & 1273 & 191 & 157 & 45 & 471 & 9 & $\begin{array}{r}107 \\
8\end{array}$ & 3224 \\
\hline Poecilus puncticollis & -0.18 & 0.27 & 0 & 22 & 0 & 0 & 0 & 0 & 0 & 22 \\
\hline Poecilus purpurascens & 0.73 & -0.61 & 0 & 0 & 0 & 0 & 0 & 13 & 8 & 21 \\
\hline Poecilus versicolor & -0.04 & 0.29 & 2 & 0 & 0 & 0 & 44 & 0 & 0 & 46 \\
\hline Pseudoophonus griseus & -0.59 & 0.83 & 0 & 0 & 0 & 0 & 0 & 0 & 6 & 6 \\
\hline Pseudoophonus rufipes & -0.11 & 0.92 & 70 & 0 & 8 & 202 & 459 & 0 & 226 & 965 \\
\hline Pterostichus macer & 0.60 & 0.00 & 0 & 0 & 0 & 0 & 6 & 0 & 0 & 6 \\
\hline Pterostichus madidus & -0.29 & 0.55 & 14 & 0 & 35 & 131 & 0 & 0 & 13 & 193 \\
\hline Pterostichus melanarius & -0.50 & 0.52 & 257 & 6 & 0 & 502 & 3315 & 0 & 29 & 4109 \\
\hline Pterostichus niger & -0.02 & 0.60 & 9 & 7 & 0 & 42 & 32 & 0 & 0 & 90 \\
\hline Pterostichus strenuиs & -0.45 & -1.16 & 5 & 0 & 0 & 1 & 47 & 0 & 0 & 53 \\
\hline Pterostichus vernalis & -0.35 & -1.14 & 14 & 0 & 0 & 0 & 56 & 0 & 0 & 70 \\
\hline $\begin{array}{l}\text { Semiophonus } \\
\text { signaticornis }\end{array}$ & 0.05 & 3.93 & 0 & 0 & 0 & 0 & 1 & 0 & 15 & 16 \\
\hline Syntomus obscuroguttatus & -0.27 & -0.80 & 12 & 13 & 0 & 0 & 0 & 0 & 20 & 45 \\
\hline Synuchus vivalis & -0.50 & 3.49 & 0 & 0 & 0 & 0 & 9 & 0 & 0 & 9 \\
\hline Trechus quadristriatus & -1.57 & -0.32 & 159 & 27 & 21 & 21 & 954 & 2 & 103 & 1287 \\
\hline Trechus rubens & 0.10 & -0.73 & 11 & 0 & 0 & 0 & 0 & 0 & 0 & 11 \\
\hline Zabrus tenebrioides & 0.37 & 1.01 & 0 & 0 & 0 & 1 & 1 & 128 & 2 & 132 \\
\hline \multicolumn{11}{|l|}{ Spider } \\
\hline Aelurillus blandus & 1.04 & -2.51 & 0 & 0 & 0 & 0 & 0 & 13 & 0 & 13 \\
\hline Agraecina lineata & 2.07 & -0.53 & 0 & 0 & 28 & 0 & 0 & 25 & 0 & 53 \\
\hline Agroeca cuprea & 1.65 & -0.80 & 0 & 1 & 0 & 0 & 0 & 0 & 5 & 6 \\
\hline Agroeca lusatica & 1.85 & -0.67 & 0 & 0 & 4 & 0 & 0 & 0 & 1 & 5 \\
\hline Alioranus pauper & -1.97 & -1.36 & 0 & 10 & 0 & 0 & 0 & 2 & 0 & 12 \\
\hline Alopecosa accentuata & 2.31 & -0.37 & 0 & 0 & 0 & 0 & 0 & 0 & 58 & 58 \\
\hline Alopecosa albofasciata & 1.56 & 1.40 & 0 & 4 & 28 & 0 & 0 & 780 & 34 & 846 \\
\hline Alopecosa barbipes & 1.36 & 1.27 & 0 & 0 & 5 & 0 & 0 & 0 & 0 & 5 \\
\hline Alopecosa cuneata & 2.18 & -0.46 & 0 & 0 & 34 & 0 & 50 & 0 & 14 & 98 \\
\hline Alopecosa pulverulenta & 1.28 & 1.22 & 9 & 1 & 0 & 30 & 105 & 0 & 11 & 156 \\
\hline Altella lucida & -1.99 & -1.37 & 0 & 0 & 0 & 0 & 0 & 6 & 0 & 6 \\
\hline Araeoncus humilis & -1.98 & -1.36 & 0 & 3 & 0 & 0 & 24 & 2 & 26 & 55 \\
\hline Arctosa fulvolineata & 1.87 & 1.60 & 0 & 5 & 0 & 0 & 0 & 0 & 0 & 5 \\
\hline Arctosa perita & 0.44 & -0.64 & 0 & 1 & 3 & 0 & 0 & 0 & 118 & 122 \\
\hline Argenna subnigra & -1.87 & -1.29 & 0 & 1 & 1 & 0 & 7 & 3 & 1 & 13 \\
\hline Asagena phalerata & -1.41 & -1.00 & 0 & 0 & 5 & 0 & 0 & 25 & 10 & 40 \\
\hline Aulonia albimana & 0.58 & 0.78 & 56 & 0 & 45 & 0 & 9 & 1 & 38 & 149 \\
\hline Bathyphantes gracilis & -1.26 & 0.41 & 393 & 125 & 0 & 38 & 243 & 1 & 7 & 807 \\
\hline Bathyphantes parvulus & -0.18 & -1.15 & 3 & 0 & 0 & 0 & 127 & 0 & 2 & 132 \\
\hline Canariphantes zonatus & -0.72 & -2.81 & 0 & 0 & 0 & 0 & 0 & 6 & 0 & 6 \\
\hline Centromerus succinus & -1.94 & -1.34 & 0 & 0 & 17 & 0 & 0 & 0 & 0 & 17 \\
\hline Chalcoscirtus infimus & 1.41 & -0.95 & 0 & 0 & 0 & 0 & 0 & 9 & 2 & 11 \\
\hline Clubiona reclusa & 1.28 & -2.35 & 1 & 0 & 0 & 1 & 10 & 0 & 0 & 12 \\
\hline Collinsia inerrans & -1.22 & 0.44 & 107 & 0 & 0 & 0 & 94 & 0 & 1 & 202 \\
\hline Dicymbium nigrum & -1.24 & 0.43 & 8 & 0 & 0 & 0 & 19 & 0 & 0 & 27 \\
\hline Diplocephalus graecus & -1.94 & -1.34 & 0 & 0 & 20 & 0 & 0 & 451 & 152 & 623 \\
\hline
\end{tabular}


Diplocephalus latifrons

Diplocephalus picinus

Diplostyla concolor

Drassodes lapidosus

Drassyllus lutetianus

Drassyllus praeficus

Drassyllus pumilus

Drassyllus pusillus

Drassyllus villicus

Dysdera crocata

Dysdera erythrina

Enoplognatha

mandibularis

Enoplognatha mordax

Enoplognatha thoracica

Eratigena picta

Erigone atra

Erigone dentipalpis

Erigone promiscua

Erigonella hiemalis

Erigonoplus turriger

Ero furcata

Euophrys herbigrada

Euryopis episinoides

Gnathonarium dentatum

Gongylidiellum

latebricola

Gongylidiellum vivum

Hahnia nava

Hahnia ononidum

Hahnia pusilla

Haplodrassus aenus

Haplodrassus dalmatensis

Haplodrassus macellinus

Haplodrassus minor

Haplodrassus severus

Haplodrassus signifer

Harpactea serena

Histopona torpida

Leptodrassus albidus

Leptorhoptrum robustum

Liophrurillus flavitarsis

Maso sundevalli

Mecopisthes peusi

Mecopisthes silus

Meioneta affinis

Meioneta fuscipalpa

Meioneta mollis
$-0.26$

$-0.24$

$-1.13$

1.74

1.92

2.00

1.60

1.70

1. 81

2.86

2.52

$-1.46$

$-0.64$

$-0.92$

$-1.04$

$-1.22$

$-1.21$

$-1.24$

$-1.32$

$-2.01$

0.49

0.94

$-1.79$

$-1.83$

$-0.29$

$-1.33$

$-0.25$

$-0.20$

$-0.31$

1.72

0.82

2.02

1.59

3.08

1.13

1.24

0.47

0.93

$-1.61$

1.80

$-0.28$

$-1.35$

$-1.35$

$-0.25$

$-1.91$

$-1.30$
$-1.20$

$-1.18$

0.50

1.51

$-0.63$

$-0.57$

$-0.83$

$-0.76$

$-0.69$

$-0.02$

$-0.24$

$-1.03$

0.81

0.63

$-0.77$

0.44

0.45

0.43

0.38

$-1.38$

0.72

$-2.57$

$-1.24$

$-1.27$

$-1.22$

0.37

$-1.19$

$-1.16$

$-1.23$

$-0.75$

0.93

$-0.56$

$-0.83$

0.11

1.13

$-2.38$

$-0.73$

$-2.57$

$-1.13$

$-0.70$

$-1.21$

0.36

0.36

$-1.19$

$-1.32$

0.39

95

\begin{tabular}{|c|c|c|c|c|c|c|c|}
\hline 0 & 0 & 0 & 1 & 5 & 0 & 0 & 6 \\
\hline 7 & 0 & 0 & 0 & 5 & 0 & 0 & 12 \\
\hline 67 & 87 & 62 & 34 & 153 & 0 & 16 & 419 \\
\hline 8 & 2 & 5 & 0 & 0 & 8 & 11 & 34 \\
\hline 11 & 1 & 3 & 0 & 3 & 0 & 39 & 57 \\
\hline 1 & 14 & 8 & 0 & 7 & 0 & 27 & 57 \\
\hline 0 & 0 & 5 & 0 & 0 & 0 & 0 & 5 \\
\hline 4 & 0 & 56 & 20 & 36 & 0 & 68 & 184 \\
\hline 12 & 0 & 1 & 0 & 0 & 0 & 8 & 21 \\
\hline 0 & 3 & 4 & 1 & 0 & 20 & 3 & 31 \\
\hline 12 & 11 & 15 & 0 & 5 & 0 & 1 & 44 \\
\hline 0 & 0 & 0 & 0 & 0 & 40 & 0 & 40 \\
\hline 0 & 0 & 0 & 0 & 0 & 0 & 9 & 9 \\
\hline 16 & 0 & 0 & 0 & 3 & 0 & 18 & 37 \\
\hline 14 & 0 & 1 & 0 & 0 & 1 & 2 & 18 \\
\hline 1805 & 0 & 0 & 58 & 1150 & 0 & 97 & 3110 \\
\hline 1043 & 4 & 10 & 4 & 282 & 121 & 419 & 1883 \\
\hline 0 & 0 & 0 & 8 & 0 & 0 & 0 & 8 \\
\hline 0 & 0 & 0 & 1 & 7 & 0 & 0 & 8 \\
\hline 0 & 0 & 0 & 0 & 0 & 164 & 0 & 164 \\
\hline 0 & 3 & 0 & 0 & 0 & 0 & 2 & 5 \\
\hline 0 & 0 & 0 & 0 & 0 & 5 & 1 & 6 \\
\hline 0 & 0 & 0 & 0 & 0 & 8 & 0 & 8 \\
\hline 0 & 146 & 0 & 0 & 0 & 0 & 0 & 146 \\
\hline 0 & 0 & 0 & 0 & 5 & 0 & 0 & 5 \\
\hline 6 & 0 & 0 & 0 & 0 & 0 & 0 & 6 \\
\hline 2 & 0 & 8 & 2 & 0 & 1 & 0 & 13 \\
\hline 0 & 0 & 0 & 0 & 5 & 0 & 0 & 5 \\
\hline 0 & 0 & 0 & 0 & 3 & 0 & 5 & 8 \\
\hline 0 & 0 & 14 & 0 & 0 & 0 & 0 & 14 \\
\hline 0 & 0 & 0 & 0 & 0 & 106 & 81 & 187 \\
\hline 0 & 0 & 0 & 0 & 0 & 15 & 0 & 15 \\
\hline 0 & 1 & 0 & 0 & 0 & 4 & 0 & 5 \\
\hline 0 & 0 & 0 & 0 & 0 & 88 & 0 & 88 \\
\hline 1 & 0 & 7 & 0 & 0 & 2 & 37 & 47 \\
\hline 0 & 0 & 0 & 0 & 0 & 6 & 0 & 6 \\
\hline 0 & 0 & 0 & 0 & 8 & 0 & 0 & 8 \\
\hline 0 & 0 & 0 & 0 & 0 & 8 & 0 & 8 \\
\hline 0 & 0 & 0 & 0 & 29 & 0 & 0 & 29 \\
\hline 0 & 5 & 16 & 0 & 0 & 6 & 0 & 27 \\
\hline 10 & 0 & 0 & 0 & 0 & 0 & 0 & 10 \\
\hline 0 & 0 & 0 & 0 & 0 & 9 & 0 & 9 \\
\hline 0 & 0 & 0 & 0 & 0 & 8 & 0 & 8 \\
\hline 3 & 0 & 0 & 0 & 2 & 0 & 0 & 5 \\
\hline 0 & 0 & 0 & 0 & 0 & 87 & 0 & 87 \\
\hline 5 & 0 & 0 & 0 & 1 & 0 & 2 & 8 \\
\hline
\end{tabular}
12 34 57 57 84 21 44$$
5
$$ 
Meioneta pseudorurestris

Meioneta rurestris

Meioneta saxatilis

Mermessus trilobatus

Micaria albovittata

Micaria pulicaria

Micrargus herbigradus

Micrargus subaequalis

Microlinyphia impigra

Microlinyphia pusilla

Micrommata ligurina

Microneta viaria

Nomisia exornata

Nurscia albomaculata

Oedothorax apicatus

Oedothorax fuscus

Oedothorax gibbosus

Oedothorax retusus

Ostearius melanopygius

Ouedia rufithorax

Ozyptila furcula

Ozyptila praticola

Ozyptila simplex

Pachygnatha clercki

Pachygnatha degeeri

Palliduphantes arenicola

Palliduphantes stygius

Panamomops sulcifrons

Pardosa agrestis

Pardosa agricola

Pardosa amentata

Pardosa hortensis

Pardosa lugubris

Pardosa nigriceps

Pardosa occidentalis

Pardosa paludicola

Pardosa palustris

Pardosa prativaga

Pardosa proxima

Pardosa pullata

Pardosa saltans

Pardosa vittata

Pelecopsis bucephala

Pelecopsis inedita

Pelecopsis parallela

Pellenes brevis

Phlegra bresnieri
$-0.18$

$-0.88$

1.19

0.91

$-1.25$

$-1.29$

$-1.57$

$-1.59$

0.78

$-0.17$

0.24

0.04

$-1.17$

$-1.20$

$-1.84$

$-1.18$

$-1.86$

$-1.29$

0.87

1.54

0.49

$-0.71$

$-1.00$

$-1.88$

$-1.90$

$-0.32$

0.73

2.06

0.96

0.75

0.85

0.17

2.14

2.25

0.92

0.94

2.01

0.71

1.93

2.00

$-1.84$

$-1.93$

$-1.35$

1.04

1.15

\begin{tabular}{|c|c|c|c|c|c|c|c|c|}
\hline-1.31 & 0 & 0 & 0 & 0 & 0 & 426 & 0 & 426 \\
\hline 0.43 & 14 & 41 & 25 & 0 & 87 & 0 & 122 & 289 \\
\hline-1.15 & 1 & 0 & 0 & 0 & 16 & 0 & 0 & 17 \\
\hline-2.92 & 8 & 0 & 1 & 0 & 44 & 0 & 4 & 57 \\
\hline-2.41 & 0 & 3 & 0 & 0 & 0 & 0 & 13 & 16 \\
\hline-2.59 & 15 & 10 & 44 & 4 & 20 & 0 & 19 & 112 \\
\hline 0.42 & 1 & 0 & 1 & 0 & 26 & 0 & 0 & 28 \\
\hline 0.40 & 23 & 0 & 0 & 3 & 137 & 0 & 0 & 163 \\
\hline-1.10 & 0 & 7 & 0 & 0 & 0 & 0 & 0 & 7 \\
\hline-1.12 & 0 & 0 & 1 & 0 & 1 & 3 & 2 & 7 \\
\hline-0.42 & 0 & 1 & 1 & 0 & 0 & 3 & 0 & 5 \\
\hline-1.14 & 4 & 0 & 0 & 0 & 3 & 0 & 1 & 8 \\
\hline-0.76 & 0 & 0 & 2 & 0 & 0 & 150 & 0 & 152 \\
\hline 1.24 & 0 & 17 & 0 & 0 & 0 & 3 & 0 & 20 \\
\hline 0.48 & 527 & 2 & 567 & 43 & 1968 & 26 & 300 & 3433 \\
\hline 0.45 & 261 & 16 & 0 & 4 & 0 & 0 & 14 & 295 \\
\hline-1.27 & 7 & 0 & 0 & 0 & 0 & 0 & 0 & 7 \\
\hline 0.47 & 301 & 0 & 0 & 7 & 377 & 0 & 0 & 685 \\
\hline-1.29 & 0 & 1 & 2 & 0 & 0 & 0 & 2 & 5 \\
\hline 0.39 & 0 & 0 & 0 & 0 & 0 & 34 & 0 & 34 \\
\hline-2.61 & 0 & 11 & 0 & 0 & 0 & 4 & 0 & 15 \\
\hline-0.87 & 13 & 0 & 0 & 0 & 4 & 0 & 5 & 22 \\
\hline 0.72 & 19 & 0 & 8 & 0 & 6 & 0 & 4 & 37 \\
\hline 0.77 & 125 & 78 & 1 & 0 & 40 & 0 & 6 & 250 \\
\hline 0.58 & 36 & 45 & 76 & 54 & 716 & 2 & 46 & 975 \\
\hline-1.30 & 0 & 0 & 0 & 0 & 0 & 0 & 7 & 7 \\
\hline-1.31 & 0 & 0 & 0 & 0 & 0 & 8 & 0 & 8 \\
\hline-1.24 & 0 & 0 & 7 & 0 & 1 & 0 & 0 & 8 \\
\hline 0.87 & 50 & 9 & 139 & 0 & 13 & 0 & 496 & 707 \\
\hline-0.54 & 0 & 5 & 2 & 0 & 0 & 0 & 0 & 7 \\
\hline 1.02 & 6 & 0 & 0 & 1 & 235 & 0 & 0 & 242 \\
\hline 0.88 & 12 & 0 & 1 & 0 & 0 & 26 & 93 & 132 \\
\hline 0.95 & 0 & 0 & 15 & 0 & 8 & 0 & 0 & 23 \\
\hline-0.81 & 0 & 0 & 6 & 1 & 0 & 0 & 0 & 7 \\
\hline-0.48 & 0 & 6 & 0 & 0 & 0 & 19 & 0 & 25 \\
\hline-0.41 & 0 & 0 & 10 & 0 & 0 & 0 & 1 & 11 \\
\hline 0.99 & 136 & 0 & 0 & 44 & 338 & 0 & 3 & 521 \\
\hline 1.00 & 157 & 121 & 128 & 94 & 0 & 0 & 65 & 565 \\
\hline-0.56 & 83 & 374 & 548 & 0 & 0 & 56 & 248 & 1309 \\
\hline 0.86 & 23 & 0 & 67 & 43 & 374 & 4 & 5 & 516 \\
\hline-0.61 & 158 & 0 & 0 & 0 & 0 & 0 & 154 & 312 \\
\hline-0.57 & 0 & 3 & 21 & 0 & 0 & 1 & 673 & 698 \\
\hline-1.28 & 0 & 1 & 0 & 0 & 0 & 14 & 0 & 15 \\
\hline-1.33 & 0 & 0 & 0 & 0 & 0 & 35 & 0 & 35 \\
\hline 0.36 & 0 & 1 & 2 & 0 & 0 & 3 & 0 & \\
\hline-2.51 & 0 & 0 & 0 & 0 & 0 & 32 & 0 & 32 \\
\hline-2.43 & 0 & 0 & 0 & 0 & 0 & 24 & 0 & 24 \\
\hline
\end{tabular}




\section{Phrurolithus festivus}

Phrurolithus minimus

Phrurolithus nigrinus

Pirata latitans

Pirata piraticus

Pisaura mirabilis

Pocadicnemis juncea

Porrhomma errans

Porrhomma

microphthalmum

Porrhomma pygmaeum

Porrhomma rosenhaueri

Prinerigone vagans

Robertus arundineti

Robertus lividus

Robertus neglectus

Savignia frontata

Setaphis carmeli

Silometopus elegans

Tegenaria fuesslini

Tegenaria hasperi

Tenuiphantes flavipes

Tenuiphantes mengei

Tenuiphantes tenuis

Tenuiphantes

zimmermanni

Thanatus atratus

Thanatus vulgaris

Tiso vagans

Titanoeca hispanica

Trachyzelotes fuscipes

Trachyzelotes pedestris

Trochosa hispanica

Trochosa robusta

Trochosa ruricola

Trochosa terricola

Troxochrus scabriculus

Typhochrestus bogarti

Walckenaeria atrotibialis

Walckenaeria dysderoides

Walckenaeria nudipalpis

Walckenaeria vigilax

Xerolycosa miniata

Xysticus acerbus

Xysticus bliteus

Xysticus cristatus

Xysticus kochi

Zelotes atrocaeruleus
1.41

1.40

1.42

1.63

0.99

1.37

$-0.23$

$-1.16$

$-1.16$

$-1.86$

$-1.92$

$-1.85$

$-1.22$

0.02

$-1.24$

$-1.95$

0.57

$-1.99$

$-0.10$

0.66

$-1.24$

$-1.26$

$-1.11$

$-1.16$

0.04

0.30

$-1.26$

$-0.82$

1.73

2.08

1.53

3.33

2.59

1.47

$-1.29$

$-1.35$

$-0.14$

$-0.22$

$-1.10$

$-1.21$

1.92

1.41

1.29

0.20

1.42

1.48
$-0.95$

$-0.96$

$-0.94$

$-0.81$

1.04

$-0.04$

$-1.18$

0.48

0.48

$-1.29$

$-1.33$

$-1.28$

0.44

$-1.02$

0.43

$-1.35$

0.77

$-1.37$

1.15

$-0.61$

0.43

0.42

0.51

0.48

$-0.89$

$-0.73$

0.42

0.70

$-0.74$

$-0.52$

1.38

0.27

$-0.20$

1.34

0.40

0.36

$-1.12$

$-1.17$

0.52

0.45

$-0.62$

$-2.27$

$-2.35$

$-0.79$

$-2.27$

$-2.23$

97

\begin{tabular}{|c|c|c|c|c|c|c|c|}
\hline 6 & 34 & 70 & 3 & 14 & 0 & 68 & 195 \\
\hline 13 & 0 & 4 & 0 & 1 & 15 & 0 & 33 \\
\hline 0 & 4 & 86 & 0 & 0 & 0 & 3 & 93 \\
\hline 16 & 1 & 4 & 0 & 13 & 0 & 1 & 35 \\
\hline 2 & 67 & 0 & 0 & 0 & 0 & 0 & 69 \\
\hline 11 & 0 & 1 & 0 & 0 & 18 & 1 & 31 \\
\hline 13 & 0 & 0 & 0 & 10 & 0 & 1 & 24 \\
\hline 0 & 0 & 0 & 0 & 29 & 0 & 0 & 29 \\
\hline 1 & 0 & 0 & 0 & 43 & 0 & 0 & 44 \\
\hline 1 & 0 & 0 & 4 & 1 & 0 & 0 & 6 \\
\hline 0 & 0 & 12 & 0 & 0 & 0 & 0 & 12 \\
\hline 6 & 222 & 0 & 0 & 0 & 12 & 3 & 243 \\
\hline 26 & 0 & 10 & 0 & 0 & 0 & 6 & 42 \\
\hline 3 & 0 & 0 & 0 & 9 & 0 & 1 & 13 \\
\hline 0 & 0 & 0 & 0 & 7 & 0 & 0 & 7 \\
\hline 17 & 0 & 0 & 3 & 0 & 0 & 0 & 20 \\
\hline 0 & 0 & 8 & 0 & 0 & 247 & 47 & 302 \\
\hline 0 & 1 & 6 & 0 & 0 & 0 & 0 & 7 \\
\hline 0 & 19 & 0 & 0 & 0 & 61 & 0 & 80 \\
\hline 0 & 9 & 0 & 0 & 0 & 0 & 0 & 9 \\
\hline 4 & 0 & 0 & 0 & 7 & 0 & 0 & 11 \\
\hline 0 & 0 & 0 & 5 & 0 & 0 & 0 & 5 \\
\hline 369 & 40 & 149 & 143 & 695 & 58 & 340 & 1794 \\
\hline 3 & 0 & 0 & 10 & 0 & 0 & 0 & 13 \\
\hline 0 & 0 & 0 & 0 & 0 & 157 & 1 & 158 \\
\hline 0 & 7 & 0 & 0 & 0 & 0 & 0 & 7 \\
\hline 11 & 0 & 0 & 0 & 10 & 0 & 3 & 24 \\
\hline 0 & 0 & 0 & 0 & 0 & 55 & 0 & 55 \\
\hline 0 & 5 & 1 & 0 & 0 & 36 & 8 & 50 \\
\hline 59 & 5 & 15 & 1 & 0 & 0 & 65 & 145 \\
\hline 0 & 8 & 22 & 0 & 0 & 0 & 53 & 83 \\
\hline 0 & 0 & 29 & 0 & 0 & 0 & 3 & 32 \\
\hline 119 & 23 & 0 & 18 & 68 & 0 & 2 & 230 \\
\hline 3 & 0 & 0 & 0 & 89 & 0 & 1 & 93 \\
\hline 1 & 0 & 0 & 0 & 8 & 0 & 0 & 9 \\
\hline 0 & 0 & 0 & 0 & 0 & 57 & 0 & 57 \\
\hline 2 & 0 & 0 & 0 & 32 & 0 & 0 & 34 \\
\hline 4 & 0 & 0 & 0 & 5 & 0 & 0 & 9 \\
\hline 0 & 0 & 7 & 1 & 11 & 0 & 0 & 19 \\
\hline 55 & 0 & 0 & 0 & 3 & 0 & 2 & 60 \\
\hline 0 & 2 & 5 & 0 & 0 & 0 & 0 & 7 \\
\hline 0 & 0 & 3 & 0 & 0 & 5 & 7 & 15 \\
\hline 0 & 0 & 0 & 0 & 0 & 8 & 0 & 0 \\
\hline 7 & 10 & 3 & 2 & 6 & 0 & 0 & 28 \\
\hline 6 & 8 & 63 & 0 & 20 & 263 & 94 & 454 \\
\hline 0 & 7 & 28 & 0 & 0 & 7 & 0 & 42 \\
\hline
\end{tabular}




\begin{tabular}{lrrrrrrrrrr} 
Zelotes civicus & 0.00 & -0.91 & 2 & 0 & 11 & 0 & 0 & 42 & 40 & 95 \\
Zelotes fulvopilosus & 0.25 & -0.76 & 0 & 0 & 0 & 0 & 0 & 23 & 0 & 23 \\
Zelotes longipes & 1.95 & -0.61 & 0 & 0 & 6 & 0 & 0 & 0 & 0 & 6 \\
Zelotes manius & 1.97 & -0.59 & 0 & 0 & 0 & 0 & 0 & 11 & 0 & 11 \\
Zelotes minimus & 1.19 & -2.41 & 0 & 0 & 0 & 0 & 0 & 15 & 0 & 15 \\
Zelotes mundus & 1.79 & -0.71 & 0 & 61 & 0 & 0 & 0 & 0 & 0 & 61 \\
Zelotes nilicola & 1.52 & -0.88 & 0 & 0 & 0 & 0 & 0 & 30 & 0 & 30 \\
Zelotes tenuis & 0.26 & -0.75 & 0 & 4 & 4 & 0 & 0 & 30 & 4 & 42 \\
Zodarion italicum & 1.41 & -0.94 & 5 & 4 & 18 & 0 & 0 & 0 & 34 & 61 \\
Zodarion maculatum & 1.65 & -0.79 & 0 & 0 & 0 & 0 & 0 & 107 & 0 & 107 \\
Zodarion pseudoelegans & 1.56 & -0.85 & 0 & 0 & 0 & 0 & 0 & 99 & 0 & 99 \\
Zodarion rubidum & 1.50 & -0.89 & 0 & 20 & 4 & 0 & 0 & 0 & 0 & 24 \\
Zodarion styliferum & 1.49 & -0.89 & 0 & 0 & 0 & 0 & 0 & 126 & 0 & 126 \\
Zora parallela & 0.10 & -0.85 & 0 & 0 & 6 & 0 & 0 & 2 & 0 & 8 \\
Zora pardalis & 1.04 & -2.51 & 0 & 0 & 5 & 0 & 0 & 0 & 0 & 5 \\
Zora spinimana & 0.84 & 0.94 & 34 & 0 & 4 & 0 & 6 & 0 & 2 & 46 \\
\hline
\end{tabular}




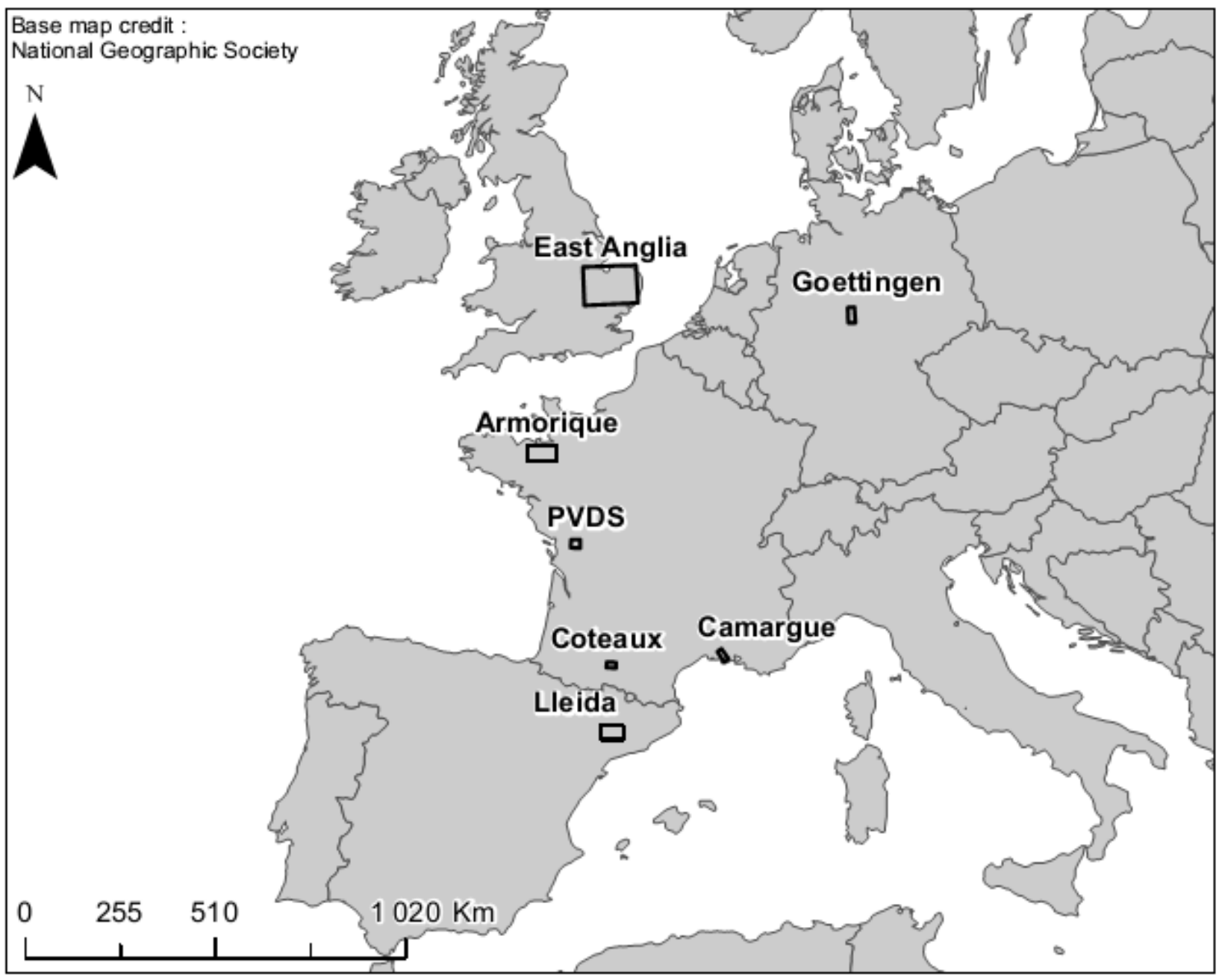

Fig. S1.1 Location of the seven sampled regions across Western Europe. 


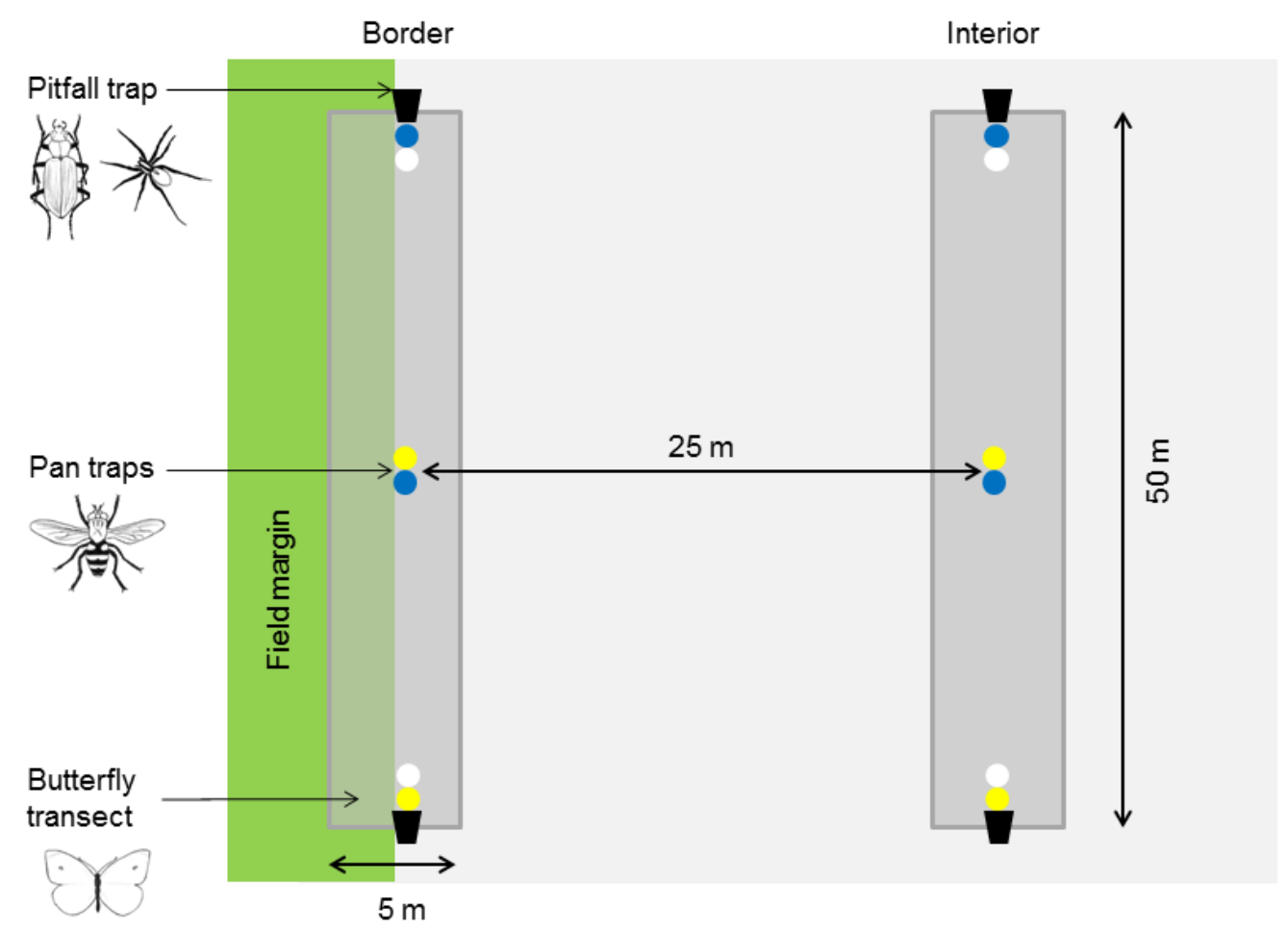

Fig. S1.2 Arthropods were sampled along two $50 \mathrm{~m}$ transects in the border and the interior of each field. Carabid beetles and spiders were sampled using pitfall traps, hoverflies with pan traps in different colours and butterflies were recorded with transect walks. Pitfall traps had a diameter of 9.5 $\mathrm{cm}$ and were installed at the endpoints of each transect (four traps per field) and filled with a solution of 10 drops of odourless dish soap and $10 \mathrm{~g}$ of salt per $1 \mathrm{~L}$ water to sample carabid beetles and spiders. Hoverflies were caught with pan traps of three different colours: UV blue, UV yellow and white. Six pan traps (two of each colour) were installed along each transect, in total 12 traps per field. Pan traps were filled with $500 \mathrm{ml}$ water and a drop of odourless detergent. Butterfly transects were $5 \mathrm{~m}$ wide and during 10 min walks we recorded all butterflies along the transect area. Butterflies were caught with insect nets for species identification if necessary. 

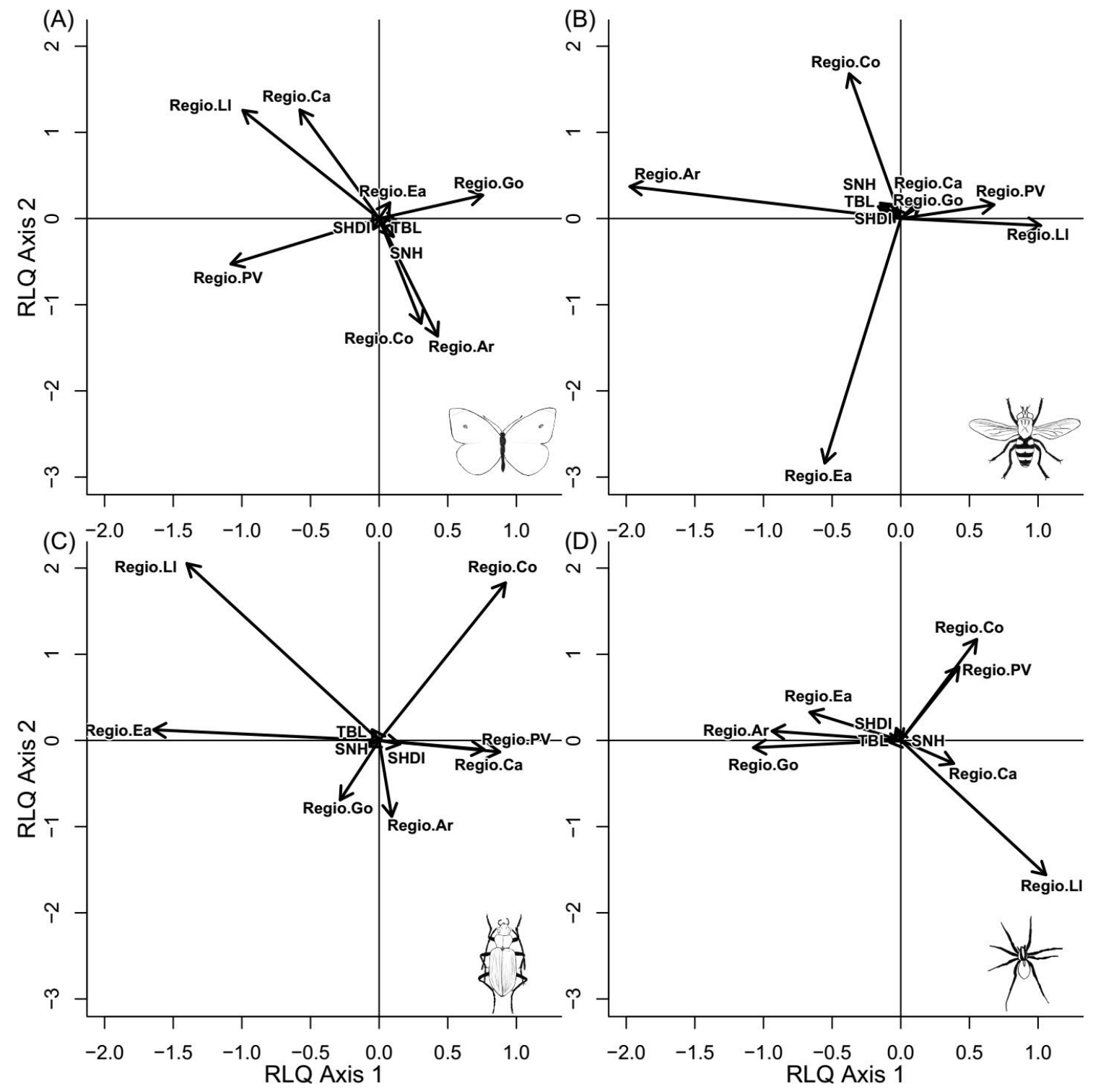

Fig. S1.3 Illustration of the importance of the regions for the structure of butterfly (A), hoverfly (B), carabid beetle (C) and spider (D) communities. Biplots represent RLQ ordination of environmental variables. Reg.Ar= Armorique region, Reg.CA = Camargue region, Reg.CO= Coteaux region, Reg.EA= East-Anglia region, Reg.Go= Goettingen region, Reg.PV= PVDS region, SHDI= Crop Shannon diversity, $\mathrm{TBL}=$ Total field border length per crop area (km.ha-1) and SNH= Semi-natural habitat area cover (\%). 


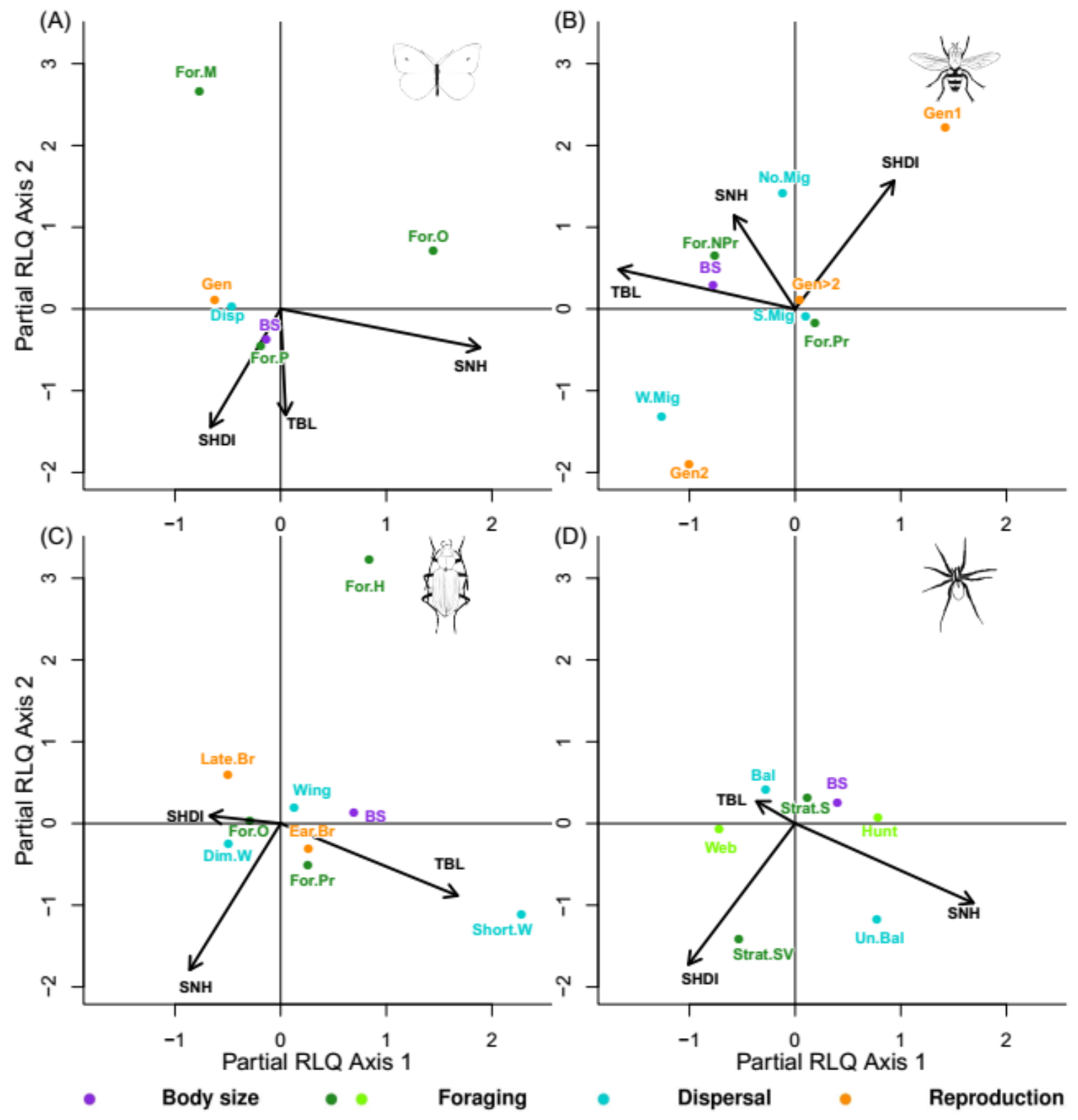

Fig. S1.4 Partial RLQ ordination of environmental variables (arrows) and traits for butterflies (A), hoverflies (B), carabid beetles (C) and spiders (D). Differently coloured dots represent traits for reproduction (orange), dispersal (blue), foraging (green) and body size (purple). For illustration purpose, environmental variable scores have been upscaled. For butterflies, BS= body size, For.P= polyphagous, For. $\mathrm{O}=$ oligophagous, For.M= monophagous, $\mathrm{Disp}=$ Dispersal and Gen= reproduction. For hoverflies, BS= body size, For.Pr= Predator, For.NPr= non predator, No.Mig= no migration, W.Mig= weak migration, S.Mig= strong migration, Gen1= 1 generation per year, Gen2= 2 generation per year and $\mathrm{Gen}>2=$ more than 2 generations per year. For carabid beetles, BS= Body size, For.Pr= Predatory, For. $\mathrm{O}=$ omnivorous, For. $\mathrm{H}=$ herbivorous, Short. $\mathrm{W}=$ short winged, $\mathrm{Dim} . \mathrm{W}=$ wing dimorphic, Wing= fully winged, $\mathrm{Ear} . \mathrm{Br}=$ early breeder and $\mathrm{Late} . \mathrm{Br}=$ late breeder. For spiders, $\mathrm{BS}=$ body size, Strat.S= soil dwelling, Strat.SV= soil and vegetation dwelling, Web= web builder, Un.Bal= uncommon ballooning and $\mathrm{Bal}=$ ballooning. See the main text for more details about traits. 


\section{3}

(a)
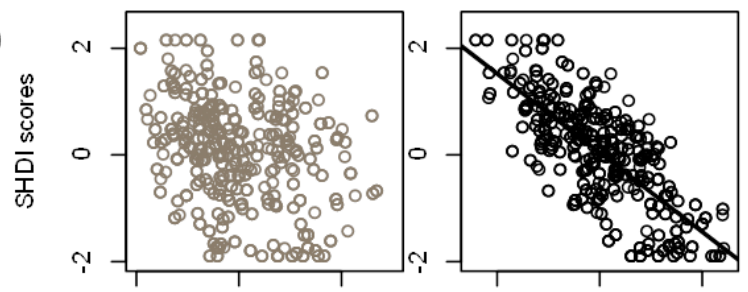

(b)
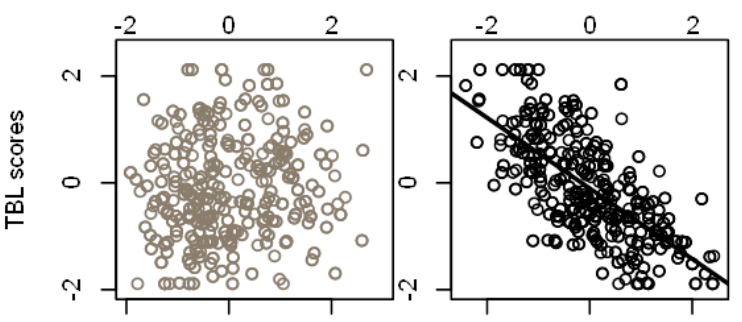

(c)
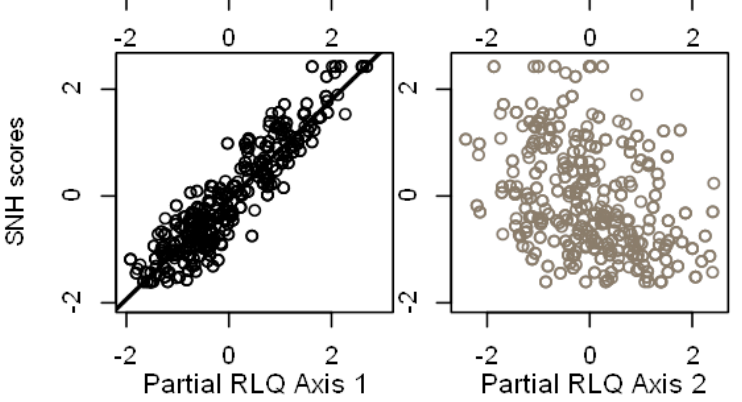

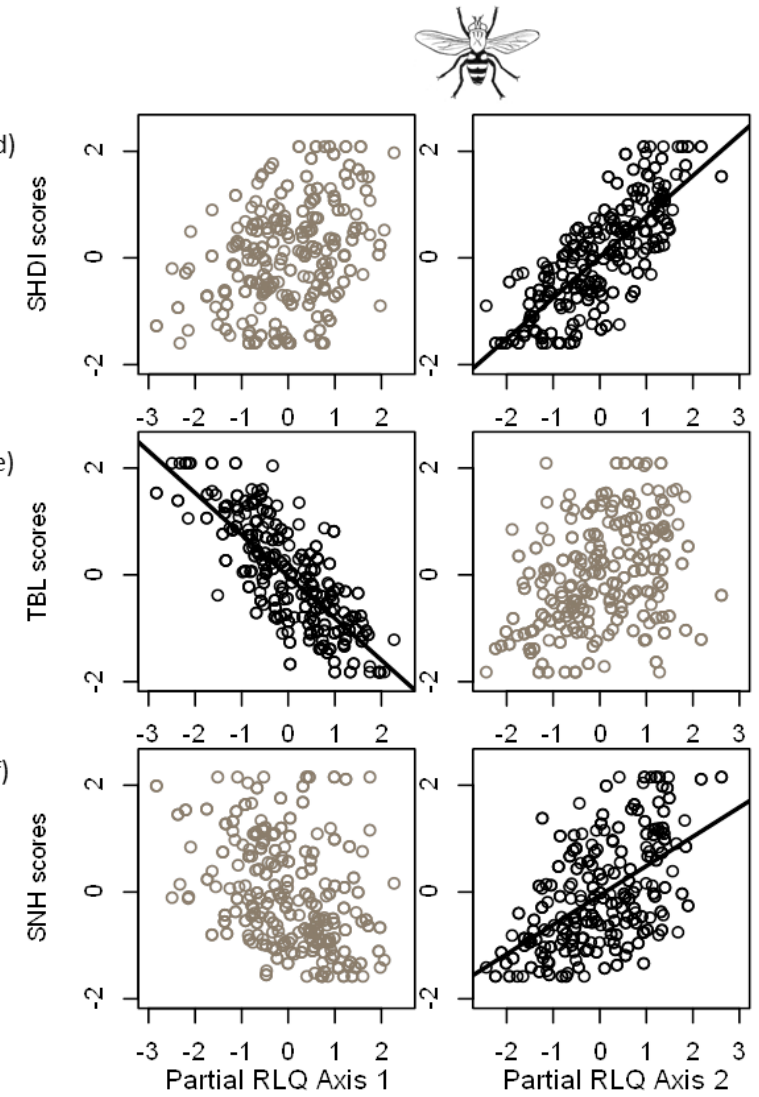

Figure S1.5 Correlation of landscape variables (SHDI: Shannon crop diversity, TBL: total border length, SNH: semi-natural habitat) with the first two axes of the partial RLQ analysis for butterflies (a-c) and hoverflies (d-f). Graphs with fitted lines represent significant correlations. Fitted lines are drawn for illustration purpose. 
(a)

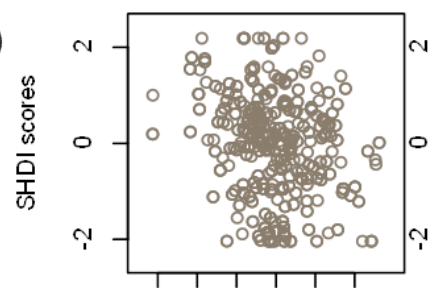

\{\}

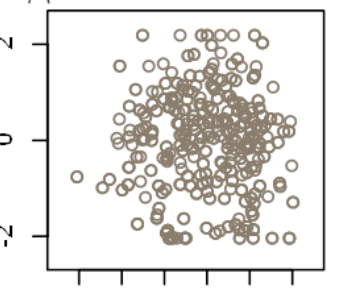

(b)

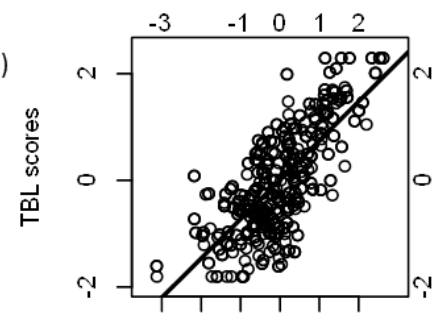

(c)

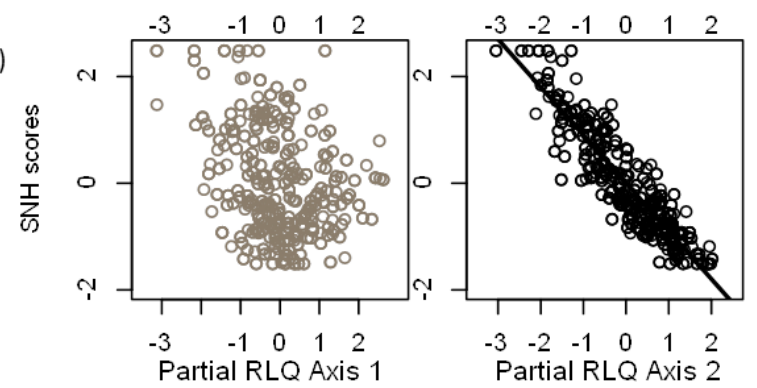

\begin{tabular}{|cccccc|}
-3 & -2 & -1 & 0 & 1 & 2 \\
\hline & $\circ$ & 90 & & \\
\hline & 8 & 8 &
\end{tabular}

(d)

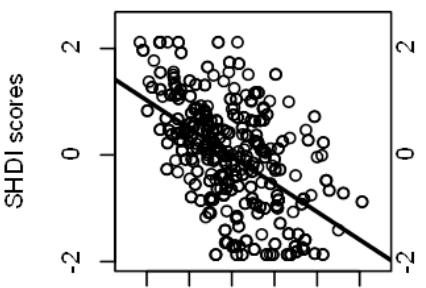

*

e)
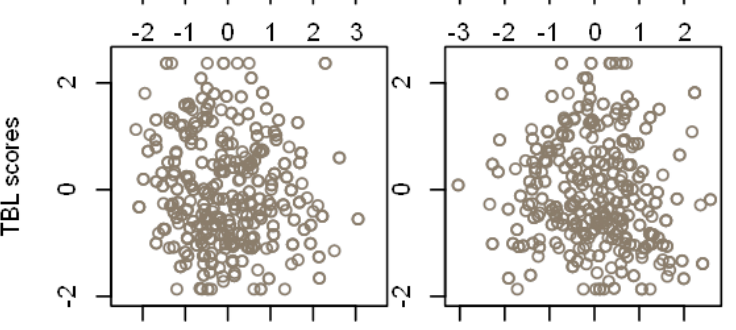

(f)

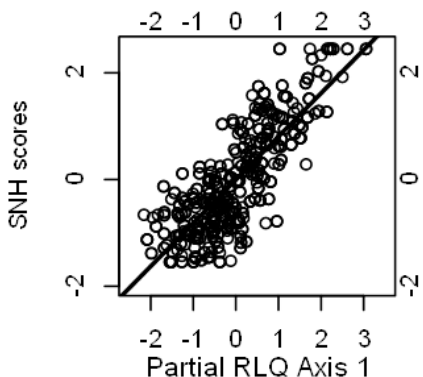

Figure S1.6 Correlation of landscape variables (SHDI. Shannon crop diversity, TBL: total border length, SNH: semi-natural habitat) with the first two axes of the partial RLQ analysis for carabids (a-c) and spiders (d-f). Graphs with fitted lines represent significant correlations. Fitted lines are drawn for illustration purpose. 


\section{Appendix S2: Correlations between traits}

Table S2.1 Correlations between traits for all taxa (butterflies, hoverflies, carabids and spiders). We used Spearman rho for correlations between two continuous variables (italic) and in all the other cases Kendall tau for correlations that included nominal variables. Strong correlations (correlation coefficients $\mid$ rho $\mid$ or $\mid$ tau $\mid>0.5$ ) are in bold. Graphs of all correlations are presented in Fig. S2.1-S2.4.

\begin{tabular}{|c|c|c|c|c|c|c|c|}
\hline \multirow[t]{5}{*}{ Butterflies } & & Body size & & Generations & & Diet & \\
\hline & Body size & - & & & & & \\
\hline & Generations & 0.20 & & - & & & \\
\hline & Diet & 0.03 & & -0.09 & & - & \\
\hline & Dispersal & 0.64 & $* * *$ & 0.43 & $*$ & 0.07 & \\
\hline \multirow[t]{5}{*}{ Hoverflies } & & Body size & & Generations & & Diet & \\
\hline & Body size & - & & & & & \\
\hline & Generations & -0.23 & & - & & & \\
\hline & Diet & -0.28 & & 0.26 & & - & \\
\hline & Dispersal & 0.09 & & 0.44 & $* *$ & 0.38 & $*$ \\
\hline \multirow[t]{5}{*}{ Carabids } & & Body size & & Breeding & & Feeding & \\
\hline & Body size & - & & & & & \\
\hline & Breeding & 0.23 & $*$ & - & & & \\
\hline & Feeding & -0.15 & & -0.15 & & - & \\
\hline & Wing morph & 0.07 & & -0.13 & & -0.19 & \\
\hline \multirow[t]{5}{*}{ Spiders } & & Body size & & Foraging (hu & t. mode) & Foraging (Stratum & use) \\
\hline & Body size & - & & & & & \\
\hline & $\begin{array}{l}\text { Foraging (hunting } \\
\text { mode) }\end{array}$ & -0.59 & $* * *$ & - & & & \\
\hline & $\begin{array}{l}\text { Foraging (Stratum } \\
\text { use) }\end{array}$ & -0.03 & & 0.04 & & - & \\
\hline & Dispersal & 0.15 & $*$ & -0.41 & $* * *$ & -0.18 & $*$ \\
\hline
\end{tabular}

$* \mathrm{p}<0.05 ; * * \mathrm{p}<0.01 ; * * * \mathrm{p}<0.001$ 
(a)

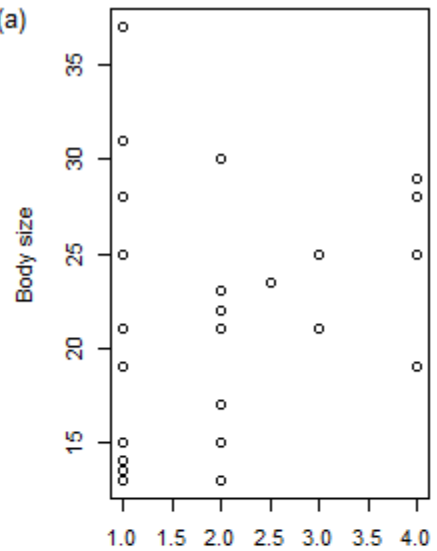

Generations

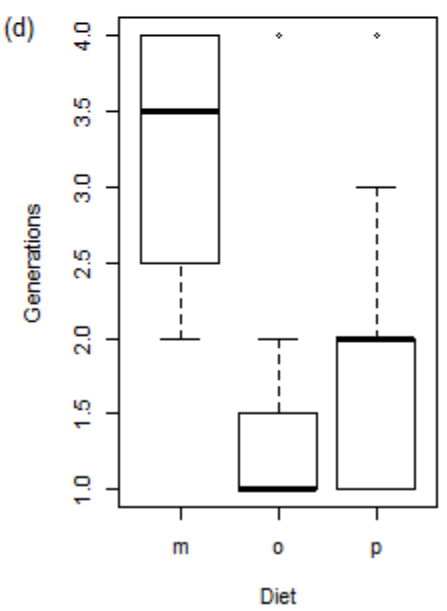

(b)

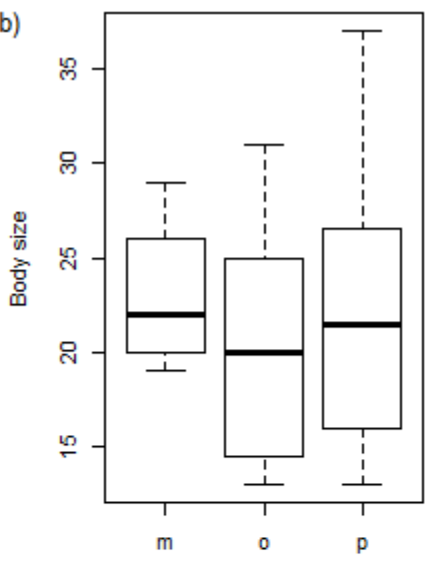

Diet

(e)

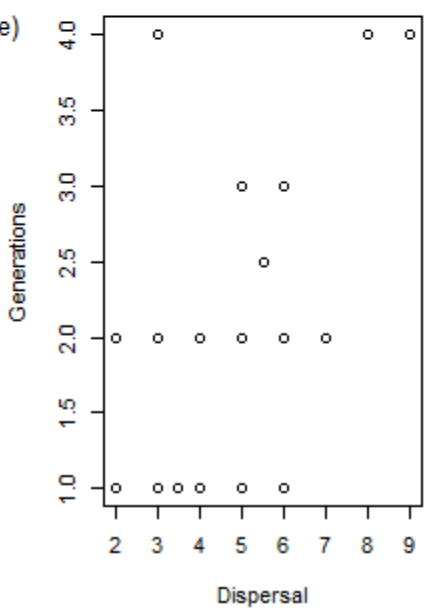

(c)

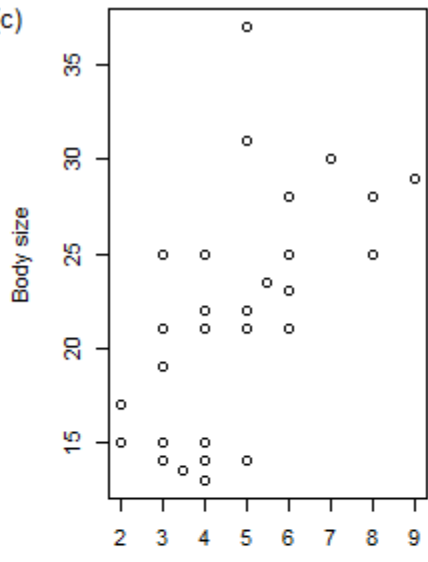

Dispersal

(f)

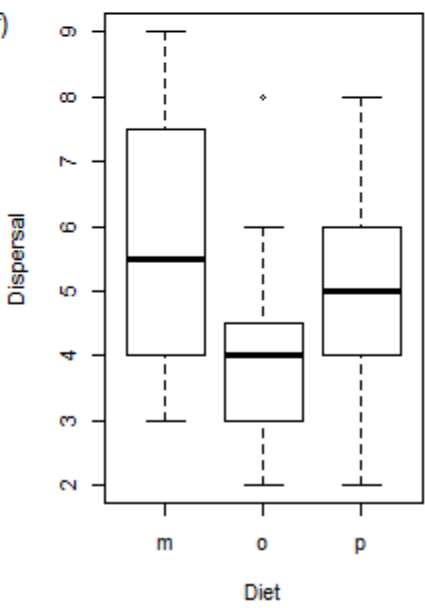

Figure S2.1 Correlation between butterfly traits: (a) body size and reproduction measured as number of generations, (b) Body size and diet, m=monophagous, $\mathrm{o}=0$ ligophagous, $\mathrm{p}=$ polyphagous, (c) body size and dispersal capacity, higher numbers indicate higher dispersal capacity, (d) Generations per year and diet, see above for abbreviations, (e) generations per year and dispersal capacity and (f) dispersal capacity and diet. 
(a)

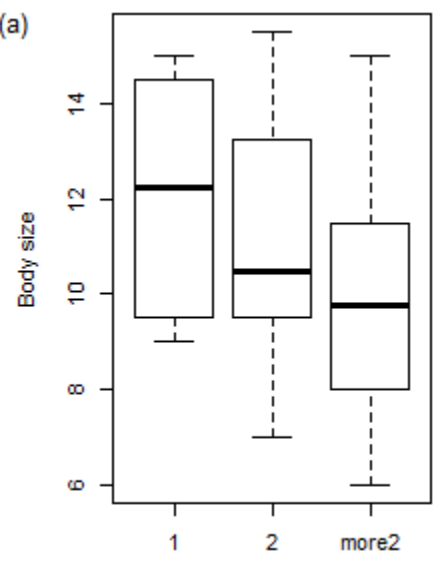

(d)

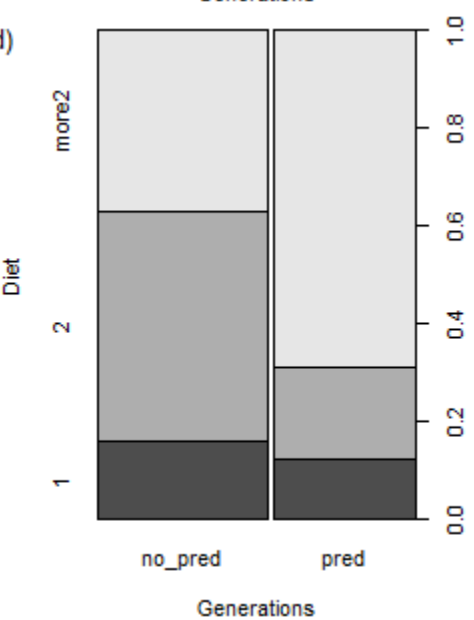

(b)

t

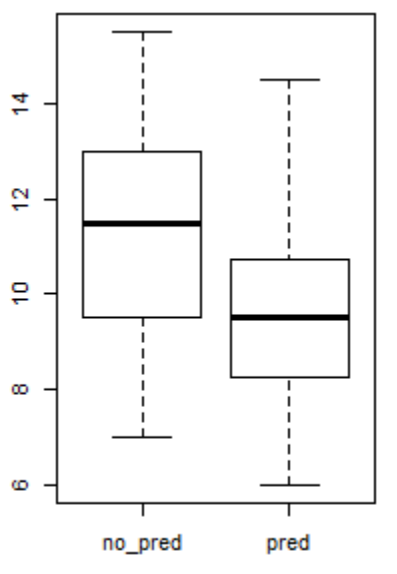

Diet

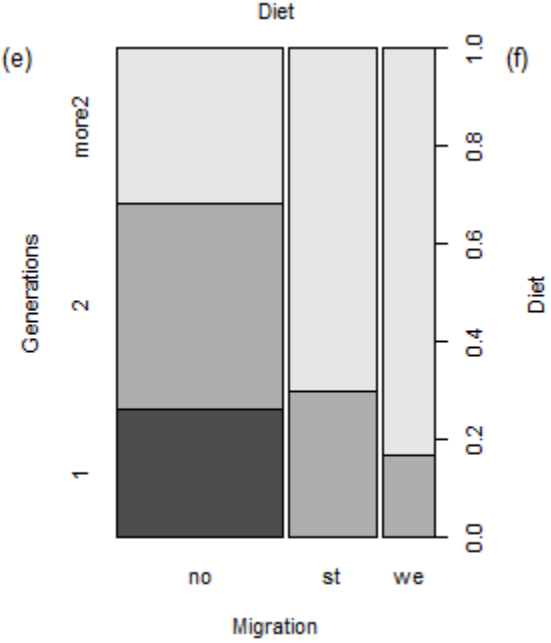

(c)
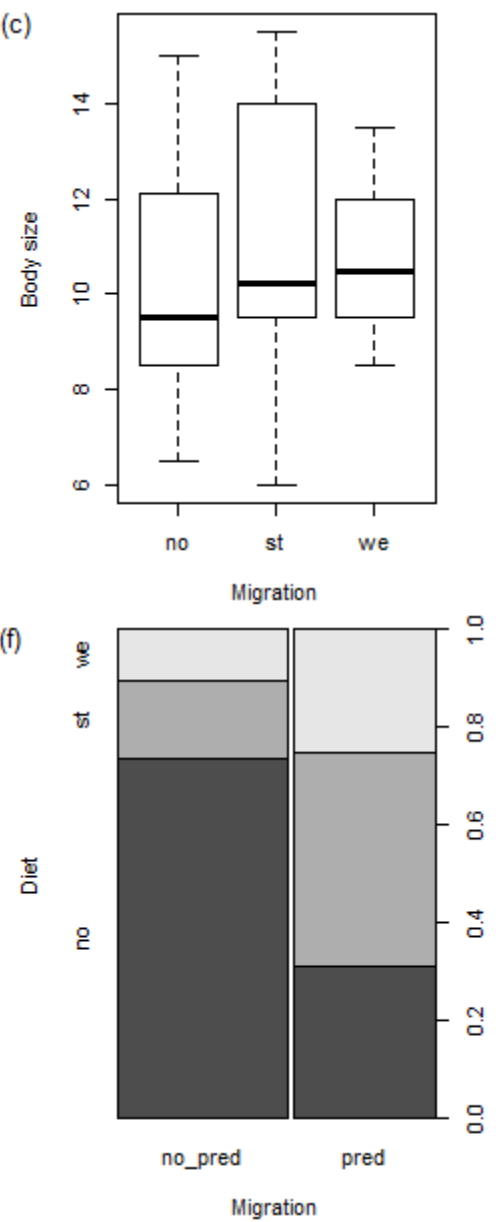

Figure S2.2 Correlation between hoverfly traits: (a) body size and number of generations, $1=1$ generation per year, $2=2$ generations per year and more $2=$ more than 2 generations per year, $(b)$ Body size and diet, no_pred $=$ non-predatory larvae, pred $=$ predatory larvae, (c) body size and migration tendency, no $=$ non-migrating, st $=$ strongly migrating, we $=$ weakly migrating,$(d)$ Generations per year and diet, see above for abbreviations, (e) generations per year and migration tendency, see above for abbreviations, and (f) migration tendency and diet, see above for abbreviations. 
(a)

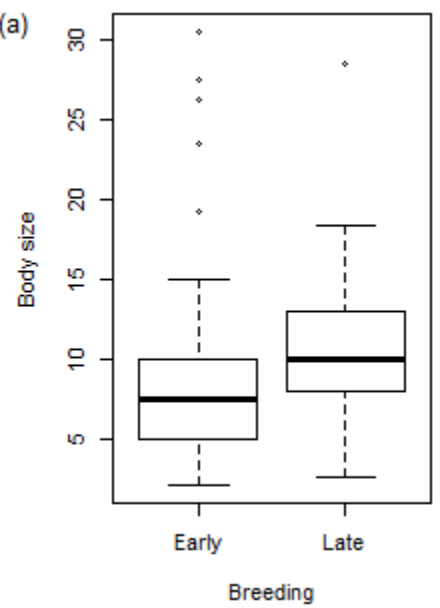

(d)

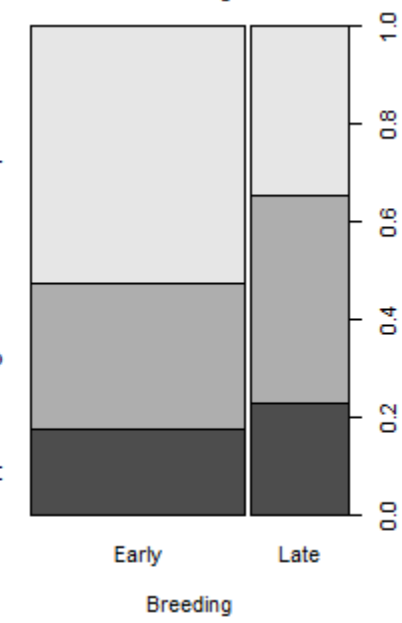

(b)

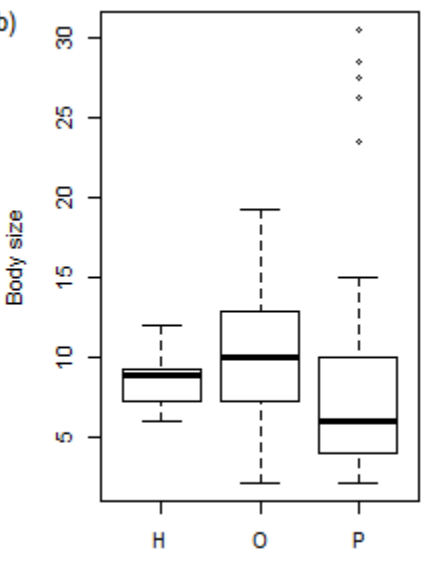

(e)

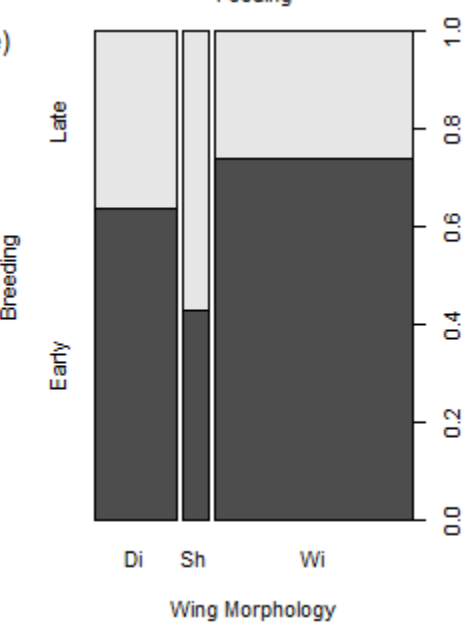

(c)
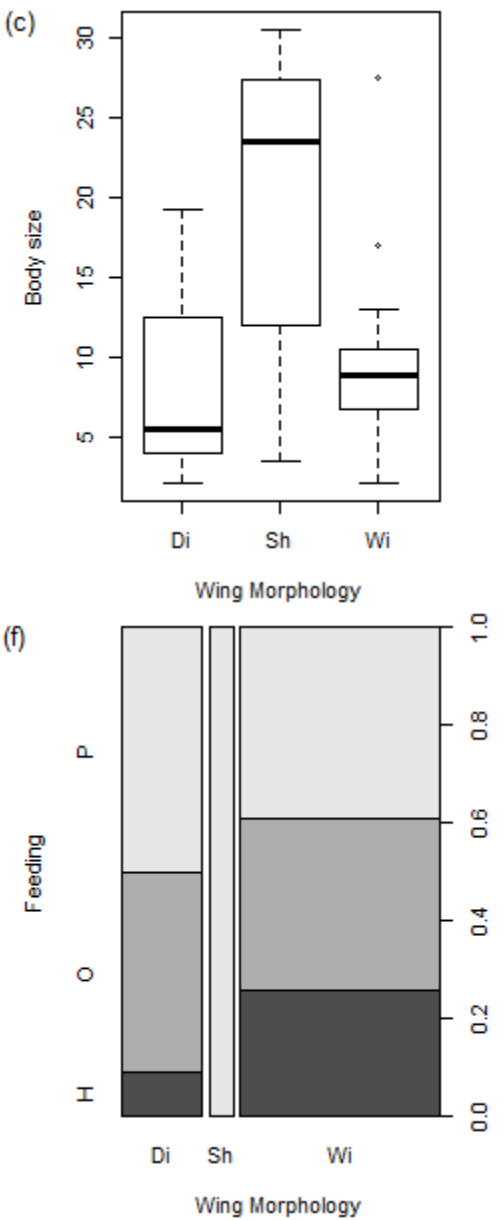

Figure S2.3 Correlation between carabid traits: (a) body size and breeding season, (b) Body size and feeding type, $\mathrm{H}=$ herbivore, $\mathrm{O}=$ omnivore, $\mathrm{P}=$ predator, (c) body size and wing morphology, $\mathrm{Di}=$ dimorphic, $\mathrm{Sh}=$ short winged, $\mathrm{Wi}=$ fully winged , (d) Feeding type and breeding season, see above for abbreviations, (e) breeding season and wing morphology, see above for abbreviations, and (f) feeding type and wing morphology, see above for abbreviations. 
(a)
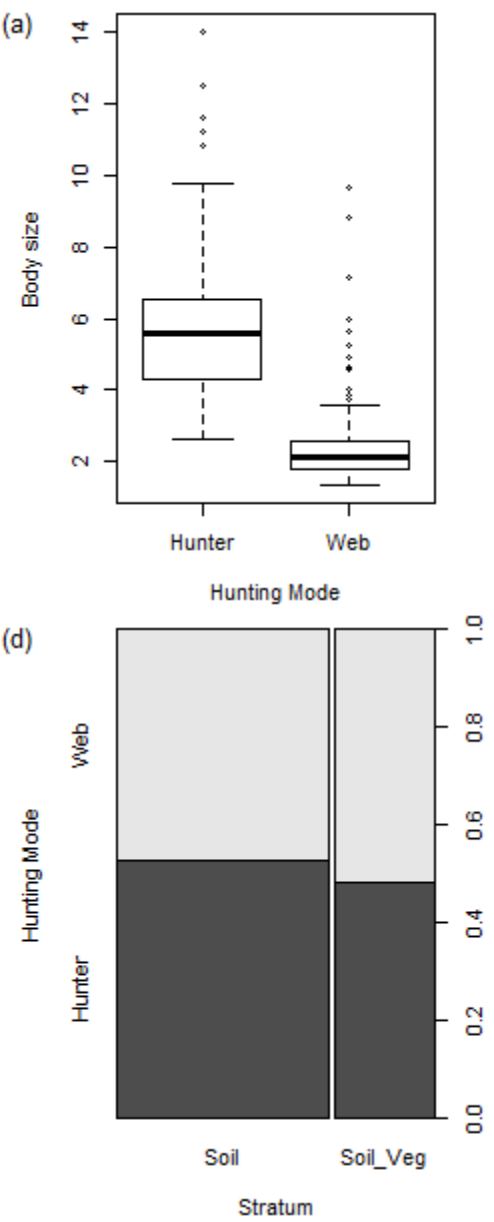

(b)
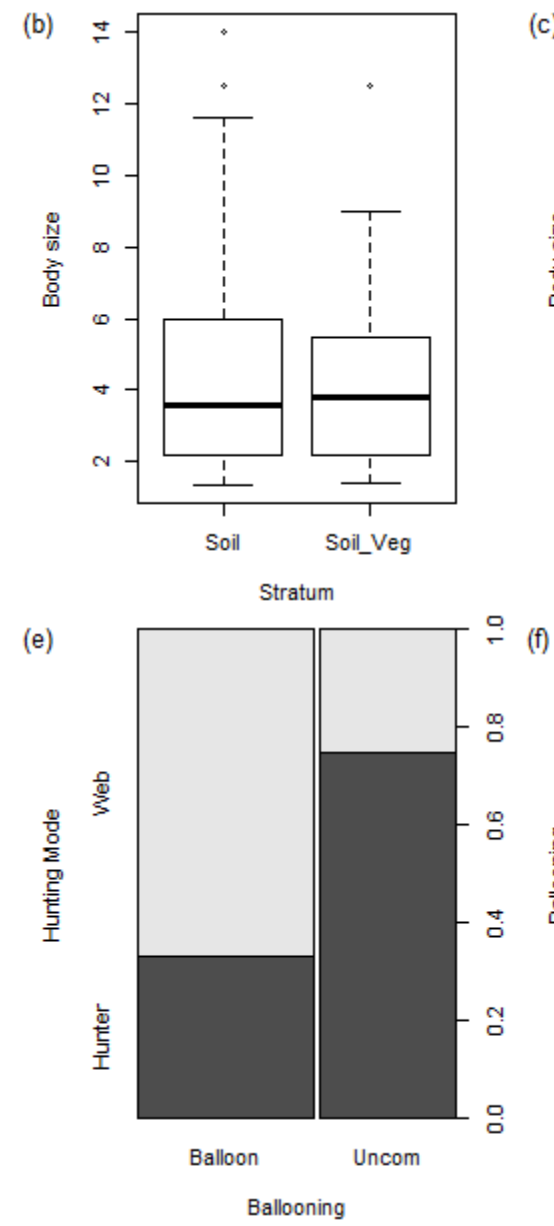

(c)
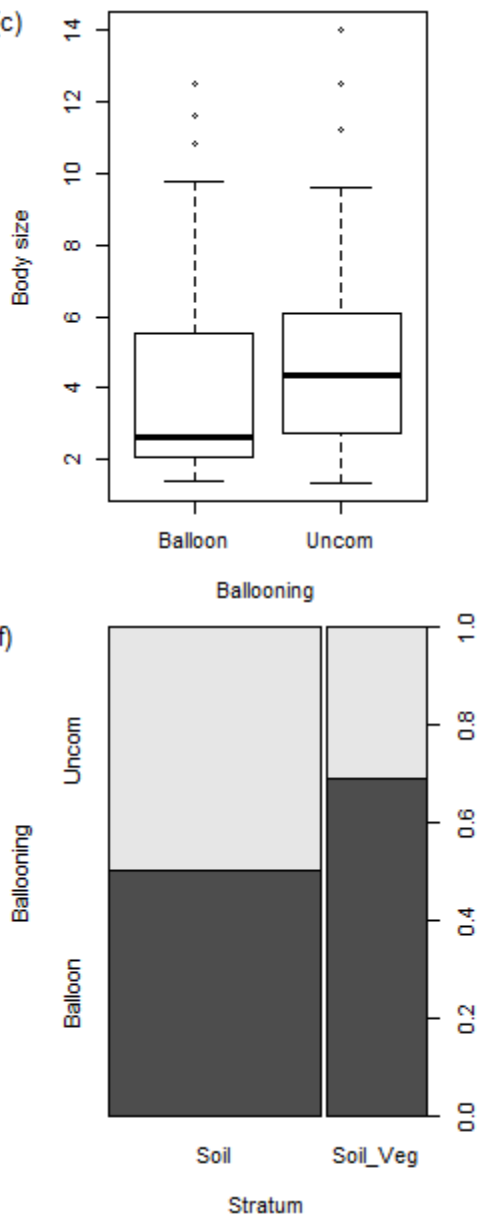

Figure S2.4 Correlation between spider traits: (a) body size and hunting mode, Hunter = hunting species, Web = web-building species, (b) Body size preferred stratum for hunting, Soil: only hunting on the soil, Soil_Veg = hunting in the vegetation or on the soil and in the vegetation, (c) body size and ballooning, Balloon = usually ballooning, Uncom = ballooning uncommon, (d) Hunting mode and stratum, see above for abbreviations, (e) hunting mode and ballooning, see above for abbreviations, and (f) ballooning and stratum, see above for abbreviations. 


\section{Chapter 3}

Landscape configurational heterogeneity by small-scale agriculture, not crop diversity, maintains pollinators and plant reproduction in western Europe

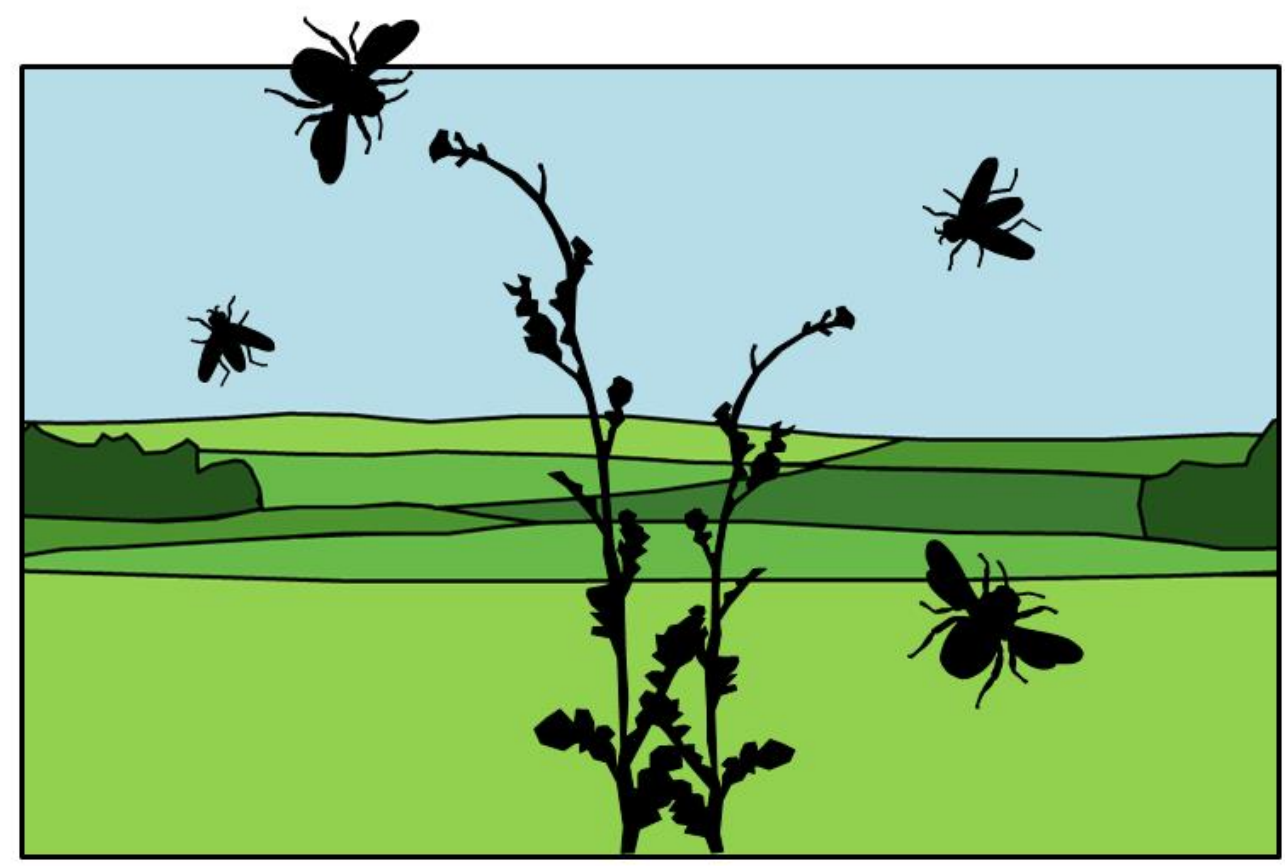

Annika L Hass, Urs G Kormann, Teja Tscharntke, Yann Clough, Aliette Bosem Baillod, Clélia Sirami, Lenore Fahrig, Jean-Louis Martin, Jacques Baudry, Colette Bertrand, Jordi Bosch, Lluís Brotons, Françoise Burel, Romain Georges, David Giralt, María Á MarcosGarcía, Antonio Ricarte, Gavin Siriwardena, Péter Batáry

Published in Proceedings of the Royal Society of London B: Biological Sciences 2018: 285, 20172242 


\begin{abstract}
Agricultural intensification is one of the main causes for the current biodiversity crisis. While reversing habitat loss on agricultural land is challenging, increasing the farmland configurational heterogeneity (higher field border density) and farmland compositional heterogeneity (higher crop diversity) has been proposed to counteract some habitat loss. Here, we tested whether increased farmland configurational and compositional heterogeneity promote wild pollinators and plant reproduction in 229 landscapes located in four major western-European agricultural regions. High field border density consistently increased wild bee abundance and seed set of radish (Raphanus sativus), probably through enhanced connectivity. In particular, we demonstrate the importance of crop-crop borders for pollinator movement as an additional experiment showed higher transfer of a pollen analogue along crop-crop borders than across fields or along semi-natural crop borders. In contrast, high crop diversity reduced bee abundance, probably due to an increase of crop types with particularly intensive management. This highlights the importance of crop identity when higher crop diversity is promoted. Our results show that small-scale agricultural systems can boost pollinators and plant reproduction. Agri-environmental policies should therefore aim to halt and reverse the current trend of increasing field sizes and to reduce the amount of crop types with particularly intensive management.
\end{abstract}

Keywords: bee, compositional heterogeneity, field size, hoverfly, landscape heterogeneity, pollen transfer 


\section{Introduction}

Pollinators provide essential services for the sexual reproduction of wild plant species, and they increase yield of many globally traded food crops and biofuels such as oilseed rape, coffee and cherry (Klein et al. 2003; Bommarco et al. 2012; Holzschuh et al. 2012). Therefore, reported wild pollinator declines are alarming, and could imperil future ecosystem stability and food security (Biesmeijer et al. 2006; Potts et al. 2010; IPBES 2016). Key drivers of these pollinator declines are habitat loss and agricultural intensification (Kovács-Hostyánszki et al. 2017). Over the last century, European farmed landscapes have undergone socio-economic changes resulting in reduced cover of semi-natural vegetation, larger field sizes, simplified crop rotations and loss of crop diversity, with emphasis on a restricted number of cash crops (Robinson \& Sutherland 2002; Batáry et al. 2017).

Because semi-natural vegetation harbours diverse pollinator communities and supports pollination services (Garibaldi et al. 2011; Kennedy et al. 2013), many agri-environment schemes attempt to compensate for biodiversity declines in agricultural landscapes by increasing the amount of semi-natural patches in these landscapes, e.g. by habitat restoration or by supporting high nature value farming. However, the global demand for agricultural products is predicted to increase during the coming decades due to human population growth and changes in consumption patterns (Alexantratos \& Bruinsma 2012). Although improvements in food chain sustainability could mitigate these effects (Godfray et al. 2010), it will be increasingly challenging to implement schemes that rely on taking land out of production or reducing farming intensity (Hodge et al. 2015).

It has been suggested that increased heterogeneity of the crop fields at the landscape scale ('farmland') may promote biodiversity in agricultural landscapes without taking land out of production (Fahrig et al. 2011). According to Fahrig et al. (2011), farmland heterogeneity can be divided in two components: Farmland configurational heterogeneity describes the spatial arrangement of fields, and can be measured for example as mean field size or density of field borders. Farmland compositional heterogeneity describes the diversity of crops grown in a landscape, and can be measured as the Shannon diversity index of crop types.

Recent studies have aimed to disentangle the effects of landscape compositional and configurational heterogeneity on pollinators as understanding the relative importance of both components is essential (Hadley \& Betts 2012), but mainly focused on the role of semi-natural vegetation patches. The few available studies investigating the impact of increased landscape configurational heterogeneity (e.g. number of patches per landscape, patch shape or interpatch connectivity) show contrasting results. Hopfenmüller et al. (2014) found a positive effect on wild bee species richness, but other studies found no or only weak evidence that configurational heterogeneity influences pollinator communities (Holzschuh et al. 2010; Kennedy et al. 2013; Steckel et al. 2014), concluding that it is of minor importance for these highly mobile organisms. On the other hand, field 
borders in European agricultural landscapes are often accompanied by strips of varying sizes with semi-natural vegetation that can be herbaceous, woody or with bare ground (Marshall 2002). These linear elements are important nesting sites (Stanley \& Stout 2013) and also crucial for pollinator orientation (Van Geert et al. 2010; Cranmer et al. 2012). Hence, high field border density may guide pollinator movements, enhance habitat connectivity and thus increase the reproductive success of native pollinator-dependent plants (Guiller et al. 2016). Yet, field borders with semi-natural boundaries might be more efficient in guiding pollinator movement due to better resource availability than simple crop-crop borders. To our knowledge it has not been tested whether smaller field sizes resulting in more field borders can promote pollinators and plant reproduction.

Landscape compositional heterogeneity effects on pollinators and associated pollination services have been measured in a variety of ways. Most studies simply used the percentage of noncrop or semi-natural cover in the landscape as their measure of landscape composition (Hopfenmüller et al. 2014; Dainese et al. 2017). Others measured the diversity of different cover types including crops and semi-natural habitats (Kennedy et al. 2013; Steckel et al. 2014). Most of these studies found that pollinators benefit from increasing landscape compositional heterogeneity. However, the effects of crop diversity on pollinators have been largely neglected by focusing only on certain crop types such as mass-flowering crops that provide ample resources for pollinators (Diekötter et al. 2014). Crop diversity is expected to increase pollinator abundance, species richness and pollination services through complementary resource provisioning (Fahrig et al. 2011). Different crop types are associated with different weed communities (Hyvönen \& Salonen 2002), and therefore provide different food resources, which pollinators in landscapes with high crop diversity can exploit (Blitzer et al. 2012; Mandelik et al. 2012). However, crop identity might also play an important role and the relationship between pollinator diversity and compositional heterogeneity could also be unimodal (Allouche et al. 2012), if the cover of certain crop types that are important for specialized species decreases with crop diversity. Nevertheless, we do not expect this, because pollinator species that are present in agricultural fields are usually generalists that can exploit a wide range of resources (Kleijn et al. 2015). To our knowledge only Fahrig et al. (Fahrig et al. 2015) aimed at disentangling the effects of crop diversity and farmland configurational heterogeneity on pollinator diversity, but they did not investigate the link to ecosystem services.

Here we test whether farmland heterogeneity increases pollination services through increased pollinator abundance and species richness using a unique, western-Europe landscape-scale dataset. We sampled bees and hoverflies, and determined seed set of experimental phytometer plants, Raphanus sativus, in 229 fields within 94 landscapes distributed over four countries. Landscapes were selected to create independent gradients of farmland configurational and compositional heterogeneity. We also assessed the role of field borders in enhancing landscape connectivity for 
pollinators using a pollen transfer experiment testing whether transmission of fluorescent dye (a proxy for pollen) was enhanced along field borders. In particular, we addressed the following hypotheses: (1) landscapes with high configurational heterogeneity show higher pollination services, mediated by an increase in pollinator abundance and species richness due to enhanced connectivity and facilitated pollinator movement, and (2) landscapes with high compositional heterogeneity enhance pollination services mediated by increased pollinator abundance and species richness due to complementary resources provided by different crops.

\section{Material and Methods}

\section{Landscape and site selection}

The study was conducted in four European agricultural regions, in France, Germany, Spain and the UK (Supporting Information, Fig. S1). Overall, we selected $941 \times 1 \mathrm{~km}$ agricultural landscapes (32 in Germany, 30 in France, 20 in Spain and 12 in the UK, see Supporting Information 1.1 for details on the landscape selection process). For each selected landscape, we mapped the crop types of all fields during the cropping season and also their semi-natural border vegetation that varied across regions and included grassy, woody and bare ground borders. These data were digitized with ArcGIS software (ESRI, USA), and afterwards we calculated three landscape variables (see Table 1 for details and measures): (1) Crop diversity (compositional heterogeneity), see Supporting Information, Table S1 for a list of crop types included; (2) Field border density (configurational heterogeneity) and (3) Nonforest semi-natural cover. Forests were excluded, because intensively managed forests usually do not provide important food resources for pollinators (Cole et al. 2017). This variable was dominated by the area of linear semi-natural vegetation which accounted for $68 \%$ of this variable across all four regions (Supporting Information 1.2). We kept the proportion of non-forest semi-natural cover as low as possible as our main emphasis was on effects of crop compositional and configurational heterogeneity. The proportion of cultivated land was therefore high in all landscapes (mean \pm SE: $85 \pm$ $0.39 \%)$. We selected the landscapes such that gradients of compositional and configurational heterogeneity were uncorrelated, both overall and in each country (Supporting Information, Fig. S2). In each landscape we chose 3 conventionally managed fields for sampling. We standardized sampled crop types within regions, because crop type might affect pollinator communities and we were not interested in local habitat effects, but in landscape scale heterogeneity effects. To achieve gradients not biased by crop type in all regions some fields were excluded (Supporting Information, 1.3). This procedure resulted in 229 focal fields (1-3 fields per landscape, 69 in France, 94 in Germany, 45 in Spain and 21 in the UK). Focal fields within the $941 \times 1 \mathrm{~km}$ landscapes were at least $200 \mathrm{~m}$ apart from each other and at least $100 \mathrm{~m}$ from the landscape borders. 
Table 1 Description and measure of all explanatory variables used in the structural equation models and in the pollen transfer experiment at the local and landscape scale

\begin{tabular}{|c|c|c|c|c|c|c|}
\hline & & Variable & Description / measure & Mean & Min & Max \\
\hline \multirow[t]{4}{*}{$\begin{array}{l}\text { Pollinator } \\
\text { survey and } \\
\text { pollination } \\
\text { experiment }\end{array}$} & \multirow[t]{3}{*}{$\begin{array}{l}\text { Land- } \\
\text { scape } \\
\text { scale }\end{array}$} & $\begin{array}{l}\text { Configu- } \\
\text { rational } \\
\text { heterogeneity }\end{array}$ & $\begin{array}{l}\text { Field border density, measured as the } \\
\text { length of all agricultural field borders (sum } \\
\text { of field perimeters) per total crop area in } \\
\text { the landscape in (m/ha), includes crop- } \\
\text { crop borders and semi-natural crop } \\
\text { borders (see pollen transfer experiment) }\end{array}$ & 285 & 68 & 625 \\
\hline & & $\begin{array}{l}\text { Compositional } \\
\text { heterogeneity }\end{array}$ & $\begin{array}{l}\text { Crop diversity, measured as Shannon } \\
\text { diversity index using crop type richness } \\
\text { and cover }\end{array}$ & 0.96 & 0 & 1.6 \\
\hline & & $\begin{array}{l}\text { Semi-natural } \\
\text { cover }\end{array}$ & $\begin{array}{l}\text { Sum of area of all patchy non-forest } \\
\text { habitats (e.g. semi-natural grasslands) and } \\
\text { the area of linear semi-natural crop } \\
\text { borders including grassy, woody and bare } \\
\text { ground borders (\%) }\end{array}$ & 5.1 & 1.5 & 10.0 \\
\hline & $\begin{array}{l}\text { Field } \\
\text { scale }\end{array}$ & $\begin{array}{l}\text { Local flower } \\
\text { cover }\end{array}$ & $\begin{array}{l}\text { Flower cover in a } 3 \mathrm{~m} \text { radius around the } \\
\text { pan traps (\%) }\end{array}$ & 4.3 & 0 & 40 \\
\hline \multirow{4}{*}{$\begin{array}{l}\text { Pollen } \\
\text { transfer } \\
\text { experiment }\end{array}$} & & Crop field & Arable crop field & & & \\
\hline & & $\begin{array}{l}\text { Crop-crop } \\
\text { border }\end{array}$ & Border between directly adjacent crops & & & \\
\hline & & $\begin{array}{l}\text { Semi-natural } \\
\text { crop border }\end{array}$ & $\begin{array}{l}\text { Field border with semi-natural vegetation } \\
\text { next to crop }\end{array}$ & & & \\
\hline & & $\begin{array}{l}\text { Crop border } \\
\text { type }\end{array}$ & $\begin{array}{l}\text { Type of adjacent crops (i.e. oilseed rape } \\
\text { next to cereal or spring crop next to } \\
\text { cereal) }\end{array}$ & & & \\
\hline
\end{tabular}

\section{Data collection}

(i) Pollinator survey and pollination experiment

In each field we established two $50 \mathrm{~m}$ transects, one in the field edge and one in the field interior, where we installed pan traps for pollinator sampling (Supporting Information 1.4 and Fig. S4). We conducted two surveys in 2013 (sampling dates in Supporting Information, Table S2) and traps were operational for four consecutive days in each survey. Additionally, we estimated the percentage of flower cover of insect pollinated plant species in a radius of $3 \mathrm{~m}$ around each of the three poles per transect. Insects were stored in $70 \%$ ethanol, and all hoverflies were identified to species. Bees were classified as honey bee or wild bee for both transects in all countries. In addition, all wild bees were identified to species or morphospecies in Germany and Spain. In France only bee species from interior transects were identified, but as bee species richness of border and interior transects were highly correlated in Germany and Spain (Pearson's $r=0.68, P<0.001$ ) we assume that using only bee species richness from the interior transect in France did not bias the results. In the UK bees could only be classified as domestic (honey bees) or wild due to logistical and financial constraints. 
To test the effects of farmland configurational and compositional heterogeneity on pollination services, we conducted a pollination experiment with common radish (Raphanus sativus oleiferus, Brassicaceae, REFORM variety, KWS, Germany), which is often used to assess insect pollination efficiency due to its dependence on insect pollination for reproduction (Albrecht et al. 2012; Dainese et al. 2017). Pollinators of radish include wild bees, honey bees, hoverflies and butterflies (Albrecht et al. 2012). We placed two pots of radish at the edge transect of each field (Supporting Information, Fig. S4) for four days during the pollinator surveys in 2013 (sampling dates in Supporting Information, Table S2). In Germany we conducted two sampling surveys (one during and one after oilseed rape bloom) and in France, Spain and the UK one pollination sampling survey (after oilseed rape bloom). To avoid seed loss, pods of the flowers that were open during field exposure (for details see Supporting Information, 1.5) were harvested shortly before full ripening. We counted the number of pods harvested from all plants of each field and the number of seeds enclosed in these pods.

\section{(ii) Pollen transfer experiment}

We examined the transfer of a pollen analogue (fluorescent dye) among experimental arrays of potted cornflowers (Centaurea cyaneus, Asteraceae, obtained from wild populations, Appels Wilde, Germany) along different field borders. Cornflowers are attractive to different bee and hoverfly species (Carreck \& Williams 2002). Fluorescent dye has been successfully used to quantify pollen transfer and gene flow among animal-pollinated plants (Van Rossum et al. 2011; Kormann et al. 2016). We performed the pollen transfer experiments at 6 replicated sites in the same study area as the pollinator survey and pollination experiment (above) in Germany. At each site we placed a central array of pollen donor cornflower pots in the semi-natural crop border vegetation next to a field. We then assessed the transmission of fluorescent dye from this donor array to recipient arrays along three different treatments: crop-crop border, semi-natural crop border and crop field treatment (Fig. 1a). The cropcrop border treatment consisted of a border between two contrasting crops without semi-natural vegetation linking the pollen donor and the recipient array $(3 \times$ oilseed rape next to cereal and $3 \times$ spring crops, i.e. sugar beet or maize, next to cereal). In the semi-natural crop border treatment an unpaved roadside with grassy crop border vegetation connected the donor and recipient array. The flower availability of naturally occurring plants in this semi-natural crop border vegetation did not differ among the six sites. Finally, in the crop field treatment we placed the recipient array in a cereal field with no crop border connecting it to the donor array. The three recipient arrays were all placed $50 \mathrm{~m}$ from the pollen donor and all experimental cornflowers were clearly visible within the surrounding vegetation.

The experiment was conducted in 2014 in three sites on May 18 and in the three remaining sites on June 5. On both sampling dates, oilseed rape was no longer flowering. We exposed always ten 
pots of cornflowers with comparable flower availability per array in the study sites at least four days before the experiment to make sure that pollinators are aware of the available food resource. Fluorescent dye (RadgloR, Radiant Color, Belgium) was applied to all fresh flowers of the pollen donor arrays (Fig. 1b) and after $24 \mathrm{~h}$ of exposure under warm and sunny conditions, we collected 20 flowers from each of the three recipient arrays per site ( $n=360$ flowers in total). We then assessed if fluorescent dye was present or absent on the stigmas of these flowers using UV light microscopy.
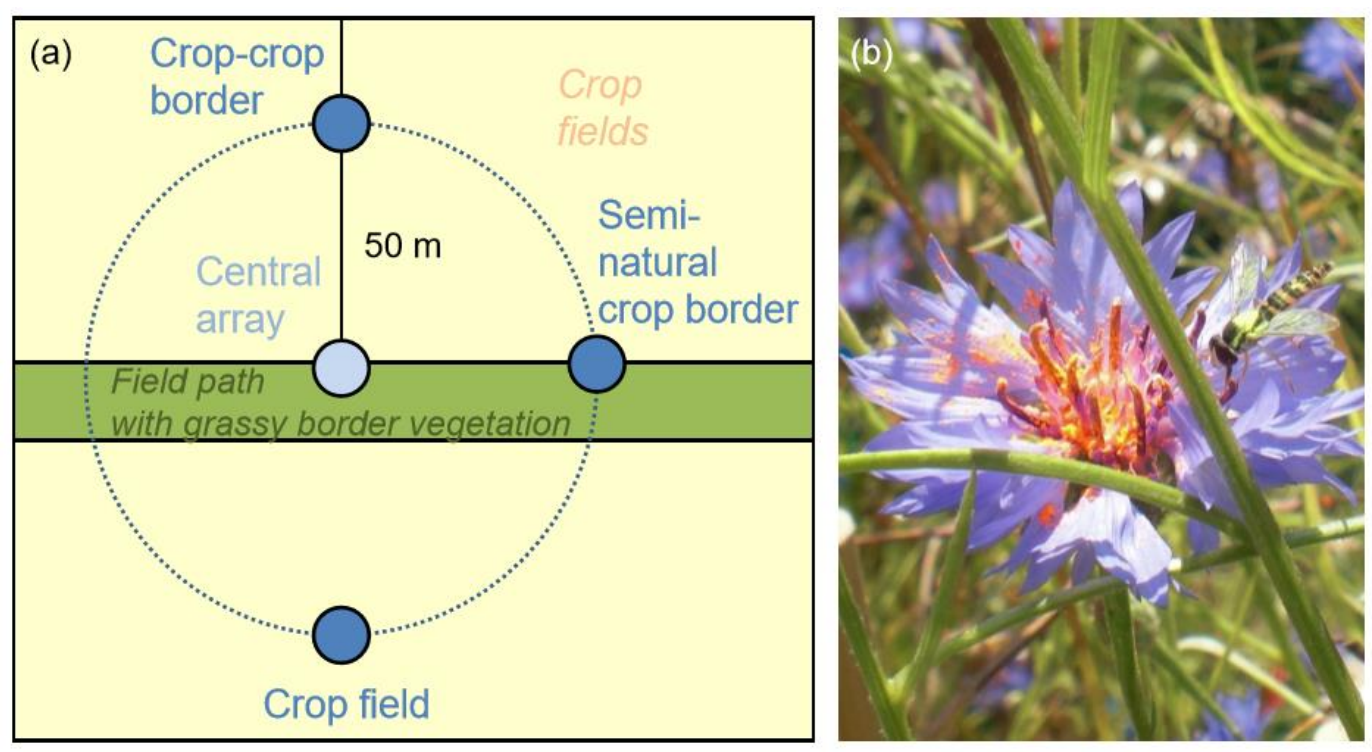

\section{$\bigcirc$ Pollen donor array of cornflowers

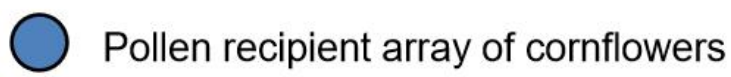

Figure 1 Experimental design of the pollen transfer experiment (a). At each site three arrays with ten pots of "recipient" cornflowers were placed at different agricultural border types (crop-crop border or semi-natural crop border) or in a field (crop field). A pollen donor array (with 10 pots of cornflowers) was placed in the centre, at $50 \mathrm{~m}$ from the three recipient arrays and was treated with fluorescent dye (b). After 24 hours of field exposure 20 flowers from each recipient array were examined for transferred dye. Photo: B. Jünemann

\section{Data analysis}

(i) Pollinator survey and pollination experiment

To examine the effects of field border density (configurational heterogeneity) and crop diversity (compositional heterogeneity) on pollinator abundance, richness and radish seed set, while controlling for the amount of semi-natural cover, we used structural equation models (SEMs). SEMs allowed us to model indirect effects (e.g. of field border density via pollinator abundance on seed set). In particular, we used piecewise SEMs, which allow for a wide range of response distributions in a hierarchical (mixed effects) framework (Lefcheck 2016). First we constructed hypothetical models. Then we used the package "piecewiseSEM" to assess the goodness-of-fit based on Shipley's test of directed 
separation that combines the P-values of all independence claims in Fisher's C (Shipley 2009). To reduce model complexity, we constructed two different hypothetical models comprising either abundance or species richness variables. The first model included effects of local and landscape variables (Table 1) on abundance (honey bee, wild bee and hoverfly abundance) and seed set (number of seeds per pod) pooled across transects and surveys, see Supporting Information, 1.6 for details on model specification and Fig. S5a). As we expected correlations between honey bee, wild bee and hoverfly abundances we added correlated errors between those variables. Additionally, we included effects of latitude and longitude on bees, hoverflies and seed set, as the geographic position might have a major impact. In the second model (species richness, Fig. S5b) we included wild bee and hoverfly species richness per field instead of abundance. Here we excluded honey bees as well as the data from the UK, because bee species richness was not available for that country.

All abundance and species richness measures were log transformed and flower cover was logit transformed to achieve a normal distribution of residuals and better model fit. The variables were then standardized to obtain comparable coefficients. We excluded four extreme outliers from the abundance data set and two additional ones from the species richness dataset (Supporting Information, Fig. S6) as these would have strongly affected the results (Zuur et al. 2010). Each pathway in the SEM represents a single model for which we used linear mixed effect models from the package "nlme" (Pinheiro et al. 2014) with landscape nested in region as a random effect. We also tested whether random intercept or random intercept and slope models were more appropriate (Supporting Information, 1.6). For the hoverfly abundance model we included crop diversity as random slope, but for all other models we used only random intercept models.

The inclusion of latitude and longitude in the models mainly accounts for the geographic position of regions, but not for the position of landscapes within each region as distances between sites within one region are minimal compared to distances between regions. Therefore, we repeated all analyses with centralised data by standardising all variables within each region. This resulted in comparable scales of all variables across regions.

All SEMs were manually simplified by removing step-wise pathways with the highest P-value until the best model was found based on the AIC. The residuals of all models were checked for homoscedasticity and normality and we used variance inflation factors (VIF) in the "car" package (Fox \& Weisberg 2011) to check for collinearity. All VIFs were <2 (Zuur et al. 2010). The final models were also checked for spatial autocorrelation of the residuals by using the "ncf" package (Bjornstad 2016). We plotted spline correlograms and did not detect spatial autocorrelation at any distance between our sampling sites. 
(ii) Pollen transfer experiment

To compare the pollen transfer among treatments, we examined the probability that pollen had been deposited on a flower of the receiver arrays. We first created a two-column object for the response containing the counts of flowers with fluorescent pollen and without fluorescent pollen per treatment. Second, we fitted a generalized linear-mixed model with binomial errors using the two-column object as the response (Zuur et al. 2009). This full model contained treatment (crop-crop border, seminatural crop border or crop field) and crop border type (oilseed rape or spring crop next to cereal) as explanatory variables, and site as random effect. Third, we assessed the significance of pairwise treatment differences using Tukey's contrasts (function "glht", package "multcomp", (Hothorn et al. 2008)). The reported P-values were adjusted for multiple testing using the single-step method. No overdispersion was detected (dispersion parameter $=0.8$, function "dispersion_glmer" package "blmeco", (Korner-Nievergelt et al. 2015)). Homoscedasticity and residual normality were visually checked and no problem was detected. As there was one flower array with very high amounts of fluorescent dye transferred along the crop-crop border, we repeated the analysis by removing all three treatments from the site containing this outlier. As the results were comparable we used the full data set for interpretation.

\section{Results}

\section{Pollinator survey and pollination experiment}

Overall, we caught 8,541 wild bees, 1,672 honey bees and 10,715 hoverflies. Most wild bee individuals (excluding UK data and border transects from France) could be identified to species (85\%), representing 179 species (Supporting Information, Table S3). However, 2\% of all bees could only be identified to morphospecies and $13 \%$ were only identified to genus. Almost all hoverfly individuals (99.9 \%) were identified to species, representing 64 species in total (Supporting Information, Table S4). We collected 7,759 pods containing 25,676 seeds from the pollination experiment with radish. The SEM including pollinator abundance fit the data well (best simplified model: $C_{10}=4.31, P=0.933$, Fig. 2a), and none of the independence claims remained significant indicating that no important links were missing in the model. Results of the best-fitting SEMs are in the Supporting Information, Table S5. The best abundance model revealed that increasing field border density (configurationalheterogeneity) had a strong positive effect on wild bee abundance (Fig. 2a \& 3a), but no effect on hoverfly abundance. Conversely, higher crop diversity (compositional heterogeneity) decreased wild bee abundance (Fig. 3b). Local flower cover had a weakly negative effect on wild bee and hoverflyabundance, but a positive effect on seed set. Semi-natural cover had a weakly positive effect on hoverfly abundance and a strong positive direct effect on seed set. Seed set was also 
positively affected by wild bee abundance (Fig. 3c). However, neither honey bee, nor hoverfly abundance influenced seed set. Latitude impacted hoverfly abundance negatively and seed set positively, whereas longitude had a negative effect on seed set.

Replacing abundance by species richness in the SEMs (best simplified model: $\mathrm{C} 14=8.79, \mathrm{P}=$ 0.844, Fig. 2 b) resulted in a weakly negative effect of local flower cover on bee richness. Landscape variables had no significant influence on pollinator species richness, but seed set was again enhanced by semi-natural cover in the landscape.

Results of SEMs based on centralised data were similar to those of the first set of analyses (Supporting Information, Table S5, Fig. S7). However, the effect of field border density was only marginally significant $(P=0.061)$, but similar to the effect size of crop diversity that remained significant $(P=0.025$, Table S5). Additionally, we found a weakly negative effect of crop diversity on hoverfly species richness.

\section{Pollen transfer experiment}

Transfer of a pollen analogue from donor to recipient cornflower arrays was about four times higher along crop-crop borders than across crop fields (Fig. 4, Supporting Information, Table S6, $P=0.002$ ) or along semi-natural crop borders $(P=0.004)$. However, crop fields and semi-natural crop borders showed comparable rates of transfer of the pollen analogue from the donor to the recipient array $(P=$ 0.955). Results did not change when we excluded the site containing the outlier, but then the difference in transfer of the pollen analogue between crop-crop borders and semi-natural crop borders was only marginally significant. Significantly more pollen analogue was transmitted along borders between oilseed rape and cereal than along borders between spring crops and cereal (Supporting Information, Table S6). 
(a)

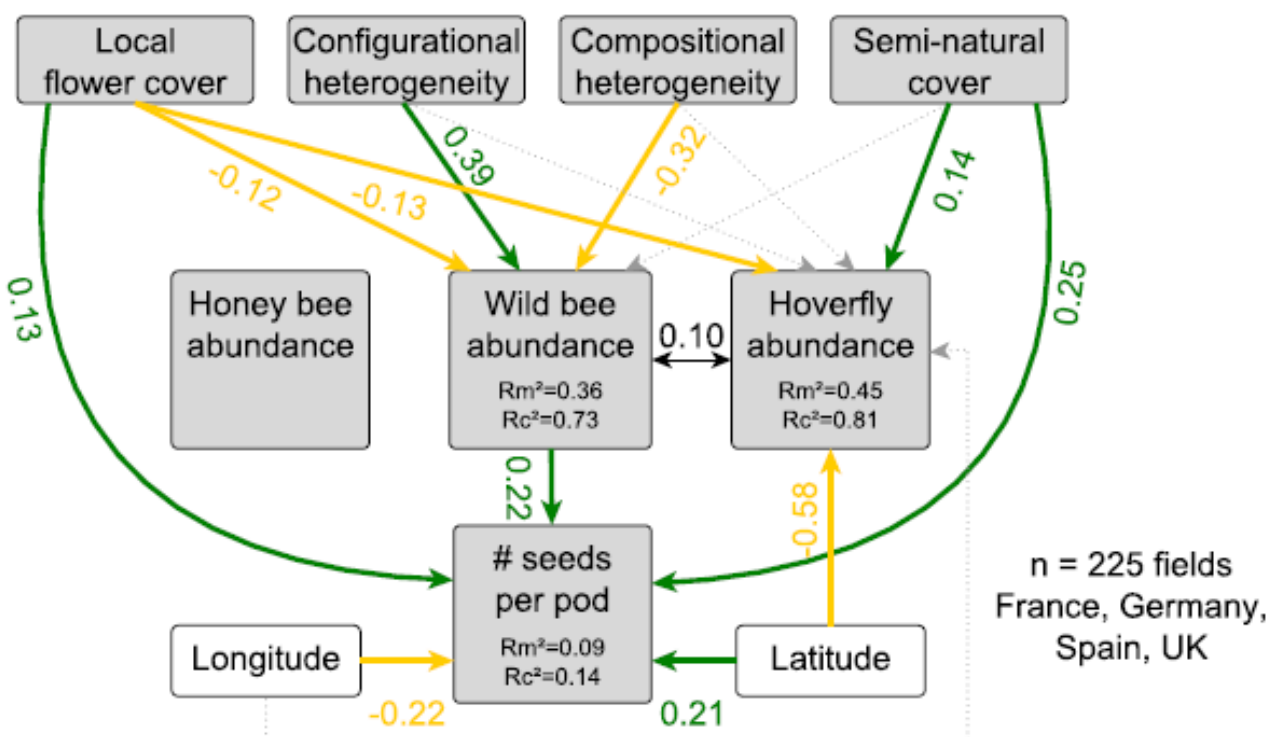

(b)

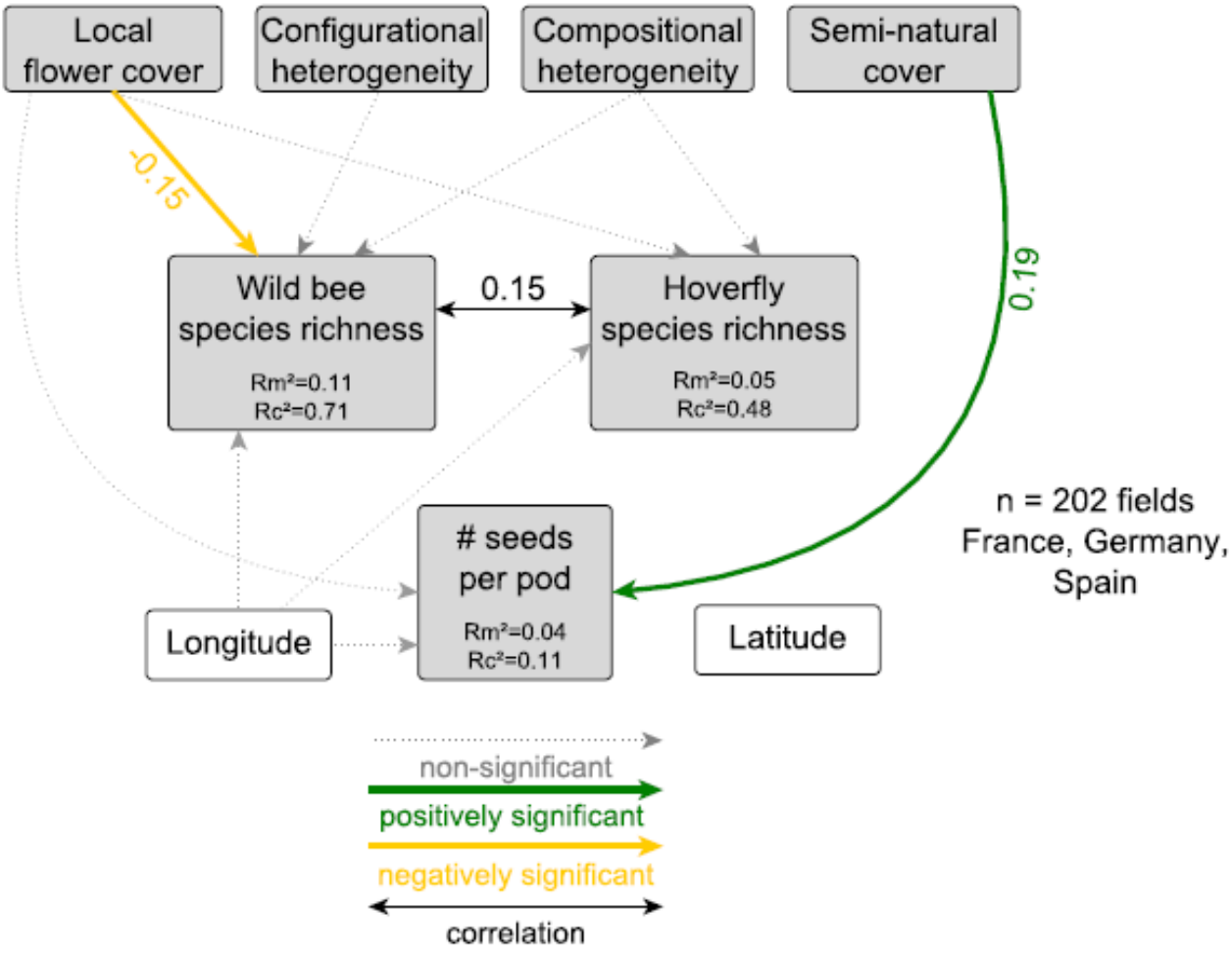

Figure 2 Results of the best piecewise structural equation models (SEMs), based on AIC values analysing the relationship between local flower cover $(3 \mathrm{~m}$ around pan traps), farmland configurational heterogeneity (field border density), farmland compositional heterogeneity (crop diversity), semi-natural habitat cover, and (a) bee and hoverfly abundances and (b) species richness and the effects on seed set of potted radish across four countries. Numbers next to arrows show standardized regression coefficients. Latitude and longitude were added as co-variates. Conditional $\left(R c^{2}\right.$, includes random effects) and marginal ( $\mathrm{Rm}^{2}$, excludes random effects) $\mathrm{R}^{2}$ values are presented for response variables. 


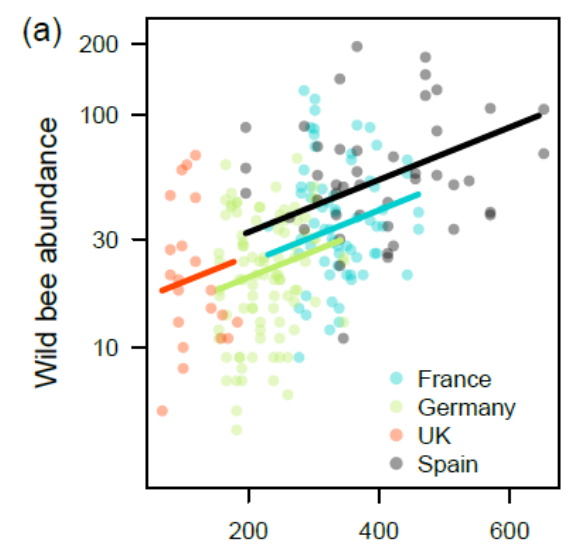

Field border density $(\mathrm{m} / \mathrm{ha})$
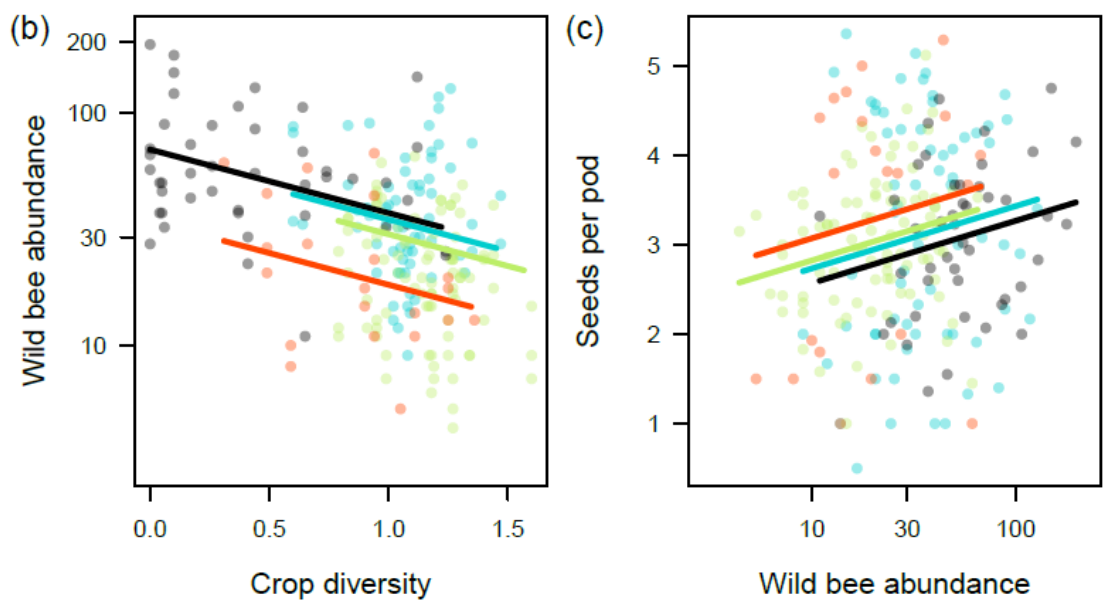

Wild bee abundance

Figure 3 Effects of (a) field border density (configurational heterogeneity) on wild bee abundance $(P<$ 0.001), (b) crop diversity (compositional heterogeneity) on wild bee abundance $(P<0.001$ ), and (c) wild bee abundance on seed set (mean number of seeds per pod for each field, $P=0.008$ ) sampled in crop fields of four countries. Lines show predictions from mixed models using random intercepts for countries. Abundances are shown on a $\log 10$ scale. The same relationships were examined in the SEMs (Figure 2).

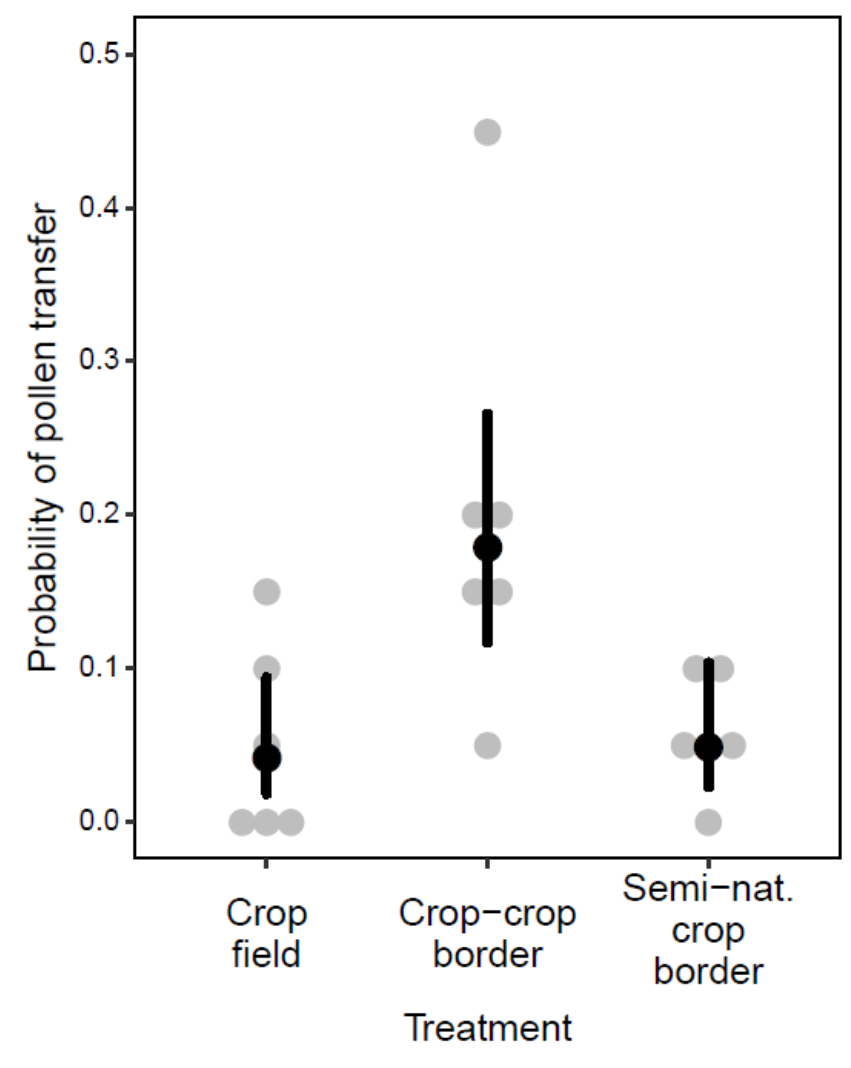

Figure 4 Probability that artificial pollen (fluorescent dye) was transferred from a central donor to flowers of a recipient array $50 \mathrm{~m}$ away, along three treatments (crop field, crop-crop border and semi-natural crop borders). Transfer of experimental pollen (fluorescent dye) was significantly higher along crop-crop borders than through crop fields $(P=0.002)$ or along semi-natural crop borders $(P=0.004)$. Treatments were placed in a blocked design ( 6 central donors with 3 treatments each). For each recipient array, 20 flowers were inspected for fluorescent dye deposition ( $n=360$ flowers in total). Shown are model estimates from generalized mixed models $\pm 95 \% \mathrm{Cl}$ (black dots and bars). 


\section{Discussion}

This study provides three novel key results: First, we found that landscapes with higher field border density had higher wild bee abundance, which translated into increased seed set across four agricultural regions. This suggests a positive, cascading effect of farmland configurational heterogeneity on plant reproductive success. Second, this effect was paralleled by improved transfer of a pollen analogue along crop-crop borders, suggesting that crop-crop borders increase connectivity by facilitating pollinator movement across agricultural landscapes. Third, and surprisingly, increased crop diversity had a consistently negative impact on bee abundance across regions.

\section{Configurational heterogeneity promotes wild bee abundance and pollination services}

Our study demonstrates that increased field border density at a landscape scale promotes pollination of plants growing in field borders by enhancing the abundance of wild bees. Higher field border density means an increase of border length between directly adjacent crops (crop-crop borders) and borders of fields with semi-natural vegetation (semi-natural crop borders). Semi-natural crop borders are important habitats for pollinators offering nesting sites and food resources (Kells et al. 2001; Van Geert et al. 2010), but the role of crop-crop borders is rarely considered independently of the area of semi-natural crop borders. However, they provide potentially more flowering weeds compared to the field interior due to less intensive management and can be moved much more easily than semi-natural crop borders which are usually permanent habitats. As semi-natural cover had no effect on pollinators in our study, the results indicate a role of different kinds of crop borders independent of the habitat contributed by semi-natural crop borders, probably by promoting pollinator dispersal. The pollen transfer experiment provides novel evidence for improved transmission rates of artificial pollen along crop-crop borders relative to continuous crop fields, demonstrating that crop-crop borders themselves can guide pollinator movement and may be important for pollinator dispersal. Enhanced connectivity through higher field border density probably leads to higher reproductive success of plant species growing in the field border vegetation. Whether pollinator dependent crops growing inside the field can also benefit from high configurational heterogeneity remains unclear and should be tested in future studies. However, the low amounts of dye transmitted along semi-natural crop borders were unexpected. This may be due to a dilution effect (Lentini et al. 2012) as pollinators that visited the donor patch could have been attracted to other abundant flowering plants in the seminatural crop border vegetation, thus hindering dye transmission to our recipient arrays. Additionally, animal movement is usually more tortuous and therefore slower within habitats than between habitats (Fahrig 2007). 
An alternative explanation for the consistent positive effect of landscape scale field border density on wild bee abundance and pollination services is that landscapes with higher configurational heterogeneity have enhanced juxtaposition and interspersion of different crop and non-crop cover types and thereby increase resource accessibility to pollinators (Fahrig et al. 2011). However, this hypothesis is not supported by the results for compositional heterogeneity (see below).

The strong importance of farmland configurational heterogeneity for wild bee abundance stands in marked contrast to the weak effect of the configuration of semi-natural cover on pollinators found in previous studies (Holzschuh et al. 2010; Kennedy et al. 2013; Steckel et al. 2014). The reason for this difference could be that these studies were not designed to create a gradient in configurational heterogeneity, which was only analysed post hoc. Their results therefore might reflect a correlation between configurational heterogeneity and some other variable that counteracts its effect; based on our results one such confounding variable might be farmland compositional heterogeneity (see below).

Results based on the centralised data set show only a marginally significant effect of field border densities. This indicates that the effects within each region are weaker as if we expand the gradient by studying multiple regions. We caution also that, despite the large spatial extent of our study, the results are based on data from only one sampling year. Therefore, more research is needed to confirm that the findings are temporally replicable. Additionally, we did not directly observe pollinator visitation, but measured pollinator abundance indirectly with pan traps which might have caused some bias (Westphal et al. 2008).

\section{Compositional heterogeneity has negative effects on pollinators}

A surprising outcome of this study was that, contrary to our expectations, greater crop diversity resulted in decreased bee abundance. One possible explanation would be an unimodal relationship between pollinators and crop diversity and that our landscapes are at the higher range of compositional heterogeneity where we expect a negative trend due to deceasing habitat cover (Allouche et al. 2012). However, this explanation is unlikely, because our gradient starts at zero (only one crop per landscape, Table 1).

An alternative explanation for the negative effect is that crop identity played a major role. We assume that the cover of crops with particularly intensive management increased with crop diversity. For example, crop diversity was associated with high maize cover (Supporting Information, Table S7), which is marked by reduced plant diversity due to higher fertilizer and herbicide inputs compared to cereal crops (Kleijn \& Verbeek 2000; Fagúndez et al. 2016). The low plant diversity of maize fields could explain the apparent negative effect of crop diversity on bee abundance, although maize was widespread only in France and Germany. Indeed, an additional analysis supported the negative impact 
of maize cover on bee abundance in these two countries (Supporting Information, Fig. S8). The explanation that high crop diversity was associated with a high proportion of mass-flowering crops distracting pollinators from our traps (Holzschuh et al. 2016) is unlikely, as most experiments were conducted after oilseed rape bloom. However, the reason for the negative effect of crop diversity on bees in all countries cannot be identified conclusively based on our data set, because the study was not designed to test for impacts of certain crop types which differed between countries (Supporting Information, Table S1) and there were multiple correlations among them. To disentangle the effects of farmland compositional heterogeneity from specific crop types studies designed to answer this question are needed.

Apart from a weak decrease of hoverfly species richness with crop diversity in the model based on centralised data which might also be due to increased cover of crops with unfavourable management, hoverflies were not affected by any landscape variables in our analysis. The reason might be that cereals were the main crop in all our regions (Table S1 \& S7). Cereals support high densities of aphids (Thies et al. 2005). Therefore, food availability might have been high in all landscapes for the dominant, aphid-feeding hoverfly species in our study (Eupeodes corollae, Episyrphus balteatus and Sphaerophoria scripta), which accounted for $89 \%$ of all hoverfly individuals captured.

\section{Semi-natural cover has no effect on pollinators}

The area of semi-natural cover including non-forest cover types (e.g. semi-natural grasslands) and linear crop borders (grassy, woody and bare ground) had only a weakly negative effect on hoverfly abundance, but no significant effect on bee abundance or species richness. The generally low amount and variability of non-forest semi-natural cover across regions due to our study design (mean \pm SE of $5.08 \pm 0.14 \%$ ) may not have provided sufficient variation in semi-natural cover among landscapes to detect this effect. Studies showing significant effects of semi-natural cover usually encompass larger gradients, at least between 1 and 30 \% (Klein et al. 2012; Hopfenmüller et al. 2014). However, we found a direct positive influence of semi-natural cover on seed set of radish, which was not mediated by any pollinator group. It is possible that other insects than bees and hoverflies contributed to radish pollination (e.g. other Diptera have been reported to visit radish (Albrecht et al. 2007)), albeit this explanation is unlikely as these insects usually depend less on semi-natural cover (Rader et al. 2015). Alternatively, biological control of pest species attacking radish may play an important role in enhancing radish seed set. For example flower damage by pollen beetles and their larvae (Meligethes aeneus) can substantially reduce seed production in Brassicaceae (Schlinkert et al. 2015). Pollen beetles are attacked by a number of parasitoid species that positively respond to semi-natural cover (Thies \& Tscharntke 1999) suggesting that higher parasitism rates could be responsible for enhanced 
seed set in landscapes with high proportions of semi-natural cover. These parasitoids depend on nectar resources which could also explain the positive effect of flower cover on seed set.

\section{Conclusion}

Our study demonstrates that the heterogeneity of the crop production area is an important, hitherto little investigated factor for pollinator communities in agricultural landscapes. Based on our finding of enhanced wild bee abundance and plant reproductive success in landscapes with high configurational heterogeneity, we recommend promoting field borders and reversing the current trend of increasing field sizes. We demonstrate that even crop-crop borders without semi-natural vegetation enhance pollinator movement and thereby landscape connectivity. However, our results indicate that major increases of field border densities may be necessary to promote wild bee abundances within a region. Additionally, we show that policies aimed to increase crop diversity are not always positive for pollinators and may even have negative effects if the increase in crop diversity is driven by crop types under intense management such as maize. Therefore, it is essential to consider crop identity and farming practises in these policies. We conclude that enhancing configurational heterogeneity combined with the reduction of crop areas with particularly intensive management could be a promising tool for supporting pollinators and pollination services in future agricultural landscapes.

\section{Author's Contributions}

ALH, UK, TT, PB, YC, as well as CS, LF, JLM, JB, LB, FB, GS developed the conceptual foundations for this manuscript. $A L H, U K, A B B, C B, R G, D G$ and GS performed the field surveys and $A L H, J B, M A M G$, and $A R$ identified species. CS compiled data and ALH and UK performed the analyses with the support of PB. ALH wrote the first draft of the manuscript. All authors contributed substantially to revisions.

\section{Acknowledgements}

This research was funded by the ERA-Net BiodivERsA, with the national funders French National Research Agency (ANR-11-EBID-0004), German Ministry of Research and Education (FKZ: 01LC1104A) and Spanish Ministry of Economy and Competitiveness, part of the 2011 BiodivERsA call for research proposals. The contribution from the UK was funded by the UK Government Department of the Environment, Food and Rural Affairs (Defra), as project WC1034.

We would like to thank Maike Sommer, who performed the greatest part of the field work for the pollen transfer experiment. Additionally, we are grateful to Rita Földesi and Xavier Lair for hoverfly identification and Frank Creuzburg and David Norfolk for help with bee identification. We thank all the participating farmers for giving access to their fields, the many persons, who helped with field work, 
GIS analysis and species identification and Cyrille Violle for valuable comments on an earlier version of the manuscript

\section{References}

Albrecht, M., Duelli, P., Müller, C., Kleijn, D. \& Schmid, B. (2007). The Swiss agri-environment scheme enhances pollinator diversity and plant reproductive success in nearby intensively managed farmland. J. Appl. Ecol., 44, 813-822.

Albrecht, M., Schmid, B., Hautier, Y. \& Mueller, C.B. (2012). Diverse pollinator communities enhance plant reproductive success. Proc. R. Soc. B-Biol. Sci., 279, 4845-4852.

Alexantratos, N. \& Bruinsma, J. (2012). World Agriculture towards 2030/2050: the 2012 revision. ESA Working paper No. 12 -03. FAO, Rome.

Allouche, O., Kalyuzhny, M., Moreno-Rueda, G., Pizarro, M. \& Kadmon, R. (2012). Area-heterogeneity tradeoff and the diversity of ecological communities. Proc. Natl. Acad. Sci., 109, 17495-17500.

Batáry, P., Gallé, R., Riesch, F., Fischer, C., Dormann, C.F., Mußhoff, O., et al. (2017). The former Iron Curtain still drives biodiversity-profit trade-offs in German agriculture. Nat. Ecol. Evol., 1, 1279-1284

Biesmeijer, J.C., Roberts, S.P.M., Reemer, M., Ohlemüller, R., Edwards, M., Peeters, T., et al. (2006). Parallel declines in pollinators and insect-pollinated plants in Britain and the Netherlands. Science, 313, 351-354.

Bjornstad, O.N. (2016). ncf: Spatial nonparametric covariance functions, R package version 1.1-7.

Blitzer, E.J., Dormann, C.F., Holzschuh, A., Klein, A.-M., Rand, T.A. \& Tscharntke, T. (2012). Spillover of functionally important organisms between managed and natural habitats. Agric. Ecosyst. Environ., 146, 34-43.

Bommarco, R., Marini, L. \& Vaissiere, B.E. (2012). Insect pollination enhances seed yield, quality, and market value in oilseed rape. Oecologia, 169, 1025-1032.

Carreck, N.L. \& Williams, I.H. (2002). Food for insect pollinators on farmland: insect visits to flowers of annual seed mixtures. J. Insect Conserv., 6, 13-23.

Cole, L.J., Brocklehurst, S., Robertson, D., Harrison, W. \& McCracken, D.I. (2017). Exploring the interactions between resource availability and the utilisation of semi-natural habitats by insect pollinators in an intensive agricultural landscape. Agric. Ecosyst. Environ., 246, 157-167.

Cranmer, L., McCollin, D. \& Ollerton, J. (2012). Landscape structure influences pollinator movements and directly affects plant reproductive success. Oikos, 121, 562-568.

Dainese, M., Montecchiari, S., Sitzia, T., Sigura, M. \& Marini, L. (2017). High cover of hedgerows in the landscape supports multiple ecosystem services in Mediterranean cereal fields. J. Appl. Ecol., 54, 380-388.

Diekötter, T., Peter, F., Jauker, B., Wolters, V. \& Jauker, F. (2014). Mass-flowering crops increase richness of cavity-nesting bees and wasps in modern agro-ecosystems. GCB Bioenergy, 6, 219226.

Fagúndez, J., Olea, P.P., Tejedo, P., Mateo-Tomás, P. \& Gómez, D. (2016). Irrigation and maize cultivation erode plant diversity within crops in Mediterranean dry cereal agro-ecosystems. Environ. Manage., 58, 164-174.

Fahrig, L. (2007). Non-optimal animal movement in human-altered landscapes. Funct. Ecol., 21, 10031015.

Fahrig, L., Baudry, J., Brotons, L., Burel, F.G., Crist, T.O., Fuller, R.J., et al. (2011). Functional landscape heterogeneity and animal biodiversity in agricultural landscapes. Ecol. Lett., 14, 101-112.

Fahrig, L., Girard, J., Duro, D., Pasher, J., Smith, A., Javorek, S., et al. (2015). Farmlands with smaller crop fields have higher within-field biodiversity. Agric. Ecosyst. Environ., 200, 219-234.

Fox, J. \& Weisberg, H.S. (2011). An R Companion to Applied Regression. 2nd edn. Sage Pubn, Thousand Oaks, USA. 
Garibaldi, L.A., Steffan-Dewenter, I., Kremen, C., Morales, J.M., Bommarco, R., Cunningham, S.A., et al. (2011). Stability of pollination services decreases with isolation from natural areas despite honey bee visits. Ecol. Lett., 14, 1062-1072.

Godfray, H.C.J., Beddington, J.R., Crute, I.R., Haddad, L., Lawrence, D., Muir, J.F., et al. (2010). Food security: The challenge of feeding 9 billion people. Science, 327, 812-818.

Guiller, C., Affre, L., Albert, C.H., Tatoni, T. \& Dumas, E. (2016). How do field margins contribute to the functional connectivity of insect-pollinated plants? Landsc. Ecol., 31, 1747-1761.

Hadley, A.S. \& Betts, M.G. (2012). The effects of landscape fragmentation on pollination dynamics: absence of evidence not evidence of absence. Biol. Rev., 87, 526-544.

Hodge, I., Hauck, J. \& Bonn, A. (2015). The alignment of agricultural and nature conservation policies in the European Union. Conserv. Biol., 29, 996-1005.

Holzschuh, A., Dainese, M., González-Varo, J.P., Mudri-Stojnić, S., Riedinger, V., Rundlöf, M., et al. (2016). Mass-flowering crops dilute pollinator abundance in agricultural landscapes across Europe. Ecol. Lett., 19, 1228-1236.

Holzschuh, A., Dudenhoeffer, J.-H. \& Tscharntke, T. (2012). Landscapes with wild bee habitats enhance pollination, fruit set and yield of sweet cherry. Biol. Conserv., 153, 101-107.

Holzschuh, A., Steffan-Dewenter, I. \& Tscharntke, T. (2010). How do landscape composition and configuration, organic farming and fallow strips affect the diversity of bees, wasps and their parasitoids? J. Anim. Ecol., 79, 491-500.

Hopfenmüller, S., Steffan-Dewenter, I. \& Holzschuh, A. (2014). Trait-specific responses of wild bee communities to landscape composition, configuration and local factors. PLOS ONE, 9, e104439.

Hothorn, T., Bretz, F. \& Westfall, P. (2008). Simultaneous inference in general parametric models. Biom. J., 50, 346-363.

Hyvönen, T. \& Salonen, J. (2002). Weed species diversity and community composition in cropping practices at two intensity levels - a six-year experiment. Plant Ecol., 159, 73-81.

IPBES. (2016). The assessment report of the intergovernmental science - policy platform on biodiversity and ecosystem services on pollinators, pollination and food production. Secretariat of the Intergovernmental Science-Policy Platform on Biodiversity and Ecosystem Services, Bonn, Germany.

Kells, A.R., Holland, J.M. \& Goulson, D. (2001). The value of uncropped field margins for foraging bumblebees. J. Insect Conserv., 5, 283-291.

Kennedy, C.M., Lonsdorf, E., Neel, M.C., Williams, N.M., Ricketts, T.H., Winfree, R., et al. (2013). A global quantitative synthesis of local and landscape effects on wild bee pollinators in agroecosystems. Ecol. Lett., 16, 584-599.

Kleijn, D. \& Verbeek, M. (2000). Factors affecting the species composition of arable field boundary vegetation. J. Appl. Ecol., 37, 256-266.

Kleijn, D., Winfree, R., Bartomeus, I., Carvalheiro, L.G., Henry, M., Isaacs, R., et al. (2015). Delivery of crop pollination services is an insufficient argument for wild pollinator conservation. Nat. Commun., 6, 7414.

Klein, A.-M., Brittain, C., Hendrix, S.D., Thorp, R., Williams, N. \& Kremen, C. (2012). Wild pollination services to California almond rely on semi-natural habitat. J. Appl. Ecol., 49, 723-732.

Klein, A.-M., Steffan-Dewenter, I. \& Tscharntke, T. (2003). Fruit set of highland coffee increases with the diversity of pollinating bees. Proc. R. Soc. B Biol. Sci., 270, 955-961.

Kormann, U., Scherber, C., Tscharntke, T., Klein, N., Larbig, M., Valente, J.J., et al. (2016). Corridors restore animal-mediated pollination in fragmented tropical forest landscapes. Proc. R. Soc. B Biol. Sci., 283, 20152347.

Korner-Nievergelt, F., Felten, S. von, Roth, T., Almasi, B. \& Korner-Nievergelt, P. (2015). Bayesian Data Analysis in Ecology Using Linear Models with R, BUGS, and STAN: Including Comparisons to Frequentist Statistics. Elsevier, Oxford. 
Kovács-Hostyánszki, A., Espíndola, A., Vanbergen, A.J., Settele, J., Kremen, C. \& Dicks, L.V. (2017). Ecological intensification to mitigate impacts of conventional intensive land use on pollinators and pollination. Ecol. Lett., 20, 673-689.

Lefcheck, J.S. (2016). piecewiseSEM: Piecewise structural equation modelling in $r$ for ecology, evolution, and systematics. Methods Ecol. Evol., 7, 573-579.

Lentini, P.E., Martin, T.G., Gibbons, P., Fischer, J. \& Cunningham, S.A. (2012). Supporting wild pollinators in a temperate agricultural landscape: Maintaining mosaics of natural features and production. Biol. Conserv., 149, 84-92.

Mandelik, Y., Winfree, R., Neeson, T. \& Kremen, C. (2012). Complementary habitat use by wild bees in agro-natural landscapes. Ecol. Appl., 22, 1535-1546.

Marshall, E.J.P. (2002). Introducing field margin ecology in Europe. Agric. Ecosyst. Environ., 89, 1-4.

Pinheiro, J., Bates, D., DebRoy, S., Sarkar, D. \& R Development Core Team. (2014). NIme: Linear and nonlinear mixed effects models. $R$ package version 3.1-117.

Potts, S.G., Biesmeijer, J.C., Kremen, C., Neumann, P., Schweiger, O. \& Kunin, W.E. (2010). Global pollinator declines: trends, impacts and drivers. Trends Ecol. Evol., 25, 345-353.

Rader, R., Bartomeus, I., Garibaldi, L.A., Garratt, M.P.D., Howlett, B.G., Winfree, R., et al. (2015). Nonbee insects are important contributors to global crop pollination. Proc. Natl. Acad. Sci., 201517092.

Robinson, R.A. \& Sutherland, W.J. (2002). Post-war changes in arable farming and biodiversity in Great Britain. J. Appl. Ecol., 39, 157-176.

Schlinkert, H., Westphal, C., Clough, Y., Ludwig, M., Kabouw, P. \& Tscharntke, T. (2015). Feeding damage to plants increases with plant size across 21 Brassicaceae species. Oecologia, 179, 455-466.

Shipley, B. (2009). Confirmatory path analysis in a generalized multilevel context. Ecology, 90, 363368.

Stanley, D.A. \& Stout, J.C. (2013). Quantifying the impacts of bioenergy crops on pollinating insect abundance and diversity: a field-scale evaluation reveals taxon-specific responses. J. Appl. Ecol., 50, 335-344.

Steckel, J., Westphal, C., Peters, M.K., Bellach, M., Rothenwoehrer, C., Erasmi, S., et al. (2014). Landscape composition and configuration differently affect trap-nesting bees, wasps and their antagonists. Biol. Conserv., 172, 56-64.

Thies, C., Roschewitz, I. \& Tscharntke, T. (2005). The landscape context of cereal aphid-parasitoid interactions. Proc. R. Soc. Lond. B Biol. Sci., 272, 203-210.

Thies, C. \& Tscharntke, T. (1999). Landscape structure and biological control in agroecosystems. Science, 285, 893-895.

Van Geert, A., Van Rossum, F. \& Triest, L. (2010). Do linear landscape elements in farmland act as biological corridors for pollen dispersal? J. Ecol., 98, 178-187.

Van Rossum, F., Stiers, I., Van Geert, A., Triest, L. \& Hardy, O.J. (2011). Fluorescent dye particles as pollen analogues for measuring pollen dispersal in an insect-pollinated forest herb. Oecologia, 165, 663-674.

Westphal, C., Bommarco, R., Carre, G., Lamborn, E., Morison, N., Petanidou, T., et al. (2008). Measuring bee diversity in different European habitats and biogeographical regions. Ecol. Monogr., 78, 653-671.

Zuur, A.F., leno, E.N. \& Elphick, C.S. (2010). A protocol for data exploration to avoid common statistical problems. Methods Ecol. Evol., 1, 3-14.

Zuur, A.F., leno, E.N., Walker, N., Saveliev, A.A. \& Smith, G.M. (2009). Mixed effects models and extensions in ecology with $R$. Springer, New York. 


\section{Supporting Information}

\section{Contents}

1 Supplementary methods

1.1 Landscape selection procedure

1.2 Calculation of semi-natural cover

1.3 Focal field selection

1.4 Pollinator sampling

1.5 Pollination experiment

1.6 Data analysis of pollinator survey and pollination experiment

2 Supplementary figures

3 Supplementary tables 


\section{Supplementary methods}

\subsection{Landscape selection procedure}

As farmland configurational and compositional heterogeneity are usually highly correlated we used a combination of GIS data available in each region and ground truthing for the landscape selection process. For example, in Germany we used GIS crop field shape data available for the region around Göttingen to select 92 landscapes with a high proportion of agricultural land (75-95\%) and a high variability in configurational heterogeneity (field border density). In these landscapes we mapped all crop types visible already in winter in the field (permanent crops like grassland, winter cereals and winter oilseed rape) and added the information to our GIS maps. Based on these data we selected 32 final landscapes with uncorrelated gradients of field size and preliminary (winter) crop diversity making sure that farmers gave permission for sampling in at least one oilseed rape and two winter wheat fields. All crop types were then mapped again during the field season to obtain the actual crop diversity including spring crops (i.e. maize and sugar beet) that was used for the final analyses.

\subsection{Calculation of semi-natural cover}

Semi-natural cover was the sum of the area of all patchy and linear semi-natural vegetation. The patchy semi-natural habitats included all non-forest ( $<50 \%$ tree cover) habitat types, e.g. semi-natural grasslands and flower strips. To estimate the area of linear semi-natural boundary vegetation we digitized the area of all boundaries in all landscapes. These included grassy, woody and bare ground boundaries as well as agricultural tracks with semi-natural boundary vegetation. To remove the area of the paved and unpaved tracks we measured for each region the width of at least 10 tracks and their corresponding boundary vegetation from different landscapes and estimated the percentage of tracks and boundary vegetation (e.g. 50 \% tracks and $50 \%$ boundary vegetation in Spain). Then we removed the percentage of tracks from all semi-natural boundaries that were classified as tracks in the corresponding region.

\subsection{Focal field selection}

In Germany focal fields were two cereal fields and one oilseed rape field in each landscape. In France, UK and Spain it was not possible to sample the same crop types in all landscapes. Therefore, we checked whether farmland configurational and compositional heterogeneity gradients differed across sampled crop types. This was the case in the UK and Spain (e.g. almond plantations occurred only in landscapes with high compositional heterogeneity) and therefore we decided to include only sampled cereal fields in these two countries resulting in 1 - 3 fields per landscape. In France sampled crop types 
did not differ along farmland heterogeneity gradients (Supporting Information, Fig. S3) and all sampled crop types were included in the analysis (cereal, grassland and maize).

\subsection{Pollinator sampling}

We established two transects (interior and edge), because we were interested in the entire species community which might differ between the field edge and interior. The edge transect was placed in the first crop row next to the semi-natural crop border vegetation and the interior transect at least 25 $\mathrm{m}$ within the field. In each transect we placed three poles with two $750 \mathrm{ml}$ pan traps each, mounted at the height of the vegetation.

Of the six traps per transect two were sprayed with UV-reflecting yellow paint, two with UV-reflecting blue paint and two were plain white traps. All were filled with water and odourless detergent. To account for season, the first survey was during oilseed rape bloom and the second survey afterwards.

\subsection{Pollination experiment}

To identify which pods were from flowers open during field exposure, we individually marked all freshly opened flowers prior to taking the pots to the field. After recovering plants from the field we marked all flowers that had opened during the four day period. Individual flowers bloom for approximately 1-2 days depending on the weather conditions. The plants were collected from field sites and covered with mesh nets to prevent further pollinator access.

\subsection{Data analysis of pollinator survey and pollination experiment}

We tested the effect of flower cover measured at the local scale ( $3 \mathrm{~m}$ around the traps) on honey bee, wild bee and hoverfly abundance as well as a direct effect of flower cover on seed set. At the landscape scale, we tested the effect of crop diversity, field border density, and the proportion of semi-natural cover on wild bee and hoverfly abundance per field (pooled across transects and surveys) and on seed set (mean number of seeds per pod for each field). As honey bee distribution depends strongly on the position of hives in the surrounding area we did not test the effect of landscape variables on honey bees. However, we included an effect of the abundance of all three pollinator groups on seed set of radish.

We also tested whether random intercept or random intercept and random slope models were more appropriate for the model including the two design variables compositional and configurational heterogeneity for bee and hoverfly species richness and abundance as response variables. We included the full set of explanatory variables for testing the best random structure. As models including random slope for crop diversity and field border density at the same time were too 
complicated and did not converge, we build separate models containing only one of these two variables as random slope (see examples for abundance in Model 1-4).

Model 1: Bee abundance $\sim$ Crop_diversity + Field_border_density + Flower_cover $+\operatorname{semi}+\mathrm{X}+\mathrm{Y}$, random $=\sim$ Crop_diversity|Region/Landscape

Model 2: Bee abundance $\sim$ Crop_diversity + Field_border_density + Flower_cover $+\operatorname{semi}+X+Y$, random $=\sim$ Field_border_density |Region/Landscape

Model 3: Hoverfly abundance Crop_diversity + Field_border_density + Flower_cover $+\operatorname{semi}+X+Y$, random $=\sim$ Crop_diversity $\mid$ Region/Landscape

Model 4: Hoverfly abundance Crop_diversity + Field_border_density + Flower_cover + semi $+X+Y$, random= Field_border_density |Region/Landscape

Afterwards we compared models with and without random slopes by using likelihood ratio tests. However, only for hoverfly abundance the inclusion of crop diversity as random slope improved model fit and was therefore included in the final model. For all other models we used only random intercepts. 


\section{Supplementary figures}
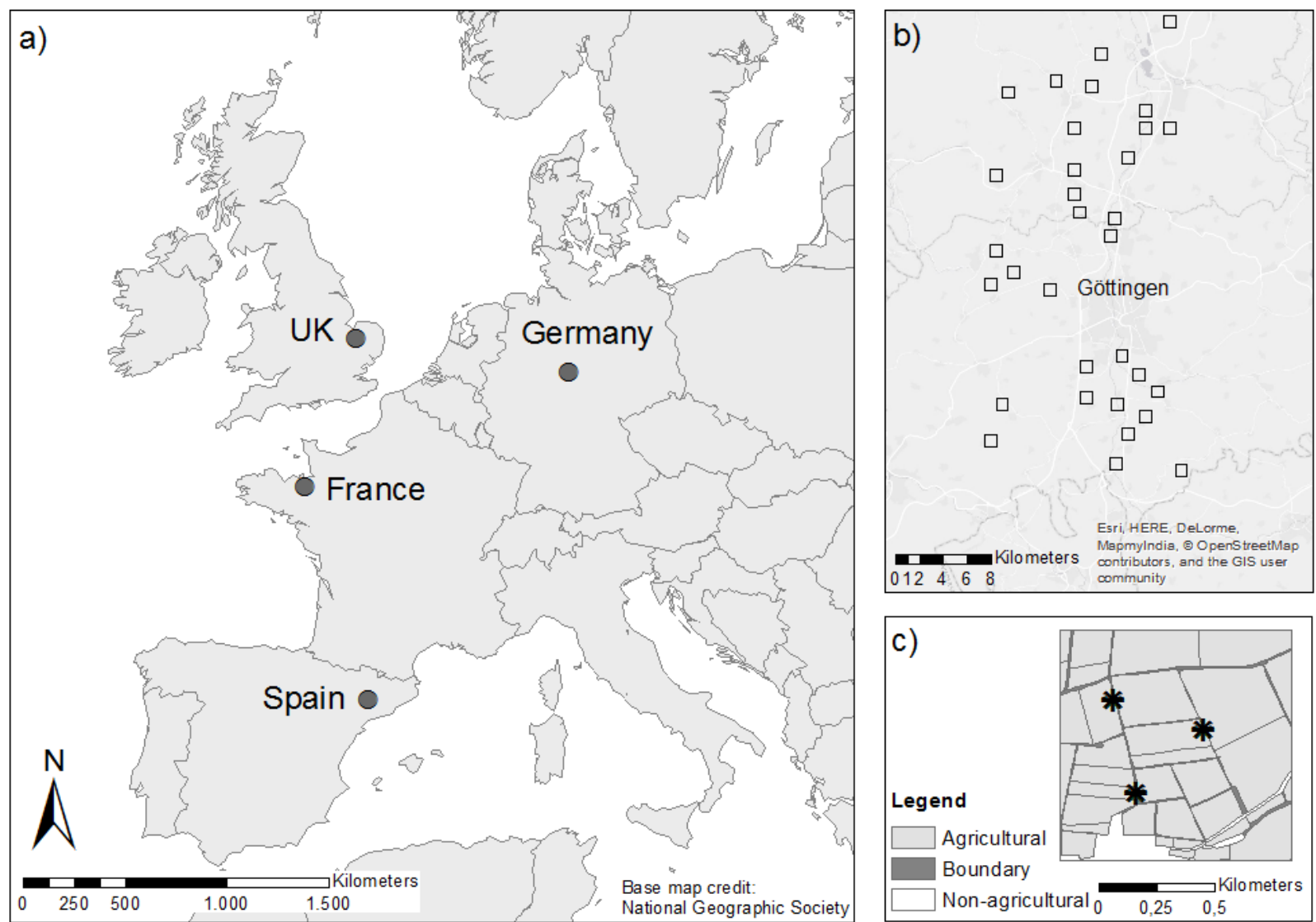

Fig. S1 Pollinator surveys and pollination experiments were conducted in four regions in France, Germany, Spain and the UK (a). In each study region $1 \times 1 \mathrm{~km}$ landscapes representing uncorrelated gradients of farmland configurational and compositional heterogeneity were selected (32 in Germany, 30 in France, 20 in Spain and 12 in the UK). As an example the distribution of landscapes in Germany is shown (b). In each landscape 1 to 3 crop fields were chosen for sampling (c). 


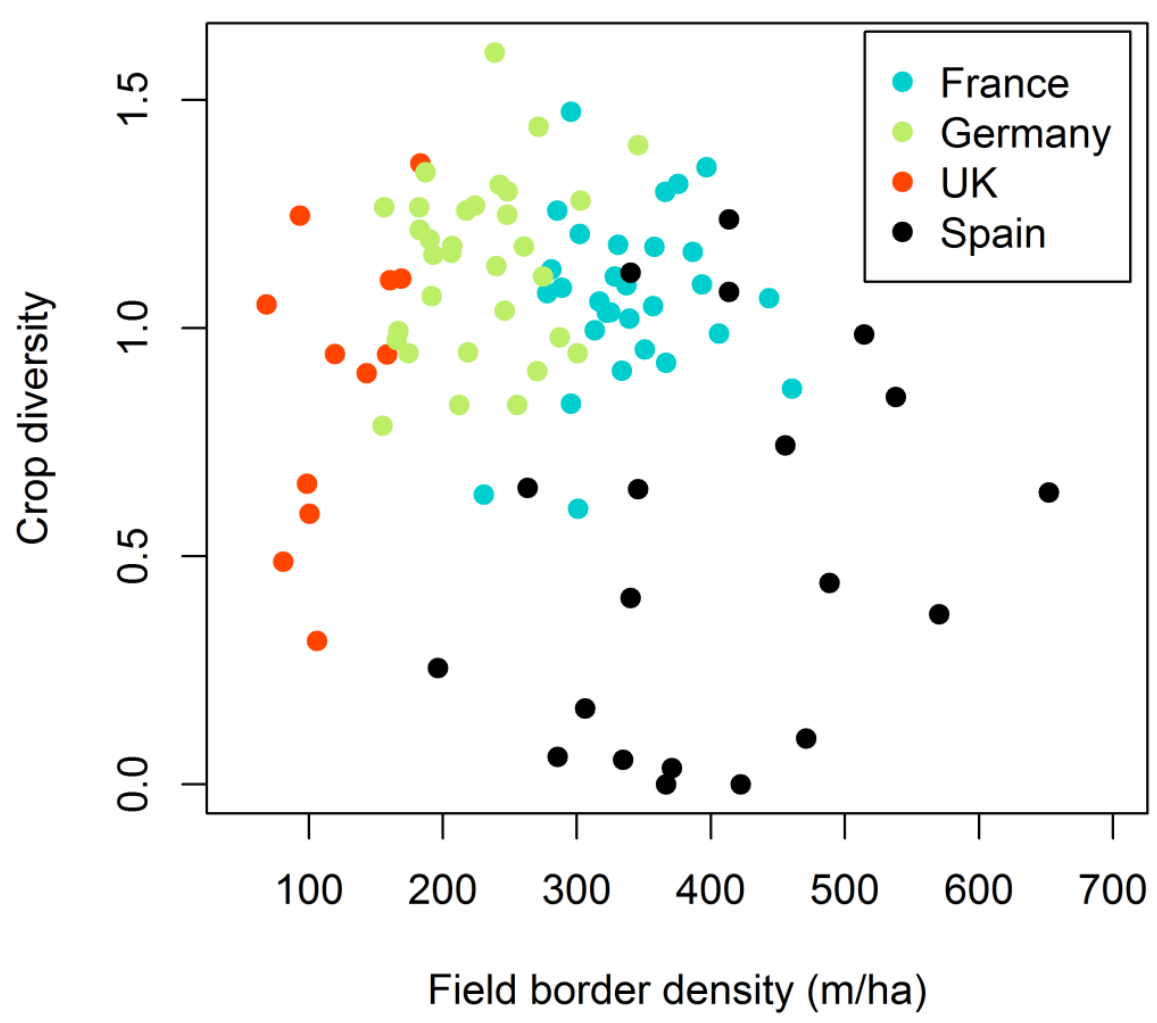

Fig. S2 We selected 229 landscapes with uncorrelated gradients of crop diversity and field border density in each region. 

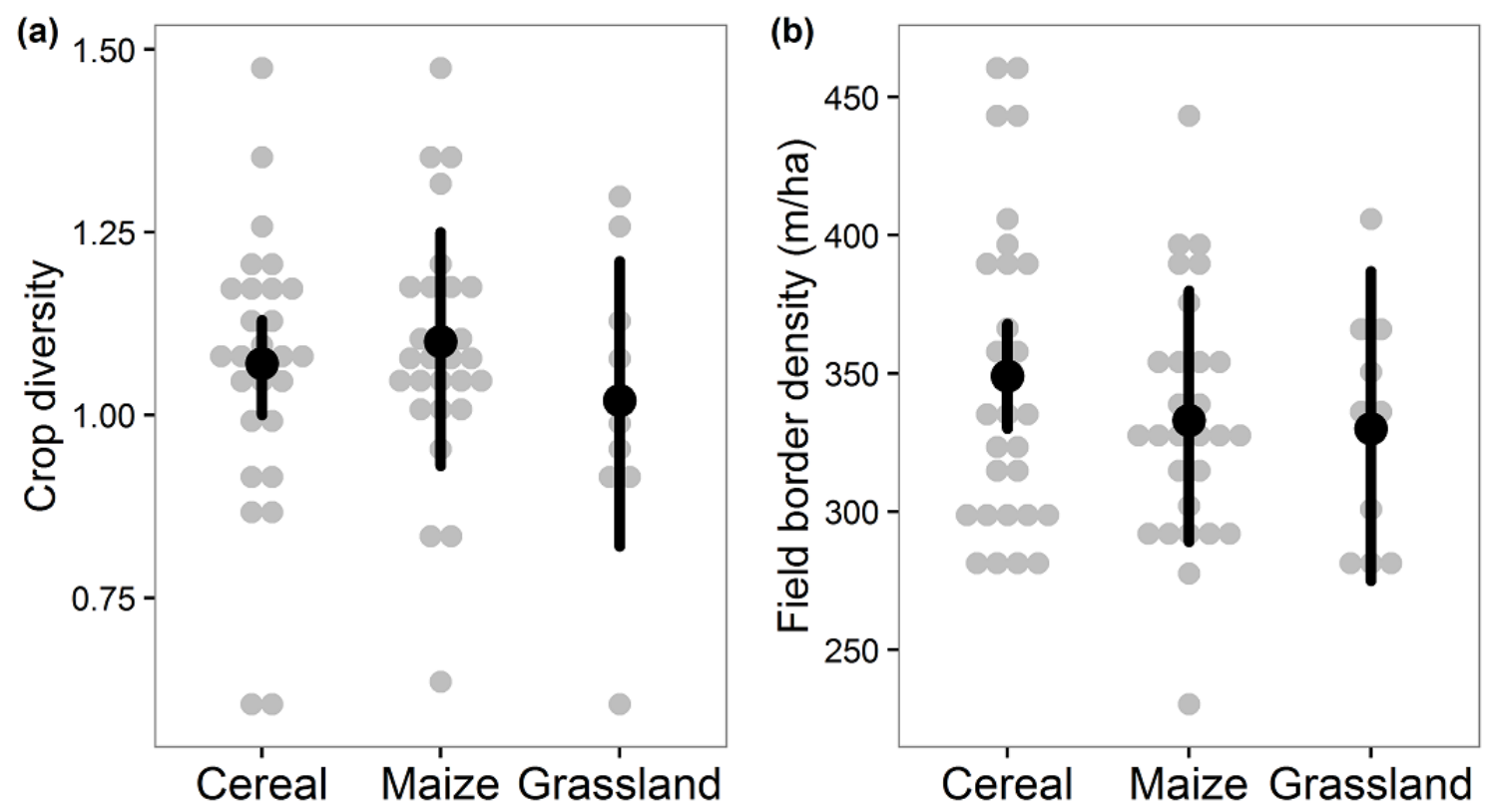

Fig. S3 Distribution of (a) compositional heterogeneity (crop diversity) and (b) configurational heterogeneity (field border density) at the landscape scale for different sampled crops in France. Mean compositional and configurational heterogeneity were not related to crop type (ANOVA, $F_{2.63}=$ $0.66, P=0.520$ and $\mathrm{F}_{2.63}=0.79, P=0.459$ ). Model estimates $\pm 95 \% \mathrm{Cl}$ are shown. 


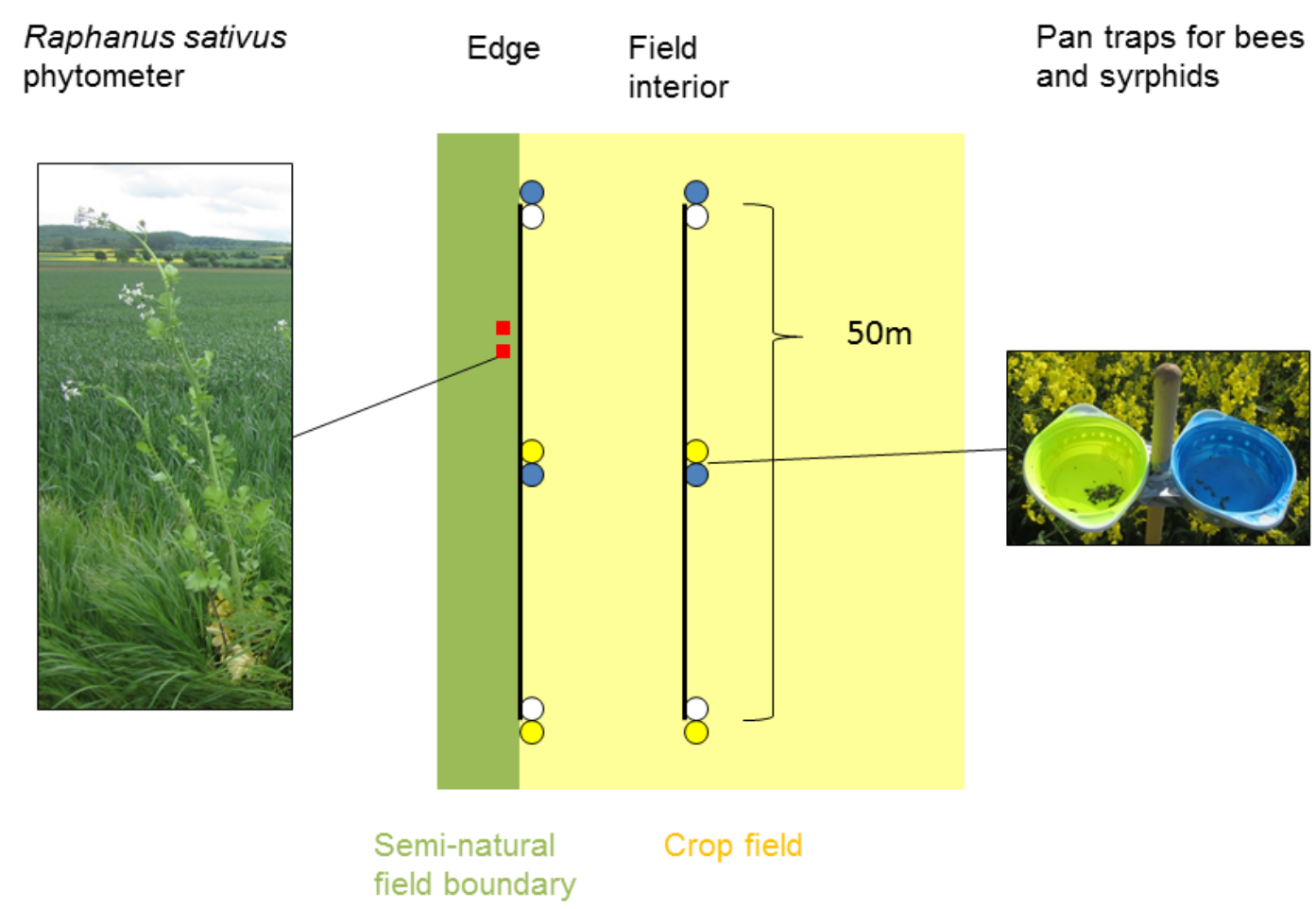

Fig. S4 Study design for the pollinator survey (bees and hoverflies) and pollination experiment with common radish (Raphanus sativus). Two $50 \mathrm{~m}$ transects were established in each sampled field, one edge and one interior transect. Six pan traps of three different colours (blue, white and yellow) were installed per transect. Two pots with radish plants were placed in the field margin next to the crop. 
(a)

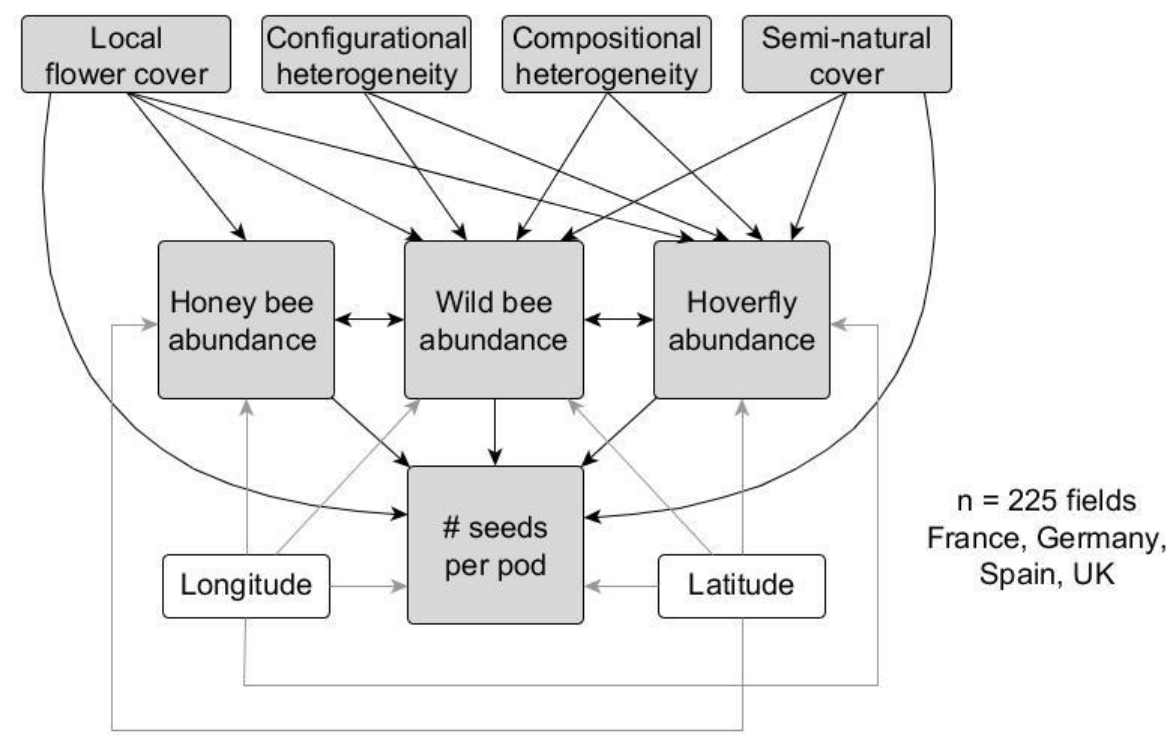

(b)

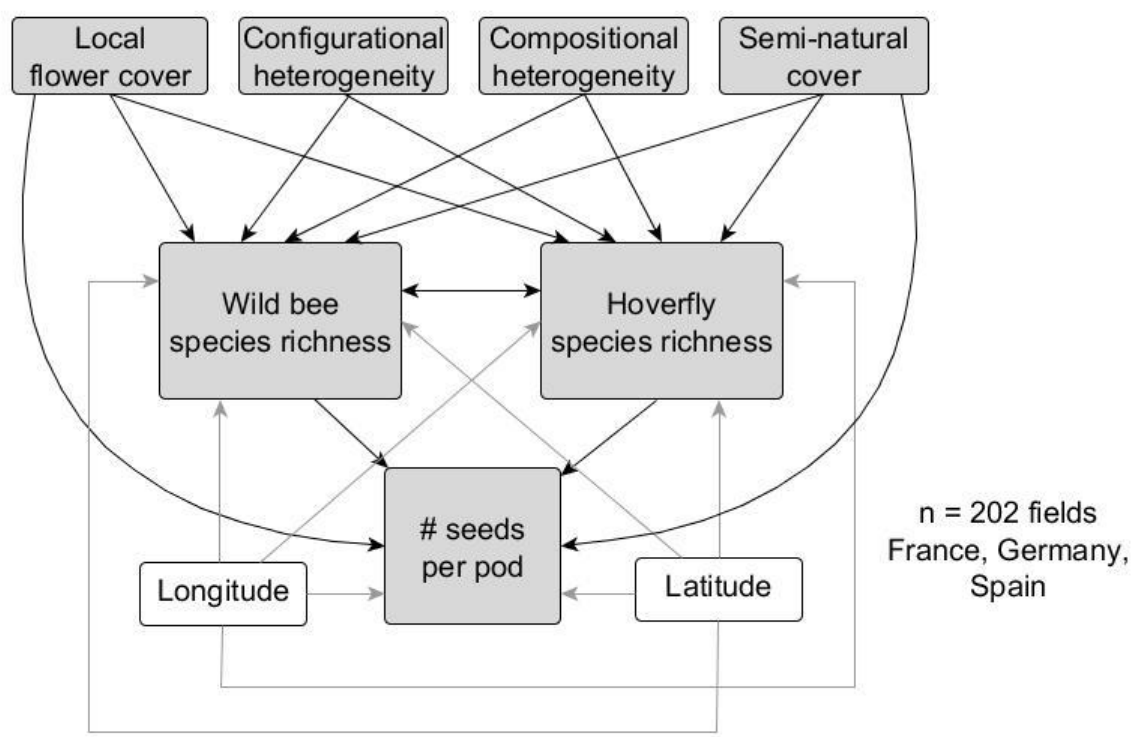

Fig. S5 Hypothetical models of full piecewise structural equation models (SEMs), before model simplification based on AIC values. We analysed the relationship between local flower cover $(3 \mathrm{~m}$ around pan traps), farmland configurational heterogeneity (field border density), farmland compositional heterogeneity (crop diversity), semi-natural cover, and (a) bee and hoverfly abundances and (b) species richness, and the effects on seed set of potted radish across four countries. Effects of longitude and latitude were added as co-variates. The results of model simplification of this full model are shown in Fig. 2. 
(a)

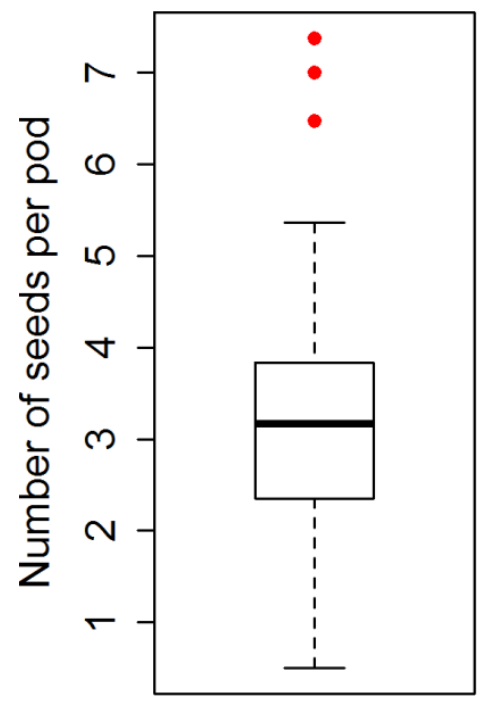

(b)

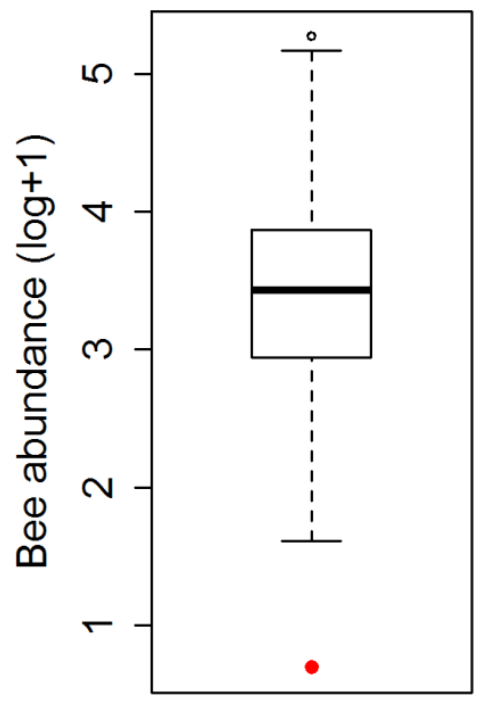

(c)

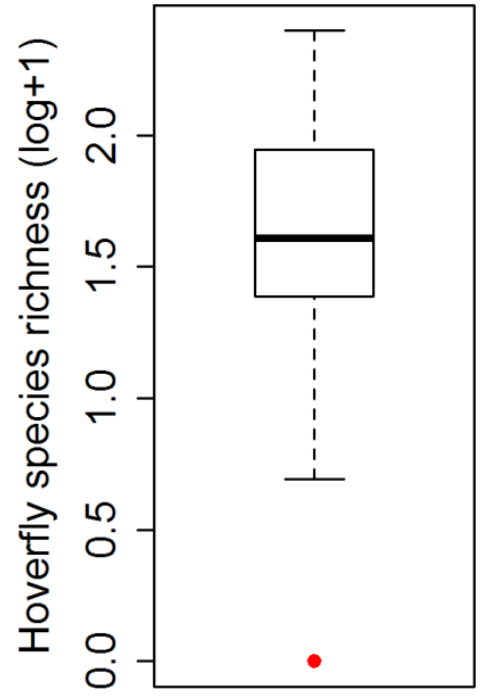

Fig. S6 Boxplots of (a) number of seeds per pod (b) wild bee abundance and (c) hoverfly species richness across all regions. Extreme outliers shown in red were excluded from the analysis. In the case of abundance these were one field with very low bee abundance and three fields with unusually high numbers of seeds per pod that may have been due to counting errors. In the case of species richness there were two outliers removed due to very low hoverfly abundance (points are overlapping). 


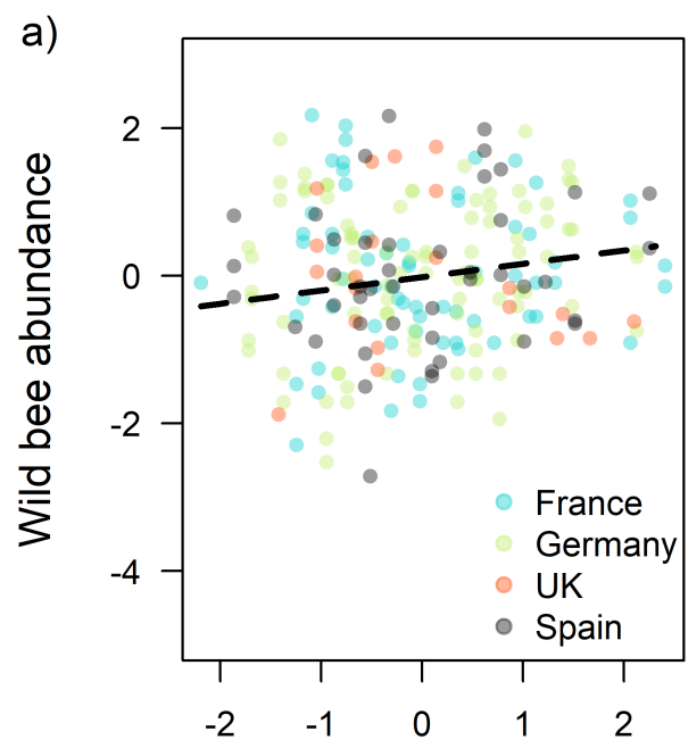

Field border density $(\mathrm{m} / \mathrm{ha})$

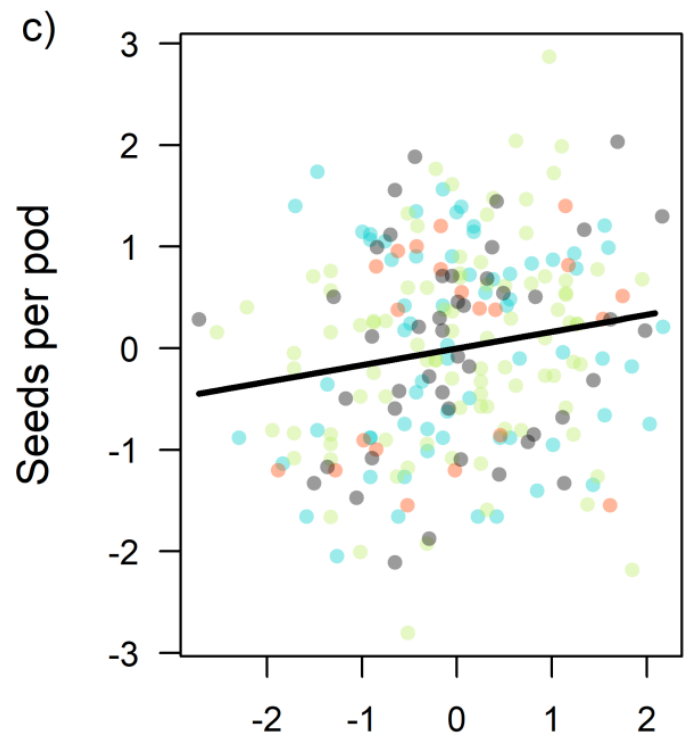

Wild bee abundance

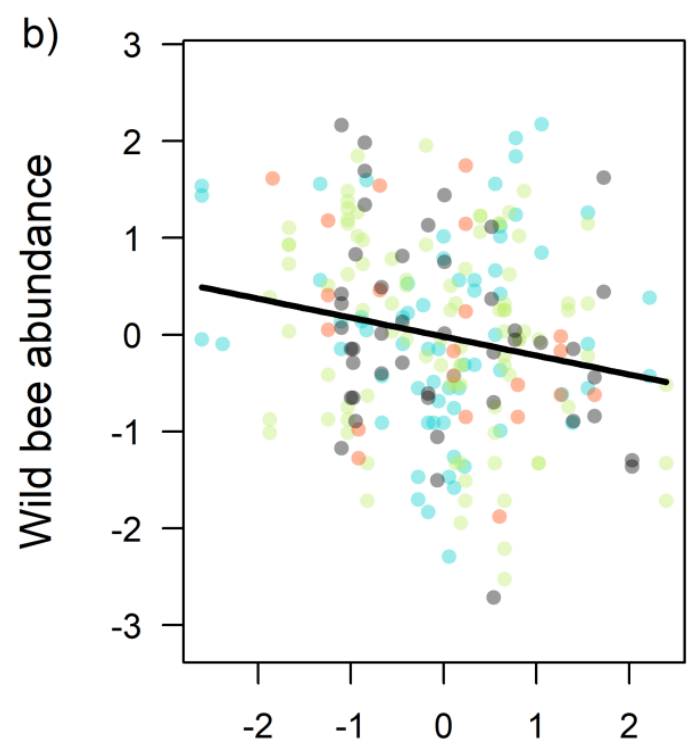

Crop diversity

d)

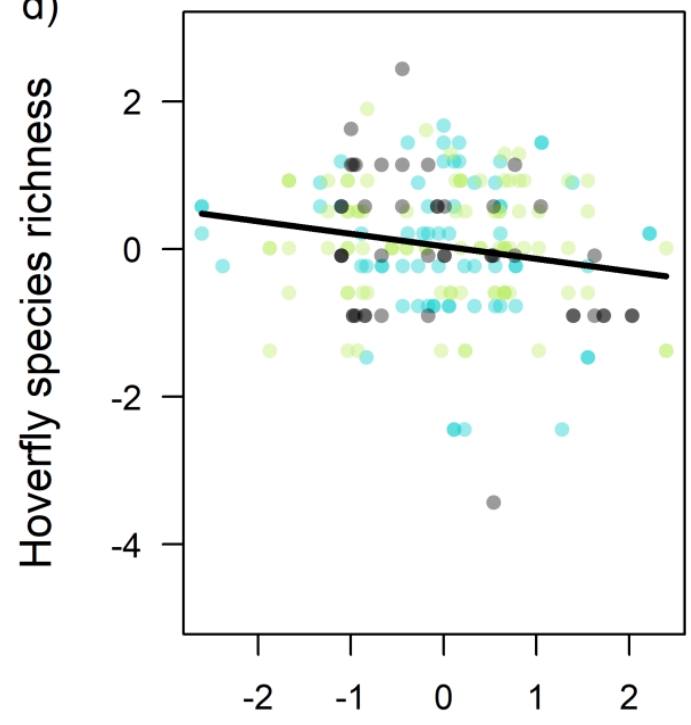

Crop diversity

Fig. S7 The effects of models with centralised data: (a) field border density on wild bee abundance, (b) crop diversity on wild bee abundance, (c) wild bee abundance on seed set and (d) crop diversity on hoverfly species richness. For these analyses the data was centralised by standardising all explanatory variables within each region. Global trends from model predictions are shown, because predictions for each country are almost identical. Solid lines show significant trends $(P<0.05)$ and the dashed line shows a marginally significant trend $(P=0.061)$. 


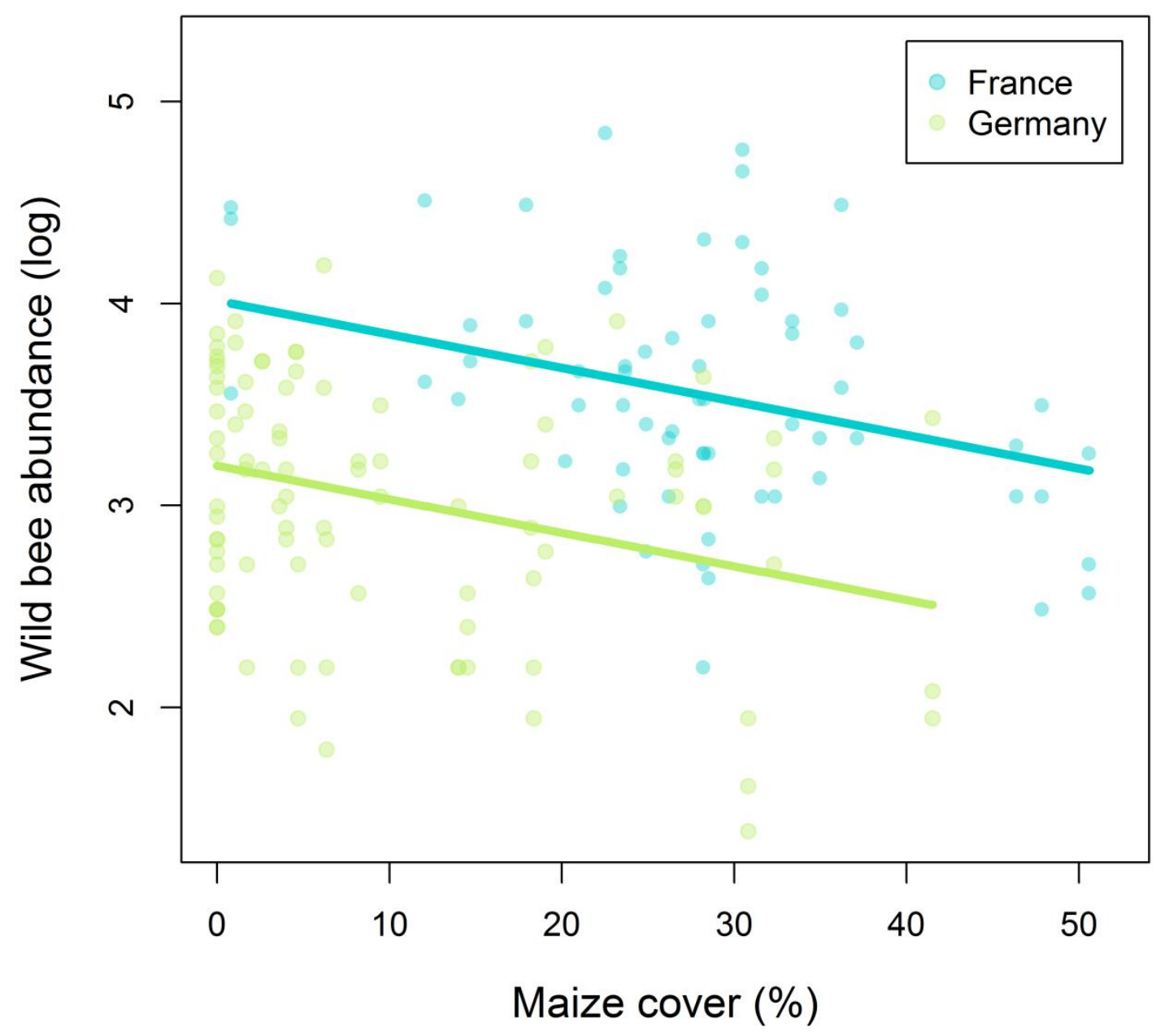

Fig. S8 Wild bee abundance decreases with the proportion of maize in the landscape in France and Germany. Lines show model predictions from linear mixed effect model with maize as fixed and landscape nested in regions as random effect $(P=0.004)$. Wild bee abundance was log transformed. 


\section{Supplementary tables}

Table S1: All crop types used for calculating crop diversity and their area in the sampled landscapes in ha for each country and in total. Additionally, the number of landscapes in which this crop was present in each country is shown (landsc.). Highlighted in bold are the three dominant crops covering the largest area in each country and in total.

\begin{tabular}{|c|c|c|c|c|c|c|c|c|c|c|}
\hline & France & & German & & Spain & & UK & & Total & \\
\hline Crop type & ha & landsc. & ha & landsc. & ha & landsc. & ha & landsc. & ha & landsc. \\
\hline Almond & 0.0 & 0 & 0.0 & 0 & 139.5 & 11 & 0.0 & 0 & 139.5 & 11 \\
\hline Asparagus & 0.0 & 0 & 3.3 & 1 & 0.0 & 0 & 0.0 & 0 & 3.3 & 1 \\
\hline Bean & 11.6 & 2 & 21.2 & 3 & 0.0 & 0 & 19.0 & 1 & 51.8 & 6 \\
\hline Carrot & 0.0 & 0 & 0.0 & 0 & 0.0 & 0 & 2.3 & 1 & 2.3 & 1 \\
\hline Cereal & 1709.0 & 30 & 4997.9 & 32 & 3891.6 & 20 & 1332.9 & 12 & 11931.5 & 94 \\
\hline Maize & 1856.0 & 30 & 947.3 & 24 & 0.0 & 0 & 1.1 & 1 & 2804.5 & 55 \\
\hline Fallow & 1.3 & 1 & 0.0 & 0 & 131.7 & 16 & 4.6 & 2 & 137.6 & 19 \\
\hline Grass & 2878.3 & 30 & 790.2 & 31 & 0.0 & 0 & 49.2 & 8 & 3717.7 & 69 \\
\hline Oilseed rape & 90.3 & 11 & 1421.5 & 32 & 45.2 & 4 & 334.2 & 11 & 1891.1 & 58 \\
\hline Olive & 0.0 & 0 & 0.0 & 0 & 151.3 & 11 & 0.0 & 0 & 151.3 & 11 \\
\hline Onion & 0.0 & 0 & 0.0 & 0 & 0.0 & 0 & 19.0 & 1 & 19.0 & 1 \\
\hline Orchard & 39.3 & 16 & 13.9 & 1 & 0.0 & 0 & 0.0 & 0 & 53.2 & 17 \\
\hline Pea & 0.0 & 0 & 0.0 & 0 & 0.0 & 0 & 47.6 & 2 & 47.6 & 2 \\
\hline Potato & 0.0 & 0 & 11.0 & 2 & 0.0 & 0 & 108.4 & 4 & 119.4 & 6 \\
\hline Raspberry & 0.0 & 0 & 7.0 & 1 & 0.0 & 0 & 0.0 & 0 & 7.0 & 1 \\
\hline Ryegrass & 0.0 & 0 & 3.1 & 1 & 0.0 & 0 & 0.0 & 0 & 3.1 & 1 \\
\hline Strawberry & 0.0 & 0 & 24.4 & 1 & 0.0 & 0 & 0.0 & 0 & 24.4 & 1 \\
\hline Sugar beet & 0.0 & 0 & 1043.7 & 23 & 0.0 & 0 & 179.2 & 6 & 1222.9 & 29 \\
\hline Vegetable & 14.2 & 1 & 15.6 & 3 & 0.0 & 0 & 0.0 & 0 & 29.8 & 4 \\
\hline Vineyard & 0.0 & 0 & 0.0 & 0 & 140.7 & 8 & 0.0 & 0 & 140.7 & 8 \\
\hline Wild bird cover* & 0.0 & 0 & 0.0 & 0 & 0.0 & 0 & 2.4 & 1 & 2.4 & 1 \\
\hline Total & 6600 & 30 & 9300 & 32 & 4500 & 20 & 2100 & 12 & 22500 & 94 \\
\hline
\end{tabular}

*seed-bearing crop mixtures grown under agri-environment schemes to support game birds 
Table S2: Sampling dates (year 2013) in the four countries. Pan traps and phytometer plants were deployed in each field for a single four day period within each survey period specified.

\begin{tabular}{l|lll}
\hline Country & $\begin{array}{l}\text { Pollinator survey } \\
\text { Survey 1 }\end{array}$ & Survey 2 & $\begin{array}{l}\text { Pollination } \\
\text { experiment }\end{array}$ \\
\hline France & 16 May - 06 June & 13 June - 15 July & 13 June - 08 July \\
Germany & 13 May - 04 June & 17 June - 09 July & 13 May - 04 June / 17 June - 09 July \\
Spain & 11 April - 10 May & 17 May - 07 June & 17 May - 31 July \\
UK & 10 May - 11 July & 24 June - 16 August & 17 June - 22 July \\
\hline
\end{tabular}


Table S3 Number of captured individuals of each bee species

\begin{tabular}{|c|c|c|c|c|c|}
\hline Species & France & UK & Germany & Spain & Total \\
\hline Andrena albopunctata & & & & 5 & 5 \\
\hline Andrena alfkenella & 2 & & & & 2 \\
\hline Andrena angustior & 11 & & 18 & & 29 \\
\hline Andrena anthrisci & & & 1 & & 1 \\
\hline Andrena cf. antigana & & & & 17 & 17 \\
\hline Andrena bellidis & & & & 1 & 1 \\
\hline Andrena bicolor & 5 & & 10 & & 15 \\
\hline Andrena bicolorata & & & & 4 & 4 \\
\hline Andrena boyerella & & & & 1 & 1 \\
\hline Andrena carantonica & & & 4 & & 4 \\
\hline Andrena chrysosceles & 1 & & 7 & & 8 \\
\hline Andrena cineraria & 43 & & 50 & 363 & 456 \\
\hline Andrena djelfensis & & & & 1 & 1 \\
\hline Andrena dorsata & 12 & & & & 12 \\
\hline Andrena ferrugineicrus & & & & 40 & 40 \\
\hline Andrena flavipes & 194 & & 15 & 40 & 249 \\
\hline Andrena fucata & & & 6 & & 6 \\
\hline Andrena fulva & 7 & & 28 & & 35 \\
\hline Andrena gravida & 33 & & 10 & & 43 \\
\hline Andrena haemorrhoa & 58 & & 190 & & 248 \\
\hline Andrena helvola & & & 70 & & 70 \\
\hline Andrena hesperia & & & & 1 & 1 \\
\hline Andrena humilis & 8 & & & & 8 \\
\hline Andrena labiata & 1 & & 3 & & 4 \\
\hline Andrena lagopus & 6 & & & & 6 \\
\hline Andrena lathyri & & & 1 & & 1 \\
\hline Andrena minutula & 21 & & 6 & & 27 \\
\hline Andrena mitis & & & 5 & & 5 \\
\hline Andrena nana & & & & 1 & 1 \\
\hline Andrena nigroaenaea & 66 & & 397 & 37 & 500 \\
\hline Andrena nigroolivacea & & & & 1 & 1 \\
\hline Andrena nitida & 25 & & 33 & 8 & 66 \\
\hline Andrena ovatula & 1 & & & & 1 \\
\hline Andrena pilipes & & & & 3 & 3 \\
\hline Andrena praecox & & & 5 & & 5 \\
\hline Andrena semilaevis & & & 1 & & 1 \\
\hline Andrena senecionis & & & & 5 & 5 \\
\hline Andrena subopaca & & & 22 & & 22 \\
\hline Andrena tenuistriata & & & & 1 & 1 \\
\hline Andrena tibialis & & & 1 & & 1 \\
\hline Andrena vaga & & & 6 & & 6 \\
\hline Andrena varians & & & 6 & & 6 \\
\hline
\end{tabular}




\begin{tabular}{|c|c|c|c|c|c|}
\hline Andrena vulpecula & & & & 2 & 2 \\
\hline Andrena sp. 1 & & & & 9 & 9 \\
\hline Andrena sp. 2 & & & & 38 & 38 \\
\hline Andrena sp. 3 & & & & 1 & 1 \\
\hline Andrena sp. 4 & & & & 12 & 12 \\
\hline Andrena sp. 5 & & & & 1 & 1 \\
\hline Andrena sp. 6 & & & & 8 & 8 \\
\hline Andrena sp. 7 & & & & 1 & 1 \\
\hline Andrena sp. 8 & & & & 2 & 2 \\
\hline Andrena sp. 9 & & & & 1 & 1 \\
\hline Andrena sp. 10 & & & & 1 & 1 \\
\hline Andrena sp. 11 & & & & 1 & 1 \\
\hline Anthocopa papaveris & & & & 1 & 1 \\
\hline Anthophora acervorum & & & & 4 & 4 \\
\hline Anthophora atroalba & & & & 2 & 2 \\
\hline Anthophora dispar & & & & 2 & 2 \\
\hline Anthophora plumipes & 1 & & 12 & & 13 \\
\hline Apis mellifera & 466 & 9 & 1105 & 92 & 1672 \\
\hline Biastes brevicornis & & & & 1 & 1 \\
\hline Bombus bohemicus & & & 13 & & 13 \\
\hline Bombus hortorum & & 28 & 137 & & 165 \\
\hline Bombus hypnorum & & & 8 & & 8 \\
\hline Bombus lapidarius & & 61 & 68 & & 129 \\
\hline Bombus lucorum & & 13 & & & 13 \\
\hline Bombus pascuorum & & 24 & 99 & & 123 \\
\hline Bombus pratorum & & 1 & 22 & & 23 \\
\hline Bombus rupestris & & 2 & 29 & & 31 \\
\hline Bombus semenoviellus & & & 1 & & 1 \\
\hline Bombus subterraneus & & & 3 & & 3 \\
\hline Bombus sylvarum & & & 9 & & 9 \\
\hline Bombus terrestris & & 19 & 530 & 25 & 574 \\
\hline Bombus vestalis & & 17 & & & 17 \\
\hline Bombus sp. & 896 & & & & 896 \\
\hline Ceratina cucurbitina & & & & 14 & 14 \\
\hline Ceratina cyanea & & & & 4 & 4 \\
\hline Ceratina dallatorreana & & & & 18 & 18 \\
\hline Ceratina dentiventris & & & & 1 & 1 \\
\hline Chalicodoma ericetorum & 1 & & 3 & & 4 \\
\hline Chelostoma edentulum & & & & 48 & 48 \\
\hline Chelostoma florisomne & & & 3 & & 3 \\
\hline Chelostoma rapunculi & 1 & & 4 & & 5 \\
\hline Colletes cunicularius & & & 2 & & 2 \\
\hline Colletes daviesanus & 1 & & & & 1 \\
\hline Dufourea sp. 1 & & & & 2 & 2 \\
\hline Eucera alternans & & & & 3 & 3 \\
\hline
\end{tabular}




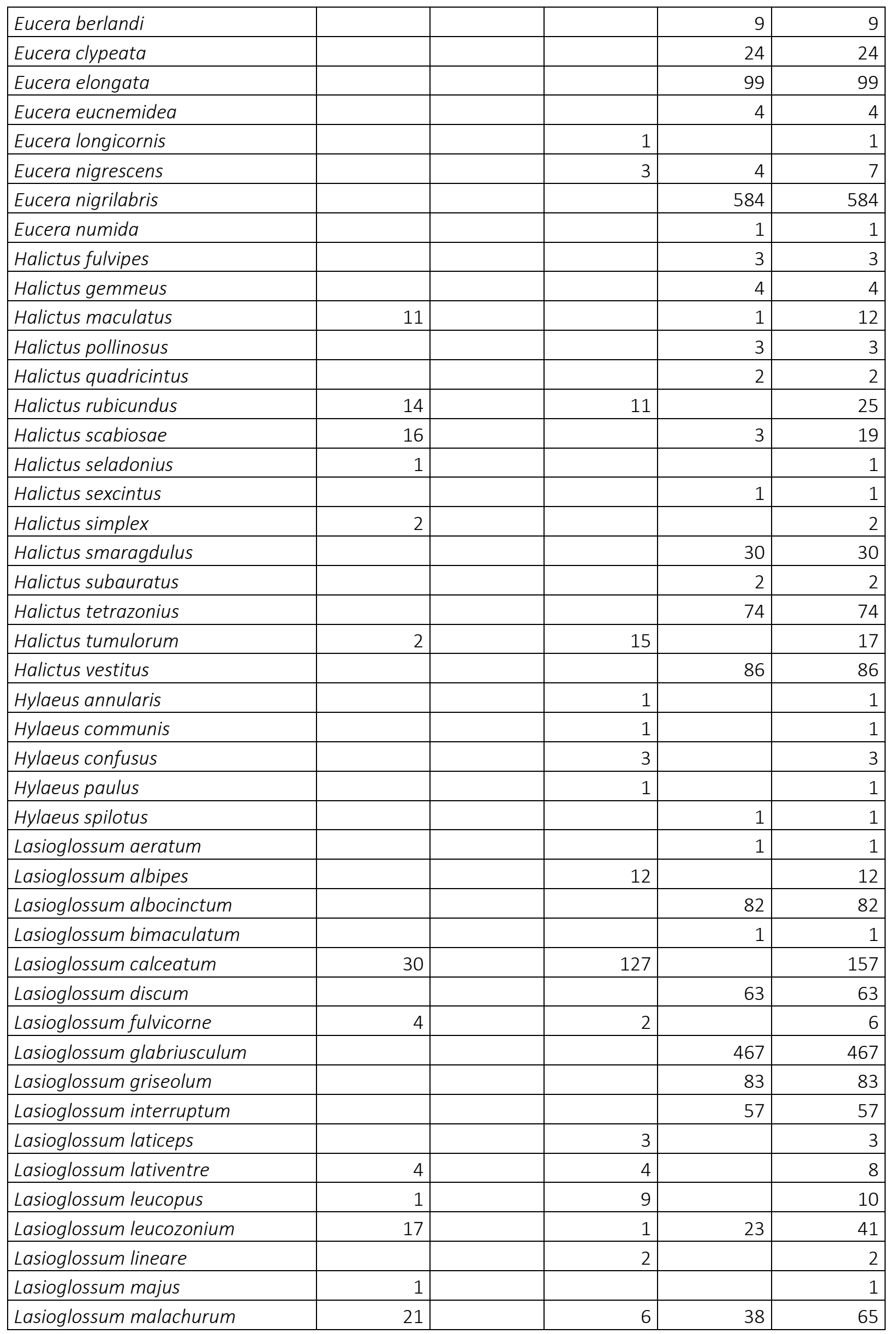




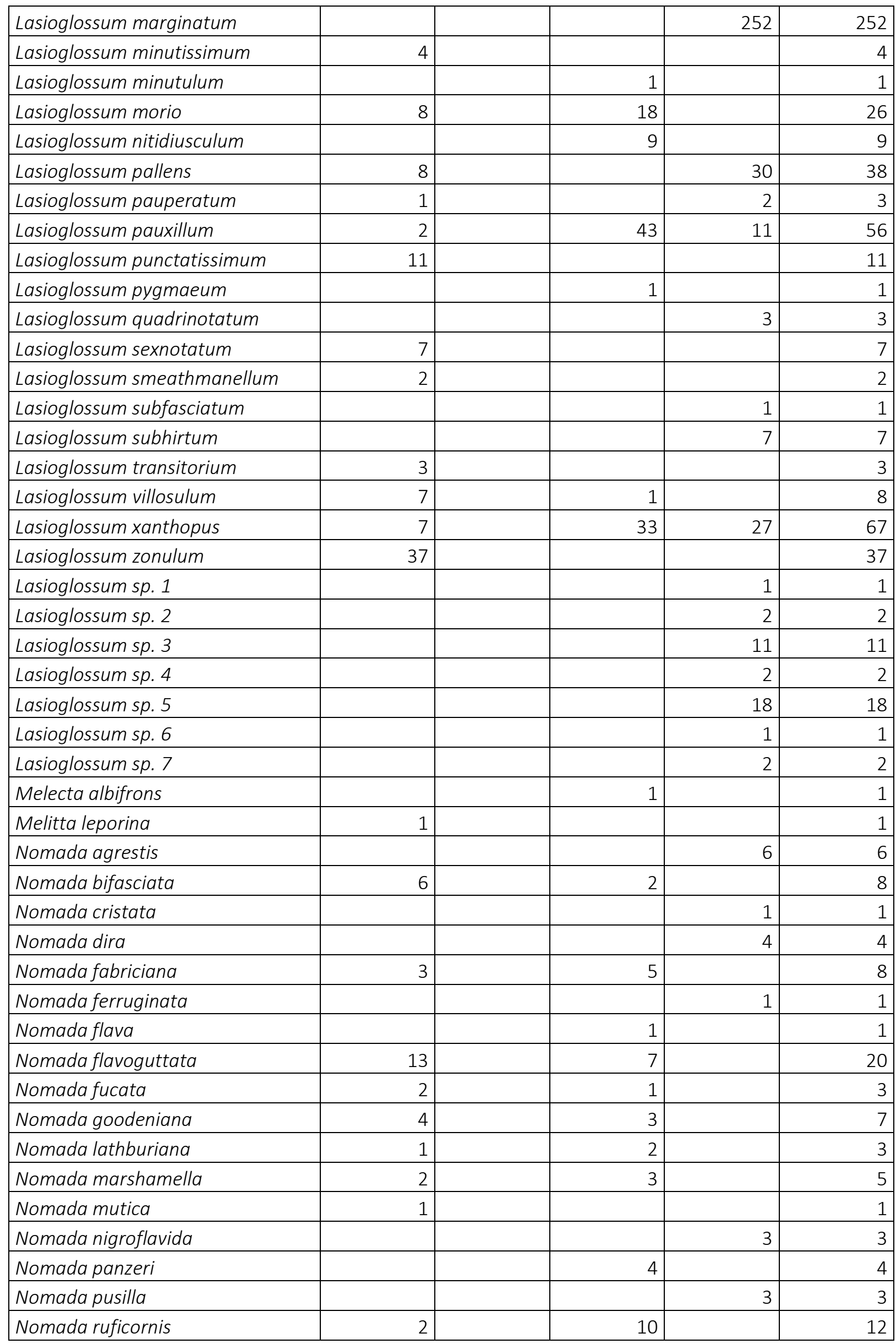




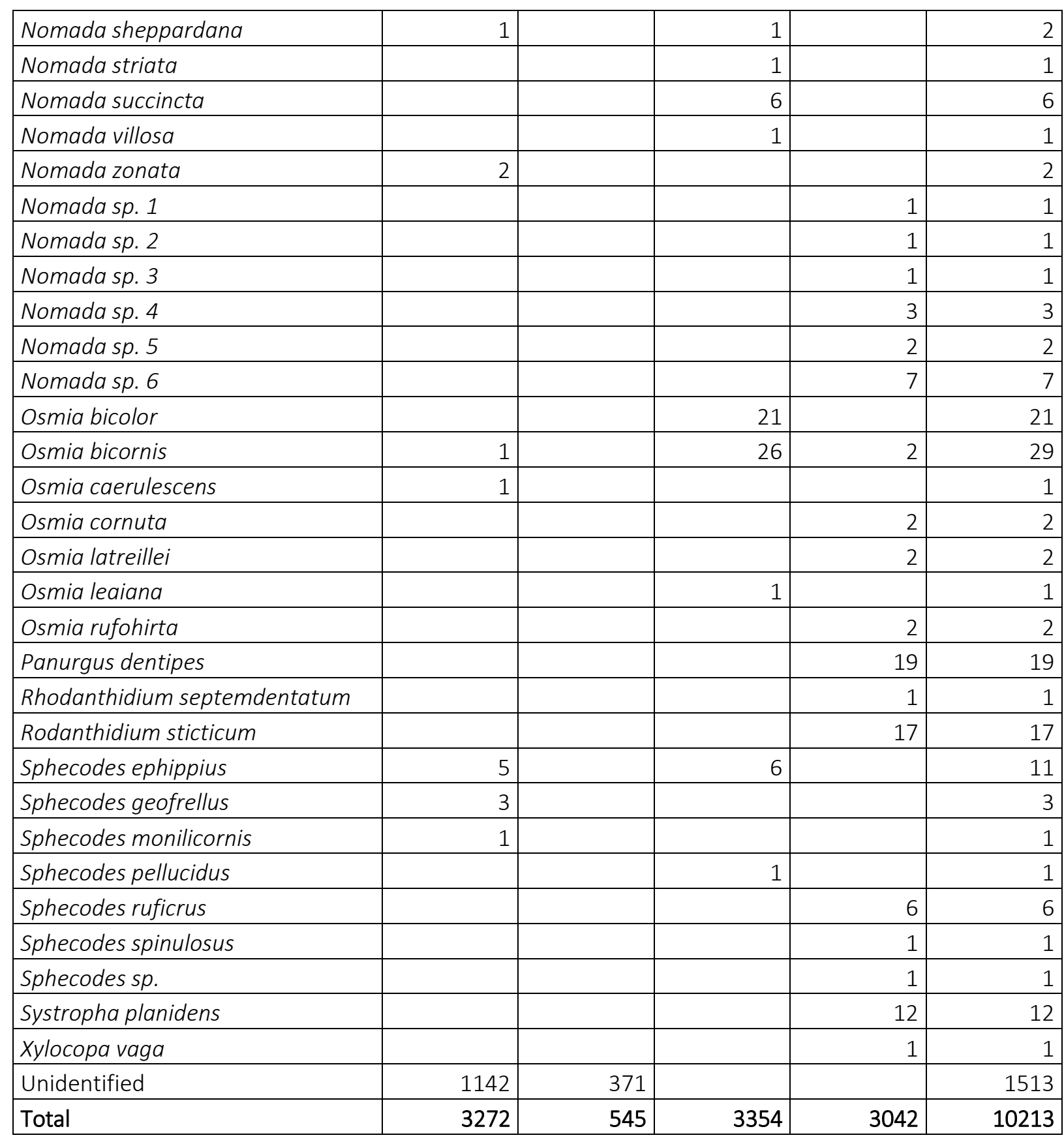


Table S4 Number of captured individuals of each hoverfly species (Syrphidae)

\begin{tabular}{|c|c|c|c|c|c|}
\hline Species & France & UK & Germany & Spain & Total \\
\hline Anasimyia lineata & 4 & & & & 4 \\
\hline Brachypalpus valgus & 1 & & & & 1 \\
\hline Cheilosia albitarsis & 2 & & 3 & & 5 \\
\hline Cheilosia bergenstammi & & & 1 & & 1 \\
\hline Cheilosia latifrons & 1 & & & & 1 \\
\hline Cheilosia pagana & 1 & & & & 1 \\
\hline Cheilosia ruficollis & & & 4 & & 4 \\
\hline Cheilosia vernalis & 2 & & & & 2 \\
\hline Cheilosia sp. & & & 1 & & 1 \\
\hline Chrysotoxum bicinctum & 2 & & & & 2 \\
\hline Epistrophe nitidicollis & & 1 & & & 1 \\
\hline Episyrphus balteatus & 32 & 54 & 479 & 1348 & 1913 \\
\hline Eristalinus aeneus & & & 2 & & 2 \\
\hline Eristalinus sepulchralis & 18 & & 5 & & 23 \\
\hline Eristalis abusiva & & & 5 & & 5 \\
\hline Eristalis arbustorum & 13 & & 21 & 6 & 40 \\
\hline Eristalis interrupta & 21 & & & & 21 \\
\hline Eristalis lineata & & & 3 & & 3 \\
\hline Eristalis pertinax & 10 & & & & 10 \\
\hline Eristalis similis & 3 & & 2 & & 5 \\
\hline Eristalis tenax & 26 & & 16 & 24 & 66 \\
\hline Eristalis sp. & 3 & & & & 3 \\
\hline Eumerus strigatus & & 1 & 5 & & 6 \\
\hline Eupeodes corollae & 486 & 9 & 514 & 5219 & 6228 \\
\hline Eupeodes lapponicus & & & 1 & & 1 \\
\hline Eupeodes luniger & 2 & 2 & 2 & 11 & 17 \\
\hline Ferdinandea cuprea & 2 & & 2 & & 4 \\
\hline Helophilus hybridus & 2 & & & & 2 \\
\hline Helophilus pendulus & 233 & & 1 & & 234 \\
\hline Helophilus trivittatus & & 2 & 42 & 1 & 45 \\
\hline Lejogaster metallina & 1 & & & & 1 \\
\hline Leucozona lucorum & 1 & & & & 1 \\
\hline Melanogaster hirtella & 3 & & & & 3 \\
\hline Melanogaster nuda & & & 1 & & 1 \\
\hline Melanostoma mellinum & 10 & 14 & 44 & 22 & 90 \\
\hline Melanostoma scalare & & 2 & & 2 & 4 \\
\hline Meliscaeva auricollis & 1 & & & 3 & 4 \\
\hline Merodon equestris & 7 & & 9 & & 16 \\
\hline Myathropa florea & 4 & & 1 & 1 & 6 \\
\hline Neoascia podagrica & 5 & & 1 & & 6 \\
\hline Orthonevra nobilis & 1 & & & & 1 \\
\hline Paragus bicolor & & & & 1 & 1 \\
\hline
\end{tabular}




\begin{tabular}{|c|c|c|c|c|c|}
\hline Pipizella viduata & 1 & & & & 1 \\
\hline Platycheirus albimanus & 7 & & 2 & & 9 \\
\hline Platycheirus fulviventris & & 1 & & & 1 \\
\hline Platycheirus immarginatus & & & 3 & & 3 \\
\hline Platycheirus manicatus & 3 & 138 & & & 141 \\
\hline Platycheirus peltatus & 6 & 8 & 7 & & 21 \\
\hline Platycheirus scutatus & 1 & 1 & & & 2 \\
\hline Platynochaetus setosus & & & & 3 & 3 \\
\hline Rhingia campestris & 180 & & 1 & & 181 \\
\hline Riponnensia splendens & 2 & & & & 2 \\
\hline Scaeva pyrastri & 1 & & 21 & 7 & 29 \\
\hline Scaeva selenitica & & & 11 & & 11 \\
\hline Sphaerophoria rueppelli & & & & 48 & 48 \\
\hline Sphaerophoria scripta & 27 & 5 & 170 & 1222 & 1424 \\
\hline Sphaerophoria taeniata & & & 2 & & 2 \\
\hline Sphegina montana & & & 1 & & 1 \\
\hline Syritta pipiens & 8 & & & 1 & 9 \\
\hline Syrphus ribesii & 2 & & 1 & 1 & 4 \\
\hline Syrphus torvus & & & 1 & & 1 \\
\hline Syrphus vitripennis & & & 2 & & 2 \\
\hline Tropidia scita & & & 14 & & 14 \\
\hline Volucella bombylans & 4 & & 1 & & 5 \\
\hline Volucella inflata & 1 & & & & 1 \\
\hline Xylota segnis & 6 & & 6 & & 12 \\
\hline Unidentified & 1 & & 2 & & 3 \\
\hline Total & 1147 & 238 & 1410 & 7920 & 10715 \\
\hline
\end{tabular}


Table S5 Results of the piecewise SEMs for the best simplified models based on AIC, containing pollinator abundance variables (a), and pollinator species richness variables (b)

\begin{tabular}{lllll}
\hline Response variable & Predictor & Estimate & SE & $P$-value \\
\hline
\end{tabular}

Models without centred variables

\begin{tabular}{|c|c|c|c|c|}
\hline \multicolumn{5}{|l|}{ (a) Abundance } \\
\hline \multirow[t]{4}{*}{ Wild bee abundance } & Crop diversity & -0.32 & 0.08 & $<0.001$ \\
\hline & Field border density & 0.39 & 0.07 & $<0.001$ \\
\hline & Flower cover & -0.12 & 0.04 & 0.002 \\
\hline & Semi-natural habitat & -0.11 & 0.07 & 0.126 \\
\hline \multirow[t]{6}{*}{ Hoverfly abundance } & Crop diversity & -0.26 & 0.17 & 0.121 \\
\hline & Field border density & -0.04 & 0.11 & 0.725 \\
\hline & Flower cover & -0.13 & 0.04 & $<0.001$ \\
\hline & Semi-natural habitat & 0.14 & 0.07 & 0.041 \\
\hline & Latitude & -0.58 & 0.15 & $<0.001$ \\
\hline & Longitude & 0.06 & 0.17 & 0.742 \\
\hline \multirow[t]{5}{*}{ Seeds per pod } & Flower cover & 0.13 & 0.07 & 0.047 \\
\hline & Semi-natural habitat & 0.25 & 0.08 & 0.002 \\
\hline & Wild bee abundance & 0.21 & 0.15 & 0.008 \\
\hline & Latitude & 0.21 & 0.09 & 0.024 \\
\hline & Longitude & -0.21 & 0.09 & 0.025 \\
\hline \multicolumn{5}{|l|}{ (b) Species richness } \\
\hline \multirow[t]{4}{*}{ Wild bee species richness } & Crop diversity & -0.17 & 0.12 & 0.155 \\
\hline & Field border density & 0.22 & 0.12 & 0.061 \\
\hline & Flower cover & -0.15 & 0.05 & 0.002 \\
\hline & Longitude & 0.44 & 0.40 & 0.273 \\
\hline \multirow[t]{3}{*}{ Hoverfly species richness } & Crop diversity & -0.21 & 0.12 & 0.083 \\
\hline & Flower cover & 0.11 & 0.06 & 0.077 \\
\hline & Longitude & 0.05 & 0.27 & 0.868 \\
\hline \multirow[t]{3}{*}{ Seeds per pod } & Flower cover & 0.10 & 0.07 & 0.134 \\
\hline & Semi-natural cover & 0.19 & 0.08 & 0.023 \\
\hline & Longitude & -0.14 & 0.09 & 0.124 \\
\hline
\end{tabular}

Models with centred variables

\begin{tabular}{llrrr}
\hline (a) Abundance & & & & \\
\hline Wild bee abundance & Crop diversity & -0.20 & 0.09 & 0.025 \\
& Field border density & 0.18 & 0.10 & 0.062 \\
& Flower cover & -0.08 & 0.05 & 0.134 \\
& Semi-natural habitat & -0.12 & 0.09 & 0.207 \\
& Latitude & 0.20 & 0.09 & 0.019 \\
& Longitude & 0.13 & 0.09 & 0.138 \\
\hline Hoverfly abundance & Crop diversity & -0.11 & 0.09 & 0.209 \\
& Field border density & -0.05 & 0.10 & 0.611 \\
& Flower cover & -0.20 & 0.05 & $<0.001$ \\
& Semi-natural habitat & 0.14 & 0.10 & 0.134 \\
& Latitude & 0.08 & 0.09 & 0.349 \\
\hline
\end{tabular}




\begin{tabular}{llrrr} 
Seeds per pod & Flower cover & 0.21 & 0.06 & 0.001 \\
& Semi-natural habitat & 0.21 & 0.07 & 0.002 \\
& Honey bee abundance & -0.08 & 0.06 & 0.198 \\
& Wild bee abundance & 0.16 & 0.07 & 0.015 \\
& Latitude & 0.14 & 0.07 & 0.037 \\
\hline (b) Species richness & & & \\
\hline Wild bee species richness & Crop diversity & -0.09 & 0.09 & 0.304 \\
& Field border density & 0.16 & 0.09 & 0.095 \\
& Flower cover & -0.11 & 0.06 & 0.060 \\
& Semi-natural habitat & 0.03 & 0.10 & 0.785 \\
& Latitude & -0.70 & 2.73 & 0.799 \\
& Longitude & 6.21 & 2.87 & 0.033 \\
\hline Hoverfly species richness & Crop diversity & -0.17 & 0.08 & 0.029 \\
& Field border density & 0.05 & 0.08 & 0.572 \\
& Flower cover & -0.07 & 0.06 & 0.226 \\
& Semi-natural cover & 0.03 & 0.08 & 0.702 \\
& Latitude & 0.04 & 0.08 & 0.578 \\
\hline Seeds per pod & Flower cover & 0.18 & 0.07 & 0.010 \\
& Semi-natural cover & 0.19 & 0.07 & 0.005 \\
& Hoverfly species richness & -0.01 & 0.08 & 0.938 \\
& Latitude & 0.02 & 0.07 & 0.809 \\
\hline
\end{tabular}

*SE - standard error 
Table S6 Results of the GLMMs of the pollen transfer experiment testing the transmission of a pollen substitute from a donor to recipient arrays of cornflowers along different border treatments (crop border, semi-natural boundary and crop field interior). In the first model we used the full data set (a); in the second model we removed all three arrays from a site that contained an outlier (b). The response variable was a two-column object containing counts of flowers with fluorescent pollen and counts of flowers without fluorescent pollen, per treatment. We tested the difference in the two counts between oilseed rape and spring crop borders, as well as all contrasts between the three different treatments (Crop border - crop field, Semi-natural boundary - crop field and Semi-natural boundary - crop border). $P$-values are corrected for multiple comparisons.

\begin{tabular}{lrrrr}
\hline & Estimate & Lower 95\% Cl* & Upper 95\% Cl* & $P$-value \\
\hline (a) Full data set ( $\mathrm{n}=18$ recipient arrays) & \multicolumn{3}{c}{} \\
\hline Intercept & -2.48 & -3.23 & -1.73 & $<0.001$ \\
Spring crop border & -1.32 & -2.04 & -0.60 & 0.002 \\
Crop-border - crop field & 1.62 & 0.80 & 2.44 & 0.002 \\
Semi-natural boundary - crop field & 0.17 & -0.81 & 1.15 & 0.955 \\
Semi-natural boundary - crop & & & & \\
border & -1.45 & -2.23 & -0.67 & 0.004 \\
\hline (b) Outlier removed ( $\mathrm{n}=15$ recipient arrays) & -3.01 & -4.05 & -1.97 & $<0.001$ \\
\hline Intercept & -0.96 & -1.73 & -0.19 & 0.035 \\
Spring crop border & 1.77 & 0.66 & 2.88 & 0.018 \\
Crop-border - crop field & 0.54 & -0.73 & 1.80 & 0.750 \\
Semi-natural boundary - crop field & & & & \\
Semi-natural boundary - crop & -1.23 & -2.15 & -0.31 & 0.058 \\
border
\end{tabular}

${ }^{*} \mathrm{Cl}$ - confidence interval 
Table S7 Pearson correlations of field border density (configurational heterogeneity) and crop diversity (compositional heterogeneity) with co-variables and the main crops grown across regions.

\begin{tabular}{l|rr}
\hline & Crop diversity & Field border density \\
\hline Crop diversity & 1.00 & -0.25 \\
Field border density & -0.25 & 1.00 \\
Semi-natural habitat & 0.00 & 0.04 \\
Local flower cover & 0.15 & -0.14 \\
Almond & -0.07 & 0.39 \\
Cereal & -0.71 & 0.01 \\
Maize & 0.45 & 0.14 \\
Grassland & 0.22 & 0.27 \\
Oilseed rape & 0.30 & -0.53 \\
Olive & -0.09 & 0.35 \\
Sugar beet & 0.30 & -0.48 \\
\hline
\end{tabular}




\section{Chapter 4}

Maize dominated landscapes reduce bumble bee colony growth through pollen diversity loss

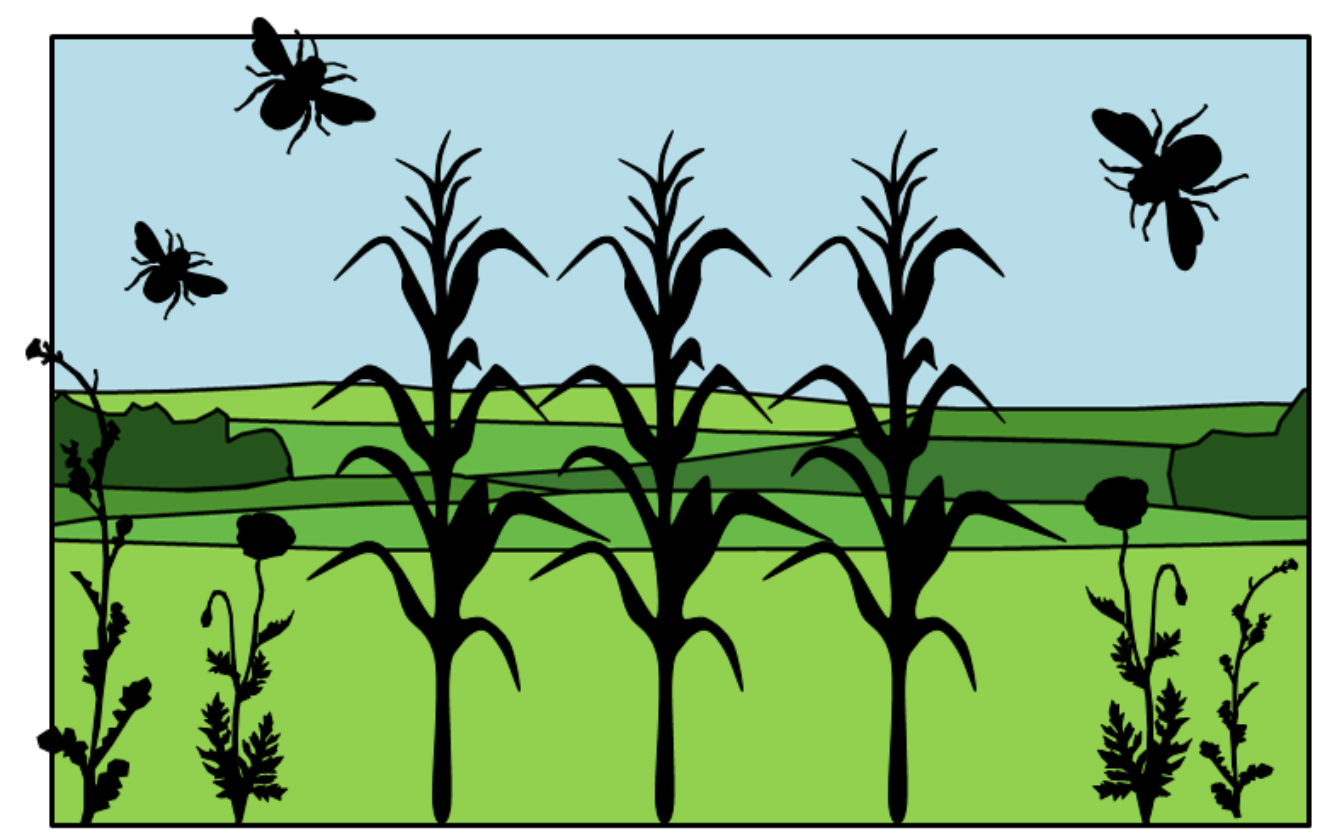

Annika Louise Hass, Lara Brachmann, Péter Batáry, Yann Clough and Hermann Behling, Teja Tscharntke

Published in Journal of Applied Ecology 2019, 56:294-304 


\section{Abstract}

Bumble bees are important pollinators for a wide range of crops and wild plants. Performance of their colonies depends on pollen and nectar as food resources, but flowering plants are scarce in modern agricultural landscapes. It is well-known that semi-natural habitats can enhance floral resources and bumble bee abundance, but the impact of different crop types and their heterogeneity at the landscape scale remains unclear.

We tested the effect of two different crop types (oilseed rape (OSR) and maize) and of configurational (field border density) and compositional heterogeneity (crop diversity) on weight gain of buff-tailed bumble bee colonies (Bombus terrestris) and the pollen diversity collected by them in 20 landscapes in Central Germany.

We found that augmenting maize cover had a detrimental effect on pollen diversity collected by bumble bees, probably due to intensive management resulting in low plant diversity. This low pollen diversity translated into reduced colony growth, since colonies with high pollen diversity gained more weight than colonies with low pollen diversity.

In contrast, OSR cover, configurational and compositional heterogeneity did neither affect colony growth nor pollen diversity. However, for OSR the timing of the flowering period was important. When OSR fields had a high flower cover at the end of the OSR blooming period, colonies showed increased growth rates.

Synthesis and applications. Our results complement previous laboratory studies by showing that high pollen diversity leads to better colony performance under field conditions. Therefore, the maintenance of floral diversity in agricultural landscapes is crucial to ensure that bumble bees can fulfil their nutritional needs. However, the heterogeneity of crops, at least under the currently very low levels of crop rotation, does not contribute to this aim. In contrast, crop identity and timing of mass-flowering crops turned out to be important factors, as maize reduced pollen resources, while late blooming oilseed rape was beneficial for bumble bee colonies. Hence, maize cover per landscape should be reduced and strategies to enhance landscape wide flower diversity, especially towards and after the end of oilseed rape bloom should be promoted to support bumble bee colonies that provide important pollination services.

Keywords: bumble bee, colony growth, crop diversity, configurational heterogeneity, landscape heterogeneity, oilseed rape, pollinator, pollen diversity 


\section{Introduction}

The production of many crop types depends on pollinators, with wild species being especially important and contributing to stable food production (Gallai, Salles, Settele, \& Vaissière, 2009; Garibaldi et al., 2013). Bumble bees are one important group of pollinators increasing yields of a wide range of crops, e.g. apples, strawberries, tomatoes and oilseed rape (OSR) (Bommarco, Marini, \& Vaissiere, 2012; Velthuis \& Doorn, 2006). However, severe declines of pollinators have been observed during the last decades (Potts et al., 2010) including many bumble bee species (Goulson, Lye, \& Darvill, 2007). The drivers include habitat loss and fragmentation as well as the application of agrochemicals like insecticides and herbicides, which have led to a dramatic reduction of floral resources in modern agricultural landscapes (Goulson et al., 2007; Robinson \& Sutherland, 2002). Therefore, reducing hostility of agro-ecosystems is a major goal of pollinator conservation and ecological intensification to safeguard pollination services in agricultural landscapes (IPBES, 2016; Kovács-Hostyánszki et al., 2017). Sufficient food resources are one important requirement for stable pollinator populations and bees feed exclusively on floral resources including nectar and pollen (Vaudo, Tooker, Grozinger, \& Patch, 2015). Nectar provides mainly carbohydrates giving energy for foraging flights, whereas pollen contains proteins, lipids and micronutrients that are essential for reproduction and larvae development (Roulston \& Cane, 2000; Vaudo et al., 2015). Nutrient content of pollen differs between plant species (Roulston \& Cane, 2000) and therefore, the availability of high floral resource diversity in the landscape is expected to be essential for the persistence of bee populations (Donkersley et al., 2017; Vaudo et al., 2015). As bumble bees can discriminate between different protein concentrations by using chemo-tactile cues (Ruedenauer, Spaethe, \& Leonhardt, 2015), they optimize nutrient intake by visiting plant species to obtain certain protein to lipid ratios (Vaudo, Patch, Mortensen, Tooker, \& Grozinger, 2016). Additionally, experimental studies have shown that bees probably reduce the negative effects of unfavourable pollen types (with low nutrient content or toxic secondary plant chemicals) by mixing them with high quality pollen (Bukovinszky et al., 2017; Eckhardt, Haider, Dorn, \& Müller, 2014). Furthermore, bumble bee larvae grow larger when fed with pollen mixes compared to single pollen diets (Tasei \& Aupinel, 2008), indicating the crucial importance of the availability of floral resource diversity.

There is ample evidence that increased floral cover and diversity enhance bumble bee abundance (reviewed in Winfree, Bartomeus \& Cariveau 2011). The few studies that investigated the effects of landscape-wide floral resources on bumble bee colony performance come to similar conclusions. Colonies in flower rich suburban sites gained more weight compared to colonies in farmland (Goulson, Hughes, Derwent, \& Stout, 2002), and especially early season resources are important for colony growth (Westphal, Steffan-Dewenter, \& Tscharntke, 2009; Williams, Regetz, \& Kremen, 2011). However, field studies investigating whether higher pollen diversity collected by 
bumble bees leads to improved colony performance are rare and did not confirm the positive effects of pollen diversity indicated by laboratory results (Kämper et al., 2016).

In agricultural landscapes the high diversity of flowering plant species growing in semi-natural habitats can improve the nutritional value of pollen collected by bees (Donkersley, Rhodes, Pickup, Jones, \& Wilson, 2014). Additionally, mass-flowering crops like oilseed rape provide ample resources of pollen and nectar for a short time period and can therefore also enhance pollinator abundance, colony growth and brood cell production (Holzschuh, Dormann, Tscharntke, \& Steffan-Dewenter, 2012; Westphal et al., 2009). Wind pollinated crops like maize can be an important pollen resource for honey bees (Danner, Härtel, \& Steffan-Dewenter, 2014), but wild bees have to our knowledge never been reported to collect maize pollen. In contrast, maize is associated with lower plant diversity than other crops inside the field and also in the adjacent boundary vegetation (Fagúndez, Olea, Tejedo, Mateo-Tomás, \& Gómez, 2016; Kleijn \& Verbeek, 2000), which might lead to reduced availability of pollen types in landscapes with high maize cover. However, the role of different crop types on wild pollinators remains unexplored and crops are usually considered as a homogeneous "hostile matrix" (Fahrig et al., 2011).

In addition to the cover of certain crop types in the landscape, higher compositional heterogeneity (higher crop diversity) and higher configurational heterogeneity (smaller field size or higher field border density) of farmland might also be beneficial for pollinators (Fahrig et al., 2015). Increased configurational heterogeneity could lead to enhanced habitat connectivity for pollinators, as they use hedgerows, grassy field margins, and potentially even the visual contrast between adjoining crops for orientation (Van Geert, Van Rossum, \& Triest, 2010; Cranmer, McCollin, \& Ollerton, 2012; Happe et al., 2018; Hass et al., 2018). With increasing compositional heterogeneity there might be more diverse resources available, as different crops usually have complementary weed communities (Hyvönen \& Salonen, 2002) leading to higher pollen diversity availability in landscapes with high crop diversity. However, the effects of compositional and configurational heterogeneity could also be interactive, because the enhanced resource availability of high crop diversity might only be accessible for pollinators if the landscape connectivity is increased by high field border density.

Here we tested how two different crop types and the configurational and compositional heterogeneity of the crop production area at the landscape scale affect the pollen diversity collected by colonies of Bombus terrestris and their colony performance. We focused on two major crops: First, oilseed rape due to the provision of ample floral resources during mass-flowering that affect wild bees at the local and landscape scale (Hanley et al., 2011). Second, we selected maize, because it can impact biodiversity and ecosystem services negatively (Landis, Gardiner, Werf, \& Swinton, 2008; Sauerbrei, Ekschmitt, Wolters, \& Gottschalk, 2014) and because its cultivation has increased by $47 \%$ 
from 2004 to 2017 in Germany (Destatis, 2017) due to high bioenergy demands. In particular, we assessed evidence with respect to the following hypotheses:

i) Maize cover deteriorates colony performance through reduced pollen diversity collected by workers.

ii) Oilseed rape cover at the local and landscape scale improves colony performance through greater pollen and nectar amounts collected by workers.

iii) Farmland configurational heterogeneity increases colony performance directly and through higher pollen diversity collected by workers, because of higher landscape connectivity and better access to diverse food resources. The positive effect of configurational heterogeneity might only be evident if compositional heterogeneity is high.

iv) Farmland compositional heterogeneity increases colony performance through higher pollen diversity collected by workers, as more different crop types offer more diverse food resources. This effect might be only important if configuration is high, facilitating movement across landscapes.

\section{Material and methods}

\section{Study sites and landscape variables}

All field experiments took place in agricultural landscapes in the surrounding of the city of Göttingen, in the state Lower Saxony of Germany (Fig. 1). The hilly region is characterised by mainly intensively managed agricultural fields with cereals, oilseed rape, maize and sugar beet being the most commonly grown crops. We selected $201 \times 1 \mathrm{~km}$ landscapes with uncorrelated gradients of compositional and configuration heterogeneity (see Table S1 in Supporting Information) and from here on we will refer to the $1 \mathrm{~km}$ grids as landscapes (see Appendix S1for more details on landscape selection). The minimum distance between landscapes was $1.5 \mathrm{~km}$ between centre points. Although Bombus terrestris individuals can travel several kilometres, the mean foraging distance is $551 \mathrm{~m}$ and the resources close to the nest are most important (Redhead et al., 2016). Therefore, we assume that the $1 \times 1 \mathrm{~km}$ grids represent a relevant spatial scale for this species.

During the field season land use and crop types were mapped in detail for each of the selected landscapes. Furthermore, we mapped semi-natural area cover including linear and open patchy habitats. Based on these data we calculated five landscape-scale variables for all $1 \mathrm{~km}^{2}$ landscapes (Table 1, see Appendix S1for more details on landscape variable calculation). 

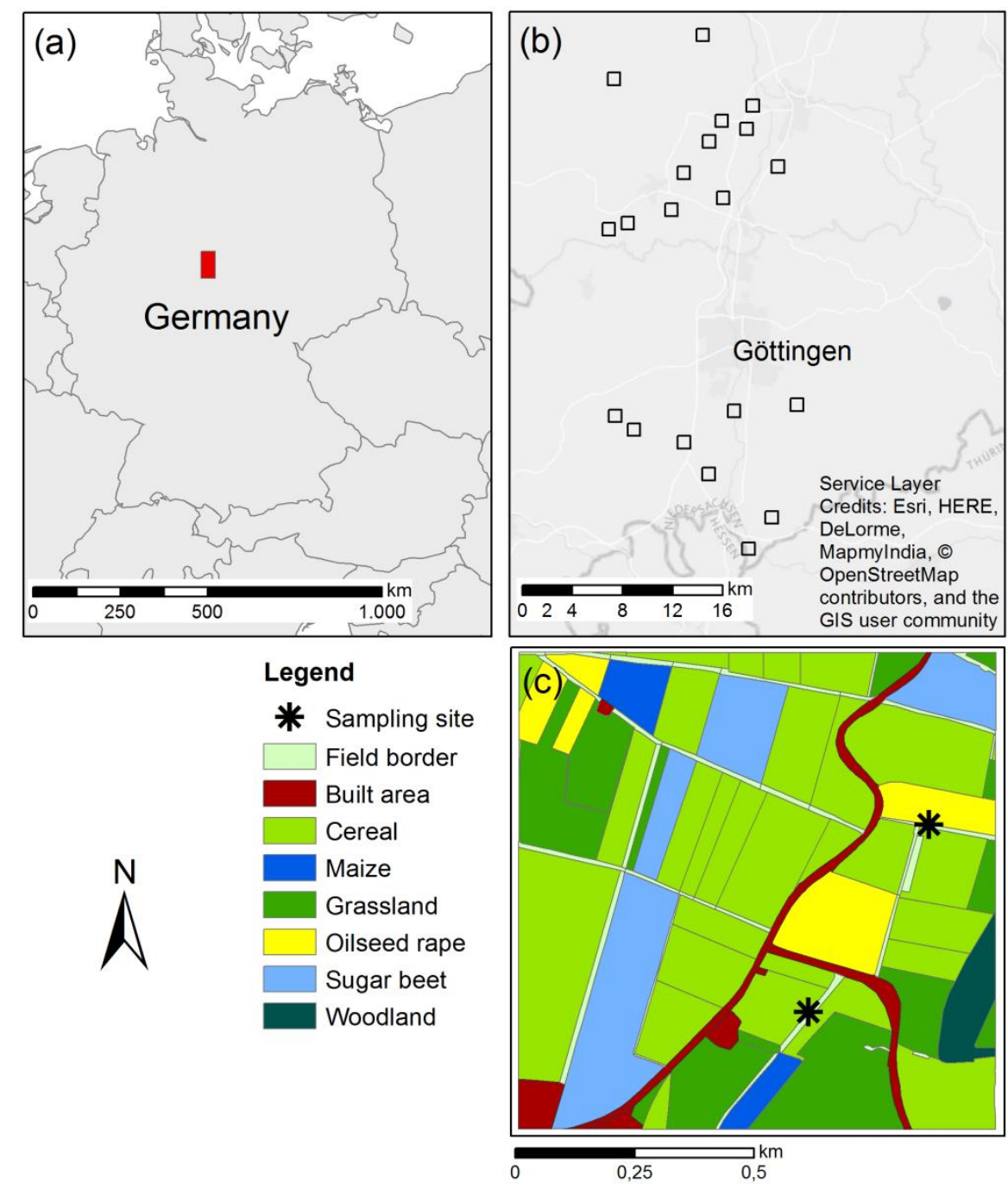

Figure 1 Location of (a) the study region in central Germany and (b) the $201 \times 1 \mathrm{~km}$ landscapes in the surrounding of Göttingen and (c) one example landscape. In each landscape all crop types and field borders were mapped and one cereal and one oilseed rape field were selected for sampling where one Bombus terrestris colony was placed in the semi-natural field boundary vegetation.

Table 1 Variables and their measures used in the structural equation model

\begin{tabular}{llrrr}
\hline Variable & Measure & mean & min & max \\
\hline Landscape scale & & & & \\
\hline Oilseed rape cover (OSR) & Landscape crop cover [\%] & 15.30 & 4.41 & 41.12 \\
Maize cover & Landscape crop cover [\%] & 8.13 & 0.00 & 46.53 \\
Compositional heterogeneity & Shannon index for crop diversity & 1.11 & 0.79 & 1.39 \\
Configurational heterogeneity & Field border density [m/ha] & 221.39 & 123.27 & 312.54 \\
Semi-natural cover & Landscape cover [\%] & 7.40 & 2.85 & 17.87 \\
\hline Local scale & & & & \\
\hline Local crop type & Cereal and oilseed rape fields & & & \\
Late flower cover OSR & Oilseed rape flower cover end May \% & 14.12 & 1.00 & 35.00 \\
\hline
\end{tabular}




\section{Field experiment and lab analysis}

We purchased 40 early stage Bombus terrestris colonies from a regional provider (STB Control, Germany). Each colony was delivered in a plastic box covered by cardboard. We placed the colonies in the grassy margins of the selected fields (one cereal and one oilseed rape field per landscape) on April 17 - 18 2014. As B. terrestris usually starts to produce workers at the end of March to mid-April (Hagen \& Aichhorn, 2014), we assume that wild colonies were also in the worker production phase at these dates. Additional sugar feeders were removed, and we protected all colonies against rain by small tents made of plastic sheets (Fig. S1). At this time OSR was already blooming due to an unusually warm and sunny spring. To measure the colony weight, the plastic box was taken out of the cardboard box and put on a field scale. Although colonies were weighed during the day we assume that this was a good proxy for colony growth as Westphal et al. (2009) found a high correlation of day time weight measurements and total brood cell production. Additionally, weighing times were randomized across the landscape gradients. The first weighing took place during the colony placement in the field and all colonies had a similar initial weight (mean \pm SD: $634.83 \mathrm{~g} \pm 29.11 \mathrm{~g}$ ). Afterwards, we conducted three subsequent measurements (May $8-9$, May $20-24$ and June 4-5). After the last weighing round we collected the colonies from the field sites. Most colonies had already died at this date, but if that was not the case, the remaining bumble bees were executed by freezing.

We collected pollen samples from the experimental colonies from May $13-21$ during warm and sunny weather conditions. Pollen samples were taken from the corbiculae of three workers of each colony. We closed the entrance hole of the colony and caught workers returning with pollen loads. Pollen loads were removed with a clean forceps and stored in an Eppendorf tube. Afterwards, the bumble bees were released. We froze the pollen samples from individual bumble bee workers until further processing. During collecting pollen samples from colonies next to OSR fields we estimated the flower cover of this adjacent OSR field in percent cover (e.g. 30\% of the whole field were covered by OSR flowers estimated from above). This was always done by the same person to reduce bias and gave an estimate of how many resources were provided by at least one field in the landscape (due to crop variety or microclimate) at this late stage of the OSR bloom at the end of May. Therefore, we named this variable "Late flower cover OSR". From seven colonies no pollen could be collected, because colonies were destroyed in the field by accidental mowing or died early for unknown reasons. These losses occurred randomly across the gradients of compositional and configurational heterogeneity as well as across the gradients of oilseed rape and maize cover in our data set (Fig. S2). These colonies were excluded resulting in a final data set of 33 colonies from 19 landscapes.

To prepare pollen samples for identification we conducted a standard acetolysis method (Faegri \& Iverson, 1989, see Appendix S1). For each sample we counted and identified 500 pollen 
grains. As some pollen (e.g. wind dispersed pollen grains) could have been found on the bumble bees randomly, without having been actively collected, we excluded all pollen types that were counted less than 5 times in a sample.

\section{Data analysis}

For each colony we calculated maximum colony weight gain, which was the difference between the first weight during placement in the field and the highest measured weight during the field experiment, which was usually the weight of the third round (May $20-24)$. However, four colonies reached their maximum weight already during the second round. For pollen diversity we pooled pollen species data for the three samples per colony and then calculated the Shannon diversity index, based on the number of different pollen types found in the sample, and their abundance. Maize, OSR and semi-natural cover were logit transformed to achieve better model fit. All analyses were conducted with R (R Development Core Team, 2016).

To analyse the effects of landscape heterogeneity and different crop types on pollen diversity collected by bumble bees and the cascading effects on colony weight gain we used structural equation modelling. Piecewise structural equation modelling makes it possible to include random effects by allowing to combine different commonly used mixed-effects models (package "piecewiseSEM", Lefcheck, 2016). First, we constructed a hypothetical model (Fig. 2a). We expected that configurational and compositional heterogeneity as well as OSR and maize cover at the landscape scale would affect pollen diversity. As co-variates, we added effects of local crop type (cereal or OSR), late flower cover of OSR (see above) and semi-natural cover on pollen diversity. Additionally, we included a two-way interaction of configurational and compositional heterogeneity. For colony weight gain we expected that it would be influenced directly by pollen diversity, configurational heterogeneity and OSR cover as well as by local crop type, late flower cover OSR and semi-natural cover. We did not include compositional heterogeneity and maize cover in this model, because the hypothesis was that these two variables affect colony growth only indirectly through pollen diversity. We are aware that there could be direct effects of certain crops due to specific pesticide applications. However, as data for pesticide applications in our landscapes were not available, we did not include these direct pathways. As modelling all these effects in one structural equation model was not possible (d-rule: the number of samples per path should be at least 5, Grace, Scheiner, \& Schoolmaster, 2015), we first constructed two common linear mixed-effects models with pollen diversity and colony weight gain as response variables including all effects mentioned above (package "nlme", Pinheiro, Bates, DebRoy, Sarkar, \& R Development Core Team, 2017). As random effects we always included landscape comprising two sampled fields. Then we used an automated step-wise backwards selection process based on AIC (Akaike information criterion) for both models until the best 
model was found. This simplification process resulted in the final SEM including six paths (Fig. 2b), which is in line with the d-rule, as data from 33 colonies were included in the model. These best models included paths of compositional and configurational heterogeneity as well as their interaction and maize cover to pollen diversity and paths of pollen diversity and late flower cover to colony weight gain. To check how our simplification method affected the results, we also fit all model subsets using the "dredge" function from "MuMIn" package (Barton, 2018) and ran linear mixed effect models with all variables included in the models with $\triangle \mathrm{AIC}<2$. Then we compared the estimates and P-values with those from the models of the step-wise reduction and the full models (including all variables without simplification). For all models we checked homoscedasticity and normality of residuals as well as collinearity of included variables by variance inflation factors, because there were correlations between some of our variables (Table S1), but no problems were detected.

\section{Results}

The 33 colonies included in the analysis developed well with their maximum weight gain at the end of May (mean weight gain \pm SD: $389.18 \mathrm{~g} \pm 222.55 \mathrm{~g}$ ). From the pollen samples we identified 19 pollen types of which few could be identified to species level and most could be assigned to a pollen type group (Table 2). The most abundant pollen type was Brassicaceae, which we expect to be all OSR due to its widespread abundance in agricultural fields and because no other frequent wild Brassicaceae species were observed in our landscapes. Other commonly collected pollen types were from the Sorbus group, Trifolium repens type and Vicia type.

The best SEM identified by the model simplification based on stepwise reduction fit the data well (Fisher's $C=16.49, P=0.086$ ) and no important path was missing, indicated by non-significant independence claims. Model results are presented in Table 3. Pollen diversity was negatively affected by maize cover (Fig. 3a). Additionally, colony weight gain benefited from high pollen diversity and was also positively influenced by a high flower cover of OSR in late spring (Fig. 3b,c). Compositional and configurational heterogeneity had no significant effect on pollen diversity collected by the colonies although included in the best model (Fig. 2b). Likewise, the interaction term of compositional and configurational heterogeneity was not significant. Comparing these results to those of the full model and those of the reduced model based on $\triangle \mathrm{AIC}<2$ we found similar effects (Table S2). For the model with pollen diversity as response variable maize cover also had a significant effect in the full model $(P=$ $0.042)$ and was very close to significance in the $\triangle A I C<2$ model $(P=0.061)$. For the model with colony 
(a)
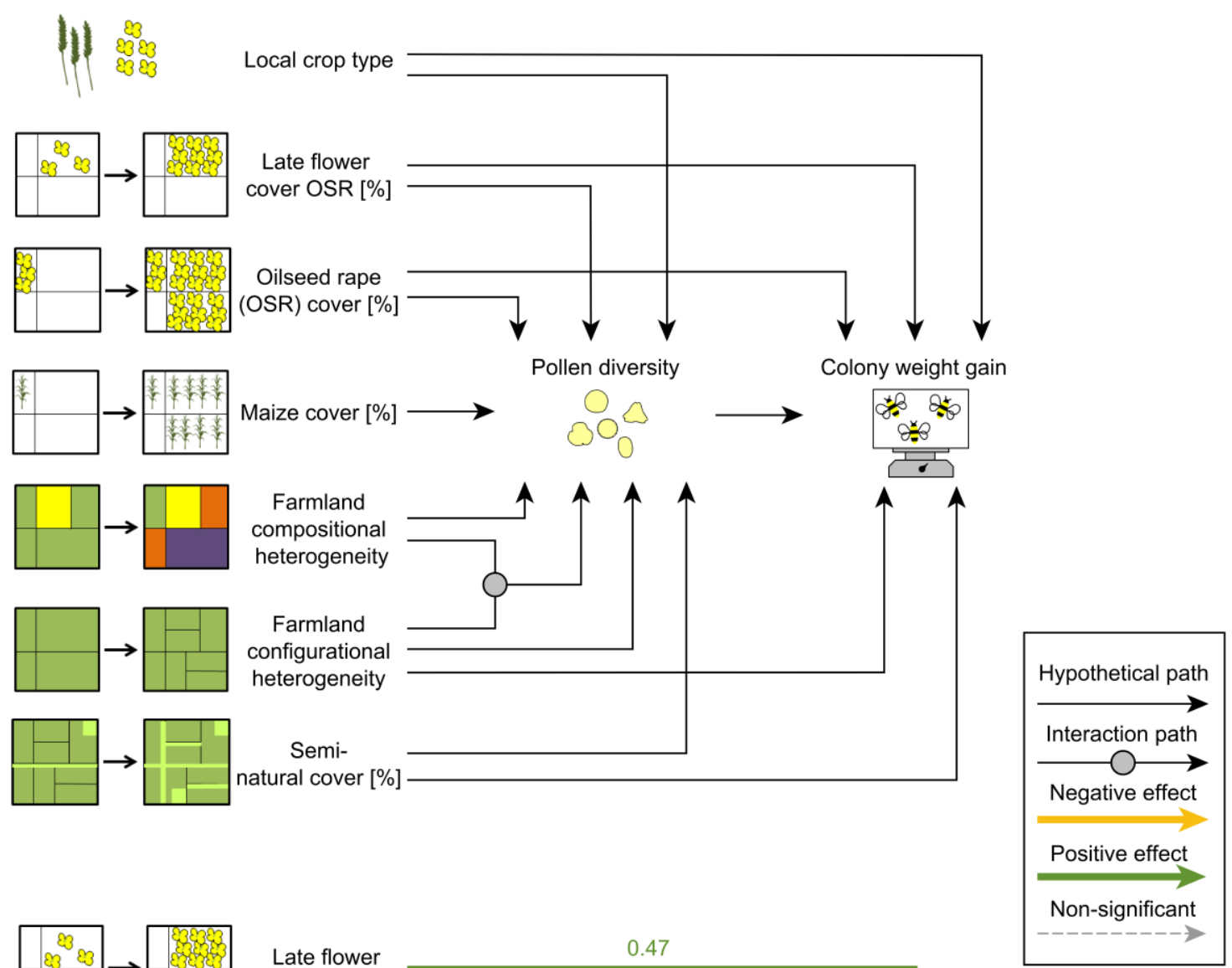

(b)
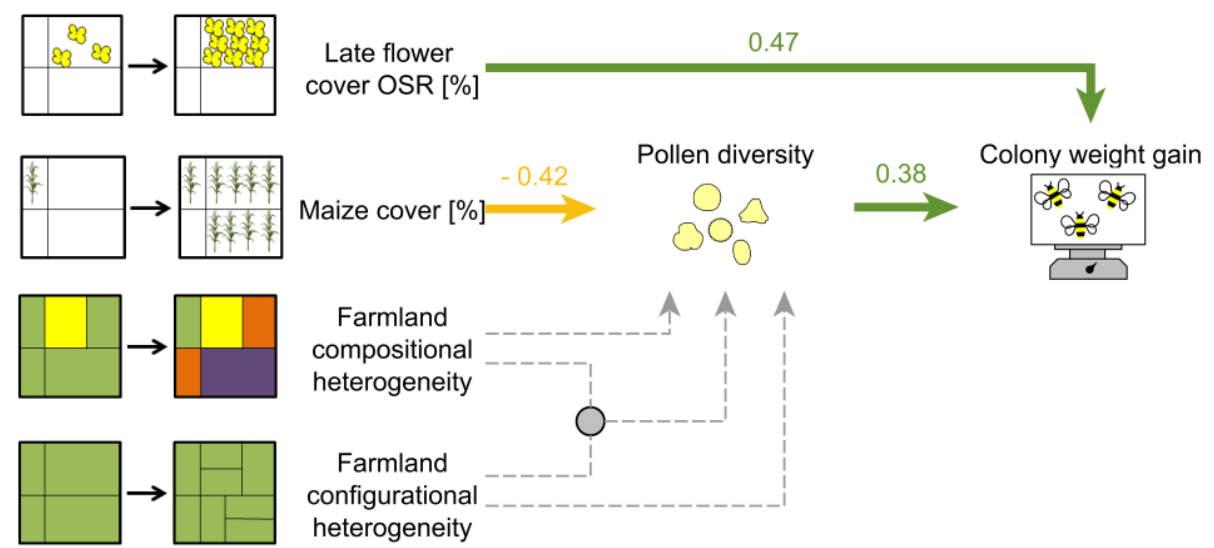

configurational
heterogeneity

Figure 2 Structural equation models including effects of local and landscape variables on pollen diversity collected by workers of $30 \mathrm{~B}$. terrestris colonies and their colony performance measured as weight gain after 4 weeks in the field: (a) Hypothetical model including all pathways and (b) final model including all pathways after model simplification based on AIC. Local crop type indicates whether a colony was placed next to a cereal or oilseed rape field and late flower cover OSR is the cover of flowers in oilseed rape fields during the late stage of blooming (end of May) when pollen samples were collected. Numbers next to arrows show standardized regression coefficients. 
(a)

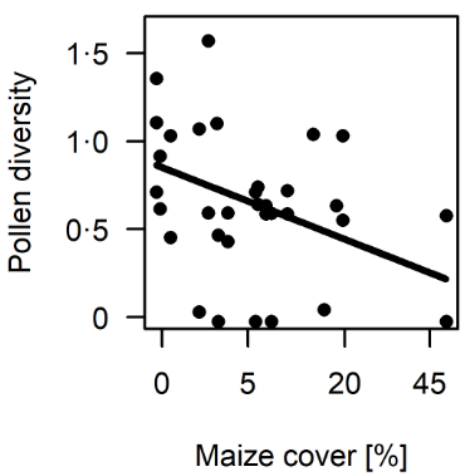

(b)

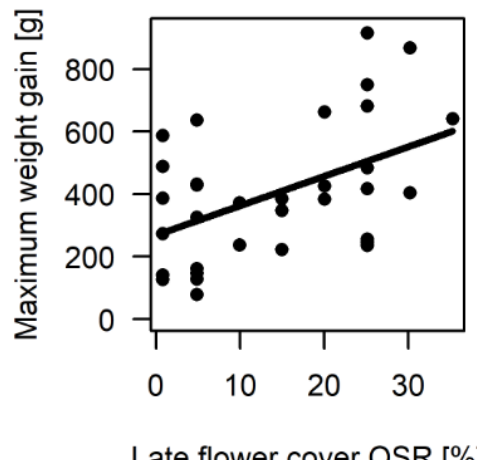

Late flower cover OSR [\%] (c)

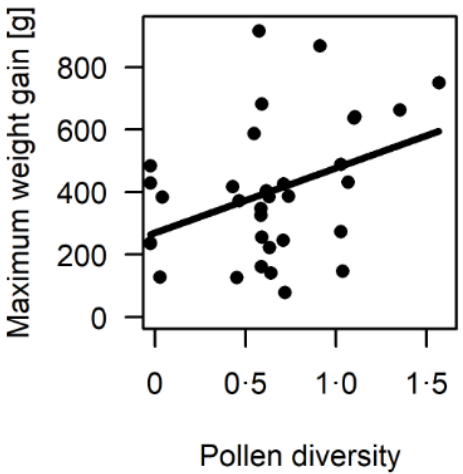

Figure 3 Effects of (a) maize cover at the landscape scale on pollen diversity (Shannon diversity index) collected by three workers of each colony. (b) late flower cover of oilseed rape (OSR) on maximum weight gain of bumble bee colonies and (c) pollen diversity (Shannon diversity index) on maximum weight gain from $33 \mathrm{~B}$. terrestris colonies. Lines show predictions of linear mixed effect models used in the structural equation model in Fig. $2 \mathrm{~b}$.

Table 2 Pollen types identified from pollen loads of Bombus terrestris workers. Abundances show the number of pollen grains found across all samples and samples indicate the number of workers that were found to carry this pollen type. Pollen types with less than 5 grains were excluded.

\begin{tabular}{lrr}
\hline Pollen type & Abundance & Samples \\
\hline Brassicaceae & 22,202 & 69 \\
Sorbus group 1 & 12,613 & 36 \\
Trifolium repens type & 6,500 & 17 \\
Vicia type 1 & 2,963 & 8 \\
Phacelia tanacetifolia & 618 & 2 \\
Ranunculus acris type & 550 & 3 \\
Sorbus group 2 & 499 & 1 \\
Cimicifuga foetida & 498 & 1 \\
Rosaceae & 496 & 1 \\
Plantago lanceolata & 478 & 2 \\
Spergularia type & 464 & 1 \\
Crataegus monogyna & 316 & 1 \\
Lamium album type & 313 & 2 \\
Vicia type 2 & 196 & 2 \\
Potentilla type & 53 & 1 \\
Sambucus nigra type & 51 & 2 \\
Viburnum opulus type & 18 & 2 \\
Symphytum officinale & 15 & 1 \\
Secale & 5 & 1 \\
Unidentified & 501 & 2 \\
\hline Total & 49,349 & 99 \\
\hline
\end{tabular}


weight gain as response variable, the results from the two simplification methods and the full model were identical.

Table 3 Model results for the two models used in the structural equation model, (a) with pollen diversity and (b) with maximum weight gain of bumble bee colonies as response variables. $\mathrm{Cl}$ : Confidence Interval

\begin{tabular}{lllll}
\hline & & $\begin{array}{l}\text { Lower } \\
\text { (a) Model 1: Response pollen diversity }\end{array}$ & $\begin{array}{l}\text { Upper } 95 \\
\% \mathrm{Cl}\end{array}$ & P-Value \\
\hline Intercept & & & & \\
Maize & 0.04 & -0.27 & 0.35 & 0.808 \\
Field border density & -0.42 & -0.77 & -0.07 & 0.034 \\
Crop diversity & -0.29 & -0.61 & 0.03 & 0.096 \\
Field border density : crop & 0.08 & -0.28 & 0.45 & 0.667 \\
diversity & -0.32 & -0.75 & 0.11 & 0.171 \\
\hline (b) Model 2: Response colony weight gain & & & & \\
\hline Intercept & 0.00 & -0.30 & 0.29 & 0.978 \\
Pollen diversity & 0.38 & 0.10 & 0.66 & 0.021 \\
Late flower cover OSR & 0.47 & 0.17 & 0.77 & 0.007 \\
\hline
\end{tabular}

\section{Discussion}

In this study we clearly demonstrate that maize cover at the landscape scale can deteriorate bumble bee colony weight gain, which appeared to be mediated by reduced pollen diversity. Additionally, colony weight gain was strongly influenced by the flower density of oilseed rape fields at the end of May.

Our results are in accordance with previous studies showing negative effects of maize on biodiversity and ecosystem services, for example for birds (Sauerbrei et al., 2014) and natural enemies of aphids (Landis et al., 2008). The reduced pollen diversity collected by the colonies in landscapes with high maize cover could be explained by the low plant diversity found not only inside the fields of this crop compared to cereal fields (Fagúndez et al., 2016), but also in semi-natural field boundaries adjacent to maize (Kleijn \& Verbeek, 2000). Probably, the intensive management of maize requiring high fertilizer and herbicide input is responsible for this reduced plant diversity (Fagúndez et al., 2016; Kleijn \& Verbeek, 2000).

As pollen diversity was directly related to high colony weight gain, increased pollen diversity under field conditions can be valued as highly beneficial for bumble bee colony performance. Thereby, we complement the results of laboratory studies showing positive effects of pollen diversity on pollinator offspring development (Eckhardt et al., 2014; Tasei \& Aupinel, 2008). Through increased pollen diversity the bumble bees are possibly able to fulfil different resource requirements as different 
pollen species provide different nutrients that include proteins, lipids and other micronutrients such as vitamins (Roulston \& Cane, 2000; Vaudo et al., 2015). It is also possible that mixing of different pollen types makes it possible for bumble bees to exploit more resources as pollen of low quality, which are lethal as pure diets for larvae, can be consumed without negative impact in mixtures with high quality pollen (Bukovinszky et al., 2017; Eckhardt et al., 2014). Although the production of queens can respond differently to environmental factors than colony growth (Westphal et al., 2009; Williams et al., 2011), larger colonies usually also produce more queens (Goulson et al., 2002; Kämper et al., 2016; Westphal et al., 2009). Therefore, it may be likely that this increase in colony growth also affected reproductive success and thereby population viability of the bumble bees (Crone \& Williams, 2016). However, we only sampled pollen during a short time period and studies on bumble bee pollen diets throughout the season are necessary to complete our understanding of the effects of pollen diversity on colony performance.

An alternative explanation for the positive effect of pollen diversity could be its strong negative correlation with the proportion of OSR pollen (Fig. S3) indicating that the bumble bees switch to other pollen resources than OSR if possible. This is in accordance with other studies showing that bumble bees and honey bees avoid OSR pollen (Kämper et al., 2016; Requier et al., 2015). One possible explanation could be that OSR pollen contains toxic secondary plant chemicals, e.g. glucosinolates, an important defence against herbivores in the order Brassicale (Kämper et al., 2016; Wittstock, Kliebenstein, Lambrix, Reichelt, \& Gershenzon, 2003). Additionally, OSR seeds were frequently treated with pesticides including neonicotinoids in our study area, which might have impacted colony growth negatively (Rundlöf et al., 2015; Woodcock et al., 2017). The EU moratorium of neonicotinoids was applicable since December 2013 and did therefore not affect winter oilseed rape sown before that date in 2013 and flowering in the fields in 2014. Additionally, OSR cover at the landscape scale did neither influence pollen diversity nor colony growth, contrasting to our expectations and the findings by Westphal et al. (2009). The reason could be that distance to the next OSR field is more important than its landscape cover, as all our colonies had at least one OSR field in the close surrounding due to the study design. However, OSR fields in our region differed in their phenology, possibly due to different varieties and local microclimate. If OSR fields provided high flower densities at the end of the OSR blooming period, the maximum weight gain of the colonies strongly increased. As this late flowering cover of OSR directly affected colony performance, but not indirectly via pollen diversity, it is likely that rather nectar than pollen resources were responsible for this impact. Indeed, OSR is much more frequently used for nectar than for pollen resources by honey bees (Requier et al., 2015), and the end of the OSR blooming period was the time when our colonies reached their maximum weight with high flight activity and possibly high nectar requirements. However, OSR fields flowering early compared to other fields might also be important for emerging 
queens during the nest foundation stage, which we did not investigate by placing already established colonies in our landscapes. Nevertheless, the timing of OSR field blooming seems to be an important and hitherto neglected factor that should be addressed in future studies.

Neither the compositional nor the configurational heterogeneity of the crops in our landscapes had an effect on pollen collection or colony growth of B. terrestris colonies. For configurational heterogeneity this result is in accordance with previous studies on pollinators, which investigated the number of patches, edge length or inter-patch connectivity of semi-natural habitats per landscape and found no or only weak effects (Kennedy et al., 2013; Steckel et al., 2014). The reason might be that $B$. terrestris is a highly mobile generalist that is little affected by habitat fragmentation, which is supported by the fact that there is no strong genetic differentiation between populations in Europe (Estoup, Solignac, Cornuet, Goudet, \& Scholl, 1996) and therefore this species might only respond to increased high quality habitat area (Carvell et al., 2017). However, this might be different for rare bumble bees (Goulson et al., 2007) or other less mobile pollinator species that could be more sensitive to configurational heterogeneity. For compositional heterogeneity it is probably more important which crops are grown than how diverse the crop fields are at the landscape scale. This should be at least the case if this diversification does not include more extensively managed crops such as temporary clover/grass-leys (Le Féon et al., 2013).

\section{Conclusions}

We conclude that the consideration of the crop production area should be an important part of agricultural landscape management and applied pollinator research. Our results show that high maize cover can imperil pollen diversity collected by B. terrestris colonies translating into reduced colony performance. Thus, the expansion of this crop by 47 \% from 2004 to 2017 in Germany, although being constant since 2011 (Destatis, 2017), is alarming. Maize cover should therefore be reduced or strategies should be developed to minimize the negative impact on plant and pollen diversity, e.g. by establishing perennial flower strips and patches offering diverse floral resources for pollinators (Haaland, Naisbit, \& Bersier, 2011). German law requires that in $205080 \%$ of the electricity should come from renewable energy sources including biomass (EEG, 2016). Our results indicate that achieving this target by expanding the area of cultivated maize could impair pollinators and possibly also pollination services. Mass-flowering crops such as OSR can increase pollinator abundance, diversity and colony performance (Diekötter, Peter, Jauker, Wolters, \& Jauker, 2014; Holzschuh et al., 2012; Westphal et al., 2009). However, our study indicates that temporal aspects are more important than spatial cover.

We demonstrate that high pollen diversity collected by bumble bee workers is essential for colony performance under field conditions complementing previous laboratory studies (Eckhardt et 
al., 2014; Tasei \& Aupinel, 2008). Thereby, we support the call for boosting floral diversity in agricultural landscapes to ensure that pollinators can fulfil their nutritional requirements (Vaudo et al., 2015). High floral cover and diversity should therefore be in the focus of future landscape management and agri-environment schemes (Batáry, Dicks, Kleijn, \& Sutherland, 2015). In contrast, the compositional and configurational heterogeneity of crops at the landscape scale seems to be of minor importance, at least for the generalist B. terrestris, but can make a difference for other wild bee species (Hass et al., 2018).

\section{Acknowledgements}

This research was funded by the Federal Ministry of Education and Research in Germany as part of the Biodiversa-Project FarmLand (FKZ: 01LC1104A). We would like to thank all farmers who gave access to their fields. Additionally, we are grateful to Kelsey Joustra for field assistance and to Aliette Bosem Baillod for joint landscape selection and critical evaluation of an earlier version of the manuscript.

\section{References}

Barton, K. (2018). MuMIn: Multi-model interference. R package version 1.40 .4 https://CRAN.Rproject.org/package=MuMln .

Batáry, P., Dicks, L.V., Kleijn, D. \& Sutherland, W.J. (2015). The role of agri-environment schemes in conservation and environmental management. Conserv. Biol., 29, 1006-1016.

Bommarco, R., Marini, L. \& Vaissiere, B.E. (2012). Insect pollination enhances seed yield, quality, and market value in oilseed rape. Oecologia, 169, 1025-1032.

Bukovinszky, T., Rikken, I., Evers, S., Wäckers, F.L., Biesmeijer, J.C., Prins, H.H.T., et al. (2017). Effects of pollen species composition on the foraging behaviour and offspring performance of the mason bee Osmia bicornis (L.). Basic Appl. Ecol., 18, 21-30.

Carvell, C., Bourke, A.F.G., Dreier, S., Freeman, S.N., Hulmes, S., Jordan, W.C., et al. (2017). Bumblebee family lineage survival is enhanced in high-quality landscapes. Nature, 543, 547-549.

Cranmer, L., McCollin, D. \& Ollerton, J. (2012). Landscape structure influences pollinator movements and directly affects plant reproductive success. Oikos, 121, 562-568.

Crone, E.E. \& Williams, N.M. (2016). Bumble bee colony dynamics: quantifying the importance of land use and floral resources for colony growth and queen production. Ecol. Lett., 19, 460-468.

Danner, N., Härtel, S. \& Steffan-Dewenter, I. (2014). Maize pollen foraging by honey bees in relation to crop area and landscape context. Basic Appl. Ecol., 15, 677-684.

Destatis. (2017). Fachserie. 3, Land- und Forstwirtschaft, Fischerei. 3, Landwirtschaftliche Bodennutzung und pflanzliche Erzeugung. 1, Landwirtschaftliche Bodennutzung. 2, Anbau auf dem Ackerland. Vorbericht.

Diekötter, T., Peter, F., Jauker, B., Wolters, V. \& Jauker, F. (2014). Mass-flowering crops increase richness of cavity-nesting bees and wasps in modern agro-ecosystems. GCB Bioenergy, 6, 219226.

Donkersley, P., Rhodes, G., Pickup, R.W., Jones, K.C., Power, E.F., Wright, G.A., et al. (2017). Nutritional composition of honey bee food stores vary with floral composition. Oecologia, 185, 749-761.

Donkersley, P., Rhodes, G., Pickup, R.W., Jones, K.C. \& Wilson, K. (2014). Honeybee nutrition is linked to landscape composition. Ecol. Evol., 4, 4195-4206. 
Eckhardt, M., Haider, M., Dorn, S. \& Müller, A. (2014). Pollen mixing in pollen generalist solitary bees: a possible strategy to complement or mitigate unfavourable pollen properties? J. Anim. Ecol.

EEG. (2016). Gesetz zur Einführung von Ausschreibungen für Strom aus erneuerbaren Energien und zu weiteren Änderungen des Rechts der erneuerbaren Energien. Bundesgesetzblatt Teil I, (49), 2258-2357.

Estoup, A., Solignac, M., Cornuet, J.M., Goudet, J. \& Scholl, A. (1996). Genetic differentiation of continental and island populations of Bombus terrestris (Hymenoptera: Apidae) in Europe. Mol. Ecol., 5, 19-31.

Faegri, K., \& Iverson, J. (1989). Textbook of Pollen Analysis (4th Edition). Chichester: Wiley.

Fagúndez, J., Olea, P.P., Tejedo, P., Mateo-Tomás, P. \& Gómez, D. (2016). Irrigation and maize cultivation erode plant diversity within crops in Mediterranean dry cereal agro-ecosystems. Environ. Manage., 58, 164-174.

Fahrig, L., Baudry, J., Brotons, L., Burel, F.G., Crist, T.O., Fuller, R.J., et al. (2011). Functional landscape heterogeneity and animal biodiversity in agricultural landscapes. Ecol. Lett., 14, 101-112.

Fahrig, L., Girard, J., Duro, D., Pasher, J., Smith, A., Javorek, S., et al. (2015). Farmlands with smaller crop fields have higher within-field biodiversity. Agric. Ecosyst. Environ., 200, 219-234.

Gallai, N., Salles, J.-M., Settele, J. \& Vaissière, B.E. (2009). Economic valuation of the vulnerability of world agriculture confronted with pollinator decline. Ecol. Econ., 68, 810-821.

Garibaldi, L.A., Steffan-Dewenter, I., Winfree, R., Aizen, M.A., Bommarco, R., Cunningham, S.A., et al. (2013). Wild pollinators enhance fruit set of crops regardless of honey bee abundance. Science, 339, 1608-1611.

Goulson, D., Hughes, W., Derwent, L. \& Stout, J. (2002). Colony growth of the bumblebee, Bombus terrestris, in improved and conventional agricultural and suburban habitats. Oecologia, 130, 267-273.

Goulson, D., Lye, G. c. \& Darvill, B. (2007). Decline and Conservation of Bumble Bees. Annu. Rev. Entomol., 53, 191-208.

Grace, J.B., Scheiner, S.M. \& Schoolmaster, D.R. (2015). Structural equation modeling: building and evaluating causal models. In: Ecological Statistics: From Principles to Applications (eds. Fox, G.A., Negrete-Yanlelevich, S. \& Sosa, V.J.). Cambridge University Press, New York.

Haaland, C., Naisbit, R.E. \& Bersier, L.-F. (2011). Sown wildflower strips for insect conservation: a review. Insect Conserv. Divers., 4, 60-80.

Hagen, E. von \& Aichhorn, A. (2014). Hummeln: bestimmen, ansiedeln, vermehren, schützen. 6th edn. Fauna, Nottuln.

Hanley, M.E., Franco, M., Dean, C.E., Franklin, E.L., Harris, H.R., Haynes, A.G., et al. (2011). Increased bumblebee abundance along the margins of a mass flowering crop: evidence for pollinator spill-over. Oikos, 120, 1618-1624.

Happe, A.-K., Riesch, F., Rösch, V., Gallé, R., Tscharntke, T. \& Batáry, P. (2018). Small-scale agricultural landscapes and organic management support wild bee communities of cereal field boundaries. Agric. Ecosyst. Environ., 254, 92-98.

Hass, A.L., Kormann, U.G., Tscharntke, T., Clough, Y., Baillod, A.B., Sirami, C., et al. (2018). Landscape configurational heterogeneity by small-scale agriculture, not crop diversity, maintains pollinators and plant reproduction in western Europe. Proc R Soc B, 285, 20172242.

Holzschuh, A., Dormann, C.F., Tscharntke, T. \& Steffan-Dewenter, I. (2012). Mass-flowering crops enhance wild bee abundance. Oecologia, 172, 477-484.

Hyvönen, T. \& Salonen, J. (2002). Weed species diversity and community composition in cropping practices at two intensity levels - a six-year experiment. Plant Ecol., 159, 73-81.

IPBES. (2016). The assessment report of the intergovernmental science - policy platform on biodiversity and ecosystem services on pollinators, pollination and food production. Secretariat of the Intergovernmental Science-Policy Platform on Biodiversity and Ecosystem Services, Bonn, Germany. 
Kämper, W., Werner, P.K., Hilpert, A., Westphal, C., Blüthgen, N., Eltz, T., et al. (2016). How landscape, pollen intake and pollen quality affect colony growth in Bombus terrestris. Landsc. Ecol., 31, 2245-2258.

Kennedy, C.M., Lonsdorf, E., Neel, M.C., Williams, N.M., Ricketts, T.H., Winfree, R., et al. (2013). A global quantitative synthesis of local and landscape effects on wild bee pollinators in agroecosystems. Ecol. Lett., 16, 584-599.

Kleijn, D. \& Verbeek, M. (2000). Factors affecting the species composition of arable field boundary vegetation. J. Appl. Ecol., 37, 256-266.

Kovács-Hostyánszki, A., Espíndola, A., Vanbergen, A.J., Settele, J., Kremen, C. \& Dicks, L.V. (2017). Ecological intensification to mitigate impacts of conventional intensive land use on pollinators and pollination. Ecol. Lett., 20, 673-689.

Landis, D.A., Gardiner, M.M., Werf, W. van der \& Swinton, S.M. (2008). Increasing corn for biofuel production reduces biocontrol services in agricultural landscapes. Proc. Natl. Acad. Sci., 105, 20552-20557.

Le Féon, V., Burel, F., Chifflet, R., Henry, M., Ricroch, A., Vaissière, B.E., et al. (2013). Solitary bee abundance and species richness in dynamic agricultural landscapes. Agric. Ecosyst. Environ., 166, 94-101.

Lefcheck, J.S. (2016). piecewiseSEM: Piecewise structural equation modelling in $r$ for ecology, evolution, and systematics. Methods Ecol. Evol., 7, 573-579.

Pinheiro, J., Bates, D., DebRoy, S., Sarkar, D., \& R Development Core Team. (2017). NIme: Linear and nonlinear mixed effects models. R package version 3.1-117.

R Development Core Team. (2016). R: A language and environment for statistical computing. R Foundation for Statistical Computing, Vienna, Austria. ISBN 3-900051-07-0, URL http://www.R-project.org/.

Redhead, J. W., Dreier, S., Bourke, A. F. G., Heard, M. S., Jordan, W. C., Sumner, S., ... Carvell, C. (2016). Effects of habitat composition and landscape structure on worker foraging distances of five bumble bee species. Ecological Applications, 26(3), 726-739. doi:10.1890/15-0546

Requier, F., Odoux, J.-F., Tamic, T., Moreau, N., Henry, M., Decourtye, A., et al. (2015). Honey bee diet in intensive farmland habitats reveals an unexpectedly high flower richness and a major role of weeds. Ecol. Appl., 25, 881-890.

Robinson, R.A. \& Sutherland, W.J. (2002). Post-war changes in arable farming and biodiversity in Great Britain. J. Appl. Ecol., 39, 157-176.

Roulston, T.H. \& Cane, J.H. (2000). Pollen nutritional content and digestibility for animals. Plant Syst. Evol., 222, 187-209.

Ruedenauer, F.A., Spaethe, J. \& Leonhardt, S.D. (2015). How to know which food is good for you: bumblebees use taste to discriminate between different concentrations of food differing in nutrient content. J. Exp. Biol., 218, 2233-2240.

Rundlöf, M., Andersson, G.K.S., Bommarco, R., Fries, I., Hederström, V., Herbertsson, L., et al. (2015). Seed coating with a neonicotinoid insecticide negatively affects wild bees. Nature, 521, 77-80.

Sauerbrei, R., Ekschmitt, K., Wolters, V. \& Gottschalk, T.K. (2014). Increased energy maize production reduces farmland bird diversity. GCB Bioenergy, 6, 265-274.

Steckel, J., Westphal, C., Peters, M.K., Bellach, M., Rothenwoehrer, C., Erasmi, S., et al. (2014). Landscape composition and configuration differently affect trap-nesting bees, wasps and their antagonists. Biol. Conserv., 172, 56-64.

Tasei, J.-N. \& Aupinel, P. (2008). Nutritive value of 15 single pollens and pollen mixes tested on larvae produced by bumblebee workers (Bombus terrestris , Hymenoptera: Apidae). Apidologie, 39, 397-409.

Tscharntke, T., Klein, A.M., Kruess, A., Steffan-Dewenter, I. \& Thies, C. (2005). Landscape perspectives on agricultural intensification and biodiversity - ecosystem service management. Ecol. Lett., 8, 857-874.

Van Geert, A., Van Rossum, F. \& Triest, L. (2010). Do linear landscape elements in farmland act as biological corridors for pollen dispersal? J. Ecol., 98, 178-187. 
Vaudo, A.D., Patch, H.M., Mortensen, D.A., Tooker, J.F. \& Grozinger, C.M. (2016). Macronutrient ratios in pollen shape bumble bee (Bombus impatiens) foraging strategies and floral preferences. Proc. Natl. Acad. Sci., 201606101.

Vaudo, A.D., Tooker, J.F., Grozinger, C.M. \& Patch, H.M. (2015). Bee nutrition and floral resource restoration. Curr. Opin. Insect Sci., Social Insects - Vectors and Medical and Veterinary Entomology, 10, 133-141.

Velthuis, H.H.W. \& Doorn, A. van. (2006). A century of advances in bumblebee domestication and the economic and environmental aspects of its commercialization for pollination. Apidologie, 37, 421-451.

Westphal, C., Steffan-Dewenter, I. \& Tscharntke, T. (2009). Mass flowering oilseed rape improves early colony growth but not sexual reproduction of bumblebees. J. Appl. Ecol., 46, 187-193.

Williams, N.M., Regetz, J. \& Kremen, C. (2011). Landscape-scale resources promote colony growth but not reproductive performance of bumble bees. Ecology, 93, 1049-1058.

Winfree, R., Bartomeus, I. \& Cariveau, D.P. (2011). Native Pollinators in Anthropogenic Habitats. Annu. Rev. Ecol. Evol. Syst., 42, 1-22.

Wittstock, U., Kliebenstein, D.J., Lambrix, V., Reichelt, M. \& Gershenzon, J. (2003). Chapter five Glucosinolate hydrolysis and its impact on generalist and specialist insect herbivores. In: Recent Advances in Phytochemistry, Integrative Phytochemistry: from Ethnobotany to Molecular Ecology (ed. Romeo, J.T.). Elsevier, pp. 101-125.

Woodcock, B.A., Bullock, J.M., Shore, R.F., Heard, M.S., Pereira, M.G., Redhead, J., et al. (2017). Country-specific effects of neonicotinoid pesticides on honey bees and wild bees. Science, 356, 1393-1395. 


\section{Appendix S1. Supplementary methods}

\section{Landscape selection}

To find landscapes suitable for our research questions, we first selected a set of $811 \times 1 \mathrm{~km}$ landscapes with a high proportion of agricultural land (at least 75\%). During winter, before the field season, we mapped all field shapes and visible land use types: permanent land use (i.e. grassland) and winter crops (i.e. cereals and OSR). Then we selected a final set of 20 landscapes with uncorrelated gradients of configurational heterogeneity (based on field border density, see below) and compositional heterogeneity (based on the distinguishable diversity of winter crops), considering field access permission by farmers. The final crop diversity included in the analysis was based on mapping of all crops in all landscapes during the cropping season (including spring crop, e.g. maize and sugar beet). To account also for the local effect of oilseed rape, two fields were selected for sampling in each landscape, one wheat field and one OSR field (mean field size: 5.75 ha), resulting in a total of 40 sampling sites.

\section{Detailed description of how the landscape variables were calculated:}

i) Maize cover was measured as the percentage of maize of the crop area.

ii) Oilseed rape (OSR) cover was measured as the percentage of OSR within the crop area.

iii) Configurational heterogeneity was measured as field border density. This was the perimeter of all fields in the landscape (excluding the parts outside the landscape border) per total area of all agricultural fields.

iv) Compositional heterogeneity was measured as crop diversity. We calculated the Shannon diversity index based on the number of crop types and their area in each of the landscapes.

v) Semi-natural cover including the area of all linear (e.g. grassy strips and hedges) and patchy open habitat types (e.g. semi-natural grasslands).

We also considered including forest cover in the analysis as woody pollen types may play a major role in B. terrestris diets (Kämper et al., 2016). However, Kämper et al. (2016) only included forests that were not managed commercially, which were not present in our landscapes. Additionally, they did not find an effect of forest cover on the amount of woody pollen collected, maybe because these included mainly Acer spp. and Rosaceae, which often grow in hedgerows within the agricultural matrix. Therefore, we decided to include hedges in the semi-natural cover, but not forests, which were in general outside of our $1 \times 1 \mathrm{~km}$ landscape windows (mean forest cover \pm SD: $4.81 \% \pm 3.98 \%$ ) 


\section{Pollen sample preparation}

During standard acetolysis method cell walls turn brownish and pollen grains become better visible under the microscope. Afterwards samples were centrifuged and washed with demineralized water and mounted on microscope slides with glycerine. The slides were then preserved with nail polish for identification. 


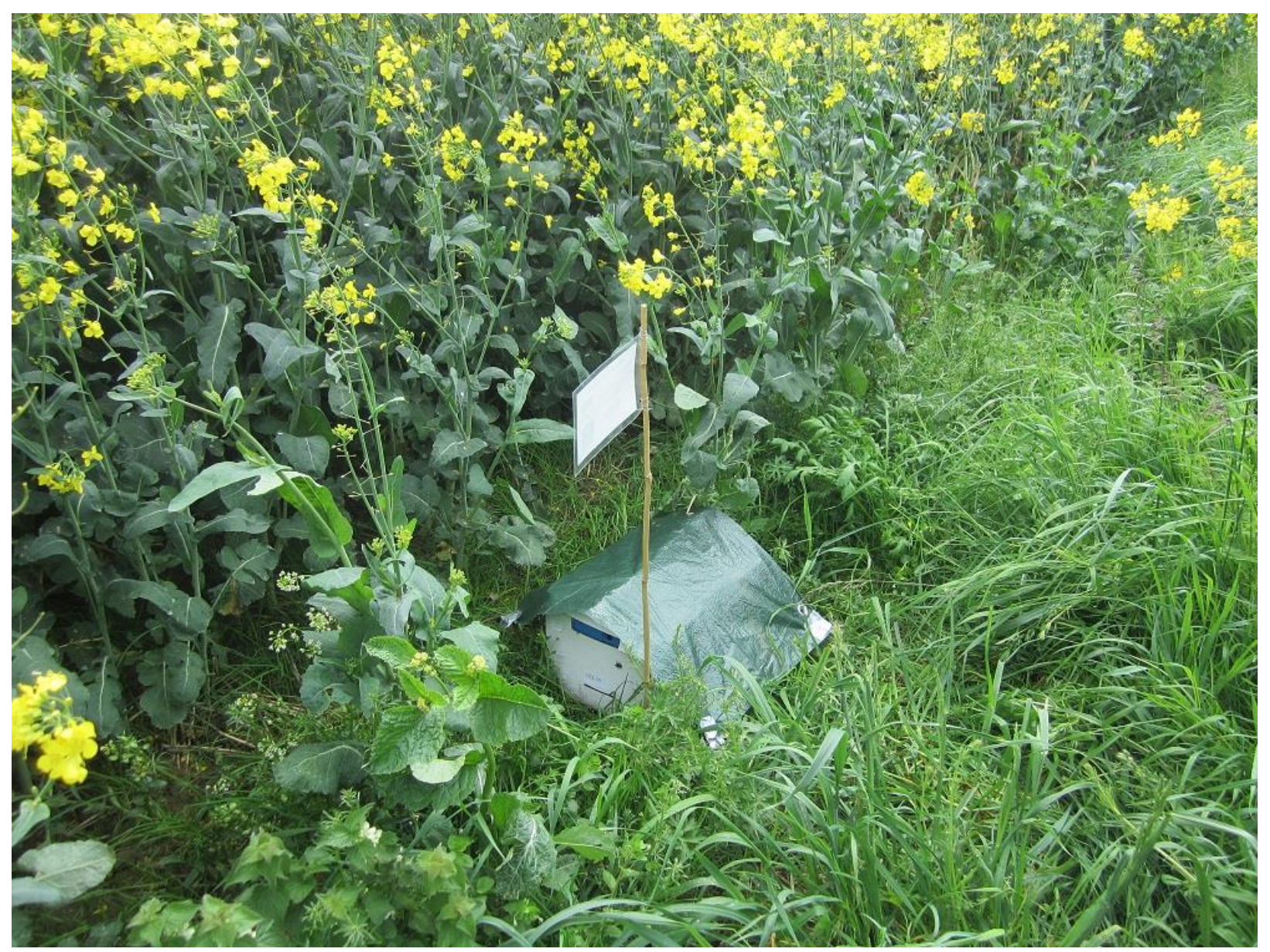

Figure S1 Colony of Bombus terrestris placed in the field border next to the crop field. Colonies stayed in the field from April 17 / 18 to June 4 / 5 and were protected from rain by plastic sheets. 
(a)

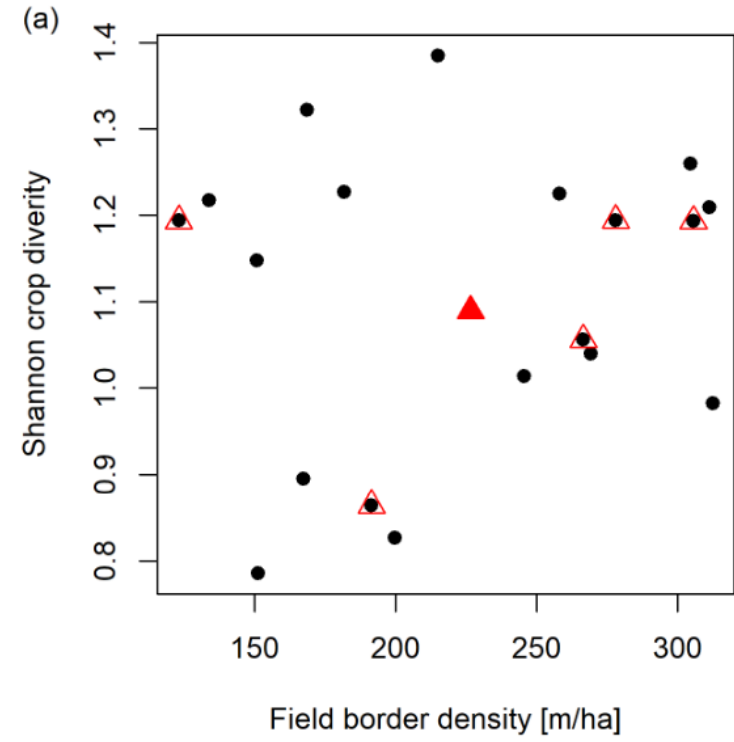

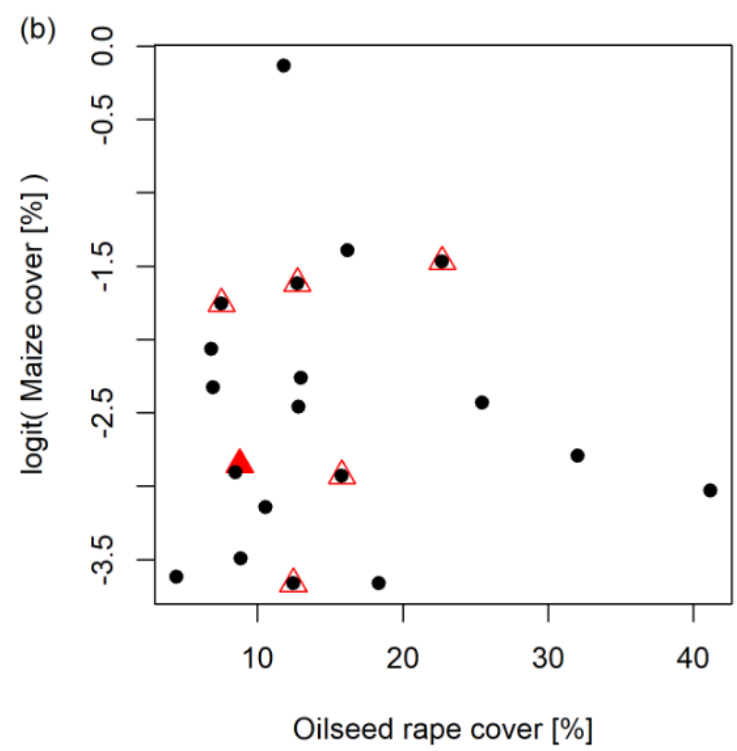

Figure S2 Landscape gradients sampled for (a) Shannon crop diversity and field border density and (b) maize and oilseed rape cover. Black points indicate landscapes in which the data from two colonies (one next to a cereal field and one next to an oilseed rape field) were included in the analysis. Open triangles with a black point indicated landscapes in which one field was excluded and the filled triangle is the landscape from which the colonies from both fields were excluded. Overall, 7 colonies were excluded resulting in a final data set of 33 colonies. 


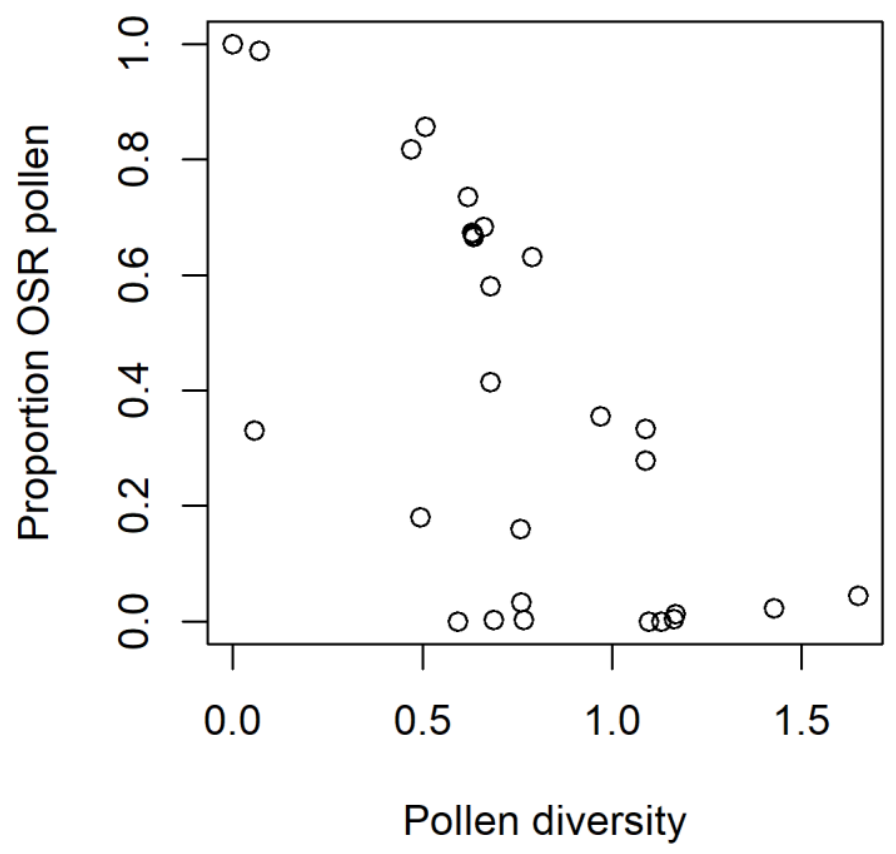

Figure S3 The proportion of oilseed rape (OSR) pollen collected per colony $(n=33)$ is strongly and negatively correlated with pollen diversity calculated as the Shannon diversity index (Pearson's $r=$ $0.74, \mathrm{P}<0.001)$. 


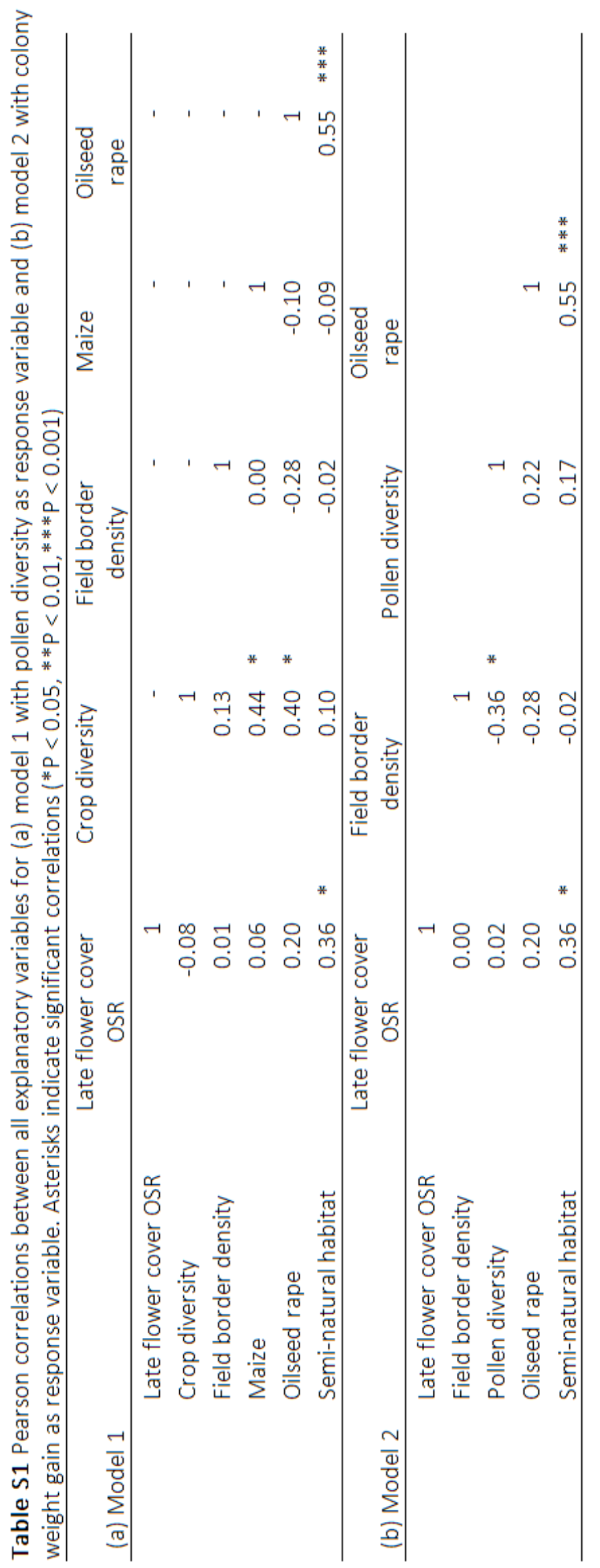


Table S2 Additional model results for the two models used in the structural equation model, (a) with pollen diversity and (b) with maximum weight gain of bumble bee colonies as response variables. For both models results of the full model and the model with all variables included with $\Delta \mathrm{AICC}<2$ from all model subsets (dredge) are presented. $\mathrm{Cl}$ : Confidence Interval

\begin{tabular}{|c|c|c|c|c|}
\hline & Estimate & $\begin{array}{l}\text { Lower } \\
95 \% \mathrm{Cl}\end{array}$ & $\begin{array}{l}\text { Upper } 95 \\
\% \mathrm{Cl}\end{array}$ & $\mathrm{p}$-Value \\
\hline \multicolumn{5}{|l|}{ (a) Model 1 (Response pollen diversity) } \\
\hline \multicolumn{5}{|l|}{ Full model } \\
\hline Intercept & -0.09 & -0.41 & 0.60 & 0.721 \\
\hline Maize cover & -0.45 & -0.83 & -0.07 & 0.042 \\
\hline Field border density & -0.34 & -0.71 & 0.03 & 0.097 \\
\hline Crop diversity & 0.13 & -0.30 & 0.57 & 0.563 \\
\hline Oilseed rape (OSR) cover & -0.09 & -0.53 & 0.34 & 0.678 \\
\hline Late flower cover OSR & -0.08 & -0.44 & 0.28 & 0.683 \\
\hline Local crop type & 0.23 & -0.43 & 0.89 & 0.504 \\
\hline Semi-natural cover & 0.14 & -0.24 & 0.53 & 0.483 \\
\hline $\begin{array}{l}\text { Field border density : } \\
\text { diversity }\end{array}$ & -0.32 & -0.80 & 0.16 & 0.216 \\
\hline \multicolumn{5}{|c|}{ Best simplified model with all variables from dredge $(\triangle \mathrm{AICC}<2)$} \\
\hline Intercept & 0.00 & -0.31 & 0.31 & 1.000 \\
\hline Maize & -0.36 & -0.70 & -0.01 & 0.061 \\
\hline Field border density & -0.34 & -0.66 & -0.02 & 0.058 \\
\hline Crop diversity & 0.18 & -0.17 & 0.52 & 0.331 \\
\hline \multicolumn{5}{|c|}{ (b) Model 2 (Response colony weight gain) } \\
\hline \multicolumn{5}{|c|}{ Full model } \\
\hline Intercept & -0.11 & -0.57 & 0.36 & 0.660 \\
\hline Pollen diversity & 0.37 & 0.05 & 0.69 & 0.041 \\
\hline Oilseed rape (OSR) cover & 0.00 & -0.37 & 0.38 & 0.980 \\
\hline Late flower cover OSR & 0.45 & 0.09 & 0.81 & 0.030 \\
\hline Local crop type & 0.17 & -0.39 & 0.72 & 0.562 \\
\hline Semi-natural cover & 0.04 & -0.34 & 0.43 & 0.828 \\
\hline Field border density & -0.04 & -0.41 & 0.33 & 0.839 \\
\hline \multicolumn{5}{|c|}{ Simplified based on best models from dredge $(\triangle \mathrm{AICc}<2)$} \\
\hline Intercept & 0.00 & -0.30 & 0.29 & 0.978 \\
\hline Pollen diversity & 0.38 & 0.10 & 0.66 & 0.021 \\
\hline Late flower cover OSR & 0.47 & 0.17 & 0.77 & 0.007 \\
\hline
\end{tabular}




\section{Synthesis}

In the chapters of this thesis we studied the effects of farmland configurational heterogeneity (field size/field border length) and compositional heterogeneity (crop diversity) on biodiversity, the community trait composition of arthropods, pollinators and pollination services. We found strong positive effects of configurational heterogeneity on multidiversity (comprising birds, plants, butterflies, hoverflies, bees, carabids and spiders) and wild bee abundance translating into increased pollination services. The positive effect of configurational heterogeneity is most likely due to the increased connectivity of habitats and resources in landscapes with smaller fields and more field borders. Landscape connectivity enhances dispersal, resource availability and genetic exchange which are keys for population viability in fragmented landscapes (Hanski 1998; Kool et al. 2013). This hypothesis was supported by the elevated movement of pollinators along field borders between two adjacent crops. Thereby, we complement previous studies showing movement of pollinators along semi-natural field borders (Van Geert et al. 2010; Cranmer et al. 2012). Additionally, our trait analysis showed that especially large species benefited from high field border density, probably because they have the highest resource demands and depend therefore most strongly on high habitat connectivity. Thereby, we demonstrate that trait communities in farmland respond totally differently to configurational heterogeneity of fields than grassland communities to configurational heterogeneity of semi-natural habitats (Gámez-Virués et al. 2015; Perović et al. 2015), probably due to the high disturbance regimes in agricultural systems. The results of this thesis add new evidence to the importance of small-scale agriculture with many field borders on pollinators (Happe et al. 2018) that has previously been thought to be of minor importance for these organisms (Holzschuh et al. 2010; Kennedy et al. 2013; Steckel et al. 2014). However, weight gain and pollen diversity collected by bumble bee colonies of Bombus terrestris was not affected by configurational heterogeneity indicating that these generalist pollinators with large foraging ranges do not depend as strongly as other species on enhanced habitat connectivity.

On the contrary, the results for compositional heterogeneity were less clear. Increased compositional heterogeneity measured as crop diversity had a positive effect on multidiversity if seminatural habitat was high, but a negative effect if semi-natural habitat was low. Furthermore, there was no evidence for more specialized species as hypothesized (Gámez-Virués et al. 2015), in contrast we found more polyphagous butterflies in landscapes with high crop diversity that probably benefited from higher resource diversity. We also found more hoverfly species with low reproduction and dispersal potential in landscapes with high crop diversity which are probably sensitive to habitat loss. Regarding pollinators we found again no effects of compositional heterogeneity on bumble bee colony 
growth and, surprisingly, even negative effects on wild bee abundance. The reason might be that the cover of unfavourable crop types increased with crop diversity, e.g. maize in France and Germany. Maize is associated with particularly low plant diversity (Kleijn \& Verbeek 2000; Fagúndez et al. 2016), which might impair pollinators. This is supported by the results of the bumble bee colony experiment as colonies collected less diverse pollen diets, which translated into reduced colony growth. The low pollen diversity available in landscapes with high maize cover might also be the reason for the low wild bee abundance leading to decreased pollination services and seed set in the pollination experiment.

Overall, this thesis contributes to understand the effects of farmland heterogeneity on biodiversity and ecosystem services and possible underlying mechanisms. We showed that the effects of the heterogeneity of the crop fields on biodiversity have been underestimated, and we propose that they should be considered for future agri-environment schemes (Batáry et al. 2015). In the European Union the Common Agricultural Policy (CAP) regulates these policies. Recently, greening measures have been made a precondition for parts of the subsidy payment to farmers, including crop diversity requirements. However, this "greening" has faced heavy criticism as measures are expected to be insufficient to safeguard biodiversity in agricultural landscapes (Pe'er et al. 2014, 2017). For example, farms with more than 20 or 30 ha have to cultivate at least two or three crops, respectively, which is below the mean of crop types that was already cultivated on farms of the corresponding size in many EU member states before the new legislation (Pe'er et al. 2014). As multidiversity of different taxa can benefit from crop diversity in landscapes with high complexity (>11\% semi-natural habitat), as shown by the results of this thesis, further increasing the required standards for crop diversity on European farms could be an important step forward. However, crop identity should be considered in these policies as the increase of certain particularly intensively managed crops can be counterproductive as we demonstrate for pollinators. Measures that enhance the configurational heterogeneity by reducing field sizes are currently not part of the CAP. However, our results demonstrate beneficial effects across taxa and different European regions that even translated into enhanced pollination potential. The effects were equal or even stronger than those of semi-natural habitat cover across the different chapters of this thesis highlighting its importance for biodiversity and pollinators. Additionally, we found interactive effects of compositional and configurational heterogeneity with semi-natural habitat on multidiversity indicating that the amount of semi-natural habitat can modulate the effects of crop heterogeneity. Therefore, the landscape context of different habitat types should be considered if crop heterogeneity is promoted. We encourage measures that aim at decreasing mean field sizes and at increasing crop diversity while considering crop identities and other landscape habitats to complement semi-natural habitats for supporting biodiversity and maintain important ecosystem services such as pollination in future agricultural landscapes. 


\section{References}

Batáry, P., Dicks, L.V., Kleijn, D. \& Sutherland, W.J. (2015). The role of agri-environment schemes in conservation and environmental management. Conserv. Biol., 29, 1006-1016.

Cranmer, L., McCollin, D. \& Ollerton, J. (2012). Landscape structure influences pollinator movements and directly affects plant reproductive success. Oikos, 121, 562-568.

Fagúndez, J., Olea, P.P., Tejedo, P., Mateo-Tomás, P. \& Gómez, D. (2016). Irrigation and maize cultivation erode plant diversity within crops in Mediterranean dry cereal agro-ecosystems. Environ. Manage., 58, 164-174.

Gámez-Virués, S., Perović, D.J., Gossner, M.M., Börschig, C., Blüthgen, N., de Jong, H., et al. (2015). Landscape simplification filters species traits and drives biotic homogenization. Nat. Commun., $6,8568$.

Hanski, I. (1998). Metapopulation dynamics. Nature, 396, 41-49.

Happe, A.-K., Riesch, F., Rösch, V., Gallé, R., Tscharntke, T. \& Batáry, P. (2018). Small-scale agricultural landscapes and organic management support wild bee communities of cereal field boundaries. Agric. Ecosyst. Environ., 254, 92-98.

Henle, K., Davies, K.F., Kleyer, M., Margules, C. \& Settele, J. (2004). Predictors of Species Sensitivity to Fragmentation. Biodivers. Conserv., 13, 207-251.

Holzschuh, A., Steffan-Dewenter, I. \& Tscharntke, T. (2010). How do landscape composition and configuration, organic farming and fallow strips affect the diversity of bees, wasps and their parasitoids? J. Anim. Ecol., 79, 491-500.

Kennedy, C.M., Lonsdorf, E., Neel, M.C., Williams, N.M., Ricketts, T.H., Winfree, R., et al. (2013). A global quantitative synthesis of local and landscape effects on wild bee pollinators in agroecosystems. Ecol. Lett., 16, 584-599.

Kleijn, D. \& Verbeek, M. (2000). Factors affecting the species composition of arable field boundary vegetation. J. Appl. Ecol., 37, 256-266.

Kool, J.T., Moilanen, A. \& Treml, E.A. (2013). Population connectivity: recent advances and new perspectives. Landsc. Ecol., 28, 165-185.

Pe'er, G., Dicks, L.V., Visconti, P., Arlettaz, R., Báldi, A., Benton, T.G., et al. (2014). EU agricultural reform fails on biodiversity. Science, 344, 1090-1092.

Pe'er, G., Zinngrebe, Y., Hauck, J., Schindler, S., Dittrich, A., Zingg Silvia, et al. (2017). Adding Some Green to the Greening: Improving the EU's Ecological Focus Areas for Biodiversity and Farmers. Conserv. Lett., 10, 517-530.

Perović, D., Gámez-Virués, S., Börschig, C., Klein, A.-M., Krauss, J., Steckel, J., et al. (2015). Configurational landscape heterogeneity shapes functional community composition of grassland butterflies. J. Appl. Ecol., 52, 505-513.

Steckel, J., Westphal, C., Peters, M.K., Bellach, M., Rothenwoehrer, C., Erasmi, S., et al. (2014). Landscape composition and configuration differently affect trap-nesting bees, wasps and their antagonists. Biol. Conserv., 172, 56-64.

Van Geert, A., Van Rossum, F. \& Triest, L. (2010). Do linear landscape elements in farmland act as biological corridors for pollen dispersal? J. Ecol., 98, 178-187. 


\section{Acknowledgements}

First of all, I would like to thank my supervisors for supporting me during all the years of my PhD. Thank you Teja, for giving me the chance to work in the FarmLand project, for being enthusiastic about my ideas and for supporting me when necessary. You always pushed the project in the right direction and you were ready to argue with the right persons when it looked like the money for my contract could not be prolonged. And of course you provide an inspiring, co-operative and productive atmosphere in the Agroecology group that all members profit from. Second, I'm very grateful to Péter who was always ready to discuss and answer all kind of questions. I could always knock on your door and get immediate and very practical advice which I really appreciated. Yann was located a little bit more remote during most of my PhD. However, he always critically evaluated my manuscripts and especially the statistics, which greatly improved my thesis.

Furthermore, I want to thank Aliette. Together we organised and conducted the massive tasks of landscape selection and field work. We drove through half of Europe and experienced all kinds of weather conditions during field work, including a whole month of continuous rain, without giving up! I am happy that we did that together. For help with field and lab work I would like to thank Orsolya Máthé, Lunja Ernst, Felipe Benra, Kelsey Jourstra, Cornelia Harries, Lara Brachmann and Dagmar Jahn. Brigitte helped me with growing plants in the greenhouse and analyzing the harvested seeds. I also thank the farmers who gave access to their fields and the whole Agroecology group, especially Susanne, Jutta and Heike for their support.

It was also a great experience to be part of the FarmLand team with so many nice PhD students and other researchers. I'm really grateful to all the persons in the different FarmLand regions who contributed to the field and lab work. Without them this project would not have been possible. I also have to mention Clélia, who played an important role in developing joint field protocols that needed to work in Mediterranean almond plantations, British wheat and French rice fields. Additionally, Clélia joined the data from all regions, which was a difficult task, but an essential precondition for analysing the data. Many persons helped to accomplish the massive task of species identification. I thank Frank Creutzburg and Zsolt Józan for assistance with the identification of bees from Germany and Jordi Bosch identified bee species from Spain. Hoverflies from Germany were identified by Rita Földesi and from Spain by Antonio Ricarte and María Marcos-García.

Finally, I want to thank José for supporting me during all these years and for believing in me and my project. Your programming skills were very helpful and that you decided to care for Elena made it possible for me to finalize this thesis. Thanks for being there! And also many thanks to Antonio and Elena for reminding me every day what is really important in life. 


\section{Curriculum Vitae}

Annika Louise $\mathrm{Haß}$

Personal details

University of Göttingen

Functional Agrobiodiversity, Department of Crop Sciences

Grisebachstr. 6

37077 Göttingen

Germany

ahass@gwdg.de

two children ( 2 and 4 years)

Scientific Education

2013 - $2018 \quad$ PhD student, University of Göttingen, Agroecology group

Thesis: "Farmland heterogeneity effects on biodiversity and pollination services", supervisors: Teja Tscharntke, Péter Batáry and Yann Clough

$2010-2012 \quad$ MSc "Biodiversity, Ecology and Evolution"

University of Göttingen

Thesis: „Habitat heterogeneity is the key: Polycultures determine bee diversity and complexity of plant-pollinator-webs in rice dominated landscapes"

$2007-2010$ BSc "Landscape Management and Nature Conservation", University for Sustainable Development Eberswalde (HNEE)

Thesis: "Blütenbesuchende Insekten auf einer Kurzumtriebsplantage bei Jamikow und Umgebung"

Secondary School

2006

Abitur, Wald-Oberschule (Gymnasium) in Berlin

Scientific positions

since 2018

$2017-2018$

$2012-2016$

$2010-2012$

2010
Postdoc position, Functional Agrobiodiversity group, University of Göttingen

Research position, Agroecology group, University of Göttingen (maternal leave from Feb. 2017 until August 2017)

Research position in the "FarmLand" project, Agroecology group, University of Göttingen (maternal leave from Nov. 2014 until Oct. 2015)

Student assistant in the Agroecology group, University of Göttingen, Assistance with field work, GIS and insect identification

Student assistant at the University for Sustainable Development Eberswalde (HNEE), assistance for the course "Plant identification" 
2012

Research stay at the International Rice Research Institute (IRRI), Los Baños, Philippinen, LEGATO-Project for sustainable rice production

2009-2010 Voluntary environmental education and guided tours for children in cooperation with Panke e.V. in Berlin

2008-2009 Internship at Balkani Wildlife Society in Sofia, Bulgaria, conservation and restoration of Dragoman wetlands

2006-2007 Voluntary ecological year (FÖJ), Freilandlabor Britz in Berlin, environmental education and guided tours for children

Languages

English: fluently

Spanish: basic knowledge (level B1)

Scholarships and prizes

2017

Poster "highly commended for student poster prize" at the Joint Annual Meeting of the British Ecological Society (BES) and of the Ecological Society of Germany, Austria and Switzerland (GfÖ)

2012

Prize for best poster at the Annual Meeting of the Ecological Society of Germany, Austria and Switzerland (GfÖ)

2011

Schubert-Prize for Bachelor thesis, Johannes-Schubert-Stiftung, Eberswalde

2010

Lower Saxony Scholarship (Landesstipendium Niedersachsen, 500€)

Reviewer activities for

Agriculture Ecosystems and Environment, Ambio, Basic and Applied Ecology, Biological Conservation, BMC Ecology, Environmental Entomology, European Journal of Entomology, Global Ecology and Conservation, Insect Conservation and Diversity, Journal of Applied Ecology, Oecologia, Peer J 


\section{List of publications}

\section{Published articles}

\section{Journal articles}

Hass, A.L., Brachmann, L., Batáry, P., Clough, Y., Behling, H., Tscharntke, T. (2019). Maize dominated landscapes reduce bumble bee colony growth through pollen diversity loss. Journal of Applied Ecology 56,294-304

Settele, J., Heong, K.L., Kühn, I., Klotz, Spangenberg, J.H., Arida, J.H., Beaurepaire, A., Beck, S., Bergmeier, E., Burkhard, B., Brandl, R., Bustamante, J.V., Butler, A., Cabbigat, J., Catindig, J.L.A., Dang, K.B., Escalada, M., Dao, T.T., Dominik, C., Franzén, M., Fried, O., Görg, C., Grescho, V., Grossmann, S., Gurr, G.M., Hadi, B.A.R., Hai, L.H., Harpke, A., Hass, A.L., Hirneisen, N., Ho, V.C.,Horgan, F., Hotes, S., Isoda, Y., Jahn, R., Kettle, H., Klotzbücher, A., Klotzbücher, T., Langerwisch, F., Le, Q.T., Le, Q.C., Le, X.C., Loke, W.H., Lin, Y.P., Lu, Z., Lum, K.Y., MagcaleMacandog, D.B., Marion, G., Marquez, L., Müller, F., Nguyen, H.N.,Nguyen, Q.A., Nguyen, V.S., Ott, J., Penev, L., Pham, H.T., Radermacher, N., Rodriguez-Labajos, B., Sann, C., Sattler, C., Schädler, M., Scheu, S., Schmidt, A., Schrader, J., Schweiger, O., Seppelt, R., Soitong, K., Stoev, P., Stoll-Kleemann, S., Tekken, V., Thonicke, K., Tilliger, B., Tobias, K., Trisyono, Y.A., Tscharntke, T., Türke, M., Václavík, T., Vetterlein, T, Villareal, S., Vu, K.C., Vu, Q., Weisser, W.W., Westphal, C. Zhu, Z., Wiemers, M. (2018): Rice ecosystem services in South-east Asia, Paddy and Water Enivronment 16, 211-224

Hass, A.L., Kormann, U., Tscharntke, T., Clough, Y, Bosem Baillod, A., Sirami, C., Fahrig, L., Martin, J.L., Baudry, J., Bertrand, C., Bosch, J., Brotons, L., Burel, F., Georges, R., Giralt, D., Marcos-García, M.A., Ricarte, A., Siriwardena, G., Batáry, P. (2018) Landscape configurational heterogeneity by small-scale agriculture, not crop diversity, maintains plant reproduction in Western Europe. Proceedings of the Royal Society of London B - Biological Science 285, 20172242

(Highlighted in Nature)

Hass, A.L., Liese, B., Heong, K.L., Settele, J., Tscharntke, T., Westphal, C. (2018) Plant-pollinator interactions and bee functional diversity are driven by agroforests in rice-dominated landscapes. Agriculture Ecosystems and Environment 253, 140-147

Hass, A.L., Brauner, O., Schulz, U. (2012). Diversity, distribution and abundance of honeybees (Apis mellifera) and wild bees (Apidae) on a willow short-rotation coppice. Mitteilungen der Deutschen Gesellschaft für allgemeine und angewandte Entomologie 18, 147-152

\section{Book chapters}

Loos J., Batáry, P., Grass, I., Westphal, C., Bänsch, S., Bosem Baillod, A., Hass, A.L., Rosa, J. \& Tscharntke T. (2019). Vulnerability of ecosystem services in farmland depends on landscape management. In: Schröter, M., Bonn, A., Klotz, S., Seppelt, R., Baessler, C. (Eds.), Atlas of Ecosystem Services: Drivers, Risks, and Societal Responses. Springer International Publishing, Cham, pp. 91-96.

Settele, J., Spangenberg, J.H., Heong, K.L., Kühn, I., Klotz, S., Arida, G., Burkhard, B., Bustamante, J.V., Cabbigat, J., Canh, L.X., Catindig, J.L.A., Chien, H.V., Cuong, L.Q., Escalada, M., Görg, C., Grescho, V., Grossmann, S., Hadi, B.A.R., Hai, L.H., Harpke, A, Hass, A.L., Hirneisen, N., Horgan, F.G., Hotes, S., Jahn, R., Klotzbücher, A., Klotzbücher, T., Langerwisch, F., Magcale-Macandog, D.B., Hung Manh, N., Marion, G., Marquez, L., Ott, J., Penev, L., Rodriguez-Labajos, B., Sann, C., Sattler, C., Schädler, M., Scheu, S., Schmidt, A., Schrader, J., Schweiger, O., Seppelt, R., Sinh, N.V., Stoev, P., Stoll-Kleemann, S., Tekken, V., Thonicke, K., Trisyono, A., Truong, D.T., Tuan, L.Q., Türke, M., Václavík, T., Vetterlein, D., Villareal, S., Westphal, C., Wiemers, M. (2019). Rice ecosystem services in South-East Asia: The LEGATO project, its approaches and main results with a focus on biocontrol services. In: Schröter, M., Bonn, A., Klotz, S., Seppelt, R., Baessler, C. (Eds.), Atlas of Ecosystem Services: Drivers, Risks, and Societal Responses. Springer International Publishing, Cham, pp. 373-382. 
Sirami, C., Gross, N., Bosem Baillod, A. *, Bertrand, C. *, Carrié, R. *, Hass, A.L. *, Henckel, L. *, Miguet, P.*, Vuillot, C. * , Alignier, A., Girard, J., Batáry, P., Clough, Y., Violle, C., Giralt, D., Bota, G., Badenhauser, I., Lefebvre, G., Gauffre, B., Vialatte, A., Calatayud, F., Gil-Tena, A., Quesada-Pizarro, N., Tischendorf, L., Mitchell, S., Lindsay, K., Georges, R., Hilaire, S., Recasens, J., Bosch, J., Barrientos, J. A., Ricarte, A., Marcos, M.Á., Minano, J., Mathevet, R., Gibon, A, Baudry, J., Balent, G., Poulin, B., Burel, F., Tscharntke, T., Bretagnolle, V., Siriwardena, G., Ouin, A., Brotons, L., Martin, J.-L. **, Fahrig, L. ${ }^{* *}$. Increasing crop diversity and decreasing field size enhance multidiversity across agricultural regions.

*These co-authors contributed equally as part of their PhDs and should be considered co-third authors.

**These co-authors contributed equally to the project coordination and should be considered co-last authors. (submitted to PNAS January $9^{\text {th }} 2018$, resubmission invited)

Alignier, A., Solé-Senan, X.O., Robleño, I, Baraibar, B., Fahrig,L., Giralt, D., Gross, N., Martin, J.L., Recasens, J., Sirami, C., Siriwardena, G., Bosem Baillod, A., Bertrand, C., Carrié, R., Hass, A.L., Henckel, L., Miguet, P., Vuillot, C., Badenhausser, I., Balent, G., Baudry, J., Bosch, J. , Bota, G., Bretagnolle, V., Brotons, L., Burel, F., Calatayud, F., Clough, Y., Gauffre, B., Georges, B., Gibon, A., Gil-Tena, A., Girard, J., Hilaire, S., Lefebvre, G., Lindsay, K., Mathevet, R., Mitchell, S., Ouin, A., Poulin, B., Ricarte, A., Tischendorf, L., Tscharntke, T., Vialatte, A., Violle, C., Batáry, P. High compositional and configurational crop heterogeneity contributes to enhancing within-field plant diversity (submitted to Journal of Applied Ecology March 22 $2^{\text {nd }}$ 2019)

Geppert, C., Hass, A.L., Földesi, R., Donkó, B., Akter, A., Tscharntke, T., Batáry, P. Both organic farming and flower strips support pollinators better than conventional farming in German agricultural landscapes.

(submitted to Journal of Applied Ecology March 1st 2019)

Bosem Baillod, A.* , Hass, A.L. * Batáry, P., Clough, Y., Sirami, C., Martin, J.-L., Fahrig, L., Marcos, M.Á., Barrientos, J. A., Baudry, J., Bertand, C., Bota, G., Brotons, L., Burel, F., Carrié ,R., Georges, R., Gauffre, B., Giralt, D., Hilaire, S., Minano, J., Ouin, A., Poulin, B., Ricarte, A., Saintilan, A., Siriwardena, G., Vialatte, A., Tscharntke, T. Configurational and compositional farmland heterogeneity affect trait composition of flower-visiting and predacous arthropods

* Equally contributing authors.

(in preparation)

Bosem Baillod, A., Tscharntke, T., Batáry, P., Bertand, C., Gross, N., Hass A..L., Sirami, C., Martin, J.-L., Fahrig, L., Violle, C., Barrientos, J.A., Saintilan, A., Baudry, J., Bota, G., Bretagnolle, V., Brotons, L., Burel, F., Carrié, R., Lefebvre, G., Georges, R., Gauffre, B., Giralt, D., Hilaire, S., Minano, J., Ouin, A., Poulin, B., Siriwardena, G., Clough, Y. Biological pest control across Europe depend on cascading effects of landscape crop heterogeneity and species traits.

(in preparation)

Herbertsson, L., Ekroos, J., Caplat, P., Rundlöf, M., Bommorco, R., Albrecht, M., Bartomeus, I., Chateil, C., Eikestam, J., Entling, M., Farwig, N., Gaeble, V., Gonzalez-Varo, J.P., Hass, A.L., Holzschuh, A., Hopfenmüller, S., Jakobsson, A., Jauker, B., Kovács-Hostyánsky, A., Kunin, B., Mullen, S., Öckinger, E., Petanidou, T., Porcher, E., Potts, S., Power, E.F., Seibel, K., Sober, V., Södermann, A., Steffan-Dewenter, I., Stout, J., Teder, T., Winsa, M., Smith, H.G. Assessing links between land-use intensity and reproductive output of insect-pollinated plants in European agricultural landscapes

(in preparation) 
Hass, A.L., Batáry, P., Clough, Y., Tscharntke, T. Landscape scale crop heterogeneity and crop identity affect pollinators, their pollen diets and pollination services

Talk, Student Conference on Conservation Science (SCCS), 2018, Tihany, Hungary

Fahrig, L., Collins, S., Hass, A.L., Monck-Whipp, L., Put, J., Sirami, C., Martin, J.-L. Cropland heterogeneity benefits biodiversity by facilitating resource availability and access

Talk by L. Fahrig, North American Congress for Conservation Biology 2018, Toronto, Canada

Hass, A.L., Kormann, U., Tscharntke, T., Clough, Y, Bosem Baillod, A., Sirami, C., Fahrig, L., Martin, J.L., Baudry, J., Bertrand, C., Bosch, J., Brotons, L., Burel, F., Georges, R., Giralt, D., Marcos-García, M.A., Ricarte, A., Siriwardena, G., Batáry, P. Landscape configurational heterogeneity by small-scale agriculture, not crop diversity, maintains pollination services in Western Europe

Poster, Ecology Across Borders: Joint Annual Meeting of the British Ecological Society (BES) and the Ecological Society GfÖ, 2017, Ghent, Belgium

Hass A.L., Bosem Baillod, A., Batáry, P., Sirami, C., Tscharntke T. Farmland heterogeneity effects on trait filtering of predatory and flower-visiting arthropod communities across Europe.

Talk, 46th Annual Meeting of the Ecological Society GfÖ, 2016, Marburg

Hass, A.L., Brachmann, L., Batáry, P., Clough, Y., Tscharntke, T. Landscape-wide crop heterogeneity vs. crop identity: enhanced percent maize reduces reproduction success of bumble bees

Talk, 45th Annual Meeting of the Ecological Society GfÖ, 2015, Göttingen

Hass, A.L., Heong, K.L., Settele, J., Tscharntke, T., Westphal, C. Polycultures increase abundance of cavity nesting Hymenoptera and parasitiation rate in simple, but not complex tropical rice landscapes

Poster, 43th Annual Meeting of the Ecological Society GfÖ, 2013, Potsdam

Hass, A.L., Liese, B., Heong, K.L., Settele, J., Tscharntke, T., Westphal, C. Effects of woody habitat types on bee diversity and abundance in rice-dominated landscapes in the Philippines

Poster, 42th Annual Meeting of the Ecological Society GfÖ, 2012, Lüneburg

Hass, A.L., Brauner, O., Schulz, U. (2010), Diversity, distribution and abundance of honeybees (Apis mellifera) and wild bees (Apidae) on a willow short-rotation coppice

Poster, Entomologentagung DGaaE, 2010, Berlin 


\section{Thesis declaration}

I hereby confirm that I have written this doctoral thesis independently, that I have not used other sources or facilities other than the ones mentioned, that I have not used unauthorized assistance and that I have not submitted this thesis previously in any form for another degree at any university or institution.

Göttingen, April 2019 